WSRC-TR-93-673

Rev 0

\title{
Final Report: In Situ Radio Frequency Heating Demonstration $(U)$
}

Westinghouse Savannah River Company

Savannah River Site

Aiken, SC 29808

Prepared for the U.S. Department of Energy under contract no. DE-AC09-89SR18035

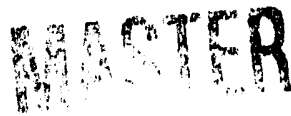




\section{Disclaimer}

This report was prepared as an account of work sponsored by an agency of the United States Government. Neither the United States Government nor any agency thereof, nor any of their employees, makes any warranty, express or implied, or assumes any legal liability or responsibility for the accuracy, completeness, or usefulness of any information, apparatus, product, or process disclosed, or represents that its use would not infringe privately owned rights. Reference herein to any specific commercial product, process, or service by trade name, trademark, manufacturer, or otherwise does not necessarily constitute or imply its endorsement, recommendation, or favoring by the United States Government or any agency thereof. The views and opinions of authors expressed herein do not necessarily state or reflect those of the United States Government or any agency thereof.

The contents of this document will also be published by Westinghouse Science and Technology Center as 93-9TDO-RFHET-R3 for internal use. 
WSRC-TR-93-673

$\operatorname{Rev} 0$

Final Report: In Situ Radio Frequency Heating Demonstration (U)

Authors:

T. R. Jarosch, Savannah River Technology Center, Environmental Sciences Section

R. J. Beleski, Westinghouse Science Technology Center, Environmental Technologies

D. Faust, KAI Technologies

January 5,1994

Authenication:

Approved by:

D. B. Moore-Shedrow, Section Manager

Environmental Sciences Section

Savannah River Technology Center

Prepared for the U.S. Department of Energy under contract no. DE-AC09-89SR18035 


\section{Contents}

\section{Executive Summary 1}

\subsection{Introduction 3}

1.1 Program Description 3

1.1.1 Background 3

1.1.2 Integrated System 3

1.1.3 Program Plan 4

1.2 Program Participants, Relationships, and Organization 4

\subsection{Program Objectives 5}

\subsection{Conclusions 11}

\subsection{General Summary 11}

2.2 Integrated System 12

2.2.1 Single Well Operation 12

2.2.2 Vacuum Extraction Rates 13

2.2.3 Horizontal Well Zone of Influence 13

2.3 Radio Frequency System 13

2.3.1 Radio Frequency Radiation Coupling to Clayey Sediments 13

2.3.2 Temperature Ramp-Up Rates 14

2.3.3 Heated Subsurface Volume 14

2.3.4 Radio Frequency Surface Fields 14

2.3.5 Thermal Stresses on Radio Frequency Transmission Line 14

\subsection{Vacuum Extraction System Thermal Catalytic} Destruction Efficiency 15

\subsection{Temperature Monitoring 15}

2.5.1 Spectrophotometric Fiber Optic Temperature Sensors 15

2.5.2 T-Type Thermocouples 15

2.5.3 Fluorescence Decay Fiber Optic Temperature Sensors 15

2.6 Sediment Characterization 16

2.6.1 Volatile Organic Contaminant Content 16

2.6.2 Moisture Content 16

2.6.3 Effect on Biopopulation 16

\subsection{Recommendations 37}

3.1 Extraction Wells 37

3.2 Drilling Technology/Well Completion Materials 37

3.3 Baseline Vacuum Extraction 37 


\subsection{Demonstration Length 37 \\ 3.5 Pretest Laboratory Studies/Modeling 38}

\subsection{System Description 39}

4.1 Equipment Description 39

4.1.1 Radio Frequency Heating System Equipment 39

4.1.2 Vacuum Extraction And Offgas Treatment System 40

4.1.3 Horizontal Well Description 40

4.1.4 Field Equipment For Monitoring Test Conditions 41

4.1.5 Sampling/Analytical Equipment 42

4.1.6 AC Power Supply 42

4.1.7 Water/Condensate Removal Equipment 42

4.1.8 Catox Monitoring Interfaces for Automatic Radio Frequency Shutdown 42

4.1.9 Final Steady-State System Configuration 42

\subsection{Operation 43}

4.2.1 Applicator Insertion and Removal 43

4.2.2 Radio Frequency Operation 43

4.2.3 Extraction Operation 44

4.2.4 Field Monitoring 45

\subsection{Results And Discussion 69}

\subsection{Mobilization 69}

5.1.1 Overall Assessment 69

5.1.2 Radio Frequency Application System 69

5.1.3 Catox System 69

5.1.4 Applicator Insertion and Removal 69

\subsection{System Operation 69}

5.2.1 Radio Frequency Heating System/Applicator Operation 69

5.2.2 Extraction System Operation 71

5.2.3 Field Monitoring 75

\subsection{Demobilization 78}

\subsubsection{Failure to Retrieve Applicator 78}

\subsection{Demonstration Economics 78}

5.4.1 Background For Economic Basis 78

5.4.2 Demonstration Costs 79

5.4.3 Commercial Cost Projections 79

\subsection{References 119}




\section{List of Tables}

Table 4.1. Fiber Optic Probes 42

Table 4.2. Fiber Optic Probes Continuously Monitored 45

Table 4.3. Thermocouples Continuously Monitored 46

Table 5.1. Total Mass of Chlorinated Solvents Extracted and Total Mass Emissions to the Atmosphere 75

Table 5.2. Distances (in feet) from Temperature Monitoring Locations to Nearest Point on RF Applicator (calculations based on field well surveys and logs) 75

Table 5.4. Actual Cost Associated with RF Demonstration 80

Table 5.5. Commercial Cost Projection Case: Basis - Time Period and Electric Power Costs Consistent with SRS Demonstration 83

\section{List of Figures}

Figure 1-1. Savannah River Site Integrated Demonstration Project Area Location Map 6

Figure 1-2. Horizontal Well Location at the SRS Integrated Demonstration Site 7

Figure 1-3. Schematic Diagram of RF-Enhanced Vacuum Extraction Process 8

Figure 1-4. Project Organization for In Situ Radio Frequency Heating Demonstration 9

Figure 2-1. Daily and Cumulative Rainfall at Demonstration Site January 1 - May 31, 199317

Figure 2-2. Schematic of Horizontal Well Surveyed Elevation View 18

Figure 2-3. Schematic of Vapor Lock Formed Downhole at Temperatures above $100^{\circ} \mathrm{C} \quad 19$

Figure 2-4. Comparison of Measured Wall Temperature, Total Flow from Well, and Vacuum Levels at Well Head during the Heating Stage 20

Figure 2-5. Comparison of Measured Horizontal Well Piezometer Vacuums to Wall Stage and Start of Cooldown 21

Figure 2-6. Illustration of Equipment Crowding Well Opening at Well Head Entry 22

Figure 2-7. Horizontal Well Head during Normal Extraction and RF Power Operations 23

Figure 2-8. Measured PCE, TCE, and TCA Gas Concentrations at Well Head during Heating Stage 24 
Figure 2-9. Piezometer Pressure for "C" Depth (28ft) Wells Heating and Cooldown Stage 25

Figure 2-10. Measured Subsurface Temperatures at Selected Monitoring Wells over the Course of the Demonstration 26

Figure 2-11. 3-D Image of Temperature Distribution in Heated Zone at End of Heating Stage April 27, 1993 (Boxes depict horizontal Well Survey.) 27

Figure 2-12. 3-D Image of Predicted Temperature Distribution of Heated Zone from Model at End of Heating Zone 28

Figure 2-13. PCE Destruction Efficiency over Course of the Demonstration 29

Figure 2-14. 3-D Image of PCE and TCE Sediment Concentration $1 \mathrm{~kg}$ ) Iso-Surface from Pre-test and Post-test Cores (Dotted vertical lines depict borehole locations.) 30

Figure 2-15. 3-D Image of PCE and TCE Sediment Concentration $1 \mathrm{ppm}$ ( $\mathrm{mg} / \mathrm{kg}$ ) Iso-Surface from Pre-test Samples (Dotted vertical lines depict borehole locations.) 31

Figure 2-16. 3-D of PCE and TCE Sediment Concentration $1 \mathrm{ppm}(\mathrm{mg} / \mathrm{kg})$ Iso-Surface from Pre-test and Post-test Core Sample (Dotted vertical lines depict borehole locations.) 32

Figure 2-17. 3-D of PCE and TCE. Scdiment Concentration $1 \mathrm{ppm}(\mathrm{mg} / \mathrm{kg})$ Iso-Surface from Pre-test and Post-test Core Sample (Dotted vertical lines depict borchole locations.) 33

Figure 2-18. Moisture Content from Pre-test (MHV) and Post-test (MHB) Cores within Heated Zone (Approximately 7 feet from Applicator) 34

Figure 2-19. Moisture Content from Pre-test (MHV) and Post-test (MHB) Cores in Heated Zone (Approximately 5 feet from Applicator) 35

Figure 4-1. Mobile KAI RF Application Unit 47

Figure 4-2. Schematic Diagram of RF Held for Demonstration 48

Figure 4-3. Transmission Cab Joint with Teflon ${ }^{\mathrm{TM}}$ Clam-Shell Cover

Figure 4-4. Modified Half Clam-Shell "Ski" Used in Operation to Reduce Flow Restrictions 50

Figure 4-5. RF Applicaiter for SRS Demonstration 51

Figure 4-6. Mechanical View of the Applicator Used in SRS Demonstration 52

Figure 4-7. Schematic of Catox System Employed at RF Heating Demonstration 53

Figure 4.8. Schematic of Horizontal Well Surveyed Elevation View 54 
Figure 4-9. Monitoring Well Layout with Respect to the Horizontal Well 55

Figure 4-10. Schematic of Piezometer Arrangement in each Borehole 56

Figure 4-11. Schematic of Temperature Probe Arrangement in each Borehole 57

Figure 4-12. Schematic of Horizontal Well Piezometer Positions 58

Figure 4-13. Schematic of Modified Air Lift Pump 59

Figure 4-14. Schematic of Air Lift Pumping System 60

Figure 4-15. Final System COnfiguration for In Situ RF-Enhanced Vacuum Extraction System 61

Figure 4-16. Photograph of In Situ RF-Enhanced Vacuum Extraction System 62

Figure 4-17. Typical TDR Record 63

Figure 4-18. Typical Return Loss Measurements of the Applicator 65

Figure 4-19. Typical Return Loss Measurement of the Tuner Input 66

Figure 4-20. Typical Applicator Insertion Scan (Return Loss vs. Distance Downhole 67

Figure 5-1. Network Analyzer Scan of Return Loss Prior to Final Heating Period on April 886

Figure 5-2. Return Loss Scan at $13.56 \mathrm{MHz}$ Versus Downhole Distance Data from Pre-heating Stage on March 2487

Figure 5-3. Return Loss Scan at $13.56 \mathrm{MHz}$ Versus Downhole Distance Data Prior to Final Heating Period on April 888

Figure 5-4. Well Flow, Applied Vacuum and Well Wall Temperature 3/25/93 - 4/8/93 89

Figure 5-5. Well Flow, Applied Vacuum and Well Wall Temperature 4/8/93 - 4/27/93 89

Figure 5-6. Well Flow, Applied Vacuum and Well Wall Temperature 4/27/ 93 - 5/31/93 (Cooldown Period) 91

Figure 5-7. Comparison of Well Wall Temperature to Subsurface Temperature Measured @ MHV-24T "B" (38 foot depth in clay zone) 92

Figure 5-8. Horizontal Well Piezometer Data Related to Well Wall Temperature During RF Heating Demonstration 93

Figure 5-9. Exploded View of Figure 5-8 During the Final Heating Stage of the RF Heating Demonstration 94

Figure 5-10. Horizontal Well Piezometer, Flow, and PCE Concentration Data During Early Stages of Cooldown 95 
Figure 5-11. Contaminant Concentration During Heating Portion of Demonstration 96

Figure 5-12. Contaminant Concentration During Cool Down Portion of Demonstration 97

Figure 5-13. Cumulative Contaminants Extracted 98

Figure 5-14. Cumulative Discharges to Environment 99

Figure 5-15. Subsurface Temperatures in Clay at $38 \mathrm{ft}$ Depth 100

Figure 5-16. Plots of Temperatures Nieasured at $<18-\mathrm{ft}$ Depth 101

Figure 5-17. Plot of Temperature taken at 28-ft Depth 102

Figure 5-18. Three-Dimensional Image of Temperature Distribution on $4 / 3 / 93 \quad 103$

Figure 5-19. Three-Dimensional Image of Temperature Distribution on $4 / 9 / 93104$

Figure 5-20. Three-Dimensional Image of Temperature Distribution on $4 / 16 / 93105$

Figure 5-21. Three-Dimensional Image of Temperature Distribution on $4 / 21 / 93106$

Figure 5-22. Three-Dimensional Image of Temperature Distribution on $4 / 27 / 93107$

Figure 5-23. Three-Dimensional Image of Temperature Distribution on $5 / 3 / 93 \quad 108$

Figure 5-24. Three-Dimensional Image of Temperature Distribution on $5 / 10 / 93109$

Figure 5-25. Three-Dimensional Image of RF Heating Model Temperature Distribution 110

Figure 5-26. Vacuum Levels at a Depth of 48 Feet 111

Figure 5-27. Vacuum Levels at a Depth of 38 Feet 112

Figure 5-28. Vacuum Levels at a Depth of 28 Feet 113

Figure 5-29. Plot of Drawdown in Well MHV-24 after Vacuum Extraction Resumed 114

Figure 5-30. Plot of the Drawdown in Several "C" Piezometers at Varying Distances from the Wellhead - 115

Figure 5-31. Graph of PCE Concentration at "C" Piezometers Located within and Surround the Heated Zone of the Demonstration 116

Figure 5-32. Plot of TCA/TCE Ratio Measured in the Soil Gas from the Control Zone Piczometers 117 
Final Report: In Situ Radio Frequency

Heating Demonstration

Contents 


\section{Final Report: In Situ Radio Frequency Heating Demonstration}

\section{Executive Summary}

A field demonstration of in silu radio frequency heating wals performed at the Savannah River Site (SRS) as part of the U.S. Department of Energy-Olfice of Technoiogy Developments Integrated Demonstration. The objective of the demonstration was to investigate the effectiveness of in situ radio frequency (RF) heating as an enhancement to vacuum extraction of residual solvents (primarily trichlorocthylene and perchlorocthylene) held in vadose zone (lay deposits. Conventiona! soil vacuum extraction techniques are mass transfer limited because of the low permeabilitics of the clays. By selectively heating the clays to comperatures at or above $l(x)^{\circ} \mathrm{C}$, the release or transport of the solfene vapors will be enhanced ats a result of several lactors including an increase in the contaminant vapor pressure and diflusivily and an increase in the effective permeability of the formation with the release of water vapor. The demonstration team included participants from the Westinghouse Savannah River Technology Center (SRTC), the Westinghouse Science and Technology Center (Piltsburgh, PA), arid KAI Technologics, Inc., the developcrs and operators of the patented borchole applicator.

The in silu heating demonstration integrated RF applicator echnolegy and vacuum extraction from a single, horizonall will. The horesontal well was drilled hrough a shallow (ombuninated, subsurlace clay layer all a kepth of approximatcly $+(0$ led and wats conunuously serecned over a 30() loot horizontal sectoon. The applicator, approximately 17 lect long, operated all a maximum power output of $25 \mathrm{~kW}$ and a frequency of $13.56 \mathrm{MH}$. The applicator was inserted to a focation approximately 100 feet from the start of the sereened zone to heal one section of the well. The rakum extration system consisted of a rotary lobe hower capable of providing a How of approximately 150 sm all 6 mches Hg vacuum. Oflgases drawn from the well were devtroyed wilh a skid-mounted, thermal-callalytic malathon system. Several sertical horeholes were placed

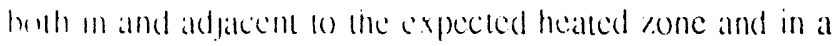
"cold" control zone lo montor temperatures, pressures, and voll gats concentratlons

The origmal kest plan for the demonstration called for a cold pump test to establish a bascline removal rate, fol-

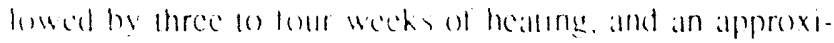

mately equal time span to monitor the cooldown period with continuous vacuum extraction. Offgas monitoring was used as the primary measure for confirmation of enhanced release of the solvents.

The heating stage of the test was conducted over a 34-day period with approximately 27 days of operation. Offgas concentrations from the well rose steadily during the initial stage (first 15 days) to levels ranging from 150 to 200 ppmv of perchloroethylene and from 20 to $30 \mathrm{ppmv}$ of trichlorocthylene. These levels were sustained over the latter half of the heating stage and appeared to correlate direclly with periods of applicator power output. The maximum soil temperature at approximately 6 feet from the center of the applicator reached $63^{\circ} \mathrm{C}$ from an initial ambient temperature slightly below $20^{\circ} \mathrm{C}$. The RF power output was controlled using commercial fiber optic temperature sensors located on the applicator and at the screen wall. The control temperatures ranged from 100 to $130^{\circ} \mathrm{C}$. Power output was cycled to maintain temperatures $v$ : thin these control values established by the limitations of the well casing material (fiberglass reinforced epoxy). The maximum RF output per cycle ranged from 10 to $25 \mathrm{~kW}$.

The radio frequency energy was coupled efficiently to the largeted clay layer from a horizontal borehole. The single RF applicator delivered over $95 \%$ of its available power to the surrounding contaminated clayey sediments. The applicator was tuned to the clay environment to present a \%olage standing wave ratio of 1.75 at its underground feed point and further tuned at the surface to present a ratio of 1.05 to the generator. The entire RF system (RF generator to applicator output) was estimated to operate with an $80 \%$ delivered energy efficiency to the clay. Excellent impedance matching existed throughout the heating test illustrating the effectiveness of pretest studies conducted to determine the dielectric properties of the targeted sediments and modeling studies conducted to design the applicator. During the demonstration period, approximately $11,(0(X)$ kilowall-hours of RF energy were successfully coupled to the subsurface sediments and heated a soil volume of nearly 1500 cubic feet to temperatures greater than $60^{\circ} \mathrm{C}$. The total volume heated to temperatures above ambient (approximately $2\left(0^{\circ} \mathrm{C}\right.$ ) was calculated at nearly $30,(X) 0$ cubic feet. The radio frequency electric ficld detected at the surface was more than two orders of magnitude below the established threshold limit values and posed no hazard to operating personnel. 
The original lest plan was moditied as a result of several lindings and unexpected behavior of the integrated system encountered during the initial stages of the demonstration. These lindings included well flooding from residual water or near salurated conditions near the screen and low vapor Hou. The first problem was eompounded by heavy rainfall encountered during the lirst hall of the test period. Rates of waller removal, performed with an air tift pump adapted (o) operate in a horizontal well alongside the RF transmission line, lypically ranged from 5 to 10 gallons per day. During the tirst hall of the test, the second problem, low vapor llow: Wals a direct result of the low permeability and high water content of the clay formation and negated aitempts ilt establishing an ambient temperature baseline release rate. During the later stage of the heating period, the low llow was a direct effect of the single well design. A high pressure ene, or vapor lock, was created at the applicator when comperatures in this region approached and aceeded 10()$^{\circ} \mathrm{C}$. This effect drastically reduced the zone of inlluence of the well vacuum on the formation and, consefuently, the extraction rate of comtaminants. Typical

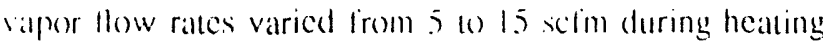
and from $20103.5 \mathrm{scl}$ (1) during coxhldown.

()er 170 kilograms of chlorinaled solvents were successlully exarated from the sediments over the course of the demonstration. The thermal catalytic oxidation system (kestroyed the contaminants with an efficiency ranging Irom sol) $1095 \%$. All discharges to the enviromment were well withon the permissible guidelines required by the vate of South Carolina.
Due to the problems encountered with the integration of RF heating using a borehole applicator combined with vacuum extraction from a single horizontal well, the results of the demonstration did not provide enough data to adequately assess the feasibility of applying the technology for thermally enhanced remediation of contaminated clays in the unsaturated zone. The demonstration provided a greater understanding of the important component and system designs, the critical operating parameters, and the essential site characterization requirements for in situ RF heating applications. The results and insights from this demonstration have also led to selecting specific solutions to address the problems encountered. The primary limitations resulted from the use of a relatively long, single horizontal well design screened within a low-permeable clay formation. A horizontal borehole application is advantageous for vadose zone remediation as the applicator can be moved through the well heating a progressively larger volume of the contaminated tabular clays. However, such an application must consider the proper choice of well completion materials that are compatible with the installation technique, RF electric fields, and the expected high temperatures. In addition, independent vertical extraction wells should be used and located within and in the perimeter of the expected heated zone to ensure adequate containment and sufficient extraction rates of both the solvent and water vapor generated by heating. 


\subsection{Introduction}

\subsection{Program Description}

\subsubsection{Background}

As part of the Integrated Demonstration of in situ remediation technologies at the Savannah River Site (SRS), a demonstration was performed to investigate in situ radio frequency (RF) heating as a means of enhancing ambient vacuum extraction of volatile organic compounds from vadose zone clay deposits. The demonstration employed a single collinear-loaded-dipole RF applicator designed for borehole applications. The demonstration team included participants from Westinghouse Savannah River Technology Center (SRTC), Westinghouse Science and Technology Center (Pittsburgh, PA), and KAI Technologies, Inc., the developers of the borehole applicator.

The final processing system for this demonstration integrated four technologies:

- soil vacuum extraction (SVE)

- radio frequency heating

- horizontal well drilling

- thermal/catalytic treatment of offgases.

The demonstration area was a shallow clay layer (kaolinite) contaminated with chlorinated volatile organic compounds (CVOCs, primarily perchloroethylene [PCE] and trichloroethylene [TCE]). The clay layer is adjacent to an excavated leaky process sewer line that ran between the M-Area metal fabrication facility and its Resource Conservation and Recovery Act (RCRA) - closed seepage hasin (see Figure 1-1). A more detailed description of the targeted site and its history is available in the field test plan for the SRS In Situ Radio Frequency Heating Demonstration (WSRC-RP-92-1428). Previous studies at the site (Eddy et al. 1991) show that a large fraction of the solvents that were released to the subsurface are held above the water table within these clay layers. Slow release of the residual solvents provides a long-term source of groundwater contamination. Because of the low permeabilities of the clays, conventional (ambient temperature) soil vacuum extraction techniques are mass transfer limited. By selectively heating the clays to temperatures at or above $10\left(0^{\circ} \mathrm{C}\right.$, the release and transport of PCE and TCE should be enhanced as a resulf of several factors:

- an increase in the solvent vapor pressures and diffusivitics
- an increase in the sediment's effective permeability with the release of water vapor and residual solvent

- favorable shifts in liquid-solid and gas-solid adsorption equilibria

- enhanced removal from steam stripping by water vapor generated in situ.

Radio frequency energy heats the soils through a dielectric heating mechanism in which the applied electromagnetic field physically distorts the atomic or molecular structure of the material. The physical distortion is transferred into mechanical and then thermal energy. Pretest studies conducted to measure the dielectric properties of the sediments (Snyder, Harold, and Kasevich 1993) showed that the clays, because of higher water content, will preferentially capture the RF energy, focusing the applied power precisely in the zones that need to be heated. For this test, selecting the KAI RF applicator technology over competing heating techniques was driven by three issues:

- Because of its ability to penetrate and couple with the soil, RF heating is faster than conductive (e.g., ohmic or joule heating) heating mechanisms and does not require a continuous conductive path from the source $t o$ the targeted zone. Convective heating mechanisms (e.g., the injection of hot air or steam) are not considered effective because of the low permeability of the clays.

- Because the RF energy from the KAI applicator can be focused to the clays, its overall energy efficiency is higher than other RF designs.

- Because the KAl collinear applicator is compatible with horizontal well applications, its use results in an efficient integrated heating process.

\subsubsection{Integrated System}

The targeted clay-layer is located at a depth approximately 40 feet below the surface and varies in thickness to a maximum of about 10 feet. A horizontal well was drilled through the clay layer and completed with a screened fiberglass casing. Figure 1-2 illustrates the location of the horizontal well with respect to the seepage basin and other significant landmarks in the Integrated Demonstration (ID) site. Integrating the RF borehole applicator and horizontal well drilling technologies was chosen for the following reasons:

- The clay layers are tabuiar in extent and the horizontal configuration can, therefore, provide better aceess 10 and extend its zone of influence over a larger volume of the targeted contaminated sediments for vacuum extraction. 
- The horizontal well permits placement of the applicator in a geometry that maximizes coupling the RF fields with the targeted clays.

- A single applicator can be moved through the well progressively heating a larger volume with a single borehole.

The same well was used to heat the formation and extract vapors. The process arrangement depicting the layout and integration of the four technologies is shown in Figure 1-3. Vacuum extraction was accomplished with a rotary lobe blower capable of providing $150 \mathrm{scfm}$ at 6 inches $\mathrm{Hg}$ vacuum. Chlorinated solvent vapors were destroyed (to $\mathrm{CO}_{2}$ and $\mathrm{HCl}$ ) prior to atmospheric discharge by passing the offgas stream through a ceramic-supported monolith halocarbon oxidation catalyst. Both the RF and SVE-catalytic oxidation systems were wholly contained portable units capable of being transported to other remediation sites.

\subsubsection{Program Plan}

Prior to the demonstration, both laboratory and field testing were performed to determine soil treatability (Snyder, Harold, anu' Kasevich 1993). Surrogates of the targeted sediment were analyzed in the laboratory to determine the dielectric properties as a function of frequency and water content. These properties were used as input to KAl's proprietary computer mociel that supported applicator design and predicted expected heating rates and temperature contours in the field (Kasevich and Benham 1992). This information was used to set the initial operating parameters of the field test unit. Onsite analyses of the test well were performed prior to heating to verify dielectric properties and to confirm applicator design. These pretest measurements were critical to RF process control and optimization to ensure that the applicator impedance is matched to the impedance of the soil load, which varies as a function of moisture, temperature, and, therefore, heating time.

The field demonstration was conducted in three stages chosen to adequately assess changes in vacuum extraction rates that could be attributed to RF heating (the listed time frames were those originally proposed):

1. Ambient temperature vacuum extraction (two wecks), conducted to cstablish a basclinc removal ratc

2. RF healing application (threc to four wecks). conducted with continued vacuum extraction to healt one zone of the screened section of the horizontal well.
3. Cooldown with continued vacuum extraction (three to four weeks), conducted to monitor changes occurring as the subsurface temperatures return to ambicnt.

The primary variable monitored to detcrmine the cffects of RF heating was the CVOC concentration in the offgas, which was sampled scveral times daily to track the changes in extraction rates over timc. In addition, scveral borcholes werc placed within and surrounding the anticipated heated zone and within a "cold" control zonc and completed with monitoring equipment to track changes in subsurface temperatures, pressures, and soil-gas concentrations. To supplement ficld monitoring, pretest and posttest characterization was performed on core samples to measure changes in the CVOC and water content. A detailed description of the characterization techniques and results can bc found in Eddy-Dilck ct al. (1993).

\subsection{Program Participants, Relationships, and Organization}

This program was a coopcrative effort between the Environmental Sciences Scction (ESS) of Savannah River Technology Center (SRTC) - Westinghousc Savannah River Company (WSRC), the Environmental Tcchnologics Department of the Westinghouse Science and Technology Center (STC), and KAI Technologies of Woburn, MA. The ovcrall organizational structure at the demonstration initiation is shown in Figure 1-4. The program was co-managed by Mr. T. L. Walton of SRTC and Dr. T. S. Snyder of STC. Mr. Walton managed the demonstration sitc preparation that included: horizontal well drilling, lining, and finishing; ficld tempcrature and pressurc monitoring well drilling and fitting; offgas treatment system procurement and well interfacing; and analytical scrvices. Dr. Snyder managed soil treatability testing and RF scrvices and interfaces. KAl Technologies (Mr. R.S. Kascvich, President) supplied the RF hardware and operational scrvices under subcontract to STC via partial order transter to the Westinghouse Environmental Scrvices Busincss Unit (ESBU).

Ficld opcrations were conducted by a cooperative effort between Mr. T. R. Jarosch of SRTC, Mr. R. J. Beleski of STC, and Mr. D. L. Faust of Eyring Corporation (subconiracted of KAl for Rf equipment operations). Mr. Jarosch coordinatcd all non-RF sitc preparation, mobilization, and operational activitics and was the ficld team leader. Mr. Fatust coordinated the RF equipment mobilization and managed its operation. Mr. Beleski coordinated all SRS- 
KAI interfaces and provided direct assistance with mobilization and operational activitics of both SRS and KAI hardware.

\subsection{Program Objectives}

The four primary objectives and criteria for determining the success of this demonstration are summarized below:

- Simple installation, start up, and trouble free operation of the integrated system. It was important to demonstratc that the RF applicator tcchnology provides controlled and efficient heating for the types and stratigraphy of sediments at SRS (i.c., interbedded clay and sand layers) and is compatible with usc of a horizontal well drilled to target the contaminated lenses.

- Accelerated volatilization of TCE and PCE from the contaminated soil. The primary purpose for the addition of heat to the contaminated zoncs was to increase the volatilization ratc significantly over that expcricnced with simple vapor cxtraction.

- Reduced cost over comparable technologies. It was important to demonstrate that the normalized cost of the RF-accelcrated vapor extraction is compctitive with altcrnative remediation technologics. Our goal was to demonstratc the cost savings from the projected reduced remediation timc will, as a minimum, compensate for the added cost of the RF capital and opcrating costs.

- Conformance of field performance with treatability studies and computer predictive modeling. Confirmation of the ability to accuratcly asscss soil trcatability and model performance prior to cquipment mobilization is cssential for accuratcly scaling the process and detcrmining costs prior to investment. The results of the actual ficld demonstration will be used to refine the treatability regimen and modeling codes. 


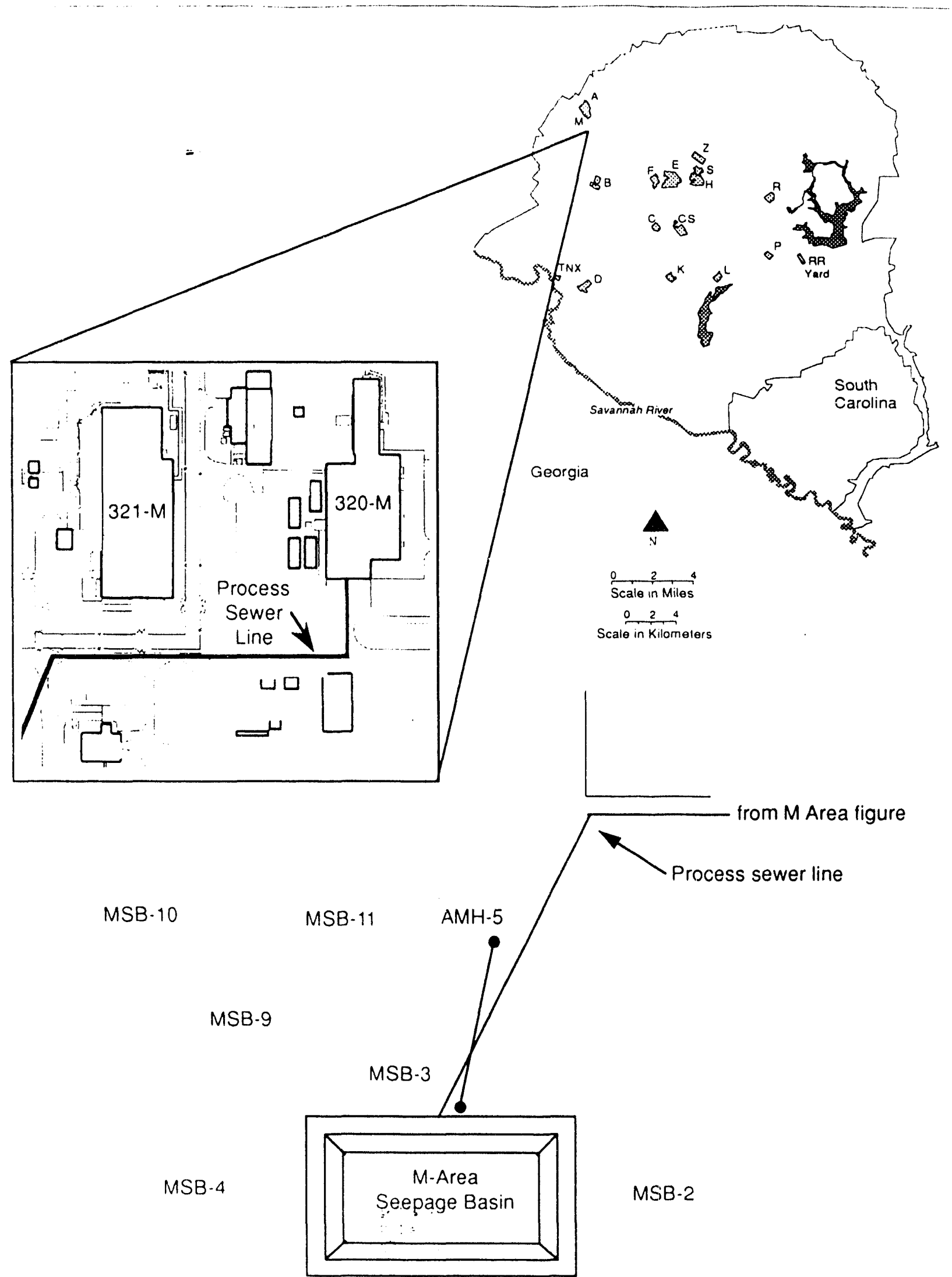

Figure 1.1. Savannah River Site Integrated Demonstration Project Area Location Map 
Final Report: In Situ Radio Frequency Heating Demonstration

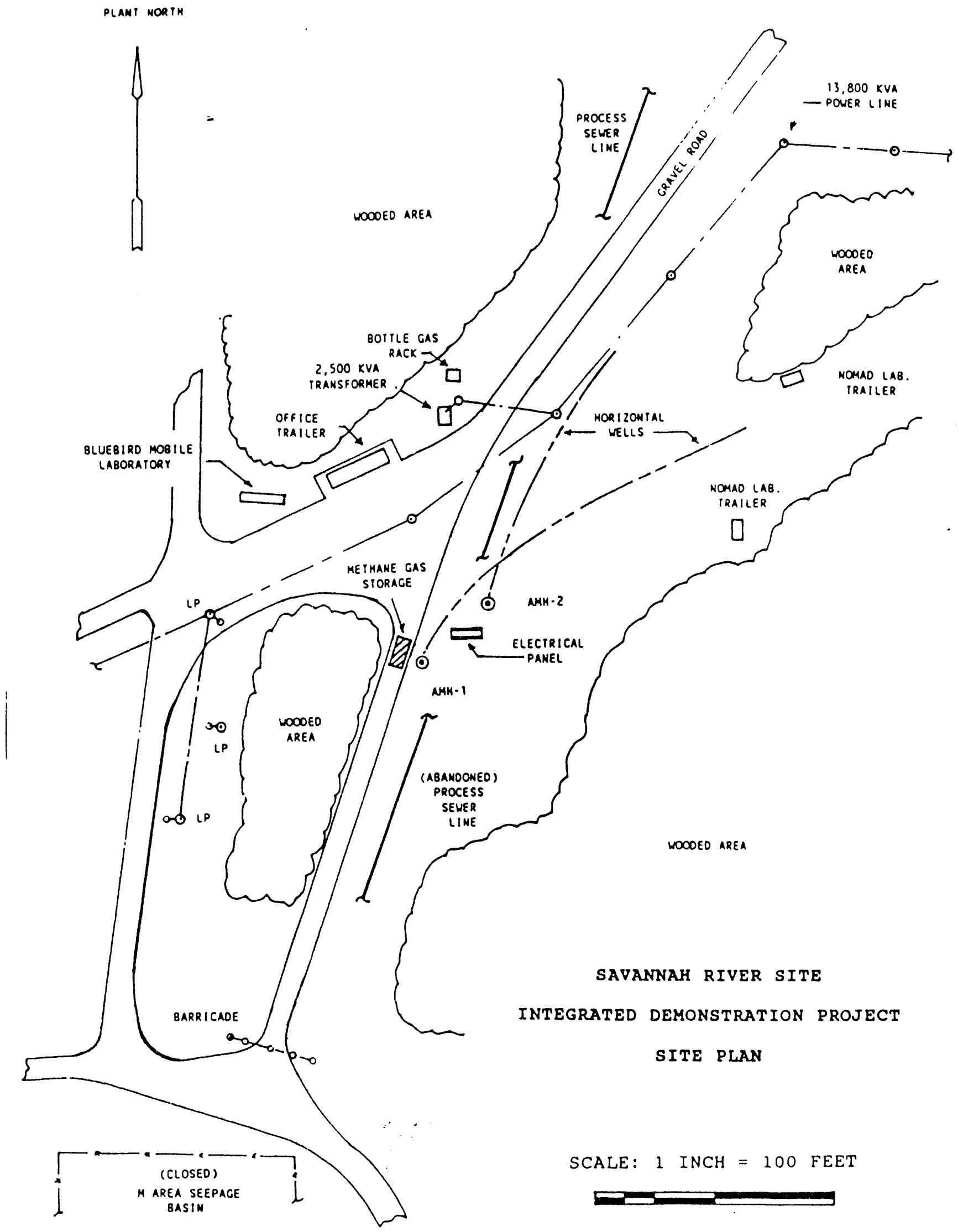

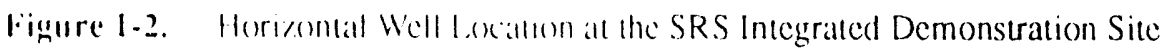




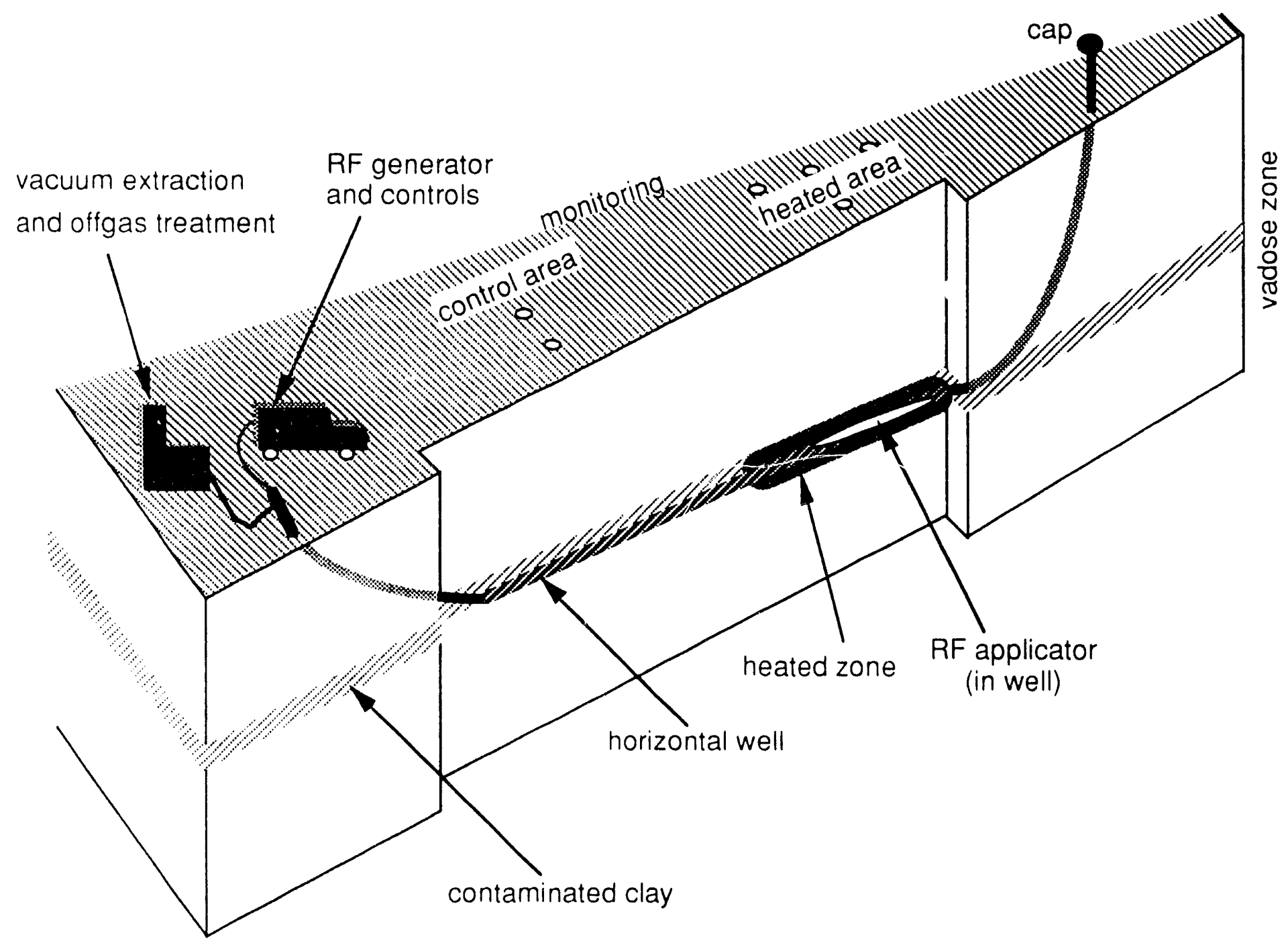

Figure 1.3. Schematle Diagram of RF.Enhanced Vacuum Extraction Process 


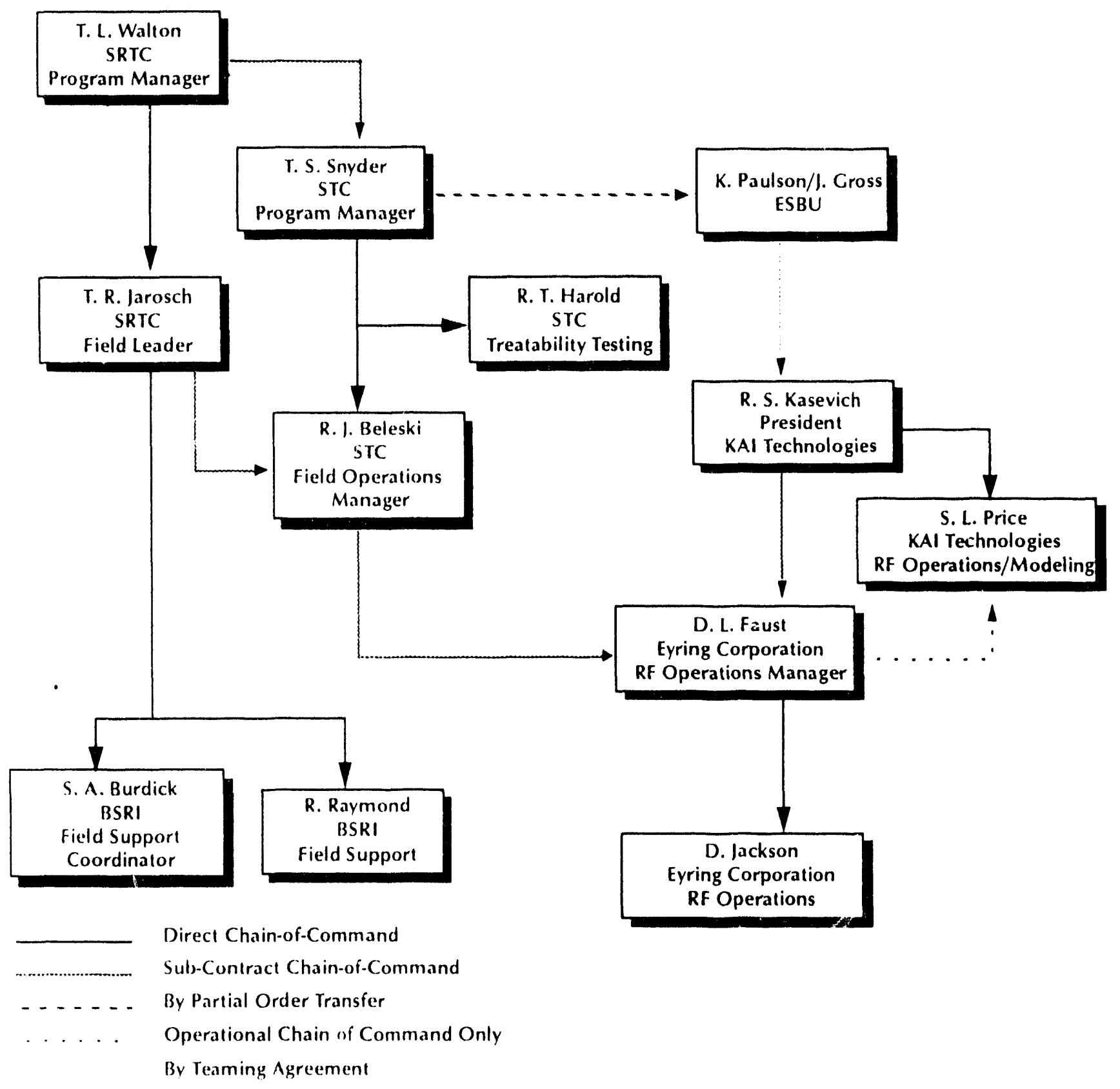

Figure 1-t. Promed Oreambatton lor In Situ Radio Frequency Heating Demonstration 
WSRC.TR.93.67.3 


\subsection{Conclusions}

\subsection{General Summary}

The performance of the individual components brought logether lor the in silu radio lrequency (RF) heating demomstration all met or exceeded expectations. However, the mllegralled system (detined als the overall design incorporalling the combination of vacuum extraction operations with the RF borchole applicator in a single horizontal well) did not perlorm optimally 10 result in definitive conclasions regarding the foisihility of RF as an in situ heatIn: source for thermal enhanced remediation. Several problems encountered in the field were solved successfully whik others were $(0)$ diflicult to approach or change in a thert demonstrattion of this nature. The latter are hurdles that can he readily owercome. Solutions are discussed further in Chapter 3. A briel description of the performance and results with regard to mectung the lour primary program objectives is listed below. The remainder of this inapler as a more detalled listlly of the pertormance, cesultio of the individual components, and the operations of the arerall megratled design.

1. The difficultes that impacted the installation, start II). and operation of the demonstration were successfully solved or minimized in the lield. The RF horehole applicalor operated successlully in a horicontal well application delivering greater than 95\% (1) its available power to the surrounding sediment while operating for approximately 500 hours at power outpuls above $20 \mathrm{~kW}$. Slightly more than 11 NWH of RF energy were coupled to the sediments wer 27 ditys of operation, heating a volume of approximallely 1.5()() cubic toct to temperatures above 6()$^{\circ} \mathrm{C}$. Hardware modifications to the transmission line design were sucessfully made and accounted for the added thermal stresses encouncered in a horizontal application. In addition, the computer control programs and diagnostic equipment integral to the KAl iystem were capable of iensing the onsed of adverse conditions in the well and could power down the sysem in an orderly lashon fo aroid unnecessary damage and, thereby minimize opkrating downtimes.

2. A gradual increasing trond of PCE and TCE concentrallons in the olligats was ohserved that enerrelated to contunued mpul of RF encrey. Concentrations rose

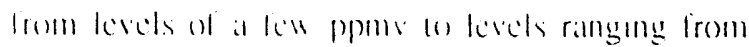

150 to 200 ppmv of PCE and from 20 to 30 ppmv of TCE. However, two significant factors related to the single well design restricted assigning these effects solely to RF heating:

- Limited flow from the formation early in the demonstration resulting from the low permeability of the clays and compounded by high saturation levcls. This effect negated attempts at obtaining bascline extraction data. A gradual increasing trend in solvent release rates may be characteristic of clays under extended periods of vacuum extraction with natural drying of the formation.

- Formation of a vapor lock down hole at the applicator from steam generated by the RF energy. Once temperatures at the applicator approached $100^{\circ} \mathrm{C}$, there was little or no vacuum in the well at the heated zone.

3. A breakdown of the costs for this dr nonstration and for a projected commercial operaton are given in Chapter 5. The basis for these studies is a cost per hour or tay of operation and cost per $\mathrm{KW}$-hour of forward-coupled RF power. As a result of the flow and vacuum elfects listed above, the extent of contaminant release from the heated volume under sufficient vacuum extraction could not be detcrmined. In addition, the duty cycle of the applicator was significantly alfected by the choice of casing material, thereby reducing the volume heated for a fixed operating period. Therefore, while this demonstration provided useful data on the cost of planning, mobilizing, and operating a remediation project, an accurate determination of the true cost per cubic yard of treated sediments is not available.

4. Pretest studies to measure the dielectric properties of the soil and modeling studies that incorporated these parameters to support the design of the applicator were successful. Excellent impedance matching of the applicator to the surrounding clayey sediments existed throughout the demonstration. However, pretest modeling to predict subsurface temperature contours was unsuccessful in predicting field results. This was due in part to the reduced duty cycle of the applicator required by the temperature limits of the well screen and in part to simplifying assumptions on the effects of water vaporization and mass trans. port. Improvements to the pretest modeling efforts are discussed further in Chapters 3 and 5. 


\section{$2.2 \quad$ Integrated System}

While important insights were gained in the operation of the inlegrated system, the single well design and the site conditions limited the ability to effectively demonstrate ficld pertormance. A summary of these issues is presented in the sections that follow.

\subsubsection{Single Well Operation}

A number of complications were encountered by attemptIng 10 combine vacuum extraction with RF heal application In a single, horizontal well. Several of the effects from these complications played critical roles in the ability to meet the demonstration's objectives. The effects associated with the use of a single horizontal well were rooted in causes unique to the demonstration design and more generally, 10 a single well application, and impacted both vac. tum extraction and RF applicator operations. The following is a list of the effects encountered in the demonstration:

- Low air How from the formation. This was the first allempl at placing a vapor extraction well screcned within a clay formation of low permeahility. Results Indleatle that the clay formation near the well was close (1) siluration, further reducing the elfectuve permeabil. ily. High salturation levels were due to excess water used in the well installation and completion and to the large ramnlall tevels in the months just preceding and during the initial stages of licld activities. Figure 2-1 displays the daily and cumulative rainlall from January 1. 1993, through Nay 31, 1993. The low flow (typically less than 2() sefm) significantly impeded the initial cold pump 心st stage of the demonstration, and, therefore, limiled allempts to obtain meaninglul baseline data. In addition. It was difficule to determine the primary cause of changes in the \%ne of inlluence of the well vacuum and in the contaminant concentrations in the offgas. These changes could have heen results induced by healing or by extended vacuum extraction with natural drying al the formation near the well screen.

- Water infiltration into the well. Vacuum applied to the well pulled in enough waler ats the valcuum levels withen the well were sulticient to overcome capillary lores, withun the sediments adjacent to the well screen. The phenomena resulted in the following effects:

blonked flow through the well. The prohlems trom is aller mbillation mos the well were compounded by the well deseng. In particular, the how pornt or "vmpl" ane of the well was localed near the entry pestll where 11 transillom from horwontal and rases (1) th: surface. Thes was the simle end of the well shere the appleater was mered and the vacuum

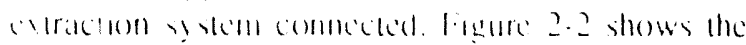

location of the well low point with respect to applicator position and flow direction. A sufficient influx of water occurred over a twenty-four hour period to physically block the well casing (approximately one cubic foot of water will fill 16 feet of casing or screen). Flow restrictions were detected by pressure changes in down hole piezometer tubes. Large pressure surges were observed when infiltration was suflicient to lill the screen, creating a manometer-like water plug. The problem was solved by adapting a commercial air-displacement pump that was modilied to operate in a horizontal position (for a further description of the pump adaptations see Chapter 4). The pump was capable of removing water at a rate of $2 \mathrm{gph}$.

Periodic quenching of the RF applicator. Evidence of water infiltration upstrearn and surrounding the applicator was observed as rapid temperature depressions of the well screen temperature probe and the RF heating applicator detuning as sensed at the RF power generator. Initially, these events automatically lowered the driving RF power level or, as a protective measure, shut down the RF heating sys. icm completely. The system control program was modified to automatically sense the presence of the water and to restart the heating cycle at full power within minutes of the conclusion of the water flow. The net effect of the quenching events was to decrease the effective heating time of the system. The worst case events subtracted as much as $20 \mathrm{~min}$ utes of heating time out of a heating hour.

- Steam formation in the well. Water converted to steam by the absorption of RF energy created a vapor lock that dramatically reduced flow. This was the most critical cffect of the single well design. Figure 2-3 schematically displays this concept. The effect of steam formation is evident by observing how well llow was inversely related to downhole temperatures at the applicator (see Figure 2-4). As the downhole wall temperature approached $100^{\circ} \mathrm{C}$, the flow dropped rapidly to approximately one-third the original rate and responded only slightly to successive increases in the applied vacuum. This vapor lock effect was also observed in pressure measurements at the piezometers located at and upstream of the applicator. Vacuum levels decreased to near standard barometric pressure despite increases in the applied vacuum once temperatures at the applicator approached or exceeded $100^{\circ} \mathrm{C}$ (sec Figure 2-5).

- Logistical complexities. The entire integrated system, including extraction operations, had to be interrupted to repair damaged or failed equipment in the well (RF application, water removal, or critical instrumentation). 
Consequently, vacuum extraction data with the RF fxower off could not be laken while repairs and modifi. cations were conducted. In addition, the operation and monitoring cquipment and instrumentation was crowded, restricting delivery of an optimally sized water pump and complicating applicator insertion and retricval. Figures 2-6 and 2-7 illustrate crowding at the horizontal well head.

- RF energy application was controlled to protect the well screen. Thi: relatively low komperature rating of the liberglass horizontal well screen (approximately $\left.12(1)^{\circ} \mathrm{C}\right)$ set a limit on the application time of the RF energy lo the formation. The borehole wall temperature ensor was used to determine if the temperature limit wats being approached. When the temperature reached a sel point the RF heating system was tumed off or shilted to a lower power level until air movement in the porchole cooled the horehole liner to a restart temperalure, typically 10 degrees below the set point temperalure. The net eflect wats 10 lower the average delivered power to the formation from nearly $25 \mathrm{~kW}$ to approximately $20 \mathrm{~kW}$.

\section{L.. Vacuum lextraclion Rates}

I. a result of high salturated conullons near the well sereen, msulficien bascline extraction data were collected (1) adcyuately assess the ellectivencss of RF healting on extracting contaminants from claty. The llow and contamimant release characteristics from clays will occur at a signiticantly slower ratle relative 10 other, more permeable sediments. Figure 2.8 displays the wellhead TCE and PCE concentrations and well wall temperature (used as an indicallor of RF "power on" conditions) over the course of the healling stage. There was some evidence that contaminant concentrations from the well showed posituve response to RF energy delivery during the heating portion. The elfects were curlenced as a gradual increasing trend in contarninamt concentrations from the well with continual power output, and rapid, smaller variations in the concentrations that appeared to correlate to RF power on/off cycles. Howcver. there was no conclusive cvidence that the gradual trend was solely related to the application of RF heat. Becaluse of insulficient data on CVOC extraction from chasy and ensufficient annbient extraction haseline data. one cannot rule oul that the oherved general trend may hase vimply been the untyue releate characteristics of

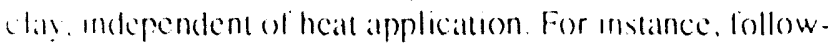
mes rach of the lirit lour healling eyckes depeled in Figure

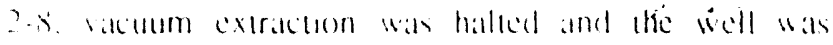
upened contenuously ower periods rangme from one lo three days. The conncident rese an offgas concentation wh renewed power oulpul $1 \mathrm{rom}$ the applacilor may be due in part to transient mass transfer effects characteristic of the clays.

Observations of the change in extraction rates during the cooldown stage illustrate the significance of the loss of vacuum downhole, which occurred with steam formation during the heating stage. An approximate order of magnilute rise in the extraction rates was observed during the cooldown stage of the test. This effect is due largely to the recovery of higher vacuum levels within the well as downhole temperatures dropped. The ability to attain a sufficicnt vacuum downhole resulted in more than doubling the llow ratc. In addition, the higher vacuum levels extended the zone of influence, yielding an approximate eight-fold increase in offgas concentration of perchoroethylene.

\subsubsection{Horizontal Well Zone of Influence}

The zone of influence of the well vacuum, which is a function of the apparent permeability of the formation, improved significanlly in the control zone (MHV 27-29) and in the area of greatest thermal exposure (MHV 24). A condition where an increase in the vacuum influence after heating stopped and the well temperatures began to cool was observed in the " $\mathrm{B}$ " and " $\mathrm{C}$ " piezometer rieasurements (screened within and above the clay lens, respectively) of the control zone monitoring wells and of the MHV 24 monitoring well. Figure 2-9, shows the changes in vacuum levels over time for the " $C$ " monitoring wells. Beyond those induced by cyclic barometric changes, litue or no effect on the recorded vacuum levels in the piezometcrs was obscrved during the initial cold vacuum extraction and heating stage. As a result of the limited zone of influence caused by high saturation levels within the clays, at the start of the test and of the low vacuum in the well from steam formation during heating, it is difficult to ascribe the change to an effect of heating. This conclusion is supported in that the strongest increases in draw-down were observed in the control zone.

Despite the enhanced zone of influence, the absolute drawdowns were small. Drawdowns in the control zone of 4 to 5 inches of water were measured at approximately 14 feet irom the well (at vacuum levels of near 70 inches of water in the well). At distances of approximately 30 feet from the well, drawdowns were on the order of two inches.

\subsection{Radio Frequency System}

\subsubsection{Radio Frequency Radiation Coupling to Clayey Sediments}

The radio frequency energy was coupled efficiently to the urgeted clay layer. The RF applicator delivered over $95 \%$ 
of its avaluable energy to the surrounding clay. The applicator was connected to the RF generator by a low-loss, 305-ft RF transmission line with a total insertion loss of $0.389 \mathrm{~dB}$ (9) 1 ; efficiency). Tho applicator was cuned to the clay chviromment to presert a volt-standing wave ratio (VSWR) (1) 1.75 to the transmission tine. This VSWR was lurther matched to the RF generator through the tuner to present a VSWR of I.OS to the generator. The entire RF system (gencrattor output to applicator outpul) was estimated to operate with an 8()$\%$ (telivered energy efficiency to the clayey layer surrounding the applicator. Excellent impedance matching extsted throughout the heating test, illustrating the effecIveness of pretest studies conducted to determine the dicleciric properties of the largeted sediments and modeling itudies conducted to support applicator design.

\subsubsection{Temperature Ramp-Up Rates}

Ihe meatsured temperalure al MHV-247 ("B") increased all an alverage rate of $\left(1.1^{\circ} \mathrm{F} / \mathrm{hr}\right.$. This monitoring point was located in the clay layer@a distance of approximately 6.25 feet from the center of the applicator slightly above the plane of the horizontal well. The maximum temperalure achicved at this location was $146^{\circ} \mathrm{F}\left(63^{\circ} \mathrm{C}\right)$, approximallely $8(1 \% F$ above ambient condiluons. A lemperalure rise abouc ambient was delected a maximum distance of 15 fee trom the applicator. Figure 2-10 shows temperatures at the monutoring points where the most significant effects "rere maisured.

\subsubsection{Heated Subsuriace Volume}

The maximum temperatures and the volume of the subsurliace heated by the RF lield was considerably smaller than predicted with pretest modeling. This result is due in part to the reduced duly cycte of the applicitor required by the cemperallure limils of the well sereen and to simplifying ansumptums used in the pretest model (Kasevich and Benhat11 1992) (for further (liscussion, see Chapter 5). Figure 2-11 is a three-dimensional (3-D) image of the heated zone at the conclusion of the heating stage of the test. An image of the healce sone predicied by the model is given in Figure 2.12. The temperature distribution mages were generalled from scaltered datal sels using a commercially analable. 3-D modeling soltware parkage (Interacuve VolImme Modeling " IIVMI, version 5.(), Dynamic Graphics, Alameda, (A). The scallered datal sec for the field test was comstrueded primarily from thermocouple data while the molel was gencraled by rolatung a 2-1) kemperalure confour plet around the applicaltor axis. To remove any hias andeclated with hoth the gredding program algorsthm and Hos dellerence in avallable datla pemts between the actual

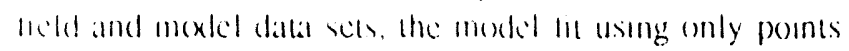

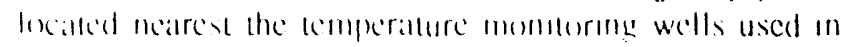

the field. The pretest modeling predicted that a volume of approximately 4000 cubic feet would be heated to temperatures at or above 6$)^{\circ} \mathrm{C}$, assuming a continuous output of 20) $\mathrm{kW}$ over a 21-day period (10.08 MWH total energy outpul). The calculation for the actual test data gives a volume of nearly 1500 cubic feet heated to temperatures in cxcess of $60^{\circ} \mathrm{C}$. The analogous calculation of volumes bounded by higher temperatures near the applicator were not made because the well wall temperature was the only monitoring point within this region. It should be noted that the well wall temperature, which was used in the data sets, underestimates the maximum temperature achieved in the clays adjacent to the well caused by enhanced convective heat transfer loses within the well casing. A more rigorous 3-D/multi-phase, heat and transport model (TOUGH2) is being investigated to improve the accuracy of the predicted performance of both the horizontal well and the RF applicator.

\subsubsection{Radio Frequency Surface Fields}

The field delected on the surface posed no hazard to personnel. The onsite measurements did not exceed $50 \mathrm{~V}^{2} / \mathrm{m}^{2}$ at any time. Typical electric field values measured above the heating zone ranged from 0.1 to $5 \mathrm{~V}^{2} / \mathrm{m}^{2}$, with 0.1 to ( $) .5$ being the most typically recorded values within 1 meter of the soil surface.

The threshold limit values (TLV) for the $13.56 \mathrm{MHz}$. heating frequency are

$$
\begin{aligned}
& \text { power density }\left(\mathrm{mW} / \mathrm{cm}^{2}\right)=4.89 \\
& \text { electric field strength squared }\left(\mathrm{V}^{2} / \mathrm{m}^{2}\right)=770 .
\end{aligned}
$$

The measured values were low enough that they would not have been measurable on some electromagnetic ficld meters designed to measure only near hazardous.

\subsubsection{Thermal Stresses on Radio Frequency Transmission Line}

The thermal expansion and contraction allowances of Industry Standard RF transmission line components were not adequate to compensate for the temperature extremes encountered during the RF heating cycle.

\footnotetext{
Thus limut is for 6 minutes of continuous exposure to this specilic frequency of non-ionzing radiation. It is calculated from ANSI standard CY5.I and is recognized by OSHA and the American Conference of Covernment Industrial Hygienists.
} 
Final Report: In Situ Radio Frequency Heating Demonstration

The thermal expansion of the transmission line center conductor caused the line to "short" or heavily "load" several Imoses during the carly heating cycles. The events were diagnosed with a time domain reflectometer (TDR) and were resolved by physically shortening the copper center conductor of the transmission line.

The thermal contraction of the transmission line also produced "opens" during the cooldown cycles of the system. The "opens" were diagnosed by the TDR in combination with power pulses from the RF generator. In these cases, the center conductor lube cooled more slowly than the center conductor junction anchors that joined the rigid transmission line sections. The difference in radial contratelon raltes created "perfect" open circuits for several minutes alter power was removed from the system. This problem limited the use of low-power diagnostic tests immediately alter a heating period was concluded. However, the open circuits proved to be "self healing", and temperatures at these points equilibrated. This problem would also not have allowed the use of typical solid-state $R F$ power generalors thal would have sensed the "open crecuil" and proteclively shut down.

\subsection{Vacuum Extraction System Thermal Catalytic Destruction Efficiency}

The CVOC destruction elficiency in the offgas stream was helow expectations. The catalytic oxidation (Catox) syskim destroyed TCE all an efficiency of greater than $99 \%$ and PCE at an elficiency ranging between $80 \%$ and $90 \%$. However, total discharges were well within those allowed by the South Carolina Departunent of Health and Environmental Control (SCDHEC) Air Permil exemption. The destrucuon performance of PCE degraded over lime. The yilem was designed to (lestroy $95+\%$ TCE and 9()$+\%$ $P C E$ at the operating conditions supplied by the vendor. The low destruction efficiency for PCE is not a result of perer calalyst pertormance, but is believed to stem from hypassing the catalyst block calused by laaks in the ceramic insulation. Figure 2-13 displays the destruction cliticiency of PCE over lime.

\subsection{Temperature Monitoring}

$\therefore$ Si. Spectrophotometric Fiber Optic
Temperature Sensors

Several problems were encountered with the fiber optic prober used ats in silu lemperalure monitors. These sensors, which were developed and palcented at SRTC, give lughly accuratc 10 mperature readings by measuring the temperature-dependent light absorption of neodymiumdoped glass. All of the probes placed in the ground were not inspected before installation. As a result, approximately half of the probes were not useful and several additional probes failed over the course of the demonstration. In addition, the transmission efficiency and quality in the fiber optic lines used at the surface were both light and temperature sensitive. This effect degraded the signal at the spectrophotometer and introduced a large background noise. The effect was minimized by placing the lines within PVC pipc. The remaining probes functioned well during the test. However, the multiplexer and spectrophotometer system were not robust enough to handle the frequent power outages encountered in the field that resulted in shifts in the baseline absorption spectra. Fortunately, no temperature monitoring boreholes were located in a strong enough RF field to adversely affect the measurements with the T-lype thermocouples. However, as a result of the loss of the fiber optic probe data, the number of monitoring locations for 3-D gridding of the heated zone was effeclively cut in half. The data from the fiber optic probes are currenuly being analyzed by the SRTC Analytical Development Section that will provide a report on the assessment of the sensors at a later date.

\subsubsection{T.Type Thermocouples}

The T-lype thermocouples operated successfully in parallel with fiber optic temperature probes and provided resolution on the order of $\pm 1^{\circ} \mathrm{F}$ even in the presence of a significant RF field (at MHV-24T " $B$ " sensor). Measurements with the isotropic electric field probe indicated that the leads did conduct low but measurable levels of RF energy to the soil surface. Even the thermocouple positioned within 6 feet of the applicator was usable throughout the entire heating program. This appears to be due to the perpendicular orientation of the thermocouple wire relative to the axis of the applicator, the use of a non-magnetic T-type thermocouple and the input common mode rejection, and filtering the temperature indication instrument. It is also believed that the use of an isolated $A C$ power source, physically distant from the RF heating system generator, may also have minimized RF interference problems that may have been associated with a common ground system.

\subsubsection{Fluorescence Decay Fiber Optic Temperature Sensors}

The fluorescence decay sensors were used to monitor the temperature of the borehole wall and the surfaces of the applicator components. The probe tips were threaded into protective Tellon ${ }^{m}$ cubes. The measurements made with this system were limited in accuracy to \pm 3 degrees on 
some channels because of the attenuation introduced by the length of the sensing tiber's interface cable and splice losses. In general, the borehole wall sensor channel operalled within \pm 2 degrees of a mean value trend. The wall sensor provided a relative indication of the borchole wall kimperalure since it was enteased in a Teflon ${ }^{\mathrm{TM}} / \mathrm{air}$ jacket that was configured to push against the wall. The exact contact pressure and air flow characteristics about the sensor could not be known precisely and, therefore, limited the imerpretation of the temperature data.

\subsection{Sediment Characterization}

A complete description of the lithology and stratigraphy at the sile and the sampling and analytical techniques used for core analysis can be found in a separate report on the rharatcriatton activities for the test (Eddy et al. 1993).

\subsubsection{Volatile Organic Contaminant Content}

The demonstration did not reduce contaminant levels in the allected sediments. Based on the small \%one of influence of the well vacuum coupled with the characteristic low permeability of the clays, this linding is not surprising. The large extent of the vadose rone plume at the site makes it difficult to analyze sediment datia with the intent 1) ohlatinng a mass balance for temonstrations smaller in siatle. This is especially true in healting demonstrations where the \%one of influence for valcuum extraction is typically signiticantly greater than the zone of influence of the healting source. The results show that there is, however, a distinet movenent of contaminant towards the well. An analysis of the contaminant extraction rates observed over the course of the demonstratton suggests that the solvents were mohilied aller heating when the well vacuum and sone of inlluenee increased signilicantly. Figures 2-14.

$2-17$ are unages of the PCE and TCE content of the sediments (all concentrations $>1 \mathrm{mg} / \mathrm{kg}$ ) for both the pre-lest and post-kest annalysis. Daltabases from the pre-test and pesitest VOC chemical analysis values were prepared for graphical representation using the same software program as kescribed in Section 2.3.3. These images clearly iden. lify the highest residual contaminant concentrations disiributed in the clay-rich sediment layers. Volumetric allilysis trom these images suggest that the concentrations whin the monitored rone (heated and control) increased as solvent valpors from regions of greater residual content are drawn in towards the hortental well.

\subsubsection{Mcisture Content}

The moisture content of the cores sampled from the clay. rich layers in the heated zone decreased substantially. (Sce Figures 2-18 and 2-19; the MHV designation refers to pre-test coring data and MHB refers to post-test data). Saturation levels were calculated based on gravimetric analysis using estimated sediment properties (density, grain size, porosity) (rom previous studies conducted at the sitc. While a general drying trend is apparent, the posttest saturations levels remain relatively high at $60-70 \%$ (these values are at or below the estimated residual saturation levels for the clays). The corings occurred approximately five months apart and no statistical information on scasonal variations in moisture content of the clays is available. It is unlikely, however, that clays at this depth would experience such variations over the time span of this demonstration.

\subsubsection{Effect on Biopopulation}

There was little observed effect of heating on the population of subsurface microorganisms. Typically, viable counts of cultured bacterial strains were below detectable limits and no enhanced thermal effects from elevated incubation temperatures were observed It is difficult, in gencral, to extract and culture microbial populations from clayey sediments. To adequately assess the impact, direct fluorescent antibodies (DFAs) were used as probes for organisms previously identified at the site. Further analyses of samples are being conducted and additional testing will he performed to assess the adequacy of the techniques for cmployment in future in situ thermal demonstrations. 


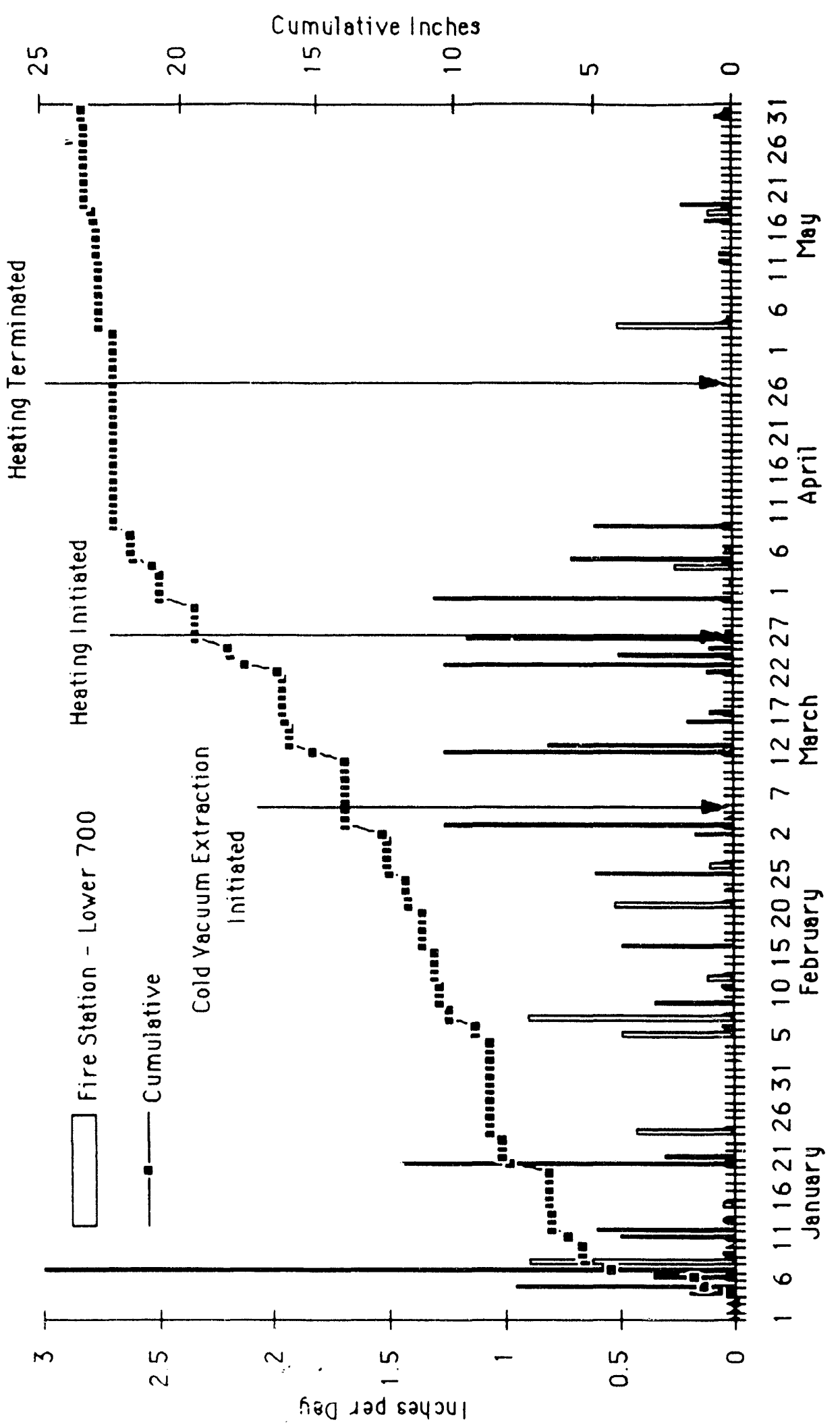

Figure 2-1. Dally and Cumulative Rannlall at Demonstration Site January 1 - May 31, 1993 


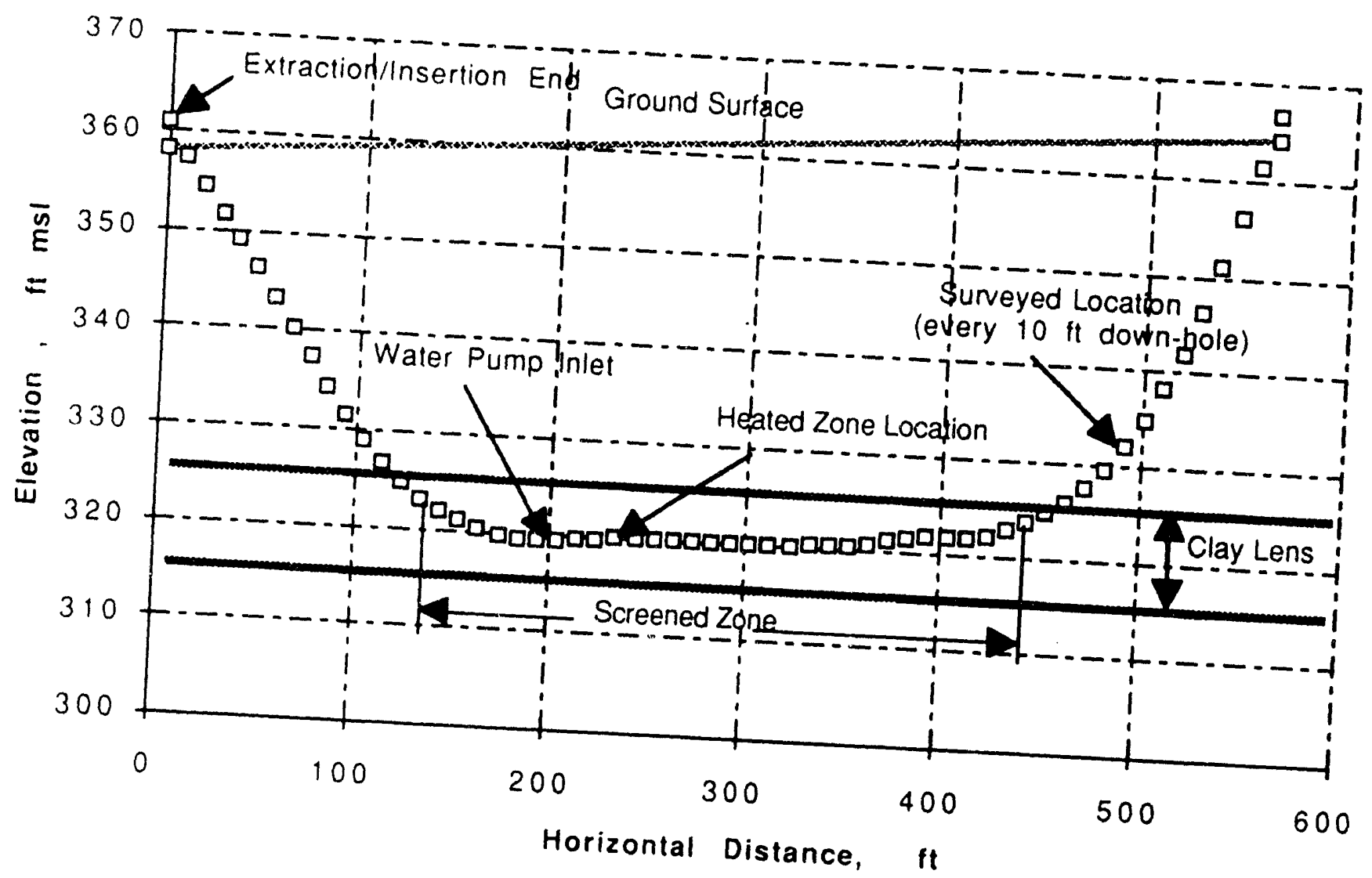

Figure 2-2. Schemalk of Hormemtal Well Surveyed Elcration Vicw 


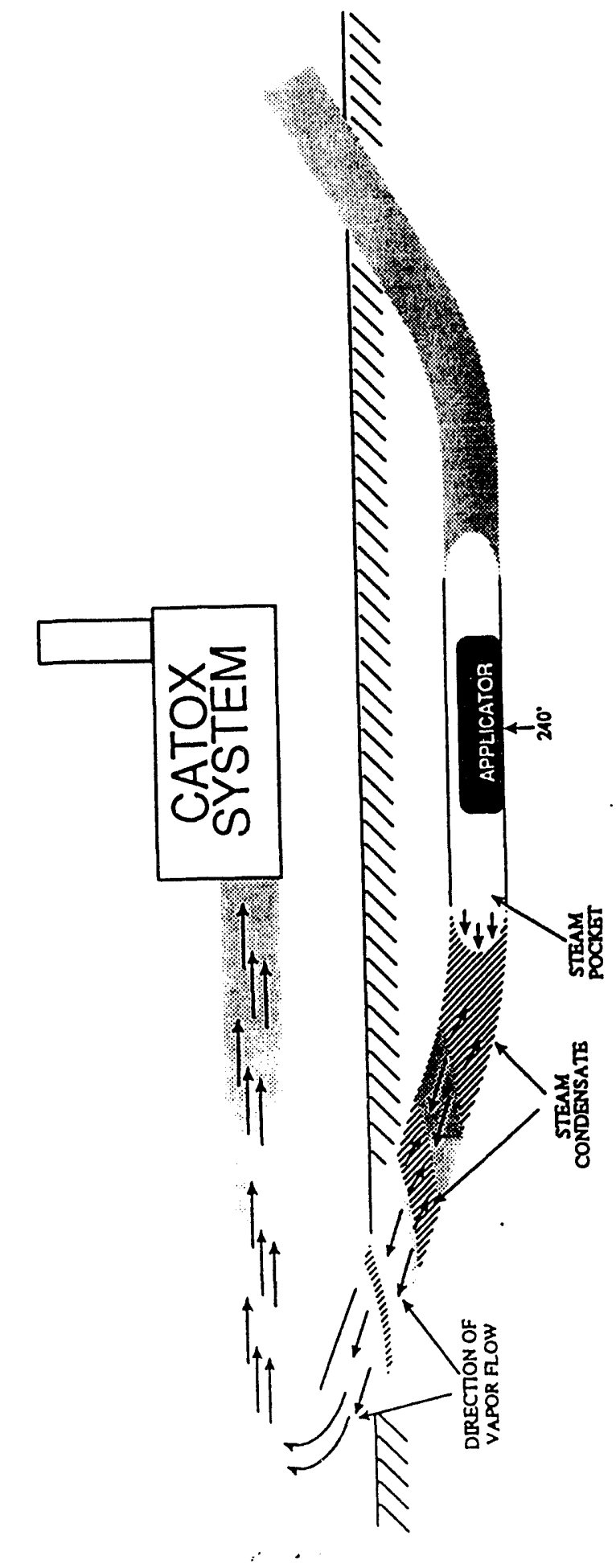

ligure 2-3. Sichematte of Vapor lock Formed Downhole al Temperatures above $10\left(0^{\circ} \mathrm{C}\right.$ 


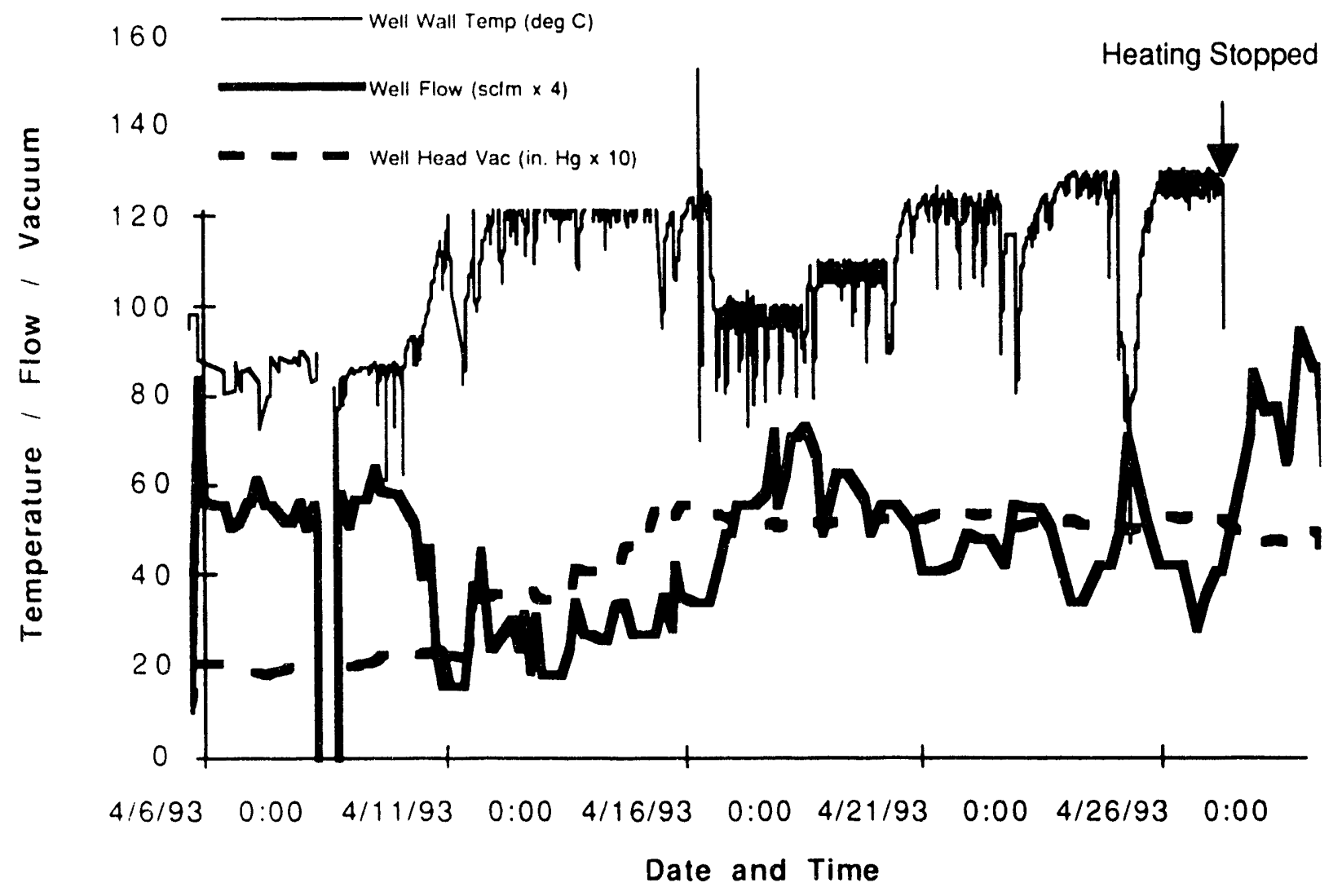

Figure 2-4. Comparison of Measured Wall Temperature, Total Flow from Well, and Vacuum Levels at Well Head during the Hoalung Stage 


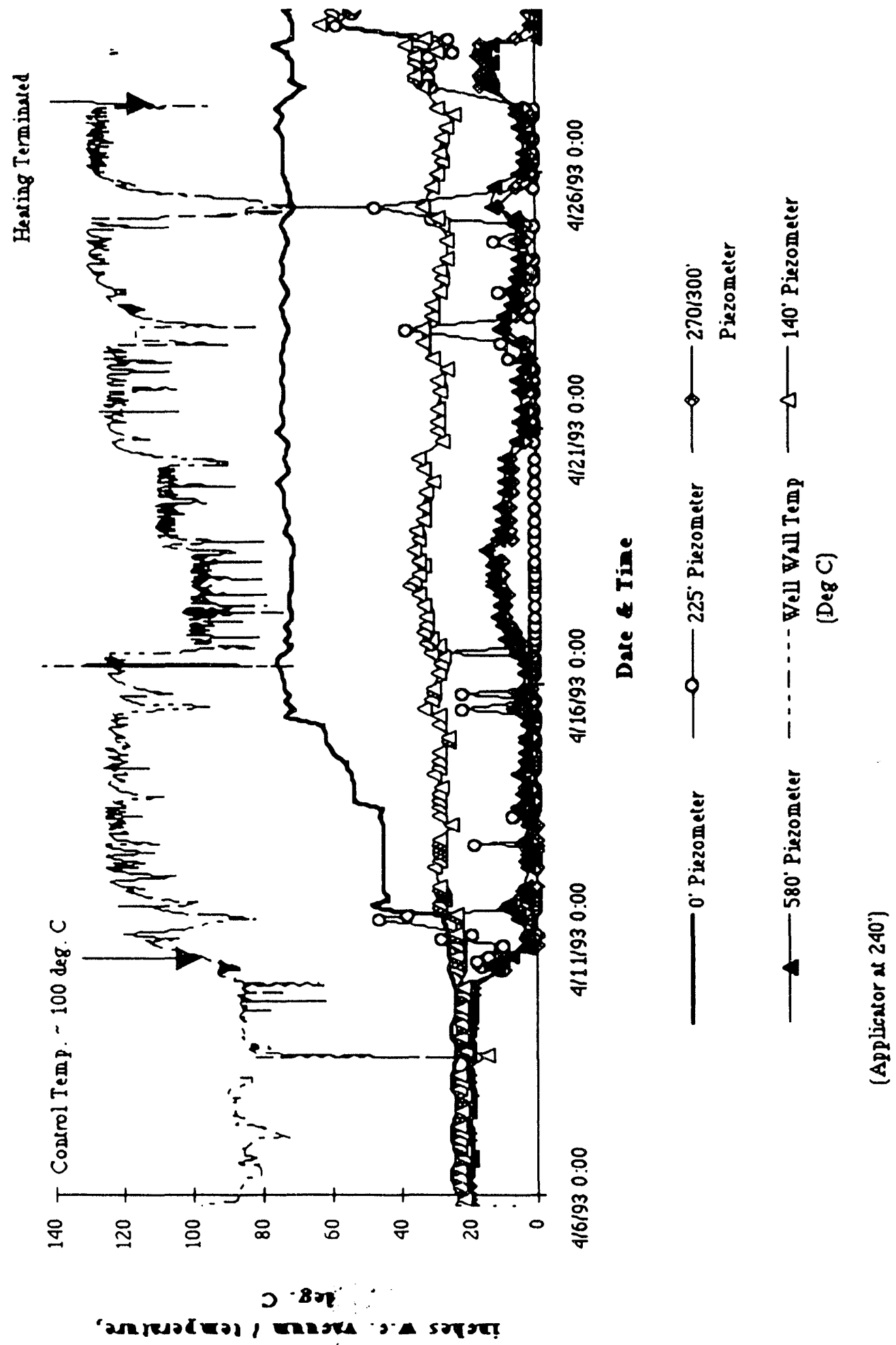

Figure 2.5. Comparison of Mealsured Hormontal Well Piczometer Vacuums to Wall Temperature during Heating Stage and Start ol Conldown 


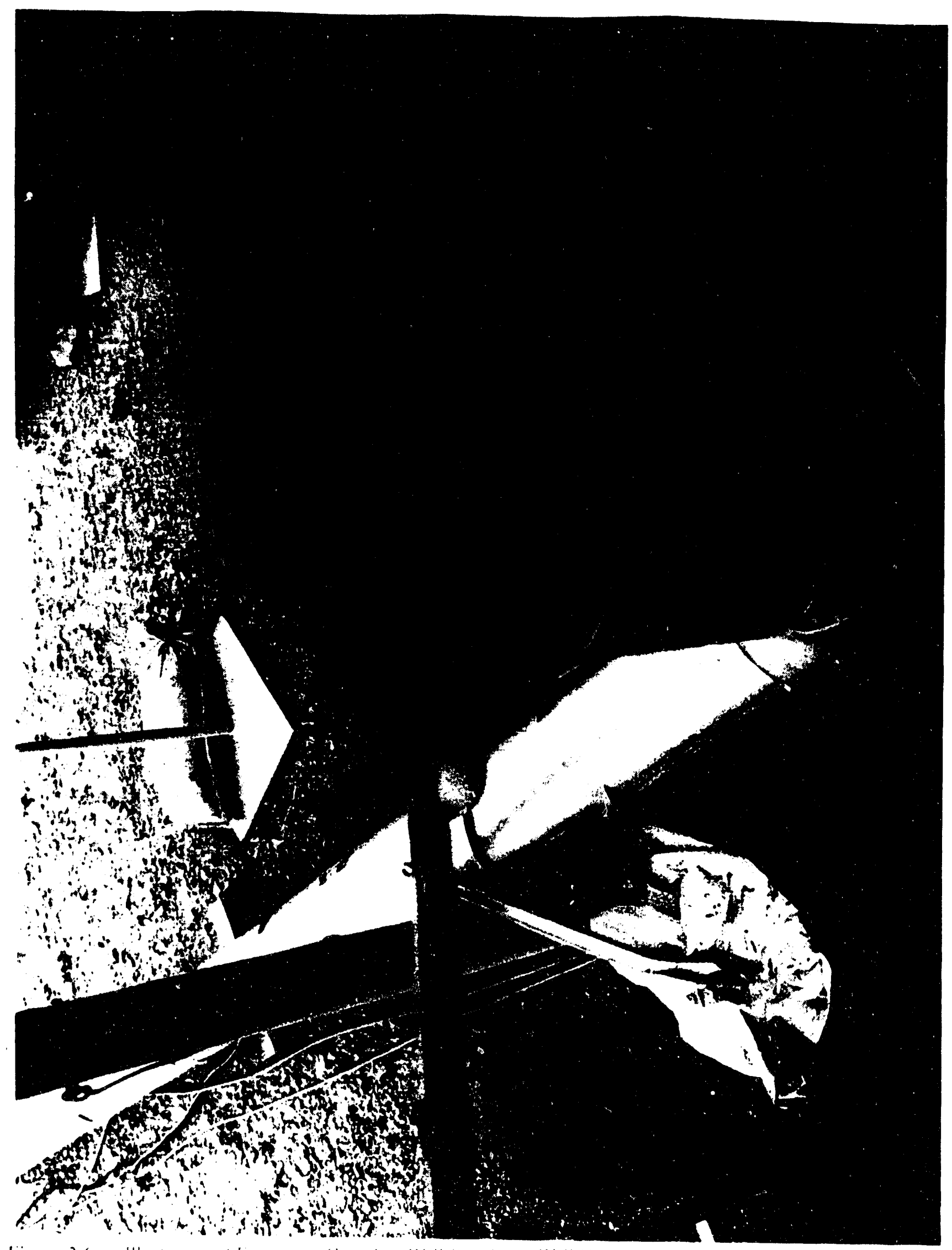

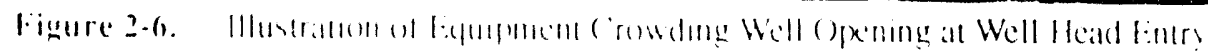


Final Report: In Situ Radio Frequency Heating Demonstration

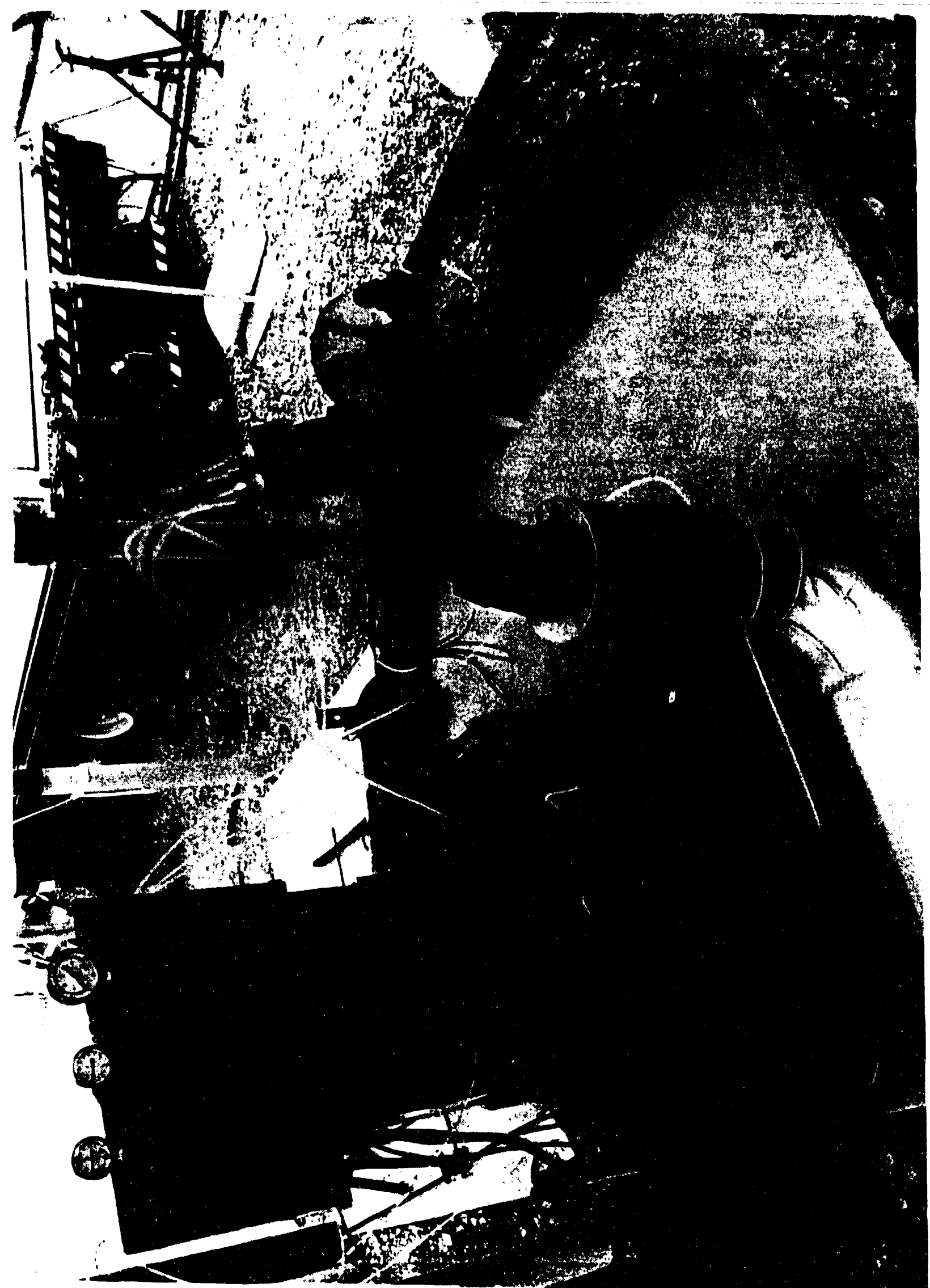

ligure 2-7. Hormantal Well Head durme Normal textractuon and RF Power Operations 


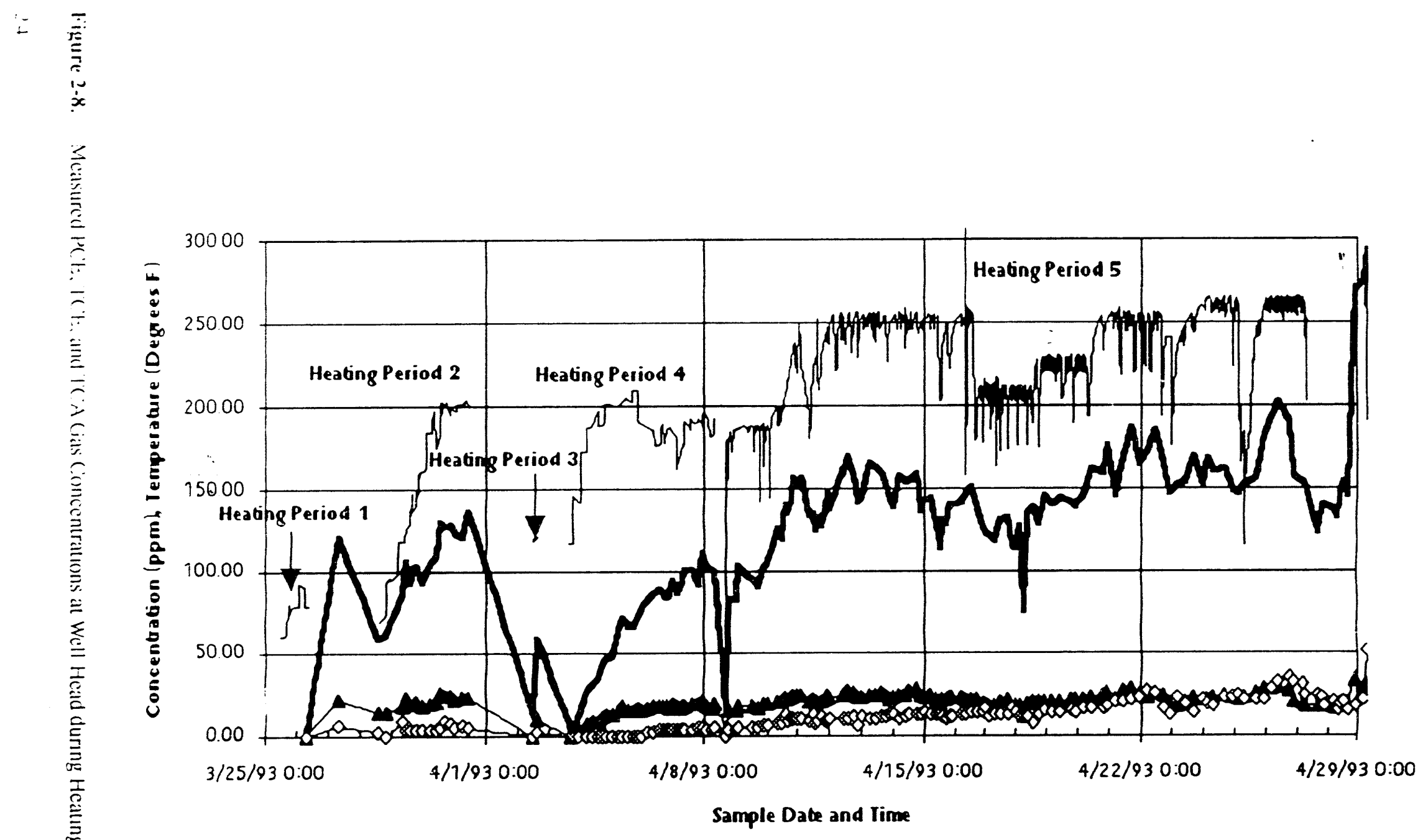

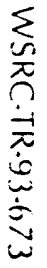




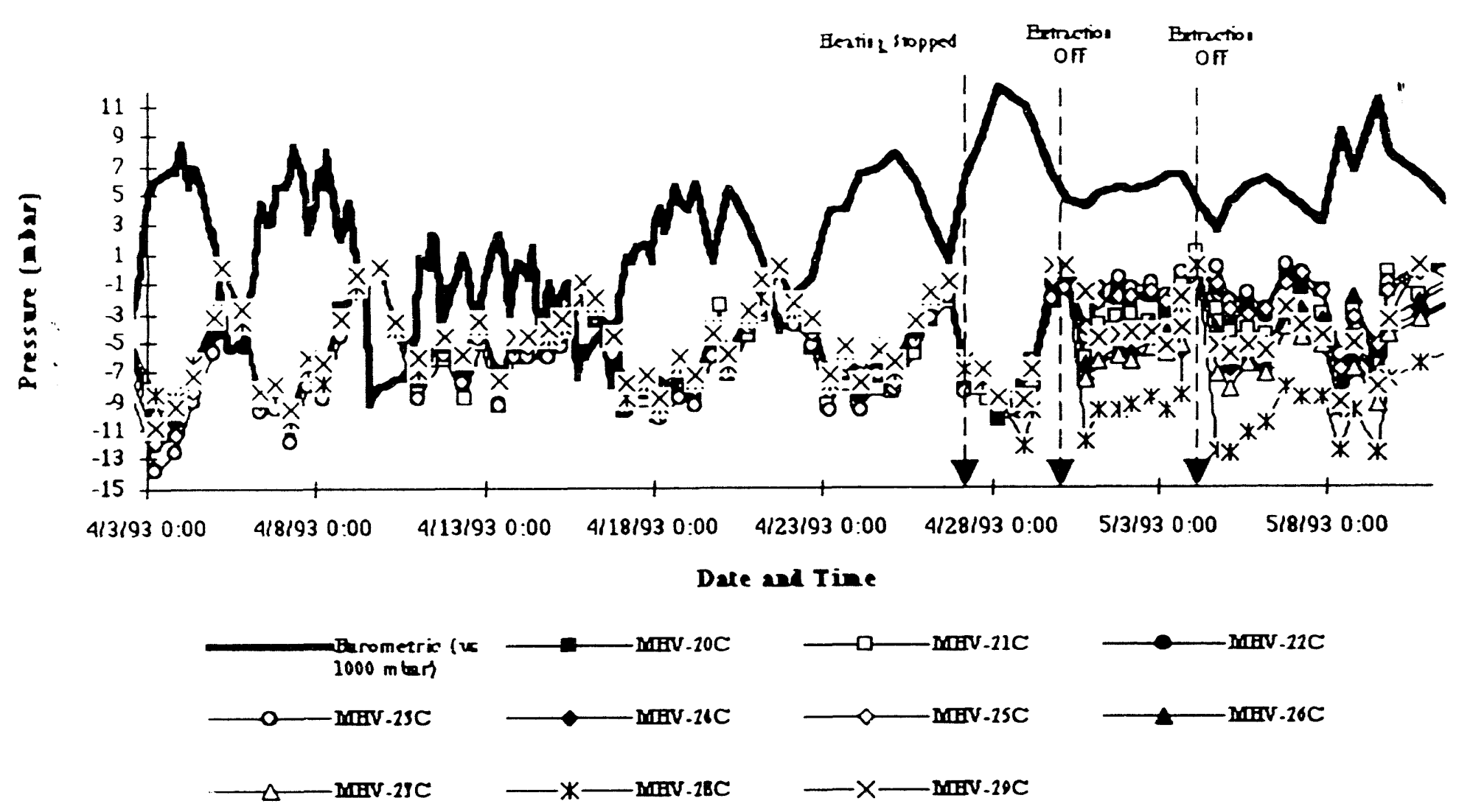




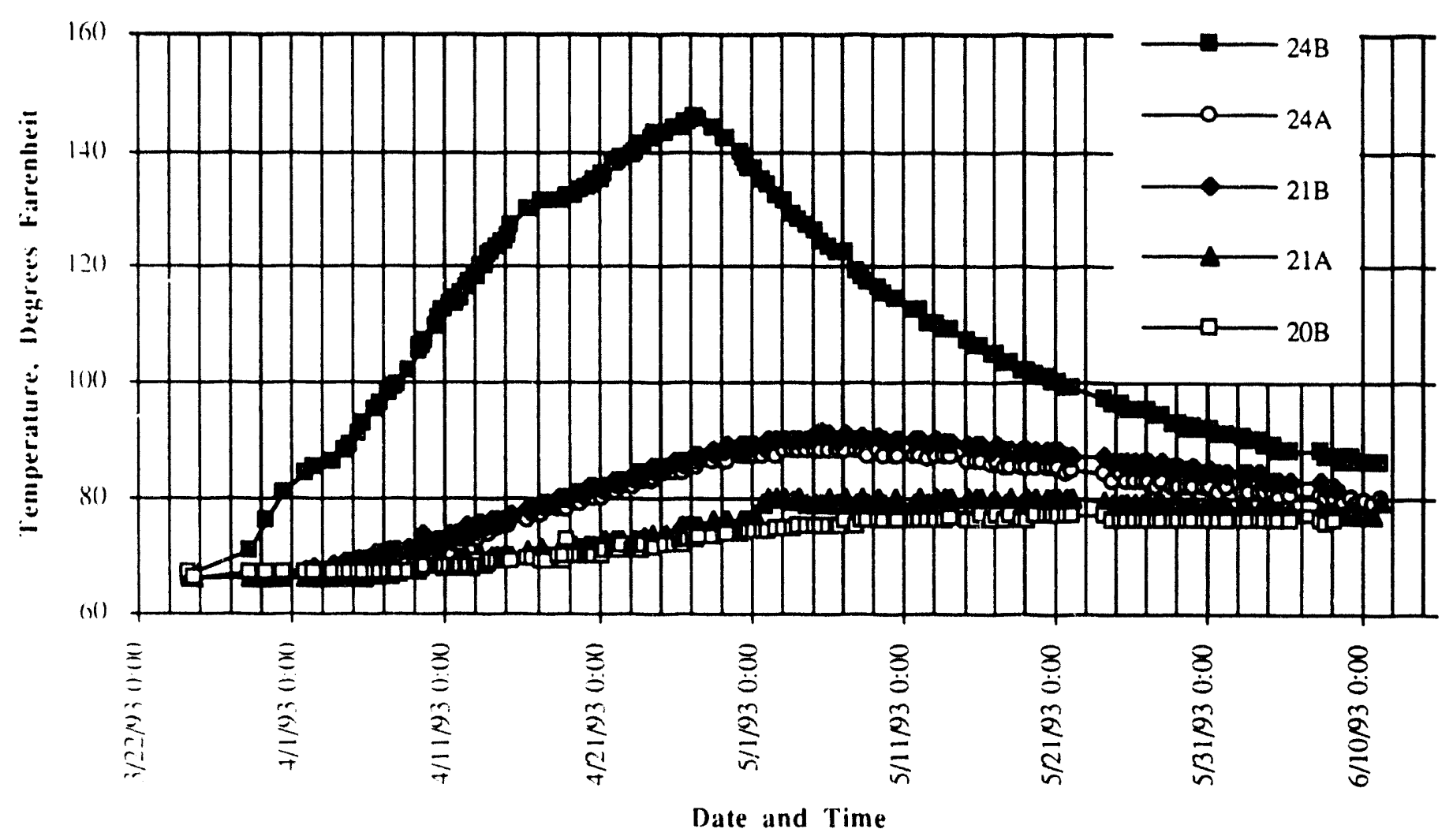

Figure 2-10. Measured Subutulate Temperalures all Selected Momitoring Wells over the Course of the Demonstration 


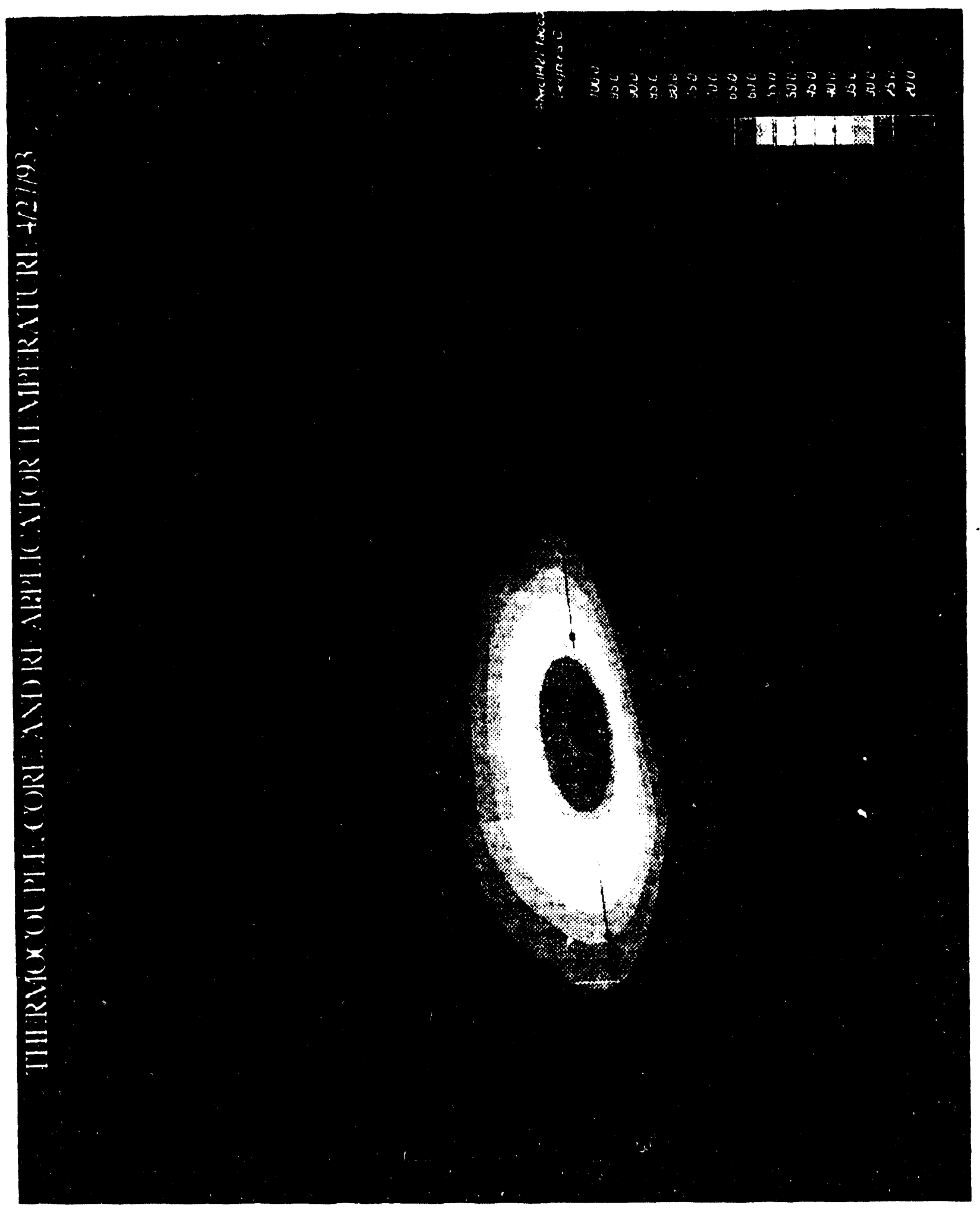

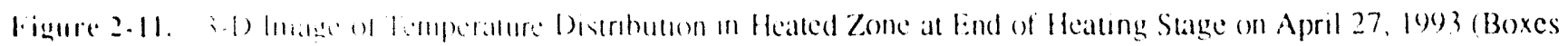

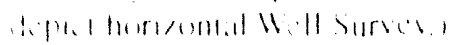


WSRC. $+1 R \cdot 93 \cdot 6,73$

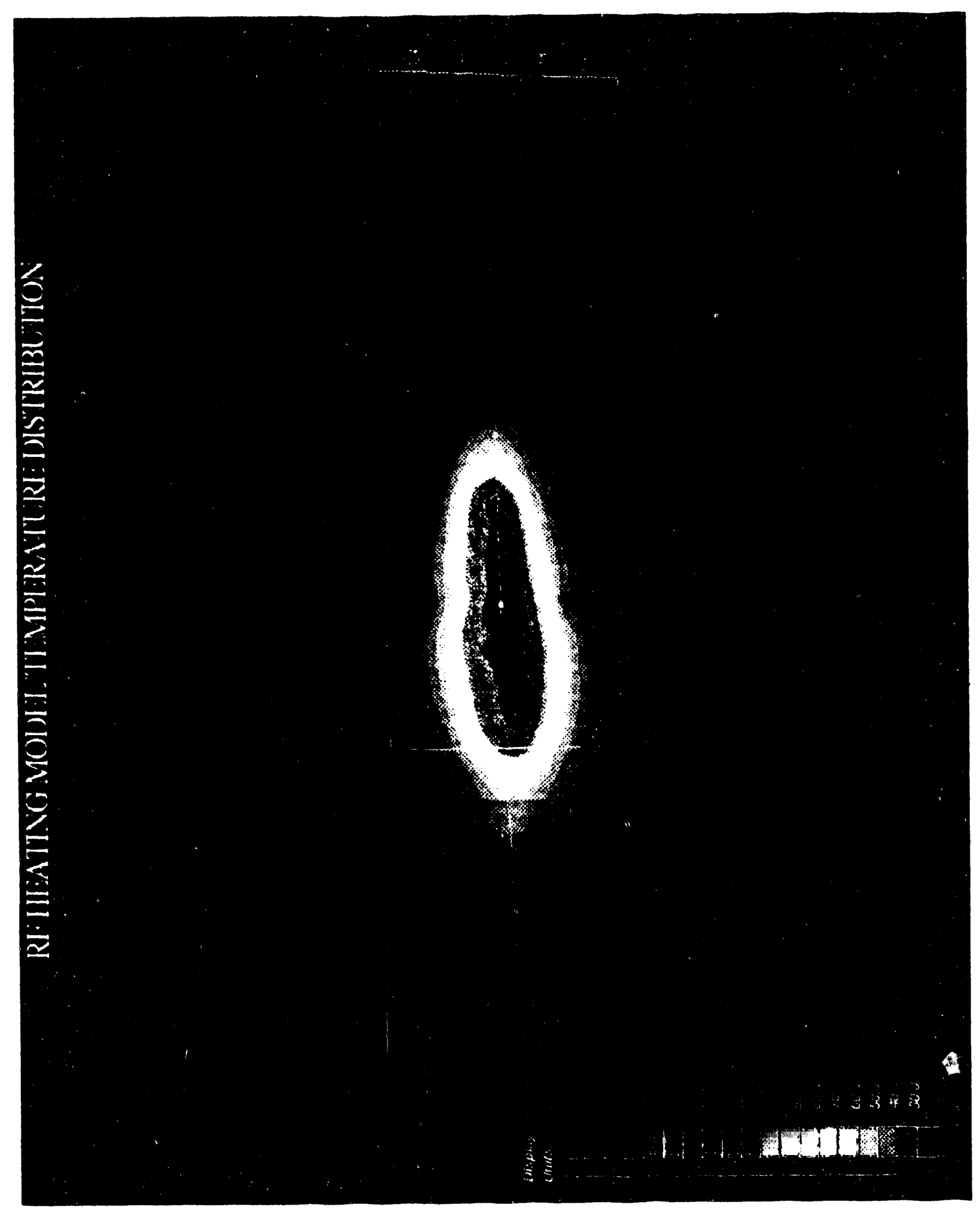

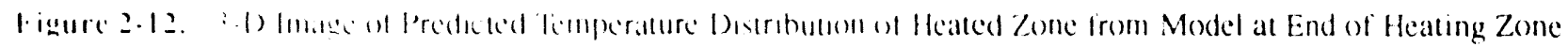




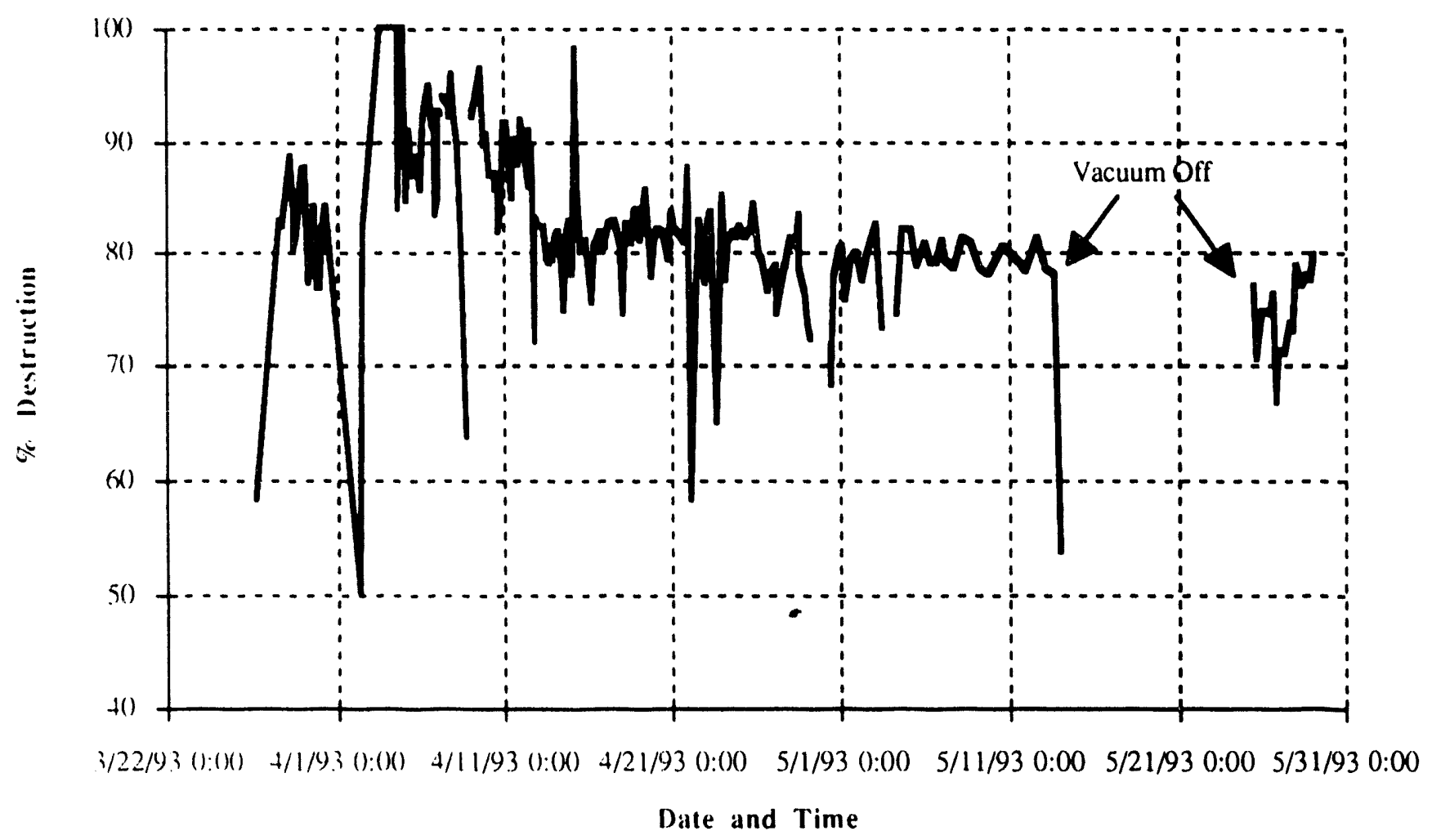

Figure 2-13. PCE Destructum Elliciency over Course of the Demonstration 


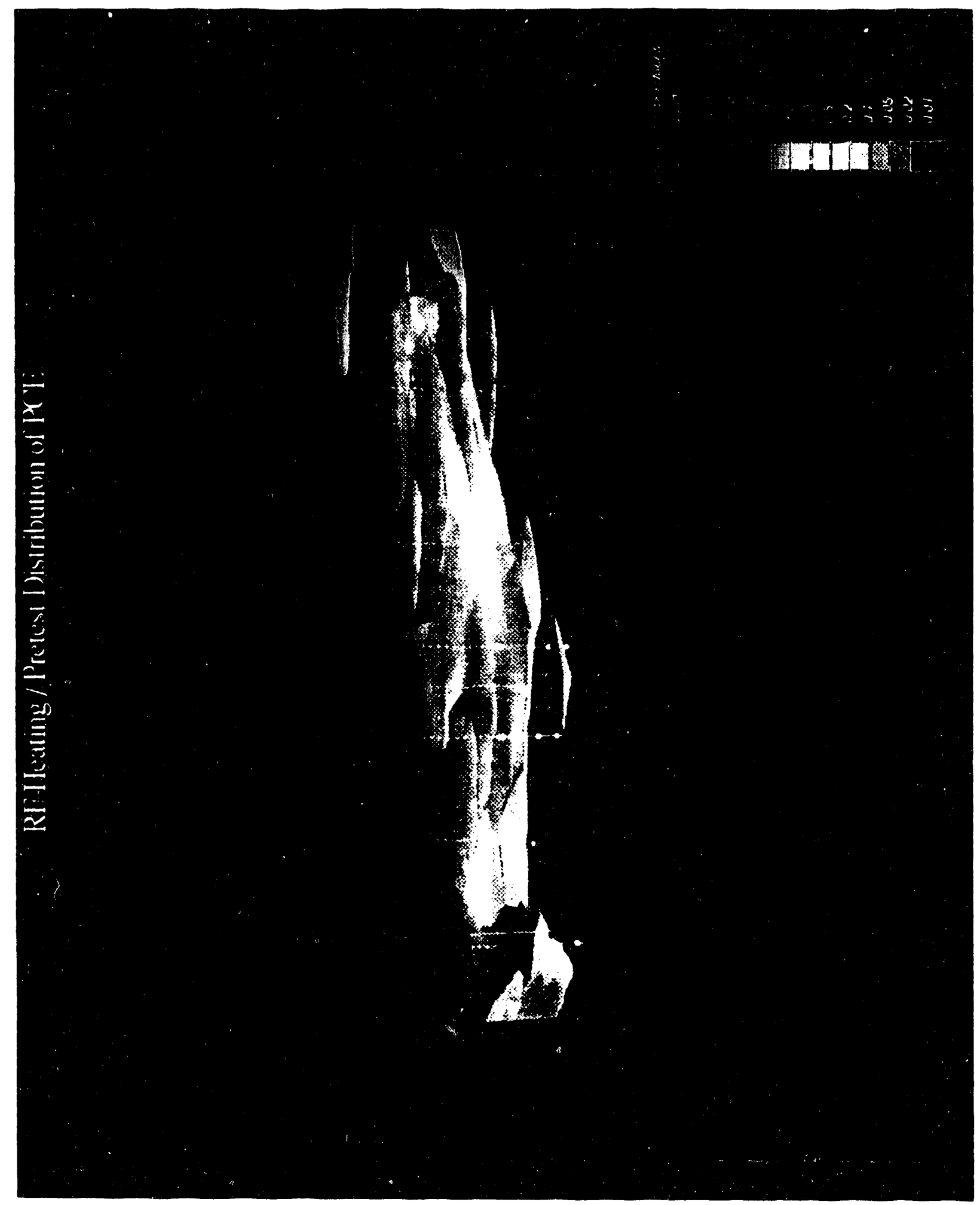

Figure 2-14. 2. J Image of PCE and TCF Sediment Concentration I ppm (mg/kg) Iso-Surface from Pre-test and Postket (im) 


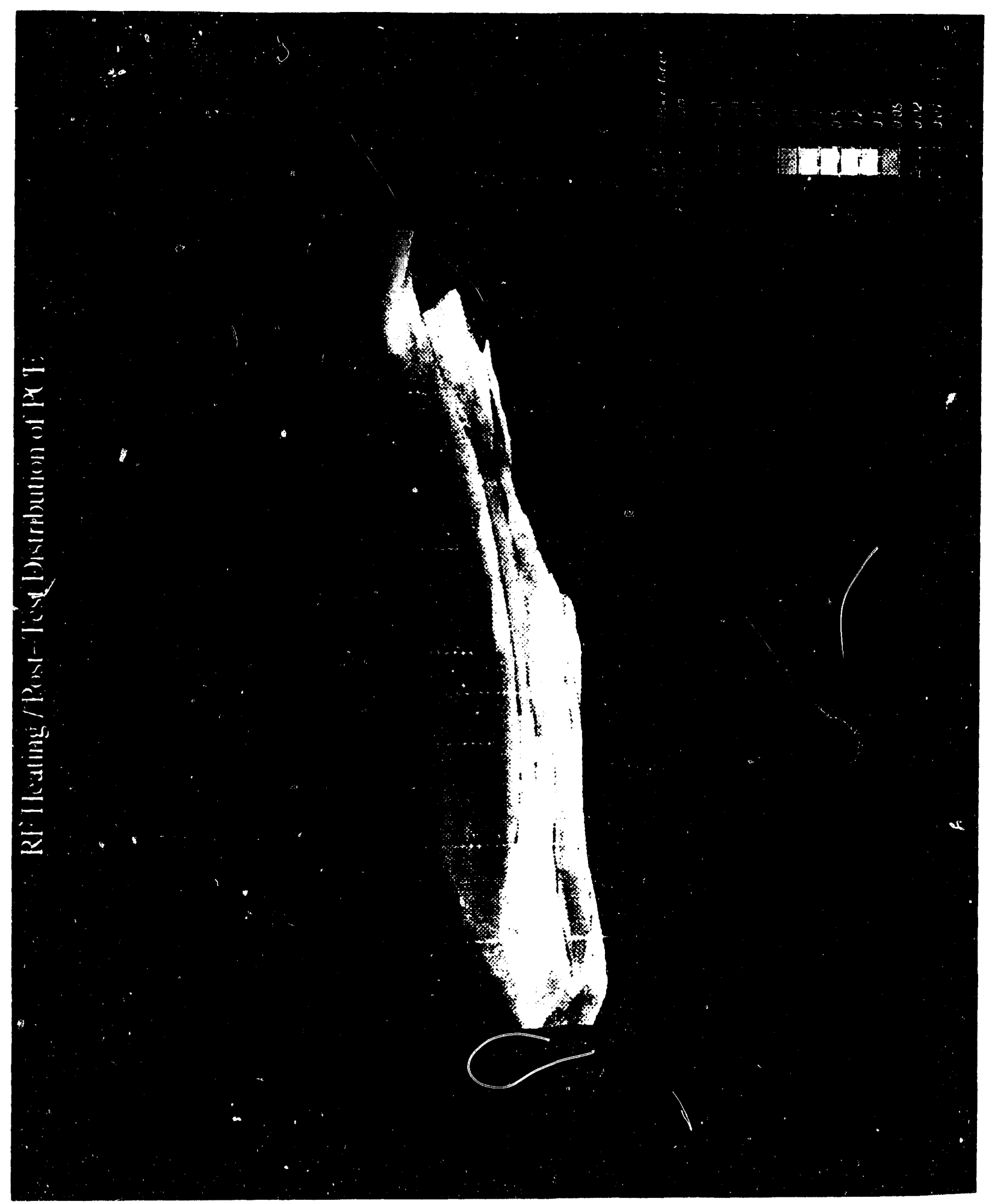

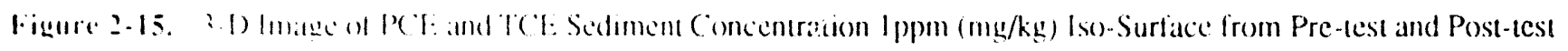

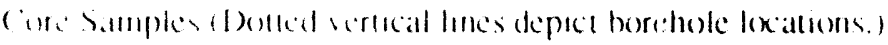




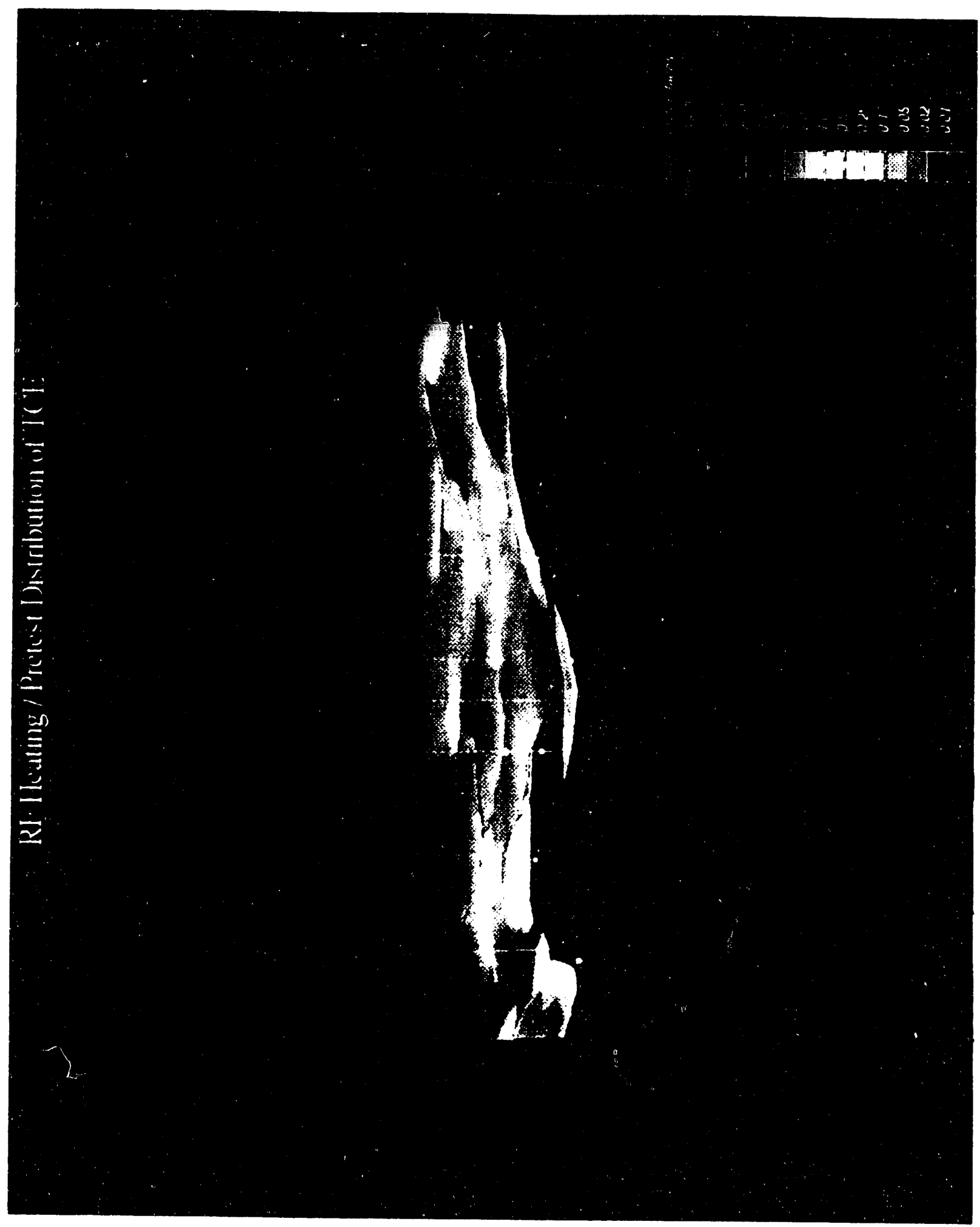

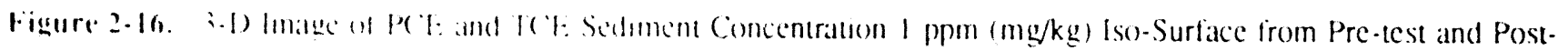

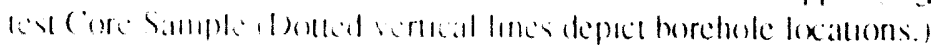




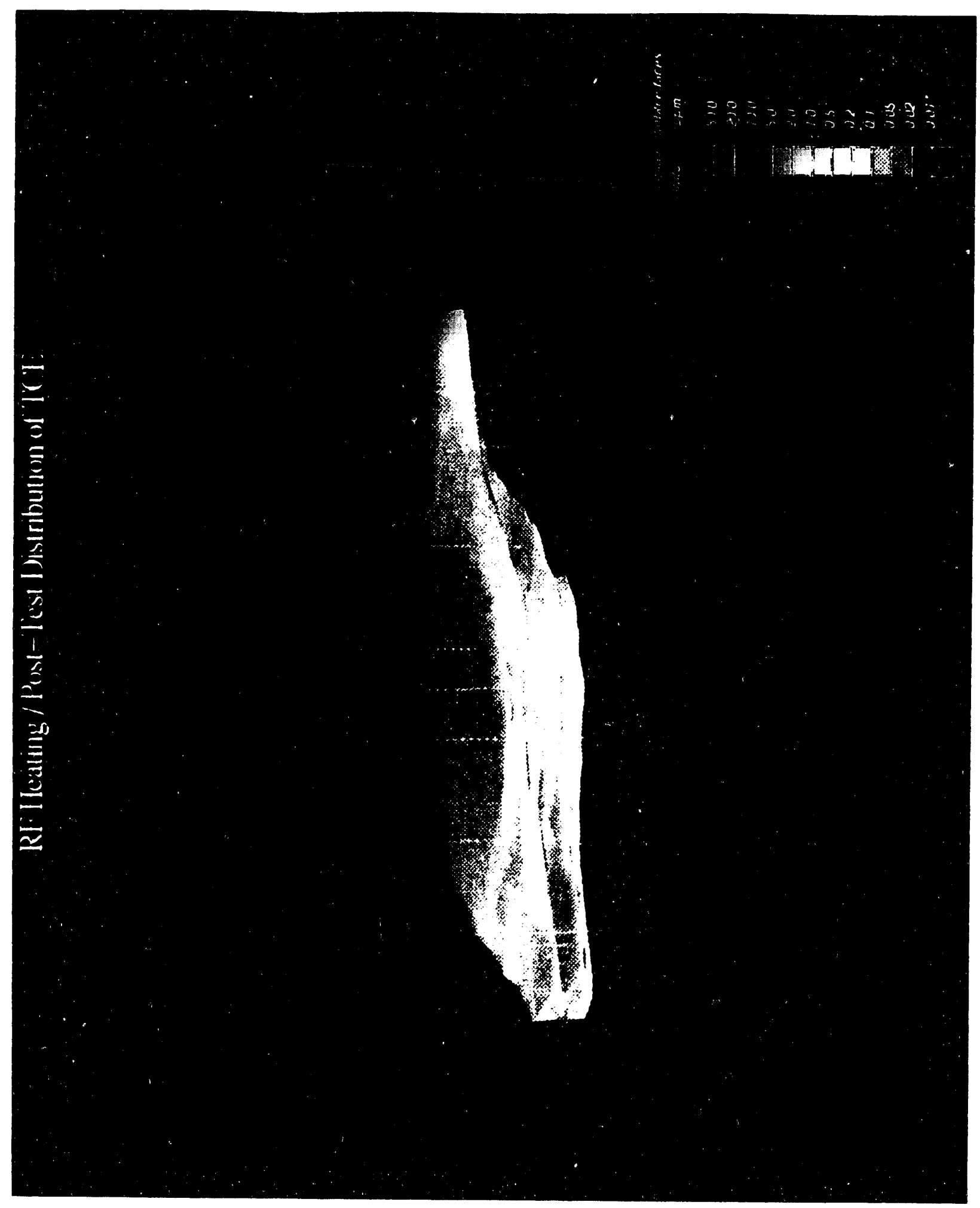

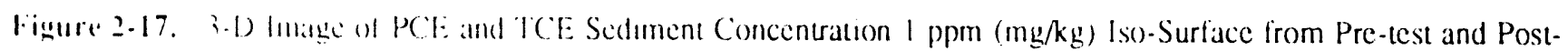

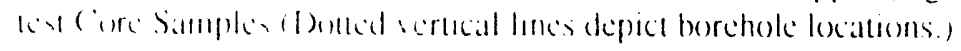




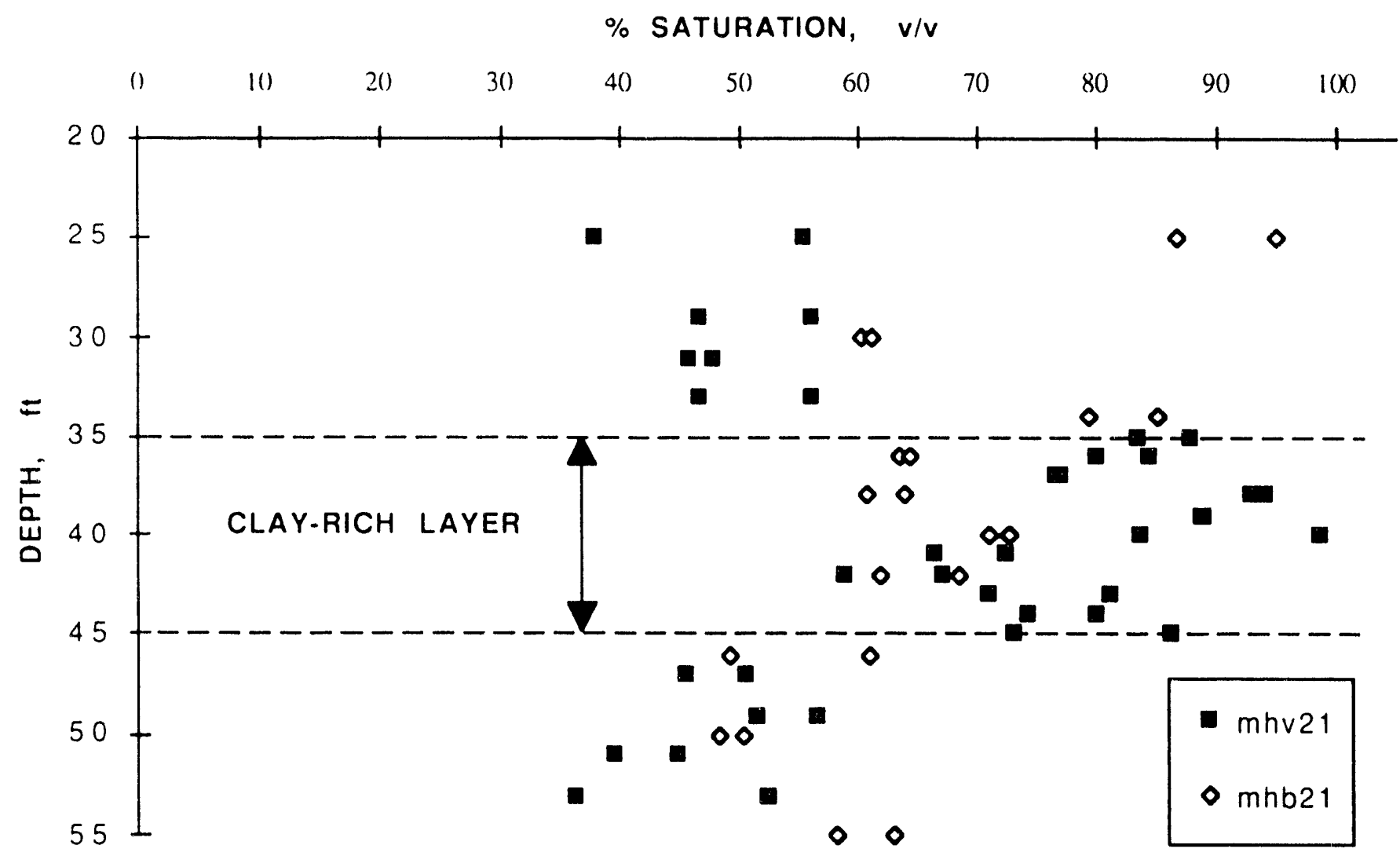

Figure 2-18. Moisture Comtent Irom Pre-test (MHV) and Post-test (MHB) Cores within Heated Zone (Approximately 7 lect irom Applicaltor) 


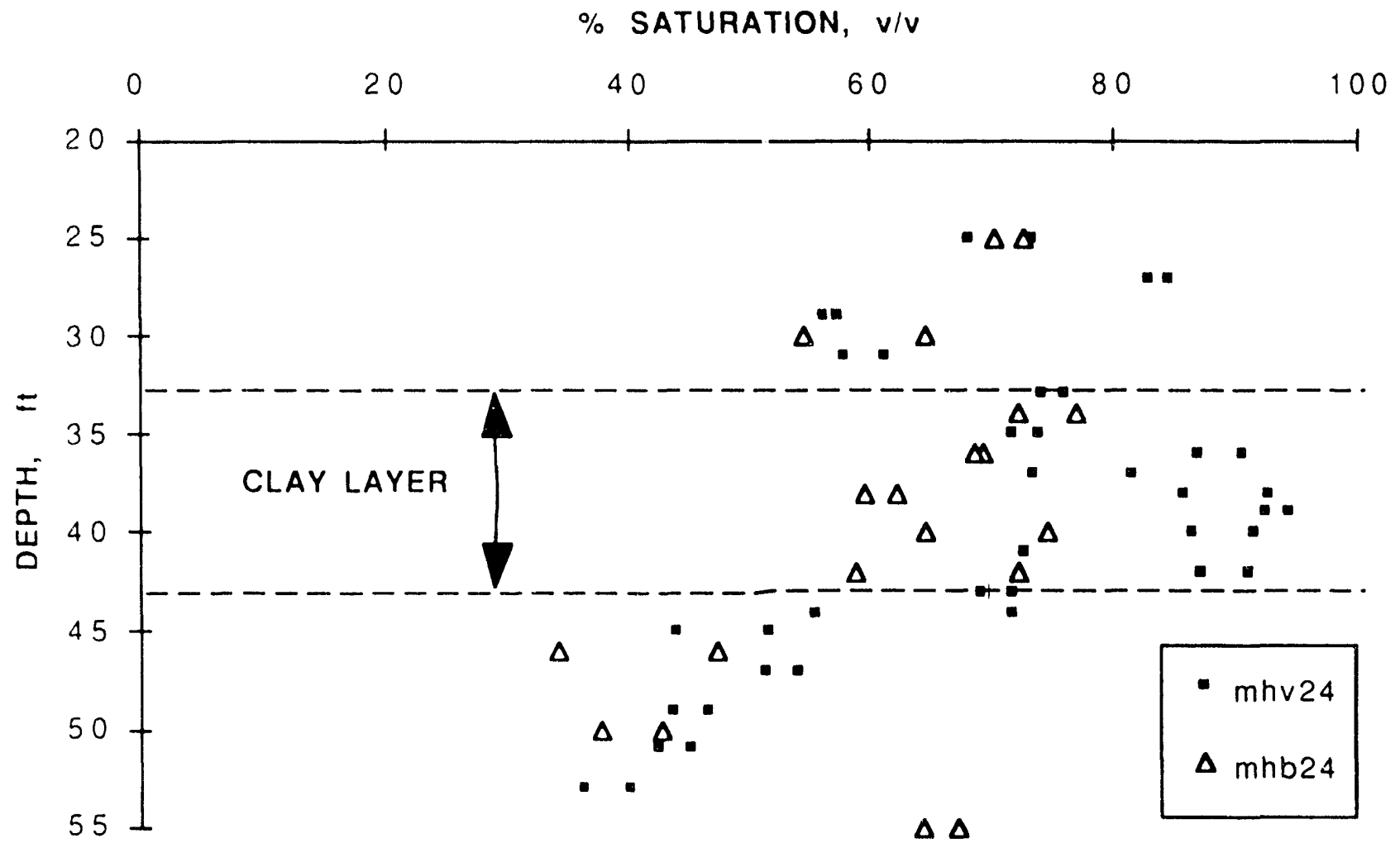

Figure 2-19. Molsture Content from Pre-lest (MHV) and Post-lest (MHB) Cores in Heated Zone (Approximately 5 feet Irom ipplacial(or) 
WSRC.TR.93.673 


\subsection{Recommendations}

The licld results suggest that a second demonstration is necessary to fully assess the radio frequency applicator technology. An improved remedial design would incorporalle the lessons learned from this demonstration and would also provide a basis to technically and economically evaluate removing residual chlorinated solvents from clayey sediments using RF thermal techniques. Specific system design considerations should include the items listed in the following sections.

\subsection{Extraction Wells}

Results demonstrate that any new system design should use extraction wells that are independent from the well used for RF application. This change would resolve most of the problems encountered during the demonstration. Using a horizontal borehole for heating is still a viable and very advantageous application, especially since clay layers tend to be tabular in extent. With such a design, the antenna can be moved through the well, progressively healting a larger volume of the clay within a single borehole. This demonstration showed that modifications can be inade to the RF hardware to minimize thermal expansion cllects in a horizontal application. Exuraction wells could he horizontal or vertical and should he located both within and on the perimeter of the zone anticipated to be heated hy the RF applicator. Problems with heal loss and condensalton from the gas stream through the long transition to the surface were encountered in this demonstration. In aldlutun, removing cxcess water is necessary in a continuous horizontal well and will require a pump that can operatle by skimming water from the boltom of the casıng. For these reasons, vertical extraction wells may be less problematic from both a technical and economic slandpoint. The perimeter radius for extraction wells should be selected such that contaminant transport caused by vacIIum inlluence will bound any possible contaminant transport that results from thermal effects, ensuring adequate containment. If the largeted region for heating is a low permeable formation (e.g., clays), then the extraction wells should be sereened both within the targeted formation and in surrounding strala with higher permeability if possible (ahove and below the clay lens for this application).

\subsection{Drilling Technology/Well. Completion Materials}

For thes demonstration, the horizontal well drilling techmology was selected independent Irom RF compatibility considerations. Choosing the completion materials that have the mechanical, thermal, and RF-compatible properties suitable for the installation technique is critical to successfully applying the technology. In this demonstration, a lower temperature-rated material was used to facilitate casing installation, thereby significantly reducing power output.

Using the RF applicator technology requires casing materials that are not typically employed in conventional environmental remediation wells, especially horizontal well installations. The added stress and flexibility required for the casing materials used in horizontal well completion may call for high temperature plastics or composites, which may add costs for tooling and machining.

An additional affect from using a horizontal well is the uncertainty of surveying its location. This uncertainty is a few feet and would not typically be critical in commercial applications. However, for this demonstration, uncertainties in the well location affected positioning the temperature monitoring boreholes. The risk of hitting the horizontal well by placing a vertical borehole within 5 feet was considered too high, so the closest temperature monitoring point in the clay was approximately 6 feet from the applicator. This effect, combined with the reduced zone of heating, limited analyzing the high temperature regions surrounding the applicator.

\subsection{Baseline Vacuum Extraction}

To adequately assess any vacuum extraction enhancement technology, the vacuum extraction parameters and charactcristics for the ambient (baseline) condition must be understood. Inadequate time was allotted in the demonstration to establish this baseline for the RF heating effects on extraction. The contaminant release characteristics observed during the demonstration were very gradual and may have been unique to that of clay, independent of heat application. Had an adequate baseline extraction rate been established, the RF heating effects on the vacuum extrac. tion process from clay could have been analyzed more conclusively.

\subsection{Demonstration Length}

Because of the unpredictable release characteristics during the vacuum extraction process and the lessons learned during the two-month in situ RF heating demonstration, a demonstration of longer duration is appropriate to effeclively test the limits of the RF-enhanced vacuum extraction process from a clay. It should be clearly understood that the length of any demonstration will depend significantly on the overall design. With a design chosen to limit the num. 
ber of interdependent variables (c.g., separate vertical extraction wells, high-temperature casing materials, and perhaps, a vertical well for the applicator), the length chosen lor this demonstration would have been adequate.

\subsection{Pretest Laboratory Studies/ Modeling}

The pretest laboratory studies to determine the dielectric propertics of the targeted clayey sediments were successful. Because of pretest study experience, matching the imperiance of the applicator, to the impedance of the surrounding lossy sediment was excellent throughout the kemonsiration. However, a more rigorous model to predice the ellecllve healed volume is necessary. The model used for this demonstration was simplistic and must be expanded to include the following critical phenomenon flor a more thorough description of the model used see: R.T. Harold, T.S. Snycler, R.S. Kalsevich, "In Situ Radio Frepuency Soil Remediation Heating Demonstration: Final Report on Treatability Sudies", Westinghouse Science and Technology Center Report No, 93-9TD()RFHET-RI, 1993, completed as partial fulfillment of Contract $N($ ). AA80586W for the Department of Energy):

1. Transport effects to account for energy luses resultIII! Irom the movement of alir and water (as liquid and vapor) through the healed fone

2. Latcont heat elfects to account for this relatively large (nergy sink required lo produce waler vapor

3. Phase change eflects 10 account for the eflects of reduced water content on both thermal and diclectric propertics.
Each of these effects is a critical aspect of the energy balance required to reasonably predict subsurface temperature contours. The latent heat effect alone can account for nearly $50 \%$ of the total energy output from the applicator to the formation. A number of computer codes are avail. able that can be coupled to codes for the RF field calculations to adequately assess the effective heated zone. At present, one such code, TOUGH2 (or Transport Qf Unsalurated Groundwater and Heat, developed at Lawrence Berkeley Laboratory) is being used to investigate ambient extraction from clays. 


\subsection{System Description}

\subsection{Equipment Description}

\subsubsection{Radio Frequency Heating System Equipment}

The KAI RF heating system is an $8-11 \times 8-11 \times 2()-f t$ shelter, that is mobilized by a 28 -foot llatbed trailer and a 1 -ton pickup truck (Figure 4-1). This system is configured for complete, unattended, remote control operation as well as for unstle support dagnosticis. Figure $t-2$ is a schematic of Ihe complete system used lor the RF demonstration. The AC power was provided by a desel generator (described in Siction 4.1.6). The delails of the system are described in the lollowing subsections.

\subsubsection{Phone l.ine}

The remote control and monitoring "phone line" is proviled by a 3-walt transporlable cellular phone with a data merlace that is connected to a high-speed modem port of lhe comerol compuler.

\subsubsection{Radiofirequency (ienerator}

The RFPP model 25,(0)()D, $25 \mathrm{~kW}, 13.56 \mathrm{MHz}$ RF generalor is a modified, industrial lube-type design. The genera(1) operates with a typical 24() volt, 3-phase AC power to RF power conversion efficiency of $6.5 \%$. The unit employs II) vilges of ceramic power lubes that have opera:ing lifelumes of between $3,(0)(x)$ and $5,0(0)$ hours. The balance of the circuitry is a stable, high-reliability design with an stlmalted mean lime helween failure (MTBF) of over $25,(x)()$ hours, which has been established over the past 10 ?cars that this gemerator has been on the market. The gencrallor has an internal analog control circuit configured to prolect the generator from rapid load (applicator) changes. The generator is monitored and controlled by a series of wilch state sensors, relays, and monitoring instruments that are interfaced to the system controller.

\subsubsection{Matching Network (Tuner)}

The $25 \mathrm{~kW}, 13.56 \mathrm{MHz}$ luner, a proprietary design of $\mathrm{KAI}$ Tichnologies, is calpable of smoothly matching. the RF sencrator 10 a wide range of load conditions. The luner is I! flually capathle of matchong 10 applicallor loads presentint! voll-slanding-walve rallos (VSWR) of gerealler than 3 lor al momenal line impedance of $5($ ) ohms.

\subsubsection{Transmission Line}

The 290-foot transmission line, external to the shelter, was constructed with 150 feet of flexible, high temperature, 7/8inch transmission line (Andrews HT5-50) and 140 feet of rigid 7/8-inch EIA (Electrical Industry Association) transmission line (Radio Frequency Systems Model 1-78-50 in 20-ft sections), which was connected to the rigid feed sectiun that was integral to the applicator. Both transmission lines contained Tellon ${ }^{\mathrm{TM}}$ spacer components that limited their useful temperature range at or below $200^{\circ} \mathrm{C}$. The total transmission line attenuation was $0.389 \mathrm{~dB}(91 \%$ efficiency). The couplings used between the rigid transmission line's sections and the applicator were 3-bolt brass termination llanges with o-ring seals. The flanges were then enclosed in ellipsoidal-shaped, clam-shell covers machined from Teflon ${ }^{\mathrm{TM}}$ to eliminate any edges that may catch in imperfections expected at the section joints in the horizontal well. Figure 4-3 and 4-4 are photographs of the termination flange, clam-shell cover joints.

\subsubsection{Radio Frequency Heating Applicator}

The applicator is a proprictary design of KAI Technologies. The basic structure of the applicator is that of a modified cnd-feed dipole antenna. The flexible 2.25-inchdiameter antenna is constructed of copper, brass, Teflon ${ }^{\mathrm{rM}}$, and ccramic components. The flexibility of this antenna was limited to a bend radius of 50 feet and operating temperatures at or below $200^{\circ} \mathrm{C}$ because of Teflon ${ }^{\mathrm{TM}}$ component limitations. The antenna elements can be adjusted to match to the site soil conditions with a VSWR of less than 2. Figures 4-5 and 4-6, respectively, show the applicator prior to insertion into the borehole and a top-level mechanical view of the applicator used in the demonstration.

\subsubsection{Controller}

The system controller was an 80386 processor with IEEE. $488, \mathrm{RS}-232 \mathrm{C}$, and modem interfaces. Control commands and system states were processed by an HP 3488A switch controller. System status was reported and polled over a high-speed modem using an MNP10 (Microcon Networking Protocol) high-reliability, error-correcting protocol for communications over the system's cellular phone link. System status and alarm states were broadcast to the sys. tem operators using a paging service supporting 8() character, alphanumeric pager receivers 


\subsubsection{Diagnostics}

The sysitem diagnostics consisted of instruments directly mlerlaked to the controller as well as portable, stand alone vipport expuipment.

Sysiem dagnostics - computer intertaced

- Vecior vollimeler - HP 8508A

- Signal generalor - Marconi 2022A

- Digilal multimeler/scanner - HP 3457A

- Digial mulimeler - HP 344()IA

- Swilch controller - HP 3488A

- Fiber oplic thermometer - Luxiron $7(x)$

- Nework analyzer - HP3577A/HP35677A

sistem diagnostics - stand alone

- Time doman reflectometer - Tektronix 1502C

- Megger-Biddle $218650 \mathrm{CL}$

- Type J thermocouple converter indicator - Omega Molel TAC-80J with Fluke Model 21 Meter

- Týc K thermocouple indicaltor - Fluke 80TK

\section{I.I.8 Environmental Monitors}

The lollowng monitor were used to verify that system operalton was within OSHA salely guadelines for RF crposure and FCC guidelines for interterence:

- Broallhand isotropic probe - Holiday Model HI-30X)S

- Calibralled receiver - Electrometrics R-70B

- Portable AM/FM/MW/shortwave receiver

- Porlathle VHF/UHFTV icl

\section{t.1.1.9 Data Analysis}

The control computer was supported for off-line data analysis by a second, identicall computer configured with a l.anerjet lllp printer for data output.

\section{+1.2 Vacuum Extraction And Offgas Treatment System}

Vacuum extraction and olfgas treatment was performed Wumg a skid mounted, Brown Enginecring (Scaltle, WA), combuned vacuum extraction and thermal-catalytic destuction iystem (Callox System). A schematic of the ysem comployed is provided in Figure 4-7. This system

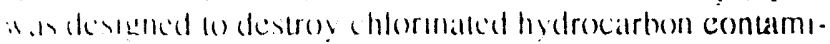
nants all all clficiency of $\geq 95 \%$ from a strcam of humid air collatmmmg a maxumum combaminame concerntratuon of $25(x)$

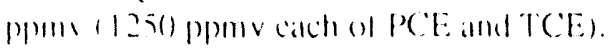

The destruction system employed a proprietary, Allied Signal monolith catalyst. The catalyst consisted of a wash coat of platinum group metals deposited on a 400 -cell/ in $^{2}$ honcycomb alumina substrate. The reaction chamber was eyuipped with silicon carbide resistance heaters, which heated the incoming stream to the catalytic reaction temperature of $850-900^{\circ} \mathrm{F}$. Power to the heaters and furnace temperature was controlled by a Payne Engineering. Moxtel 18E-4-80H silicon controlled rectifier in conjunction with an Omron ESAX temperature controller.

Vacuum extraction was driven by a Roots (Division of Dresser Industries), Frame 36, rotary lobe blower. This blower has maximum input of 10 inches $\mathrm{Hg}$ vacuum at 2()() scfim.

\subsubsection{Horizontal Well Description}

The horizontal well used for the RF heating test was installed with an experimental compaction/dry drilling technique developed by Charles Machine Works (Ditch Witch $^{\text {TM }}$ ) of Perry, Oklahoma. Additional detailed information on the drilling rig and tool, the steering technique, and the liner installation can be found in WSRC-TR-93(x)8. The compaction drilling technique produces no surlace returns and uses a minimal amount of fluid to cool and lubricate the drill bit and steering equipment. However, a disadvantage is that the method requires using materials significantly stronger than conventional nonmeballic casings (tensile strength greater than $5000 \mathrm{psi}$ ). In addition, the completion technique does not permit installation of a gravel-packed zone around the screen and the drill bit produces a low permeable skin immediately adjacent to the borehole.

The well was completed with casing and well screen consisting of 30-fool sections of 3-inch nominal (3.35 inch ID, 0.110 inch wall thickness) Centron $^{T M}$ fiberglass epoxy line pipe connected by pin and box screw joints. Three rows of 0.010 -inch slots were machined into the pipe to construct the well screen (available surface area is approximately $1.84 \mathrm{in}^{2} /$ foot). The pipe has an axial wall tensile strength of 12,000$)$ psi. No measurements were made to determine the final strength of the screened sections. The joints were belled for added strength. The elevation view of the well is given in Figure 4-8. Each point in the diagram is a surveyed location taken every 10 feet downhole. The well consists of two 140-foot surface transition zones constructed of solid casing connected by a 300 -foot tone screened within the clay-rich lens at $315-325 \mathrm{msl}$. The minimum radius of curvature in the transition zones is approximately 250 feet. 


\subsubsection{Field Equipment For Monitoring Test Conditions}

\subsubsection{Monitoring Borehole Layout}

Ten parrs of vernical monitoring boreholes were drilled in the licld around the horizontal well bounded between the $160)-100 t$ and 26()$-100 t$ positions of the horizontal well as shown in Figure 4.9. One borehole in cach pair was used for pressure monitoring and the other borchole for temperallure monitoring. Seven of the horehole pairs were posilioned around the expected heated zone in an injemmetrical pallern relative to the location of the horifontal well. The remaining three borchole pairs were posilloned well outside the bounds of the expected heated tone, and were used as control points. Figure 4.9 also displiys the post-lest borehole locillions (labeled as MHB wills).

\subsubsection{Subsurface Pressure Monitoring}

Threc piczomecers (I inch OD) were installed in each of the pressure monitoring horeholes and sereened in the following anes:

28.33 li depih

$38-43$ it depih

48.53 ft depth

The surlike end of each picenmeter was closed with a polvingl chloride pipe cap and equipped with a quick. connecl filling. The identification numbers MHV 20 through MHV 29 were alsigined to the 10 piezometer horeholes prepared for this demonstration. The individual picemeters within the borehole were identified with an alphat designation based on piefometer depth. The letter "A" wass alssigned to the decepest piesumeters, "B" was arigned to the middle and " $C$ " was assigned to the shallowest piczometers. Figure $4-10$ schematically displays the plesmeter arrangement.

Piesometer pressures were incasured primarily with Magnathelic diaphragm differential gages, with the exception a) MHV 21. AI MHV 21, pie\%oclectric pressure uansducers were installed on the three prezometers. These transducers were installed primarily to assess their periormance. However, they also provided the capability of continuous pressure monitoring of that horehole. In addition, a fourth pressure iransducer was provided to measure ambient (harometric) pressure at MHV 21. This incasurement was considered the haseline barometric pressure reatding at the demonstration site. Barometric pressure reallings laken all the SRS Wealther Statton were used as bilckup

\subsubsection{Subsurface Temperature Monitoring}

The temperature monitoring boreholes were equipped with both fiber optic temperature probes and thermocouples as shown schematically in Figure 4-11. The fiber optics were considered the primary measuring devices because their signals is not affected by RF emissions. T-type thermocouples were installed as a backup i) fiber optics in all bore. holes at depths corresponding with the piezometers $(28,38$ and 48 (cet). Fiber optic probes were installed with greater frequency 10 provide betler temperature coverage in each borchole, and they were loaded mostly into the locations of greatest expected temperature effect. The temperature monitoring boreholes were identified as MHV 20T through MHV 29T to coincide with the analogous pressure monitoring boreholes. Table 4.1 lists the depth and location of all the fiber optic probes. Individual thermocouples were identified with an alpha designation congruous with the piezometer system. Individual fiber optic probes were simply identified by a numeric sulfix corresponding to their actual depth location in feet.

\subsubsection{Horizontal Well Monitoring}

In addition to the borehole piezometers in the field, piezometers were also installed along the length of the horizontal well. These piezometers were used to monitor pressure drop along the well. The construction of these piezometers was differing lengths of $1 / 4$-inch polyethylene tubing attached to a vacuum gage on the surface. The open ends of the piezometer tubes were located at the interfaces between the slotted and unslotted liner at both ends of the well (i.e., 140 and 440 feet from well head), immediately downstream from the applicator (i.e., 225 fect from well head), upstream from the applicator (i.e., 270-300 feet from well head), and at each end of the well (i.c., 0 and 580 feet from well head). The locations of these piezometers are shown schematically by the letters "PI" in Figure 4-12. They were identified by their distance into the well relative to the well head (well head $=0$ feet). 
Table t.l Fiber Opuc Probes

\begin{tabular}{|c|c|c|}
\hline $\begin{array}{l}\text { Temperature } \\
\text { Monitoring Well } \\
\text { Identification }\end{array}$ & $\begin{array}{c}\text { Number of } \\
\text { Fiber Optic } \\
\text { Probe Positions }\end{array}$ & $\begin{array}{l}\text { Fiber Optic } \\
\text { Probe Positions } \\
\text { Depth in Feet }\end{array}$ \\
\hline MHV.2OT & $2 h$ & $28,33,38,43,48,53$ \\
\hline MHV.21T & 6 & $28,33,38,43,48,53$ \\
\hline MHV.22T & 6 & $28.33,38.43,48,53$ \\
\hline NHHV.23T & 6 & $28,33,38,43,48,53$ \\
\hline MHV.24T & 6 & $28,33,38,43,48,53$ \\
\hline MHV.25T & 3 & $28,38,48$ \\
\hline MHV.26T & 3 & 28.38 .48 \\
\hline MHV.27T & 3 & 28.38 .48 \\
\hline MHV-28T & 3 & 28.38 .48 \\
\hline MHV. $29 T$ & 3 & 28.38 .48 \\
\hline
\end{tabular}

\subsubsection{Sampling/Analytical Equipment}

Routine gats/vapor samples were taken from the wellhead, Caltox inlet, Catox stack, and the borehole piezometers to monitor hoth contaminant concentrations heing extracted and changes to contaminant vapor concentrations within the formaltion itself. The samples were collected in 1-liter Tedlar" sampling bags. Representalive samples were consured hy inflating and purging (by squeczing) the hag several tumes before capturing the sample. Small, laboralory-sized diaphragm or oil-Iess rolary vane pumps were cmployed to pump samples from sample points under vacuIum. All VOC analyses were performed on a HewlettPackard 5890) Series 11 gas chromatograph via direct injec. ulon. The unit was equipped with a 6()-meter, mega-bore VOCOL. (Supelco ${ }^{i x}$ ) glass column and both an clectron capture and llame ionization detector. The instrument was cillibrated externally for gas sampling with calibrated gas vandards on a routine basis.

\subsection{AC Power Supply}

Two porlable 10()-kW diesel generators supplicd the required three-phase power. One generator supplied 480 VAC service for the Callox system and the other supplied 24) VAC' Wye service to the RF generation and application c(yuument.

Electrical power for the field monitoring and sampling cyuipment (fiber optic equipment, sampling pumps) was primarily supplied by portable, 3800)-wall gasoline-pow. cred generittors. A dicsel-powered portable light plant was also procured by loan 10 supply lighting in the monitoring lich and to serve as an aluxilary power supply

\section{1 .7}

\section{Water/Condensate Removal} Equipment

To pump water that accumulated in the well during the demonstration, a $\operatorname{Timco}^{\mathrm{rm}}$ air-displacement pump was modified to operate in a horizontal position. The small diameter (1.35-inch OD) polyvinyl chloride pump was installed along side the RF transmission line. A schematic of the pump and its operation is provided in Figure 4-13. The effectiveness of this pump was enhanced by using a vacuum to speed up filling of the pump chamber, a timer, and a three-way solenoid valve to make the pumping operation automatic. The pumping system is shown schematically in Figure 4-14. The maximum pumping rate achicved with this pump was approximately $2 \mathrm{gph}$.

\subsubsection{Catox Monitoring Interfaces for Automatic Radio Frequency Shutdown}

Key catox alarms were connected to the RF control system to shut down the RF generator if any of the following occurred with the catox system:

- Loss of power to the catox system

- Low catalyst temperature (insufficient voc destruction)

- Lo-hi liquid level alarm on vapor-liquid separator

\subsubsection{Final Steady-State System Configuration}

The final system configuration is displayed schematically in Figure 4-15. Listed below are the instruments and locations of attachment in the well:

- Open end of 440-foot piezometer (440) - It later was consolidated with the $270-$ foot piezometer into a single piezometer at 300 feet. This reduced the complexity of the insertion/removal process significantly.

- Open end of 270-foot piezometer (270)

- Center applicator fiber optic temperature probe (240)

- Well wall fiber optic temperature probe (240)

- Open end of 225-foot piczometer (225)

- Transmission line fiber optic temperature probe (225)

- Transmission line backup "J" thermocouple (225)

- Pump suction tube (205)

- Pump (145)

- Open end of 14()-foot piezometer (140)

Figure 4.16 is a photograph of the system as installed at the Savannah River Site Integrated Demonstration. 


\subsection{Operation}

\subsubsection{Applicator Insertion and Removal}

Inserung/removing the applicator to/from the horizontal wcill reyuired the lollowing actions:

- Section by section assembly/disassembly of the trans. mission line

- Allachment/removal of temperature probes, piezomelers, and water pump to the transmission line, applica(or, and/or pulling ciable

- IVell opening/scalling

- Impedance mapping scans of the horizontal well during insertion

- Instrument/gauge connection/disconnections

- Transmission line drying with $\mathrm{N}_{2}$ flushing

In general, the insertion/removal process required five or six people. Two people were required to make/break transmisison line connections and to attach/remove the monitoring hardware and water pump. One or two people were required 10 prevent langling/kinking the relatively long lenglhs of fragile liber optics cable and piczometer lubes. Finally, iwo people were required 10 manually pull the applicator into position (via cable) or (o) pull the applicator Irom the well. Mechancial pulleng devices were avoided to mımma accidentally damagng components with excessile loree.

The lime required lor one removal/insertion cycle was relined from a 20 -hour 10 an 8 -hour process as the team hecime experienced with the techniques and logistics.

\subsubsection{Radio Frequency Operation}

The hasic elements of the RF operation are:

- Prehcal Testing - A veries of measurements taken to kermine basclinc conditions and to verify that the syskin is ready to salcly operate at high power.

- Engalging RF Power ON - Turning the system on by (1)erator commands to the control computer and data logger. RF power heating cycles were iniliated for a pecilic number of heating hours (typically 4,8 , or 12 hours) that were then followed by RF Power OFF diagnostic tests.

- Monitoring RF Healling Cycles - Continuing RF Power ON measurements hy the system controller. The leallung cycles also comban periods of RF Power OFF when the applicator reaches 115 set point temperature ind is allowed to cool an a pount where the RF is again lurmed on aldomallically Roulunc surlace monutoring measurements are also made during RF Heating ON periods of the heating cycle.

- RF Power OFF - A series of measurements taken that are identical to those of preheat testing.

More detailed descriptions of these elements are provided in the following sections.

\subsubsection{Preheat Testing and RF Power OFF Measurements}

- TDR measurement of transmission line/applicator assembly - Time domain reflectometer (TDR) measurements were used to verify the integrity of the coaxial transmission line system that delivers power to the applicator. The TDR uses an electrical pulse to probe the transmission line's characteristics along its entire length. The reflections return to the TDR as the probing pulse passes line junction points. Bends and transitions are processed to display the electrical distance from the TDR to each of these reflection points.

The reflection information is typically plotted on a surip chart recorder as a record of line impedance versus transmission line length. The displays are plotted on a strip chart recorder to provide a permanent record of the condition of the transmission line before high levels of heating power are applied. The TDR can be used to verify proper transmission line assem. bly, identify thermally distorted areas of the transmission line, and note trends in the heating environment of the applicator.

Figure $4-17$ is an example of a TDR record that was lypically made before each heating cycle, during heating cycle RF OFF pauses, and at the conclusion of the heaung cycle.

The RF heating system was operated through a system control and monitoring program during all RF heating cycles. The computer monitoring and logging functions were supplemented by the observations of an operator who recorded system, heating applicator, and site environmental parameters that could not be recorded during the heating power $O N$ portions of the operating cycle.

- Megger measurements - A high voltage DC megohmmeter (megger) was used during preheat testing to verify the insulation integrity of the internal transmission preheat line spacers and junctions at a level of 5,000) volts. A typical "good" reading exceeded 300 gigohms.

The megger was also used with the applicator (attached to the transmission line and positioned in the horizontal well) during preheat, RF OFF, and post-heating cycle periods. In this manner the megger was used to estumate the conductivity of the feedpoint surface junction of the applicator and the surfaces 
which the applicator element arms contacted. The megger voltage was lypically stepped from 500 to $5,(x)$ volts. The reading ranges from under I megohm for a moist, preheated environment to over $70)$ (megohms in a dry region, immediately after fullpower heating. The mitgger was also used to verify the presence and passage of water along the floor of the horizontal well during "quenching events".

Megger readings were typically laken in conjunction with TDR measurements.

- Nework analyzer measurements - The network analyar wats used to make impedance measurements as a funclion of frequency all two points within the RF healing ristem during power OFF conditions. Measurement pount I was that of the applica!or itseli, located in the horrontal well prior to heating. Measurement point 2 wats all the input to the tuner. Mealsurement 1 was typically displayed in terns of relurn loss to display the matching trends seen during the healting cycle (Figure 4-18). Measurement 2 was typically used to guide adjustments of the tuner and to record before and after shills in the sellings (Figure 4-19). Measurement sets were lypkally taken belore and after adjustments were made lo the system.

Measurement point I was also used to scan the horisontal well heating region as the applicator was pusticed into position. Scans consisted of a number of relurn loss measurements that were typically postprecessed to VSWR or inpedance displays. Figure 4. 20) is an example of a scan.

- Transmission line thermocouple measurement - A type \& thermocouple was located on the RF transmissitu line at the slecve entrance to the heating applicator. This malsurement point was checked immediately after power OFF conditions to delennine the maximurn temperallure experienced hy the outer shell of the RF uansmsision line.

\subsubsection{Routine Radio Frequency Power (ON Measurements}

The following measurements were recorded as measurement channels of the Time Acquisition (TAQR) program or hegend in the site notebook.

- RF vectur voltmeter channels - The vecior voltmeier was used with a direcional coupler (o) measure the volt. ige of the RF power input to the applicator. The rellected voltage wals meatsured in lerms of its magn. lude and phase relatwe to the input power vollage. This inlormation. along with a preheatung calibration mea. vrement. allowed the vector voltemeler measurement liks lo be post-processed lo produce a plot of applicator fecdpoint impedance versus time. The coupler for this mcasurement was located at the output of the tuner.

- RF generator RF output power channel - This measurement recorded the power output from the RF generator into the tuner. The power pickup was via a dual port directional coupler. This measurement produced similar data to that produced by the vector voltmeter's forward voltage measurement. During heating cycle 5 . this channel was converted to sense reflected power. This channel was then used in part of an auxiliary sensing scheme to recover from horizontal well quenching crents.

- RF generator AC input power channel - This measurement recorded the $A C$ input power used by the RF power generator. The measurement was made by a three-phase true RMS (root-mean squared) transducer that was connected to make an absolute input power measurement. This measurement was used with the RF generator RF output power channel to determine the absolute efficiency of the generator.

- Horizontal well temperature sensors - A four-channel liber optic thermometer was employed to monitor horizontal well temperature conditions during the heating cycle. One to three sensors were employed during the program.

- Air temperature sensor channels - Temperature sensors were used to monitor the input ambient temperalure to the cooling system, the generator exhaust temperature, and the shelter instrumentation environment.

- AC voltage sensor channels - Three AC voltage sensor channels monitored the phase-to-phase voltages of the three-phase power input from the diesel generator.

- Transmission line nitrogen pressure - This measurement recorded the changes in pressure as the transmission line heated. This channel was monitored to alarm and turn off the RF power if the pressure dropped below 5 psi. The alarm condition indicates a failure in a transmission line seal.

\subsubsection{Routine Surface Monitoring Measurements}

- Isotropic RF probe - An isotropic broadband probe was used to detect RF fields that could approach OSHA hazard levels on the surface.

- Calibrated RF receiver - A narrowband, tuned calibrated receiver was used to map the surface electromagnetic field strength above the heating area.

\subsubsection{Extraction Operation}

\subsubsection{Preliminary Testing}

Prior to committing the unit to service, attempts were made to operate the Brown Engineering Catox system per 
Ihe vendor's operating manual and perform a final check of the pre-set system contrel, alarm, and shutdown setpoints for the system. During this testing, several errors were lound in the operating manual, as well some minor hardware problems. The details of the system check out findings were documented in SRS procurement QA records. Hardware problems were corrected and operating procedures were writen in lime for system start up on March 4, 1993. In addition to operational checks, PCE was introduced to the unit to check halocarbon destruction efficiency. Destruction elficiency during these tcsts ranged from 85 to $92 \%$.

\subsubsection{Routine Operation}

Routinc extraction operation was comprised of recording Catox system paramelers and securing a set of gas/vapor simples, one each from the wellhead between the extractoon pump and calalyst (thus referred to as the Catox Inlet), and from the Catox stack. These sample points are identificd in Figure 4-17 as a blocked "S". Catox system readings and samples were laken typically four times daily during heat application with a minimum frequency of iwice daily. Readings were laken al approximately the sane times each day. The complete record of Catox Sys$\mathrm{tem}$ raidings are provided in Volume II of this report.

\subsubsection{Planned Interruptions}

Planncel interruptions of victum extraction operations weri icheduled to perform preventive maintenance on the porlable dicsel generator and extraction pump. Downtime for these planned interruptions averaged approximately 2 hours per week.

\subsubsection{Water/Condensate Pumping}

IValcr/condensate pumping operated continuously during vacuum extraction operations. Water levels in the collection vessel and knockout pot were checked at the same timc Catox samples were secured. Water from primary collection vessels was transferred $2-3$ times daily to sec. ondary vessels. All water collected was picked up and transported (o) the SRS air stripper on a biweekly hasis. Daily alcumulation of water/condensate was recorded in the demonstration log book.

\subsubsection{Field Monitoring}

\subsubsection{Piezometer Monitoring}

Pressure measurements from the horizontal well piezome ers were recorded all a freguency in conjunctuon with

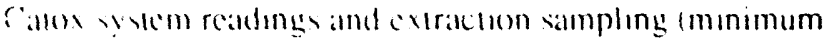

of four times daily). Pressure measurements from the 30 field monitoring piezometers were taken a minimum of twice daily. All measurements were recorded in inches of water column (w.c.), except for readings taken with the MHV 21 transducers. Transducer readings were taken in millibar (mbar). The record of all piezometer measurements taken during the course of the demonstration are provided in Volume II of this report.

\subsubsection{Temperature Monitoring}

Temperature monitoring activities were conducted with both fiber optic probes and thermocouples. Indication hardware was not available to continuously monitor all installed fiber optic or thermocouple temperature probes. Therefore, field temperature measurements focused on the expected heating area. Periodic checks of those points outside of the focus group during heating indicated no change in temperature from ambient, confirming the selected monitoring points were appropriate.

Ten fiber optic probes from inside and bounding the expected heated zone were connected to a data acquisition system and provided continuous monitoring of those points. Points continuously monitored by fiber optic probes are summarized in Table 4.2.

Ten of the field monitoring thermocouples inside and bounding the expected heated zone were connected to a multi-channel digital readout. Measurements from these ten points were recorded a minimum of twice daily. Table 4.3 lists the ten selected points. The complete record of data collected from thermocouples during the demonstration is provided in Volume II of this report.

Table 4.2 Fiber Optic Probes Continuously Monitored

\begin{tabular}{cc}
$\begin{array}{c}\text { Monitoring Well } \\
\text { Identification }\end{array}$ & $\begin{array}{c}\text { Depth(s) of Monitoring } \\
\text { Point(s) (feet) }\end{array}$ \\
\hline MHV-20T & 38 \\
MHV-21T & $33.43,53$ \\
MHV-22T & 33 \\
MHV-24T & $33,38,43,48$ \\
MHV-26Tc & 28 \\
MHV-29T & 38
\end{tabular}

${ }^{\mathrm{c}} \mathrm{MHV}$.29T (38) was used as ambient temperature at the start of heating stage then replaced by MHV-26T (28) approximately hall way through the heating stage. 
Table 4.3 Thermocouples Continuously Monitored

\begin{tabular}{cc}
$\begin{array}{c}\text { Monitoring Well } \\
\text { Identification }\end{array}$ & $\begin{array}{c}\text { Depth(s) of Monitoring } \\
\text { Point(s) (feet) }\end{array}$ \\
\hline MHV-20T & 38 \\
MHV-21T & $28,38.48$ \\
MHV-22T & 38 \\
MHV-23T & 38 \\
MHV-24T & $28.38,48$ \\
MHV-26T & 38
\end{tabular}

\subsubsection{Piezometer Sampling}

Gas/vapor sampling from the field monitoring piezometers was employed to monitor changes in contaminant concentrations in the formation during the course of the demonstration. Pictoineter samples were sccured at a rate of approximatcly cight samples per day. A schedule was Jeveloped 10 cnsure data would be obtained from all of the pic\%ometers (30), but also to ensure that the selected areas under the greatest influence of the RF heal werc sampled at a greater frequency. Sample schedule and frequency was modified accordingly as trends and events evolved during the demonstration. 


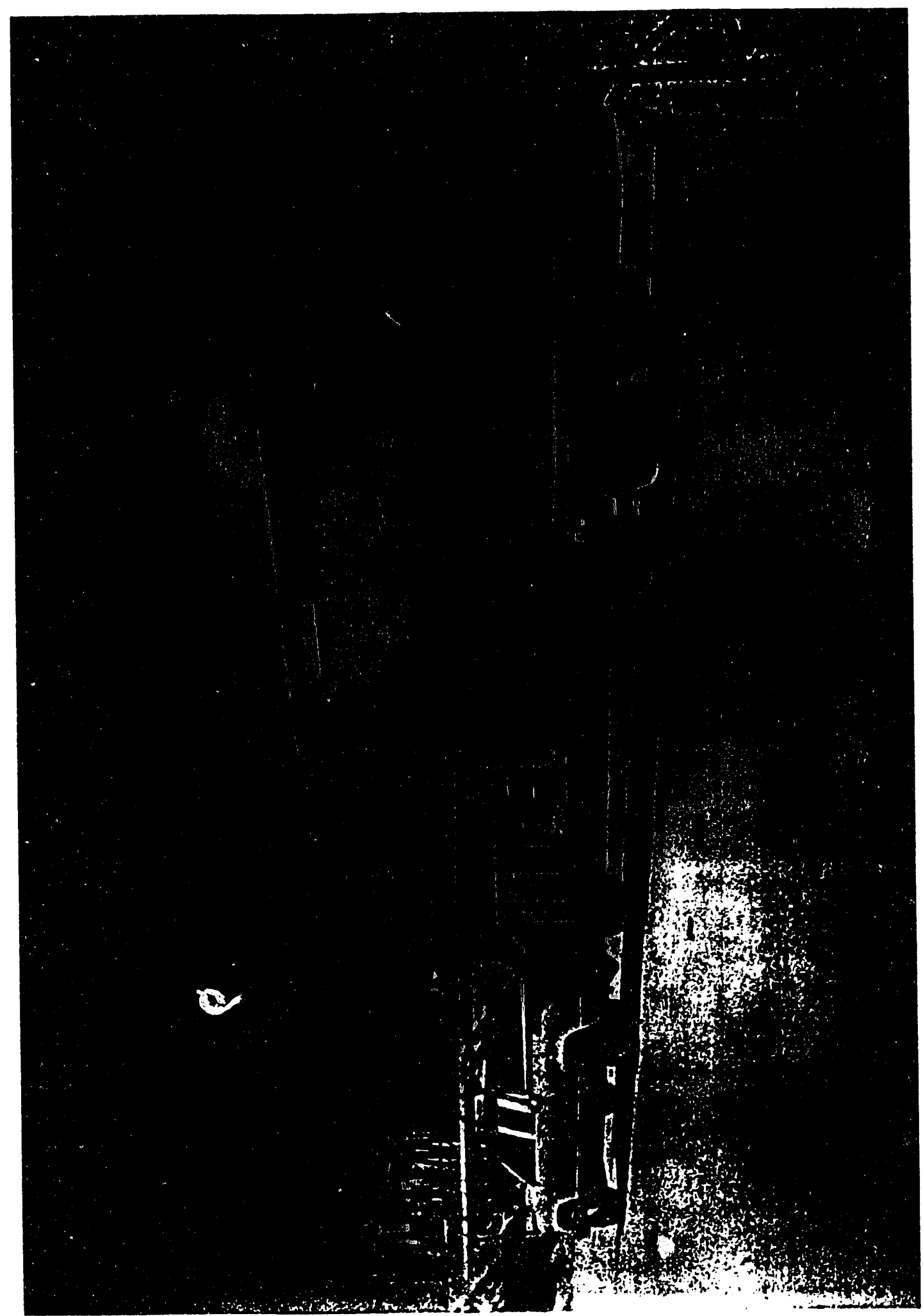

Higuret-1. Mohile KAI RFApplicilum Lint 


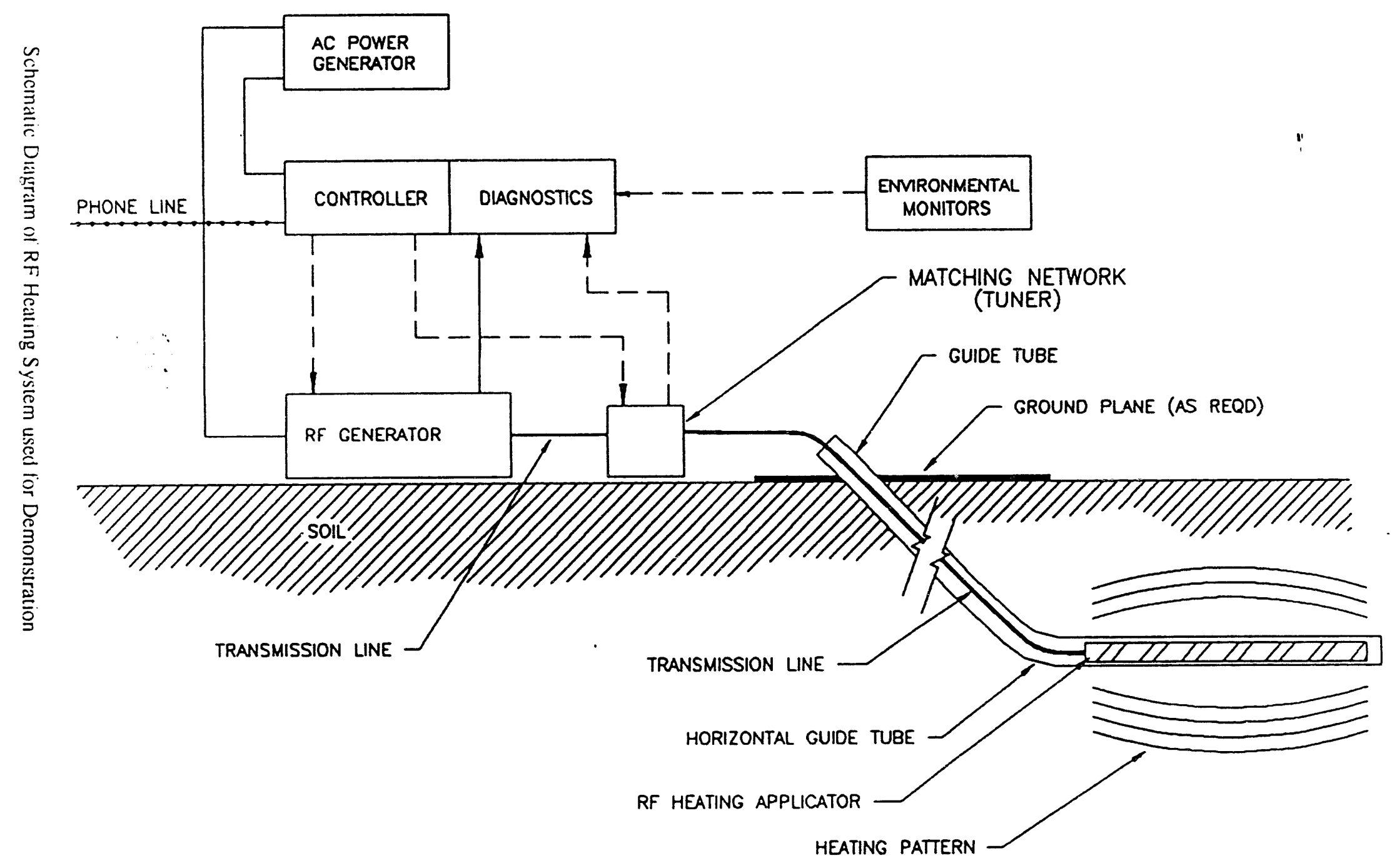




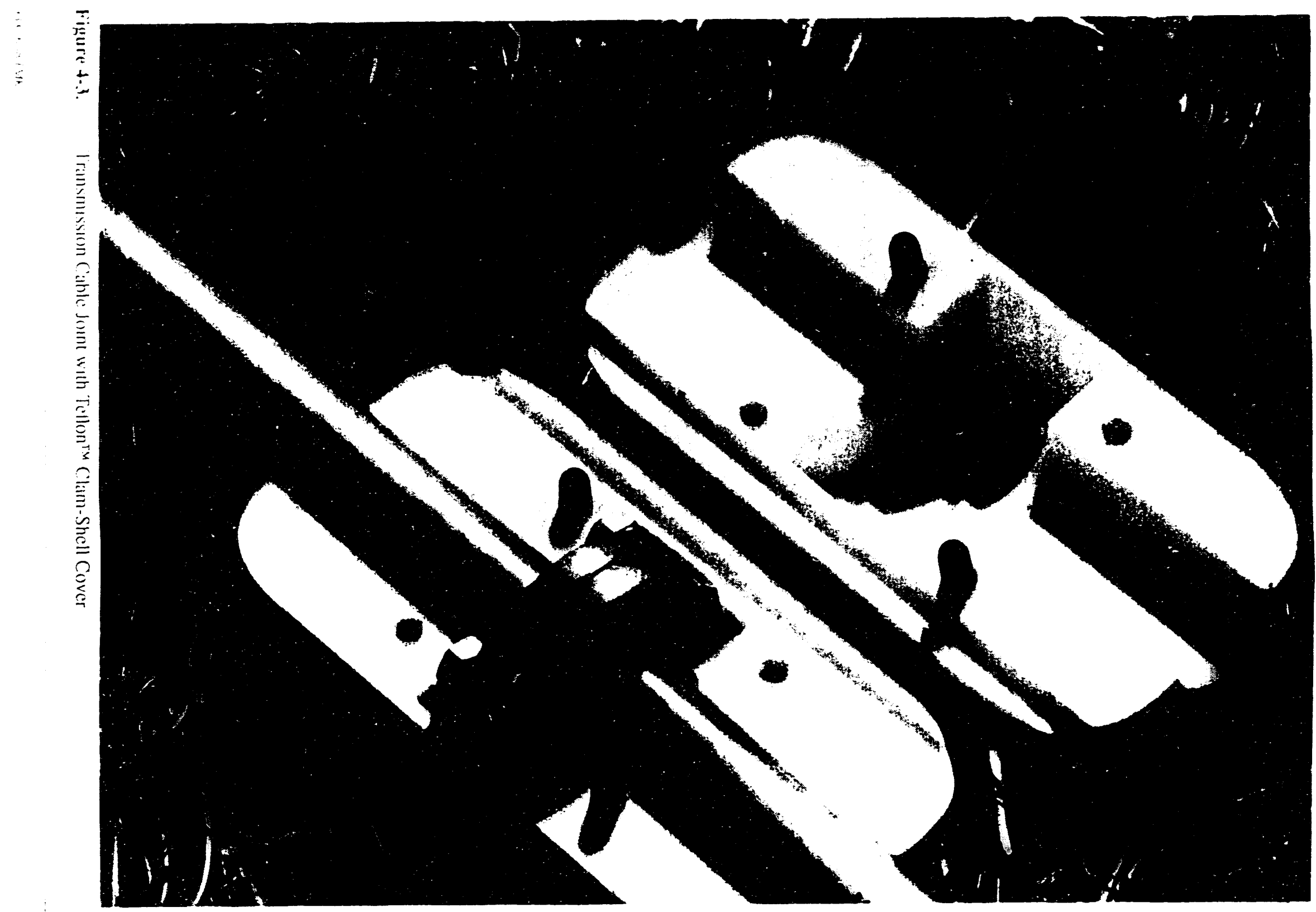




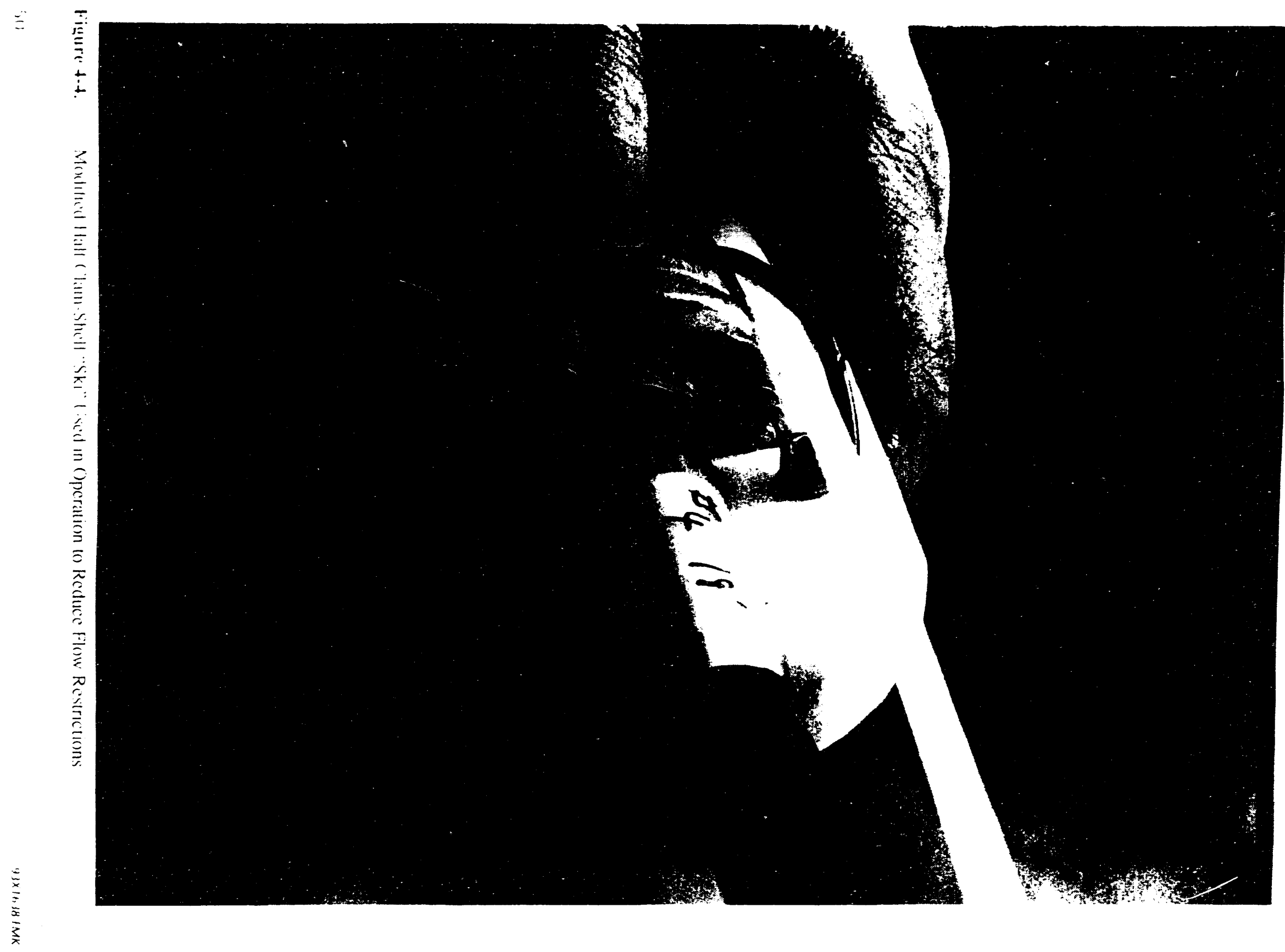




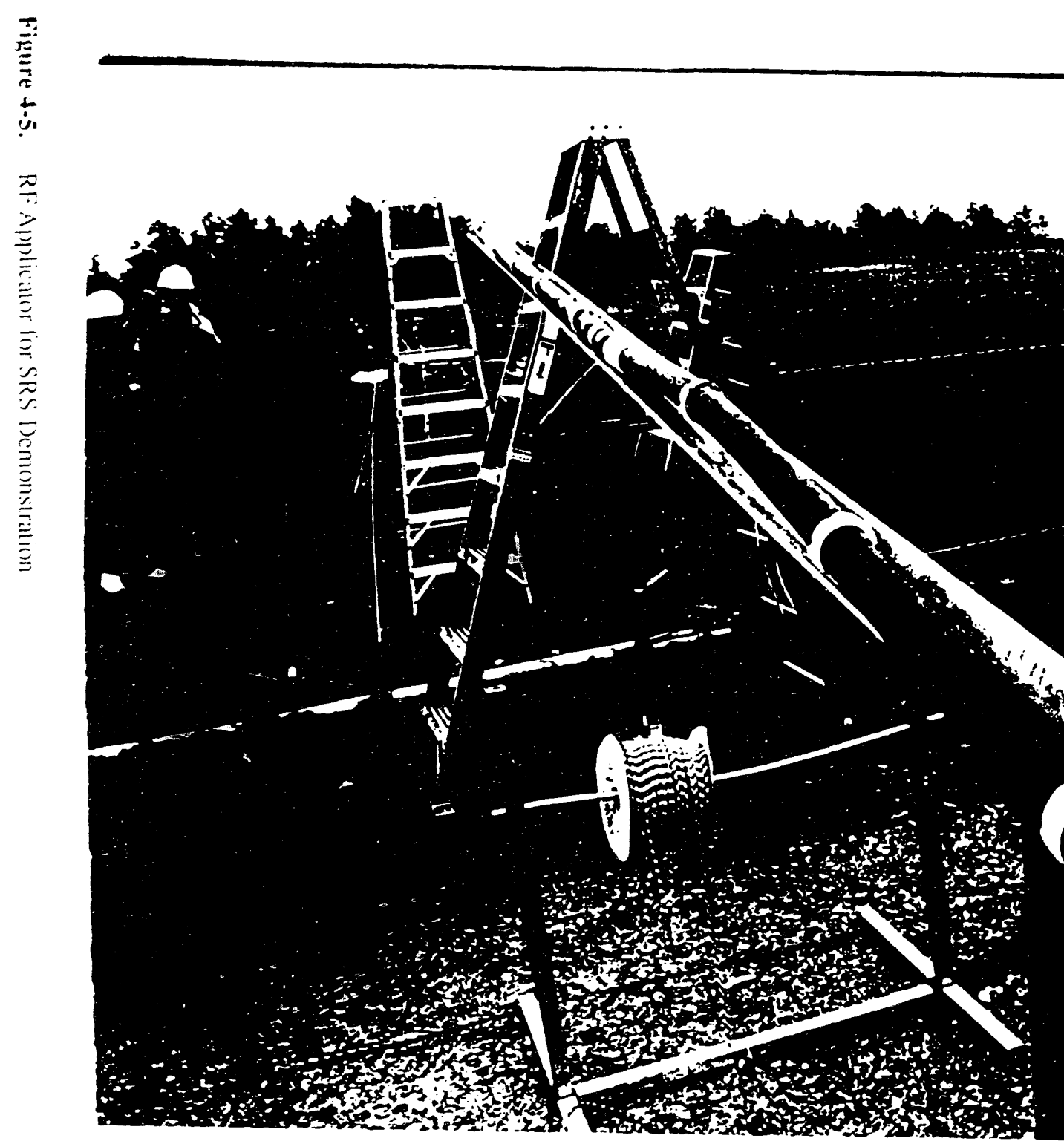

and

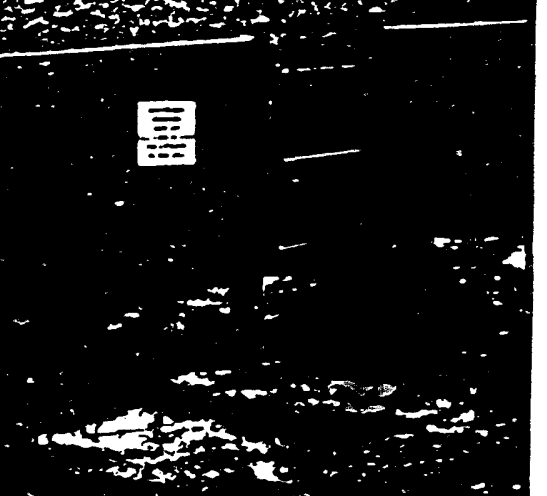



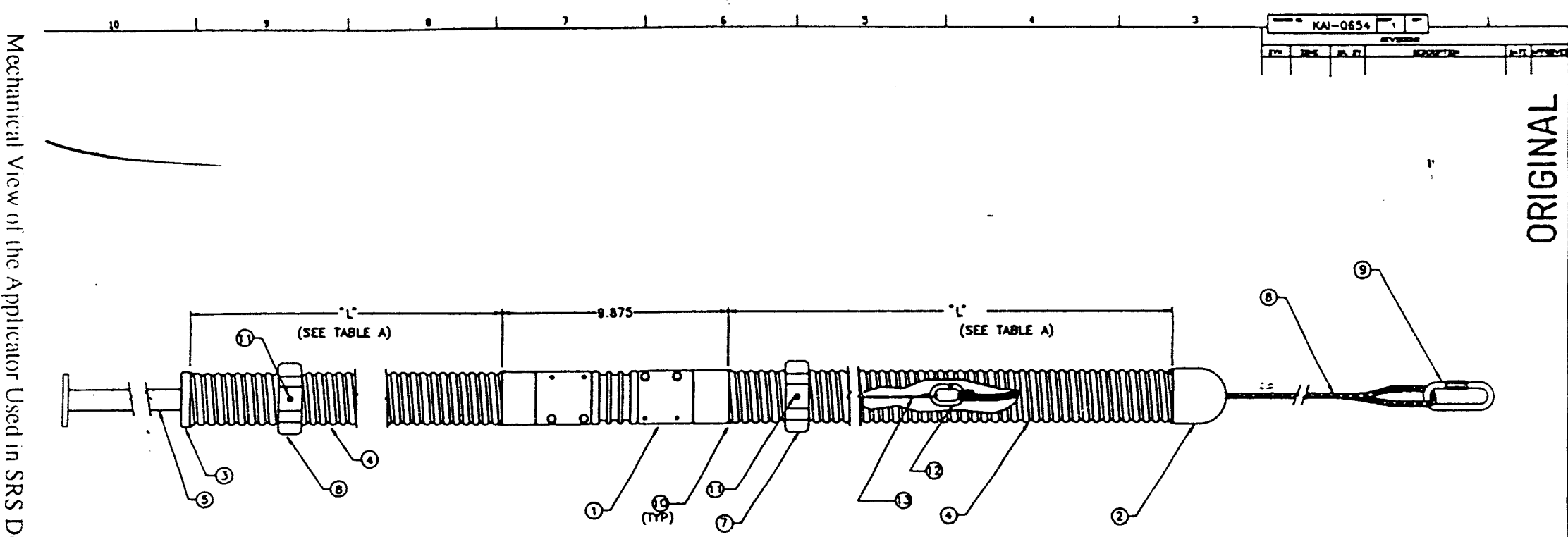

ర్

\begin{tabular}{|c|c|}
\hline \multicolumn{2}{|c|}{ TABLE A. } \\
\hline FREOUENCY & LENETH $I^{\circ}$ (RWNEE) \\
\hline$\frac{1356 \mathrm{MHz}}{27.12 \mathrm{MHz}}$ & $\frac{8-12 \pi}{4-8 \pi}$ \\
\hline & \\
\hline
\end{tabular}

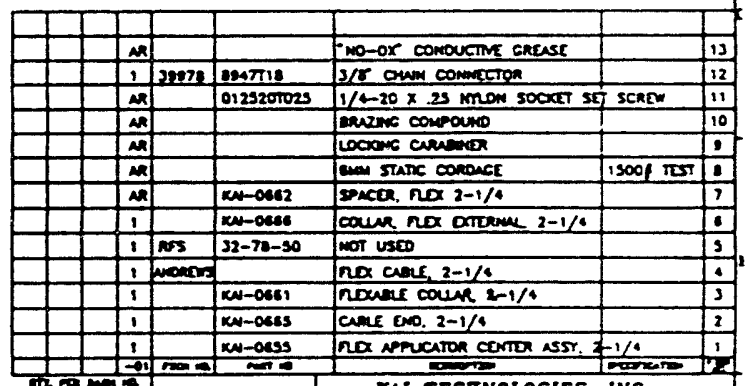

IN TRCRNOLOCISS. INC

24IE- FLEX APPLICATOR, ASSY 2-1/4

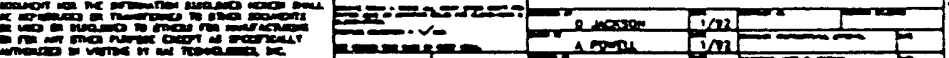

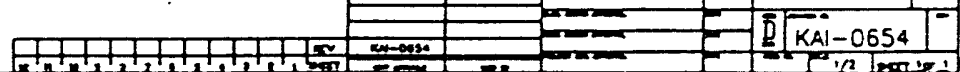




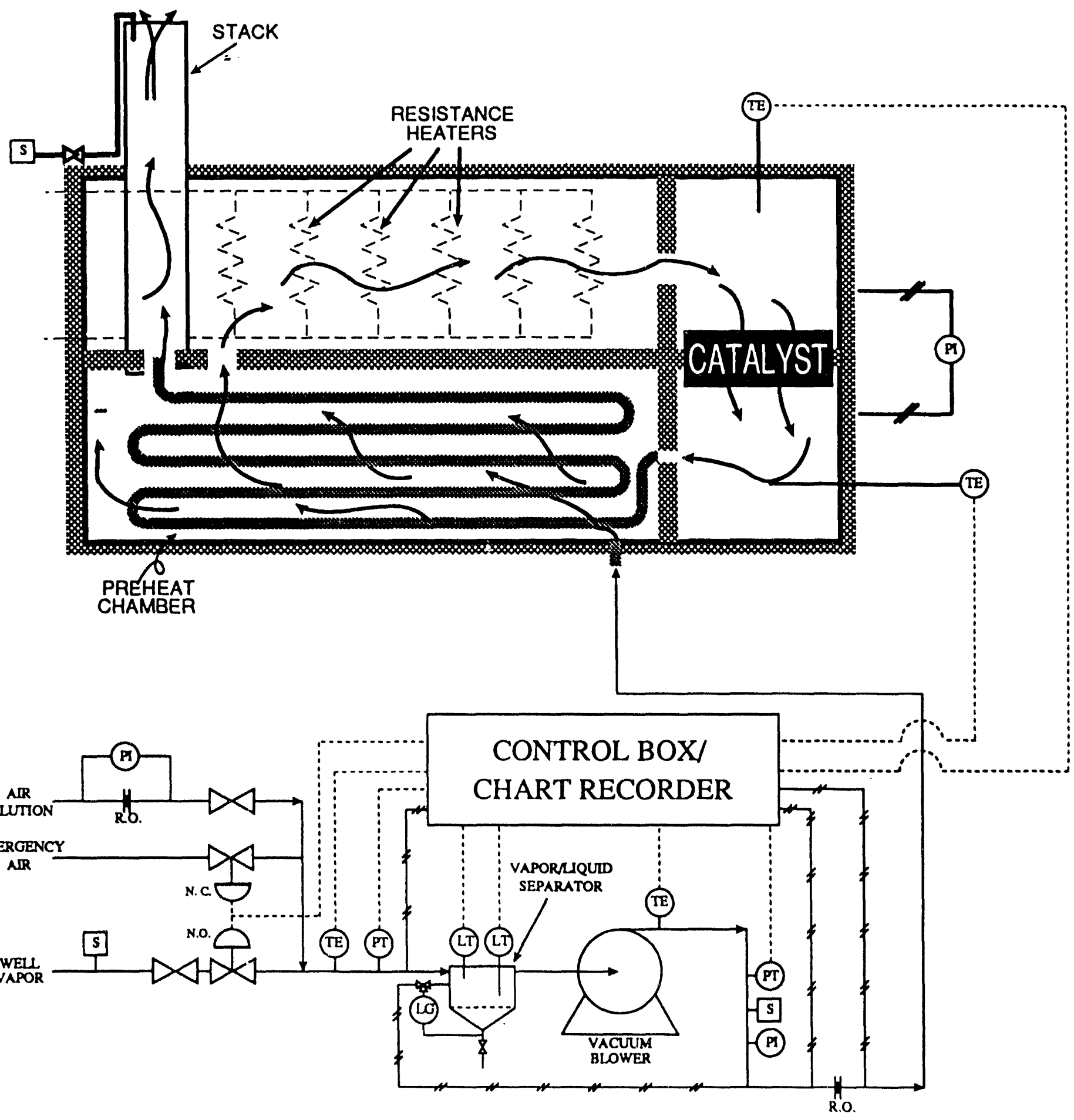

S. Sample Poins

Figure 4.7. Schemalic of Calox System Employed at RF Heating Demonstration 
HORIZONTAL WELL / RF HEATING TEST

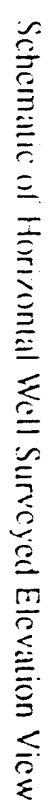

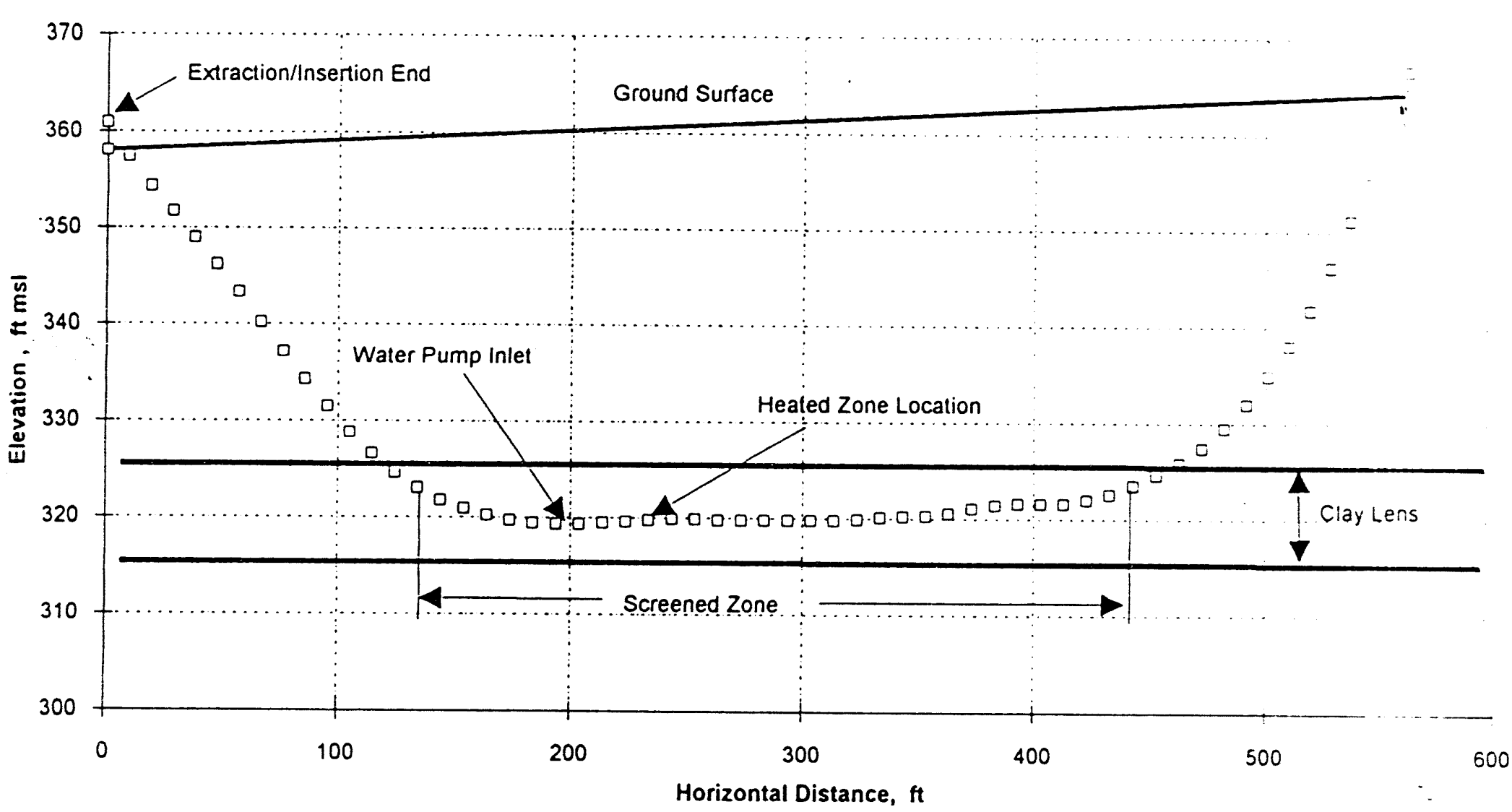




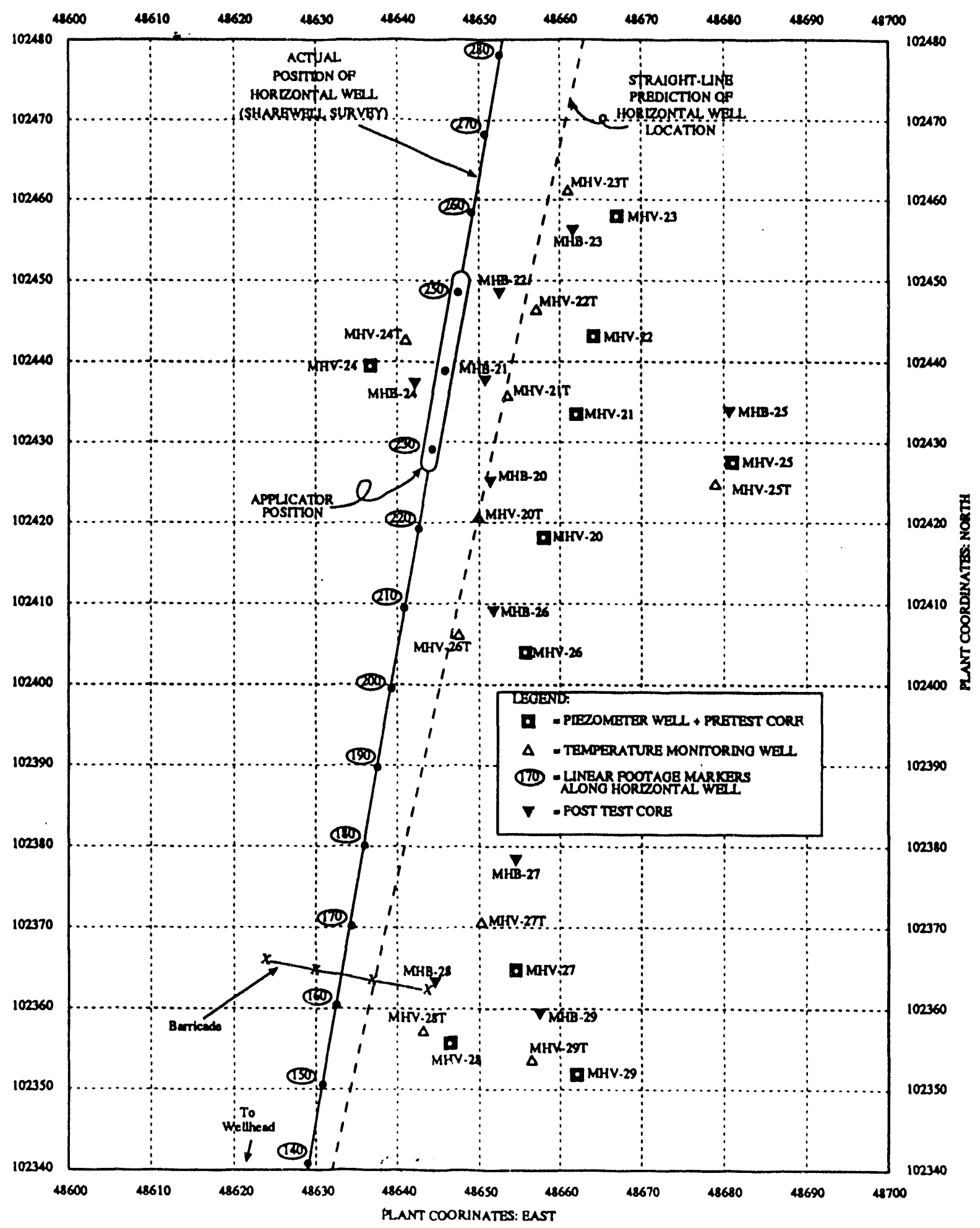

Figure 4.9. Moniloring Well Layout with Respect to the Horizontal Well 
WSRC.TR.93.673

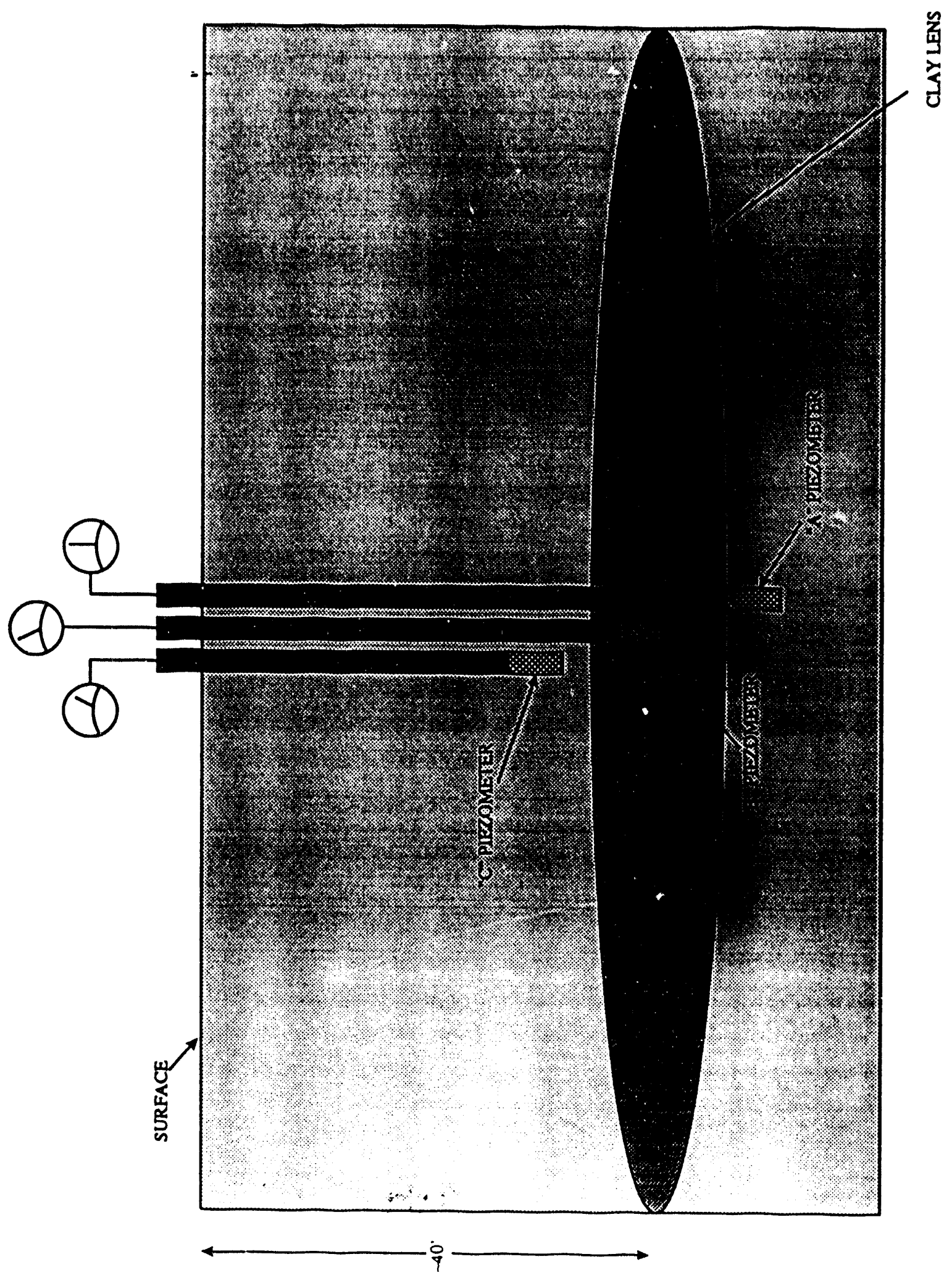

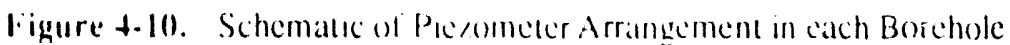




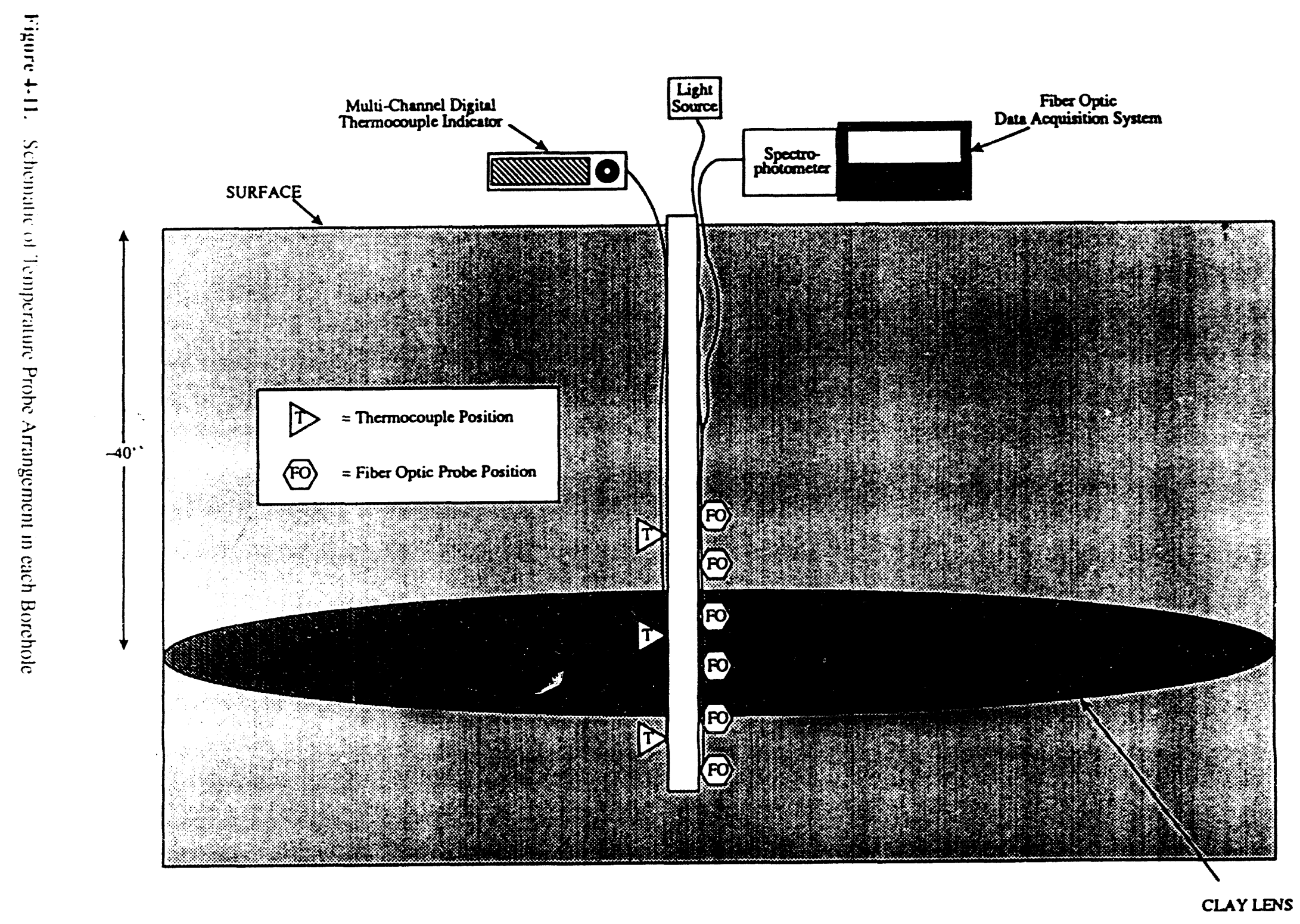


WWRC.TR.93.673

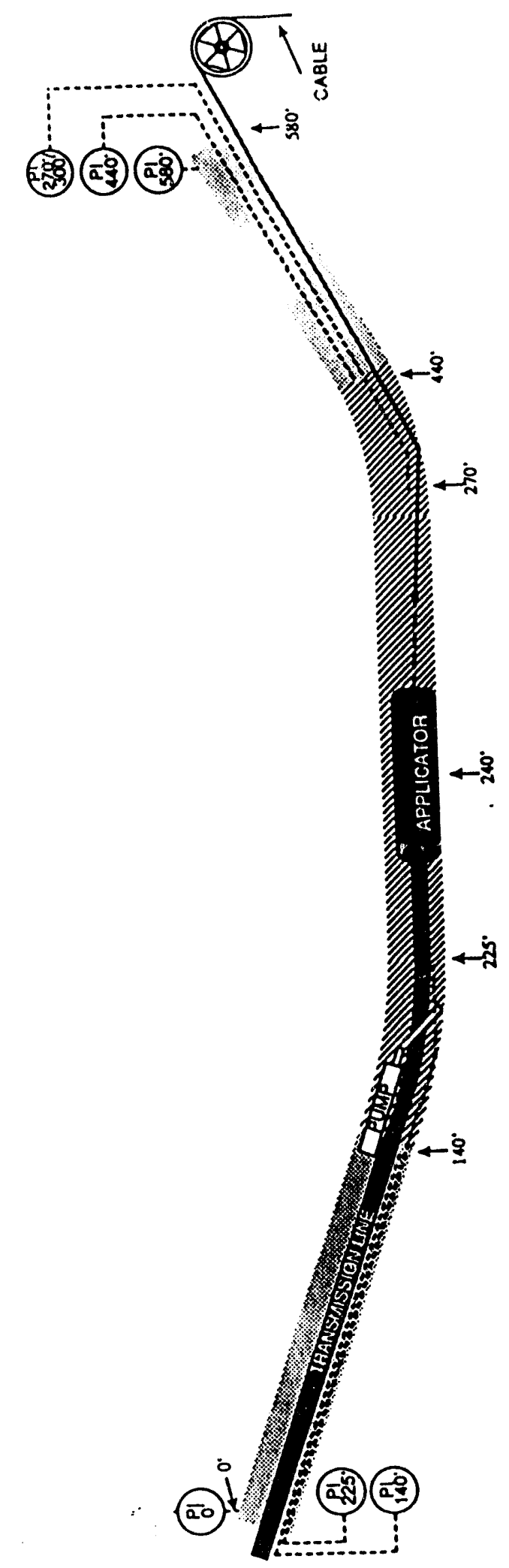

Higure +12. Schemante ol Horkental Well Pie\%ometer Positions 
Final Report: In zit:a Radio Frequency Heating Demonstration
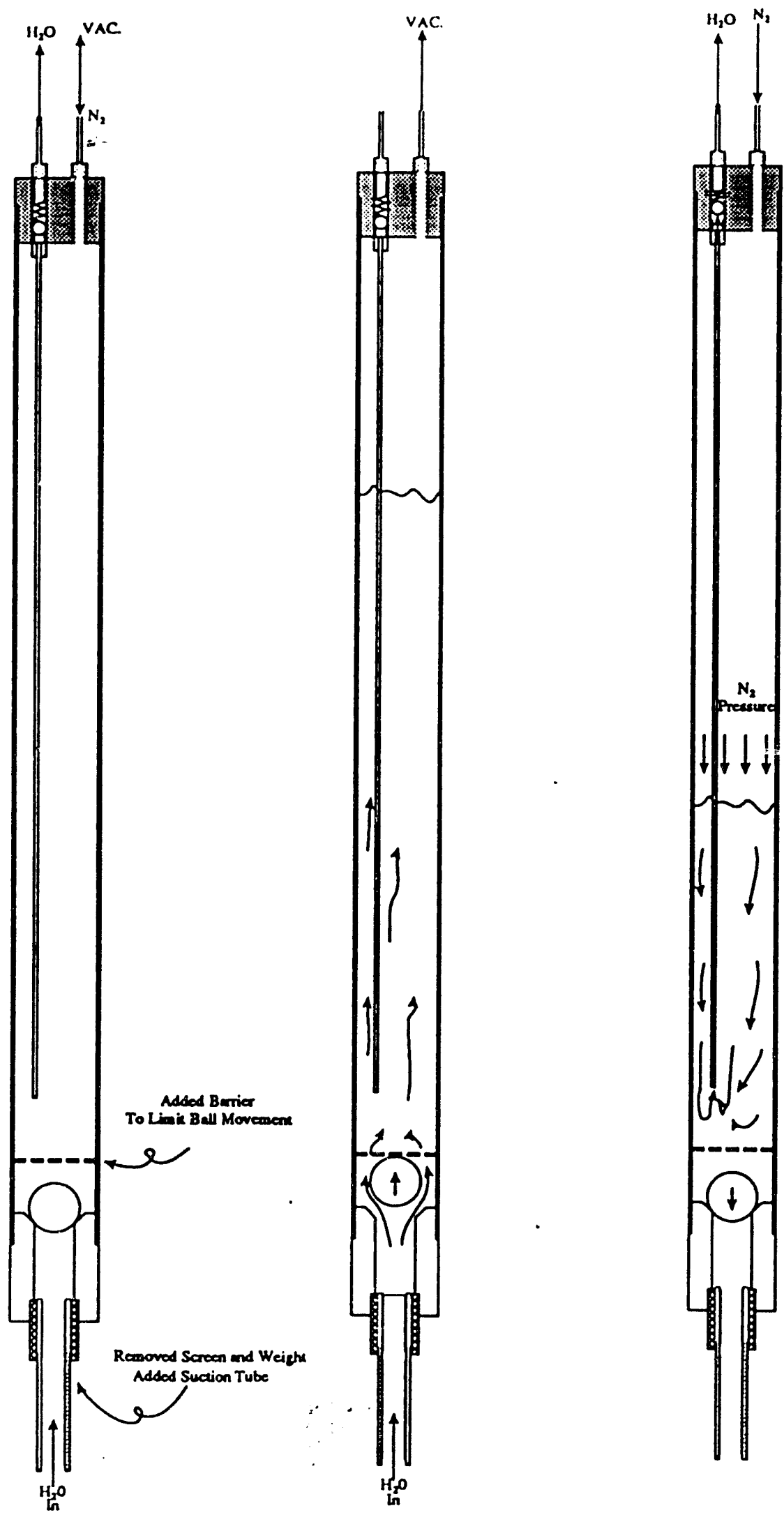

Figure 4-13. Schemalte of Meslitiod A ir Lill Pump 


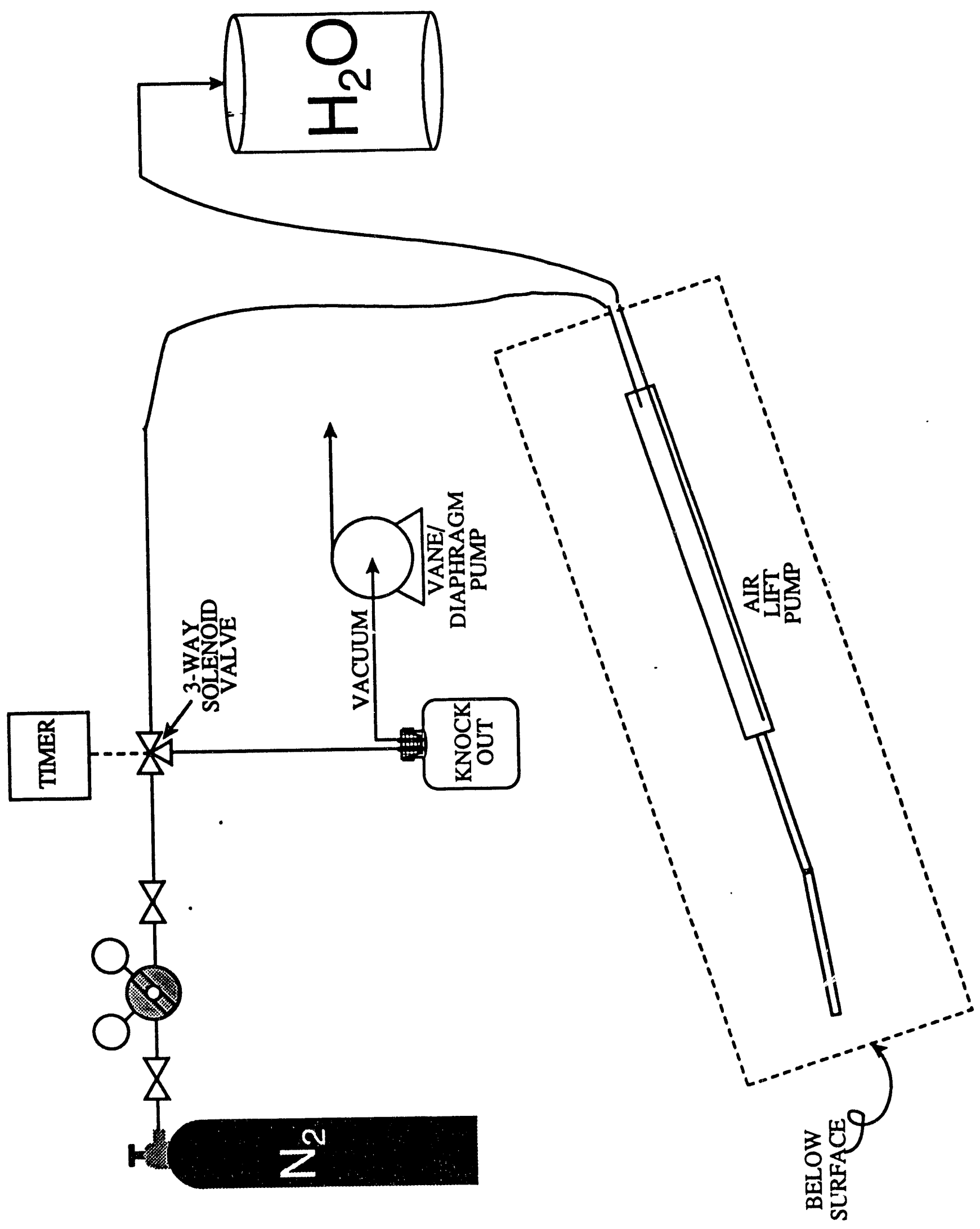

Figure 4-14. Schematic of Air Lift Pumping System 


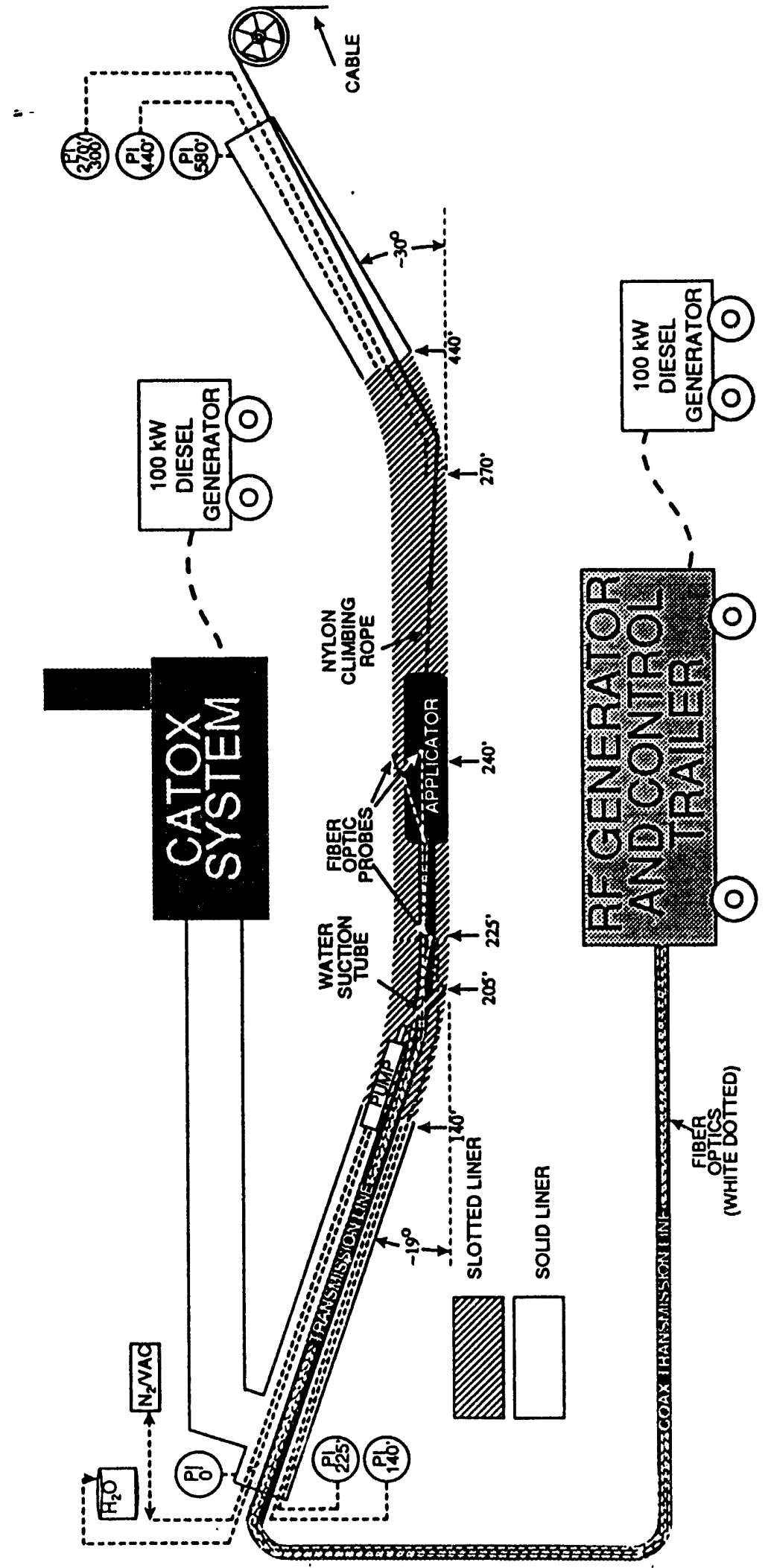

Figure 4-15. Final System Conliguration for In Situ RF-Enhanced Vacuum Extraction System 


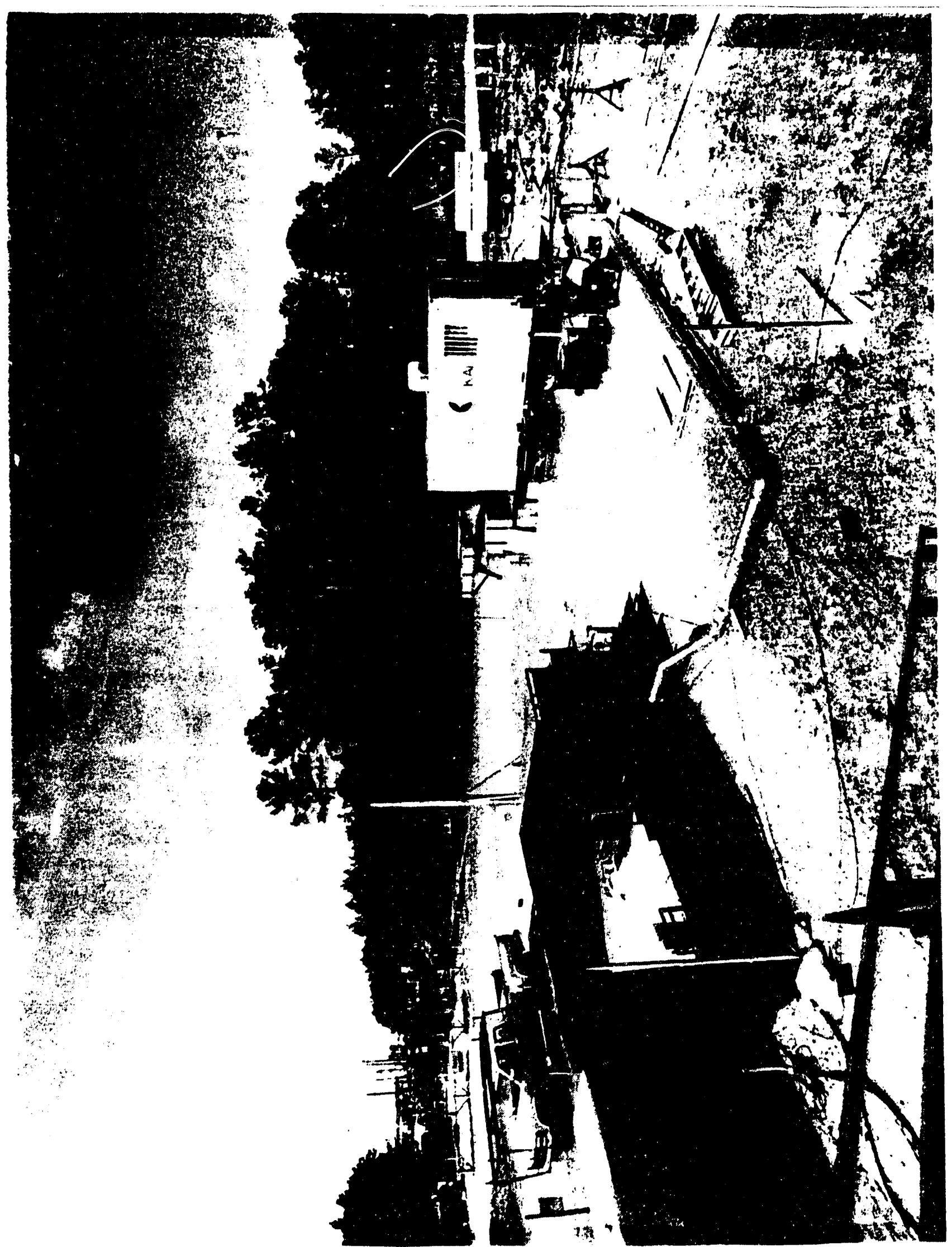

Figure 4-16. Photograph of In Sulu RF F:nt anced Vicuum Extraction System 
Cursor .......... $318.000 \mathrm{ft} \Delta$

Distance/Dir..... $50 \mathrm{ft} / \mathrm{dir}$

Vertical Scale.... $500 \mathrm{mP} /$ dir

VP ............. 0.99

Noise Filter...... 8 arg

Power........... ac

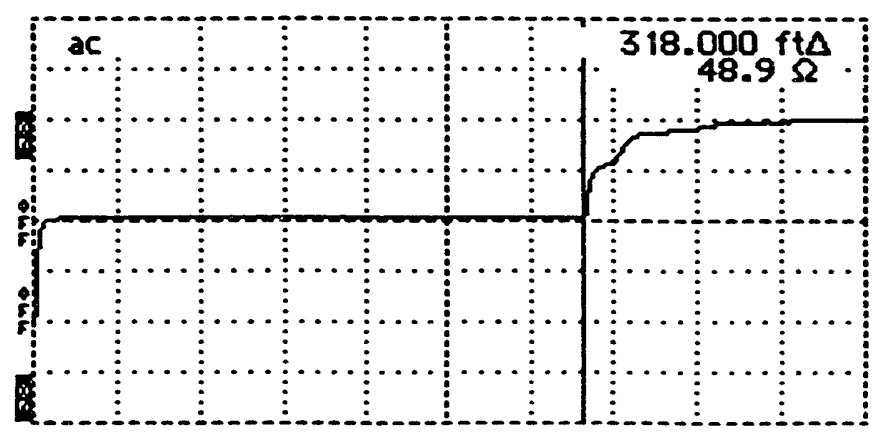

Tektronix 1502C TDR

Date $3 / 19 / 93 \quad 6: 1 /$ P 1

Cable Fed neplian e/so

Notes

Input Trace

Stored Trace

Difference Trace

Cursor .......... $318.000 \mathrm{ft} \Delta$

Distance/Dir..... $50 \mathrm{ft} / \mathrm{dir}$

Yertical Scale.... $100 \mathrm{m \rho} / \mathrm{dir}$

VP ............. 0.99

Noise Filter ...... 8 ays

Power ........... ac

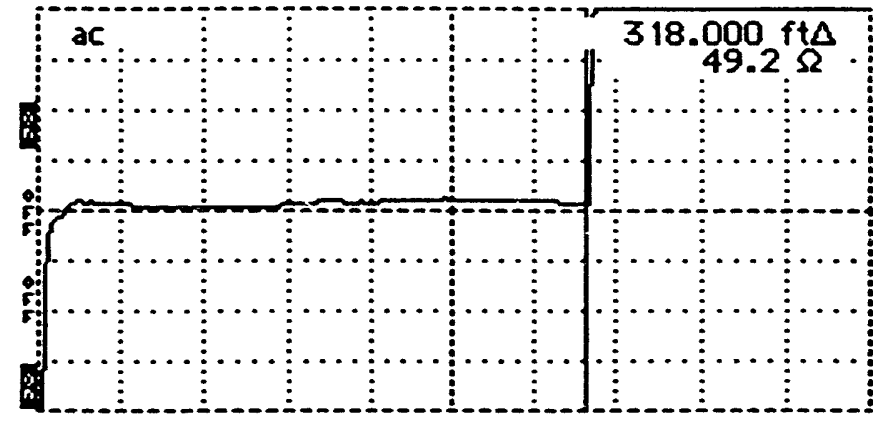

Tektronix 1502C TDR

Date $3 / 19 / 93$ 6/12 .

Cable tied Rep?.

Notes

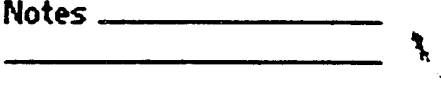

Input Trace

Stored Trace

Difference Trace

Cursor .......... $318.000 \mathrm{ft}$

Distance/Dir..... $2 \mathrm{ft} /$ dir

Vertical Scale.... $200 \mathrm{~m} / \mathrm{dix}$

Vp ............. 0.99

Noise Filter...... 8 arg

Power............ ac
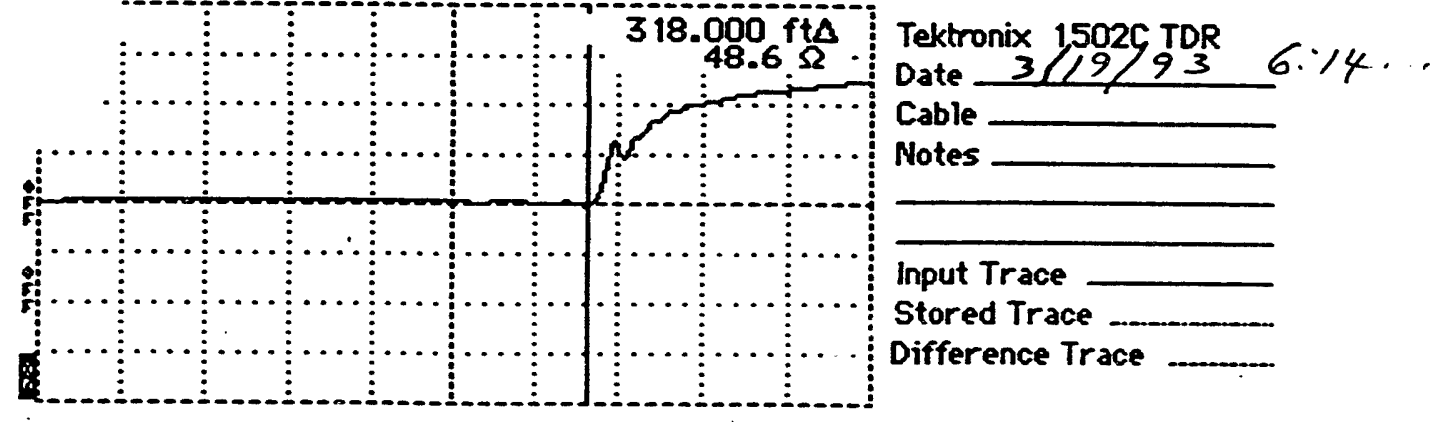

Cursor ........ 318.6

Distance/Dir.....2 $2 \mathrm{ft} /$

Vertical Scale.... 200

YP ............. 0.9s

Noise Filter ...... 8 ayg

Power............ ac

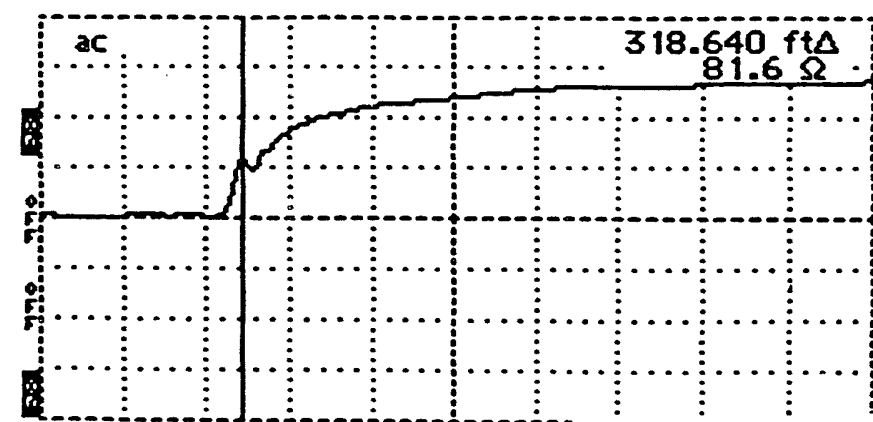

\begin{tabular}{l} 
Tektronix $1502 C$ TDR \\
Date $3 / 19 / 93$ \\
Cable $6: 15$ \\
Notes \\
\hline Input Trace - \\
Stored Trace \\
Difference Trace $\ldots$
\end{tabular} 


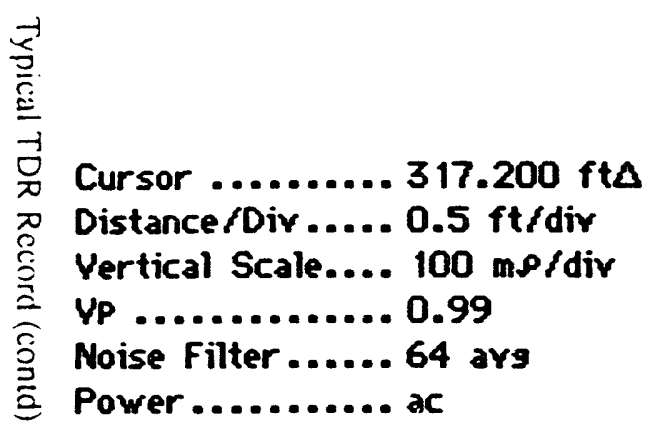

Cursor ......... 296.256 ftA Distance/Dir..... $5 \mathrm{ft} /$ dir Yertical Scale.... $200 \mathrm{mp} / \mathrm{dir}$ Vp ............ 0.99 Noise Filter..... 64 ars Power........... ac

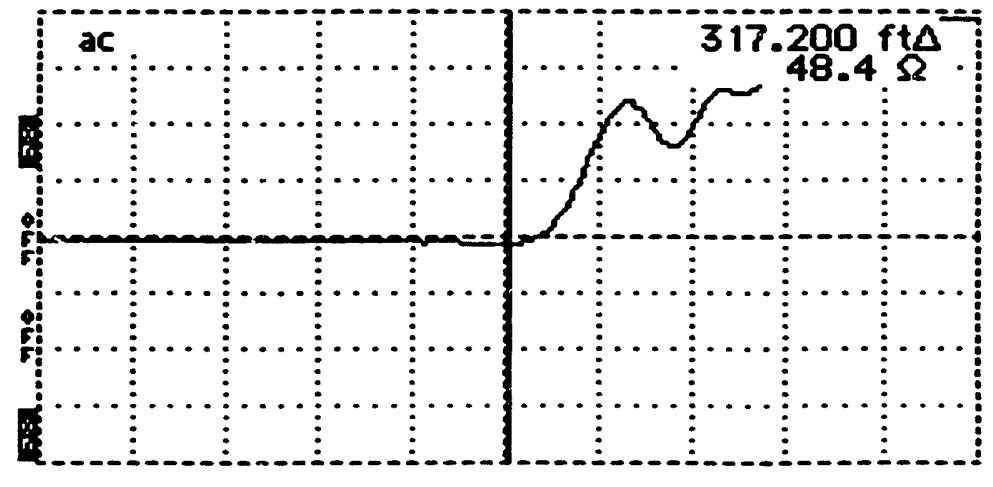

Tektronix $1502 C$ TDR

Date $4 / 2 / 93: 08: 31$

Cable apelecalo

Notes 20 me, $\propto 5 k w$

Input Trace

Stored Trace

Difference Trace

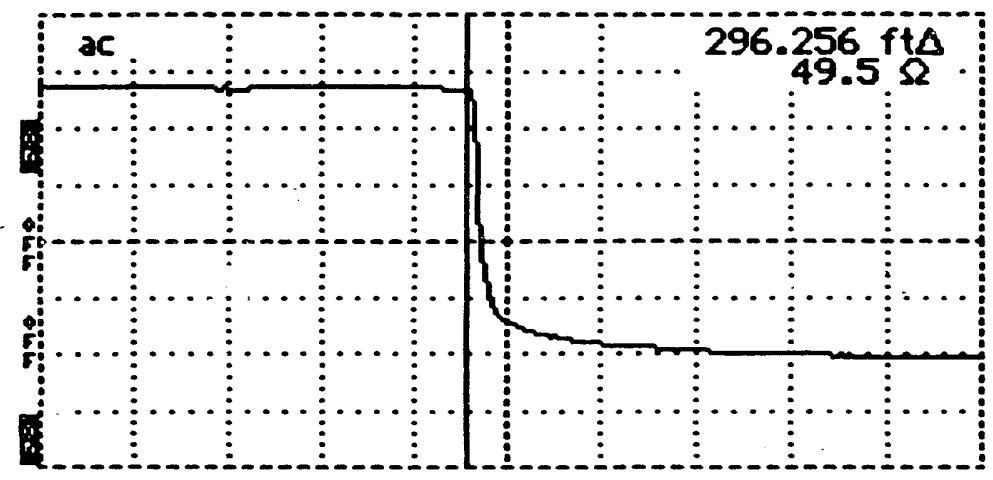

Tektronix 1502C TDR

Date $4 / 4 / 93 / 2: 16$

Cabie

Notes Tronsmissin flu

Input Trace

Stored Trace

Difference Trace 
WSRS5212.01L Heat 4 WB heat. Return Loss 8-Apr-93 7: 30: 48

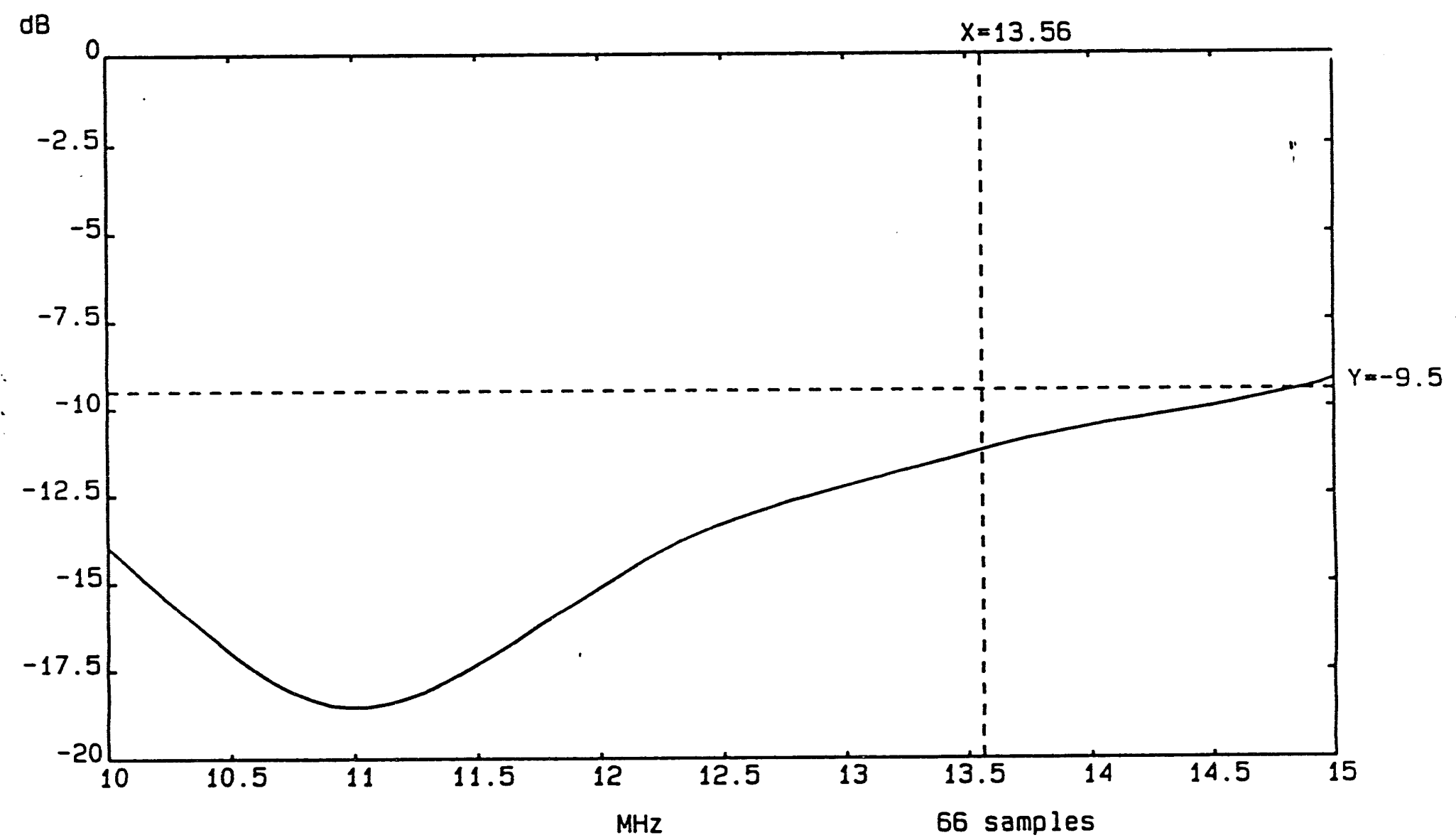

Inst $r=H P 3577 \mathrm{~A}, H$ units $=H z, V$ units $=\mathrm{dB}, \quad N p W=401, \quad V S C L=10 T 1$.

Freq $M H Z=16, H$ span $M H Z=30$. Res $K H z=1$. Avg $=1$. Wscale $=100$. 


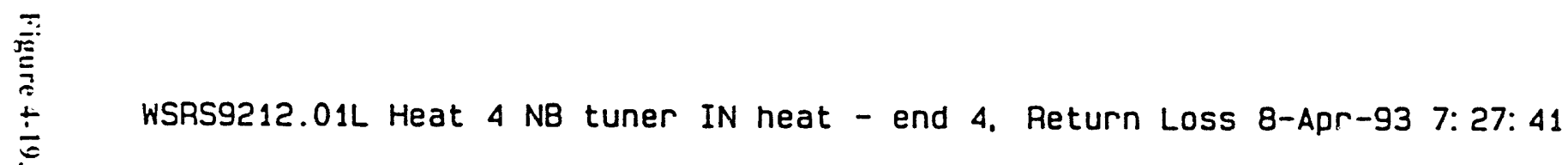

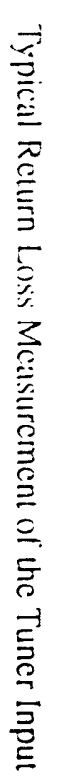

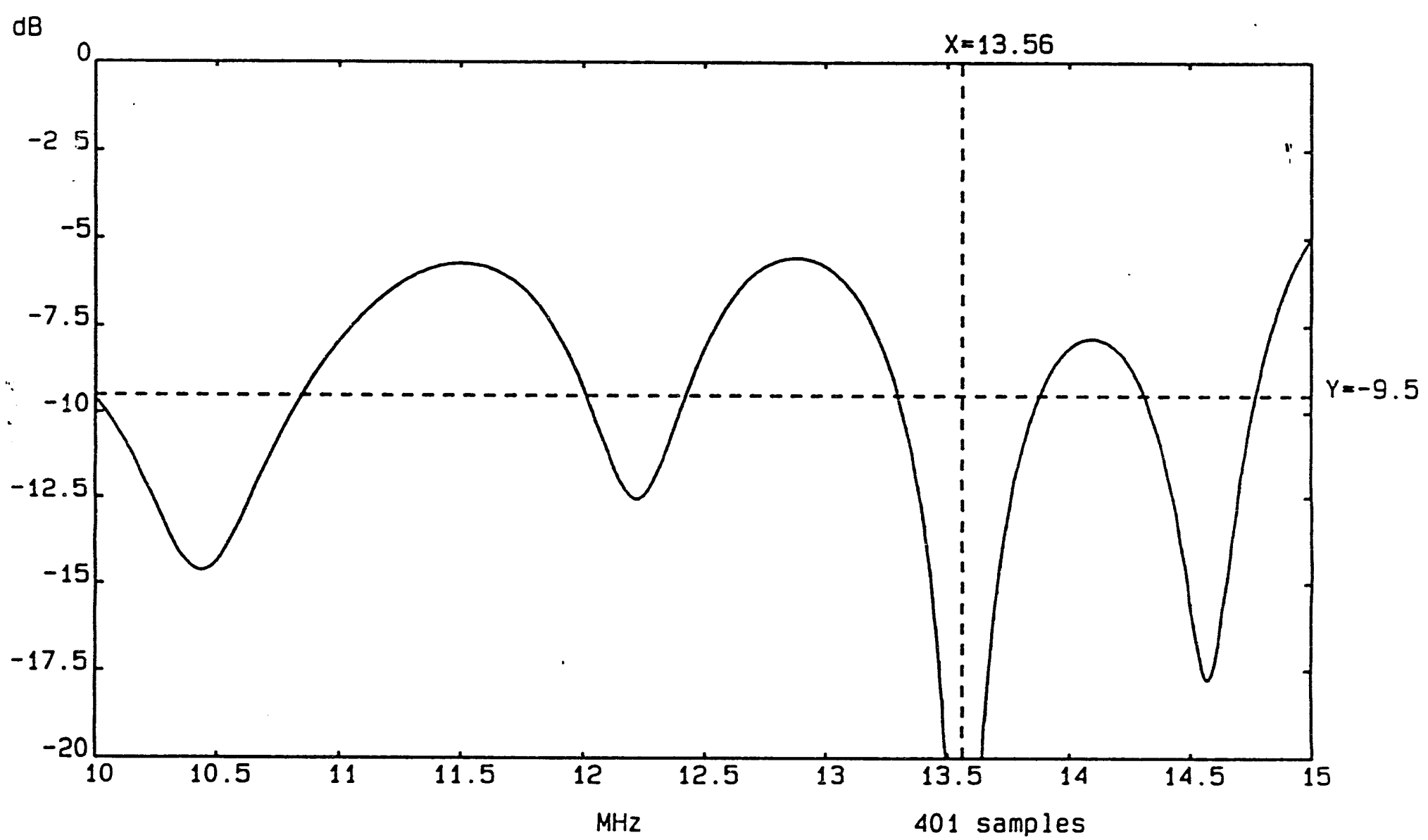

Instr $=H P 3577 \mathrm{~A}, H$ units $=\mathrm{Hz}, V$ units $=\mathrm{dB}, \quad \mathrm{Npw}=401 . \quad V S C L=2 \mathrm{~T} 1$,

Freq $M H Z=12.5$. $H$ span $M H Z=5$, Res $K H z=1$, $A v g=1$. Wscale $=100$. 


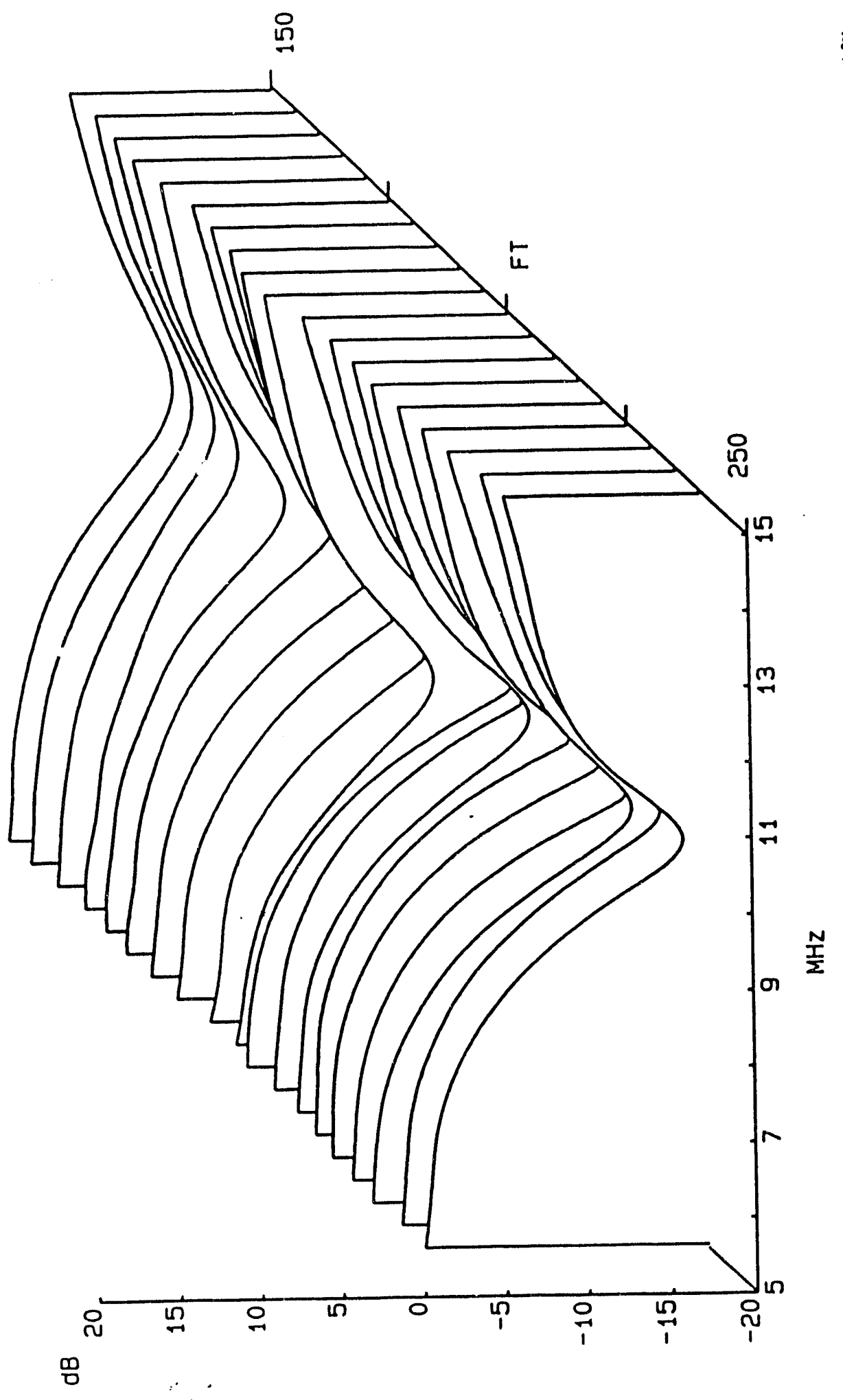

Figure 4-20. Typical appliciltor Insertion Scan (Retum Loss vs Distance Downhole) 
WSRC.TR.9.3.67.3

$=$ 


\subsection{Results And Discussion}

\subsection{Mobilization}

\subsubsection{Overall Assessment}

The critical path item in the mobilization elfort was procuring and installing the vacuum extraction/thermal calalytic oxidation system. Primarily because of catalyst supply delays, this system was not ready for operation until carly March 1993.

\subsubsection{Radio Frequency Application System}

Setting up and testing the RF application hardware consisted of connecting $A C$ power, assembling the applicator and transmission line, readying the RF generation equipment. and conducting control system and diagnostic checks. The applicator was ready for initial insertion for preliminary diagnostic checks in three days.

\subsubsection{Catox System}

Installing the skid-mounted Caltox system was relatively simple and included skid positioning, leveling, piping to the well, placing the calalyst, and connecting the AC power. After the system arrived at SRS, a llaw was discovered in the catalyst mounting frame and required a field incrification before installing the caltalyst. This modificalion was suspected as the rool cause of a bypass in the catalyst block, which potentially reduced the overall destruction efficiency of the system. In addition to the design error, several errors in the operating manual were identified. Inspecting, installing, and testing the equipment required approximately three wecks.

\subsubsection{Applicator Insertion and Removal}

The applicator insertion/removal process was cumbersome and very labor intensive. Initial plans to assemble the rigid transinission line entircly above ground had to be altered because of the likelihood of darnaging the coupling joints during inscrion. As a result, the transmission line had to he assembled (disassembled) at each step of inserting (removing) the applicator. Inserting the instrumented applicator complicated the process. Monitoring lines had to be secured to the transmission line at 2-foot intervals allong the tirse 60) leet of transmission line and every 18 lect therealier. This technigue ensured addequate protection of the delicate liber optic probes, cables, and connections and reliable delivery and retricual of the piezometer lines and waller pump. The presence and llexible nature of the down hole piezometers complicated the process. To reduce the down time when the applicator was removed, the two upstream piezometers were replaced about mid way through the demonstraiton with a single, stainless steel tube (1/4-inch OD) located 300 feet down holc.

Two factors that complicated the insertion process were a direct result of either the demonstration nature of the test (i.c., a first-run operation coupled with obtaining sufficient data for technology assessment) or the use of a single horizontal well for both heating and vacuum extraction (i.e., placing piezometer lines and the water pump). Instrumentation necessary for applicator operation (primarily fiber optic lines for temperature control) could be preassembled in a single delivery feed line to facilitate insertion.

\subsection{System Operation}

\subsubsection{Radio Frequency Heating System/ Applicator Operation}

\subsubsection{Radio Frequency Generator and Matching Network (Tuner)}

The RF generator and tuner operated without incident throughout the program. The 240 VAC, 3-phase generator provided stable input power and allowed the RF generator to provide its fully rated, 25,000 watts of RF output at $13.56 \mathrm{MHz}$. The generator's primary, analog control sys. tem protected the generator during load variations, which were caused by the quenching events from water influx to the well upstream of the applicator. The KAI control and monitoring system provided a secondary, digital system that controlled the generator's overall operation in terms of energy and temperature control. This programmable, digital system was used to adapt the generator to deal with the water quenching events that would have required significant amounts of round-the-clock onsite operator intervention if it had not been field adaptable.

The matching network was operated well within its electrical and thernal design parameters. Within the entire 27. day heating program, the tune was adjusted fewer than 10 times. The majority of these adjustments where minor trimming adjustments that represented less than $5 / 100$ th of a turn on the control capacitors. In terms of tuning, an operational period in excess of 20 days would have been possible. If a fully remote controlled tuning and measurement system were engaged, the RF system would not have required onsite support for the entire program. 


\section{\$.2.1.2 Transmission Line and Radio Frequency Applicator}

The transmission line was composed of flexible and rigid sections. The original deployment plan called for the Iransmission line to be compleiely assembled and pressurred hetore inserting the applicator and transmission line into the well. Ficld site logistics and limitations on fixture sizes available to handle the rigid line did not allow it to be lully assembled. Therefore, the line had to be assembled in 2()-loot sections. Sensor lines (pressure, temperature) were allached with heavy duly tape. This assembly-intensive approach required that the number of horizontal well insertuons be kept to a minimum.

The transmission line was operated in a higher temperalure environinent than its manufacturer had anticipated. The transmission line sections were joined with junction anchors that were designed to "slip" with the expansion and contraction of the transmission line. However, the sandard expansion range of this foint was not sulficient for the emperature differentials encountered. Electrical shorting and continuily problems were encountered on the heallng and cooling cycles of the line. These problems were solved for the specifics of this transmission line system. Analysis of the problem suggests that a number of engunecring solutions may be used to permanently address this problem in the luture.

The initial insertion included network analyzer diagnostic checks at low power to ensure that the applicator's length wats optimal for matching the output impedance to the clfective impedance of the borchole and soil. Following this initial insertion, the applicator was removed and the linal coupling brazed in place for the proper dipole length. The applicalor operated within its design range. However, because of difficultics in inserting and removing the appli. cator and rigid transmission line system from the horizonlill well and program time constraints, the tuning was not ophimised. A starting voltage standing wave ratio (VSWR) (1) I wats alecepted as the initial match for the applicator. This less than optimum match was chosen with tuning conditions that would allow the VSWR to improve toward a value of : 75 or better as the moisture in the soil surrounding the antenna decreased from drying. Figure 5-1 is a) scan of the matching characteristics of the horizontal well al the beginning of final healing cycle (4/8). It can be seen that the region between 11 and $14 \mathrm{MH}$. for the 230 . and 24()-li(x)t positions indicalc changes from that show'n in the pre-heat scan cxample in Figure 4-20. Thesc changes cin be better seen by comparing these two borehole scans with single frequency "slices" of the respective data sets. Figure 5-2 shows the return loss as the 16.7-fi applicator is pulled into the well from the 1.5() -foot to $24($ )- foot center line position. The "hump" in the return loss between 180 feet and 200 feet was most likely caused by the close coupling of the antenna to the wall within this bend region of the horizontal well. Figure 5-3 is the same type of "slice". Within the 230- to 240-foot interval occupied by one-half of the applicator, it can be seen that the return loss match has improved. This improvement is within the predicted range for "drying" the heated region. In fact, the extension of this heating zone effect to the 220foot region is also expected. At the 240-foot position, the return loss has improved to approximately $12.5 \mathrm{~dB}$ for a nominal VSWR of 1.75 . The return loss minima shown between 180 and 190 feet may again be due to bending the applicator, but the effect may be enhanced by a thin layer of water distributed along the base of the horizontal well in this region. This area is the lowest point of the horizontal well and the region that accumulated water after the vacuum was applied to the horizontal well.

\subsubsection{Temperature Monitoring and Control System}

Monitoring the temperature of the horizontal well region surrounding the applicator was necessary to protect the well liner from damage. The damage temperature was estimated to be $120^{\circ} \mathrm{C}\left(250^{\circ} \mathrm{F}\right)$. To protect against liner damage, a fiber optic temperature sensor was positioned against the borehole line wall. This sensor was used as part of a temperature control circuit to limit the RF generator's heating cycle time. Typical setpoints of $115,120,125$, and $130^{\circ} \mathrm{C}$ were used. Because of this control feedback, the RF generator operated with a duty cycle of 90 to $75 \%$, which meant that the generator RF power would be off from 6 to 15 minutes every operating hour. This duty cycle limited the amount of energy that could be delivered to the formation.

\subsubsection{Power Use/Output}

The toial AC power input to the RF generator and forward coupled RF power was monitored continuously by the $\mathrm{KAI}$ control system for each heating cycle. Data files of power values versus heating cycle time were generated by the control system and serve as the basis for power utilization and delivered power calculations. A hard copy of each of these data files appear in Volume II of this report. Each data file calculated the average power measurement over the corresponding cycle time. This averaging takes into account the duty cycle limitations. AC power was converted to RF with an efficiency of $65 \%$ based on the measured values of $\mathrm{AC}$ input and forward coupled power values. To determine actual RF power delivered to the formation, the forward coupled power measurements must be corrected to account for losses between the RF generator. 
Iuner, transmission line and applicator and reflected power. For this RF delivery system (based on KAl experience), the correction lactor is assigned a value of $(0.85$. Theretore, the overall efficiency of the power delivery is approximately $55 \%$. Of the $21,200 \mathrm{~kW} \cdot \mathrm{hr}$ of $\mathrm{AC}$ input cnergy, $11,675 \mathrm{~kW}$-hr were successfully coupled to the formaltion.

\subsubsection{Radio Frequency Elrects on Site Communications}

Transmission of the RF energy at $25 \mathrm{~kW}$ and a frequency of $13.56 \mathrm{MH} \%$ posed on detectable interference with other SRS users of RF or with sitc communications.

\subsubsection{Extraction System Operation \\ 5.2.2.1 Horimontal Well Flow, Vacuum, and Temperature Relationships}

Relatively low flow from the well was experienced throughout the demonstration with recorded values rarely exceeding 30 scim (lypical flows over the course of the initial cold pump test and heating stage ranged from $<5$ to 2) siclim). Low llow ralcs are helicved to result from the characteristic low permeability of the clays (lypical intrinsic permeabilitics for the clays range from $10^{.10}$ to $10^{-12}$ $\mathrm{cm}^{2}$ ?. High saluration levels in the clays reduced the effeclive permeability further and resulted in water influx into the well (typical water influx rates ranged from 5 to 15 gallons per day).

The llow was direclly related to the vacuum applied in the well and inversely related to the well wall temperature. Figures $5-4$ - 5 -6 displays plots of the well wall temperalure (measured all the center of the RF applicator), the measured llow from the well, and the vacuum applied in the well for the entire demonstration period.

Figure 5.4 shows the temperalure-llow-vacuum relationship during the carly stages of the demonstration. The time frame covered in Figure 5-4 includes the first 4, relatively short, heating periods where water infiltration and transmission line problems were discovered and resolved. A continued decrease in flow as the wall temperature increases is observed in the first extended heating period (from March 28 (1) March 31). The rapid rise in flow on April 5 is response 10 a 1 wo-lold increase in the vacuum level and a brief powerdown period lor the applicator (to conduct subsurface resistance measurements). The llow drops back to a steady level, slightly less than $15 \mathrm{sefm}$ therealter. To limit the eflects of water quenching events (on the applicator and luner and to reduce adverse effects of thermal expansion on the transmision line, power output was controlled to keep the well wall temperature below $100^{\circ} \mathrm{C}$ over this time frame.

Figure 5-5 shows the same parameters during the fifth and most extended (uninterrupted) heating period of the demonstration. This plot clearly shows the inverse relationship between flow and wall temperature. As the well wall tem. perature initially exceeded $100^{\circ} \mathrm{C}$ (late April 10), the flow dropped rapidly to approximately one-third of its original value (from 15 to less than 5 scfm). At this point, any water in the vicinity of the applicator was converted to steam, causing a vapor lock. The flow responded slightly to gradual increases in the vacuum level (April 11 to April 17), although of smaller magnitude than indicated in Figure 5.4. Supporting evidence for asserting steam formation in the well comes from analyzing horizontal well piezometer data and the air lift pump operation (see Seclion 5.2.2.2).

Effects consistent with steam formation and the subsequent loss of vacuum down hole at the applicator were observed in the results of the electrical resistance tomography (ERT) measurements made by Lawrence Livermore National Laboratory (LLNL) (a more detailed discussion of the monitoring technology and results can be found in A. L. Ramirez and W. D. Daily, "Monitoring Radio-Frequency Heating of Contaminated Soils Using Electrical Resistance Tomography", UCRL-ID-115373, 1993. LLNL). The ERT technique maps planar changes in subsurface resistances, which can be correlated to changes in moisture content and temperature. Two-dimensional images of a subsurface plane perpendicular to the well and applicator were collected prior to and following the onset of steam formation down hole. Changes in measured conductivity illustrate a dramatic shift in the preferred direction of heal transport in the area around the applicator. Prior to steam formation (data collected on and before April 8), the greatest increases in conductivity were observed in the region below the applicator, indicating the likelihood of higher temperatures in this zone. Following the formation of steam down hole (data collected on April 16 and April 18), the conductivity in the region above the applicator rose dramatically. This result is consistent with the loss of vacuum influence from the well and the subsequent rise of steam upward through the formation that transfcrred heat to the region above the applicator. Prior to stcam formation downhole, an adequate vacuum level within the well may have provided sufficient llow through the formation above the applicator to remove the added heat. While measured vacuum levels at the piezometer screened above the clay indicate a stronger influence from the well in this region (see Section 5.2.3.2), the magnitude of the influence during the heat stage was small. It is suspected, therefore, that variations in the rainfall levels at the 
(lemonstration site (no significant rainfall occurred after April 9) also contributed to the observed changes in conductivity. Water infiltration can provide a greater cooling cfifect than air due to a significantly larger heat capacity. Unlortunatcly, excessive drying around the ERT electrodes during the demonstratton prevented analysis during the cooldown stage when higher vacuum influences from the well should have cooled the region above the applicator more rapidly.

When it hecame evident that extraction rates were suffering at the higher control temperatures (measured at the well wall adjacent to the center of the applicator), the control temperalure was reduced to below $10(1)^{\circ} \mathrm{C}$. At a control iemperature below 10()$^{\circ} \mathrm{C}$, the llow from the well increased back 10, or slighlly exceeded previous levels (April 17 10 April 19). However. 10 maintain this lower control cemperature, the duty eycle of the applicator was significintly lowered to less than hall the original energy output. As a result, the rate of temperature increase measured at the MHV-24T " $B$ " thermocouple located in the clay approximately six leet from the center of the applicalor dropped by $70 \%$. This drop in rate is indicated in Figure 5-7. While the flow rates approximately doubled at the lower control temperature, the average ollgas concentrations dropped by a factor of roughly $20 \%$. Therefore, the net contaminant extraction rates did increase. This result demonstrates the importance of maintaining adequate flow from the formation while heating, and further illustrates the impact which the single well design had on the demonstration. Since the magnitude of enhanced extraction rates would he relatively small regardless of control temperature, ellorts to maximise extraction rates were relinfutshed in lavor of inaximizing RF energy input into the formation. Control temperalures were raised in increments in an ellort to more closely monitor contaminant concentration changes versus wall temperature. The final control temperature of $130^{\circ} \mathrm{C}$ was the highest temperature the team wats willing to risk considering the $120^{\circ} \mathrm{C}$ maximum comperature rating of the well screen. The period April 19 (1) April 27 in Figure 5-5 shows again how flow responded inverscly with temperature while vacuum was held relainely consiant.

The relatuveiy rapid response of llow to applicator "off" cyeles (downward spikes in the temperature plot) indicates that the vapor lock formed down hole generates and subsides rapicily. This rapid generation of stcam may originate Irom Iwo sources; steam generated within the well from vaporization of excess free standing water, and steam gencralled within the formation near the well screen. If the latter source is the major contributor, the results suggest that there may not be enough energy stored in the formation to overcome the latent heall of water vaporization during applicator "off" cycles (i.c., latent heat could not be overcome without the continuous energy input from the applicator). No temperature monitoring within the sediment in the region adjacent to the applicator was available (within a radial distance less than five feet), therefore, it is difficult to determine what volume of sediment was at or above $100^{\circ} \mathrm{C}$. However, analysis of temperature data, presented in Section 5.2.3.1, is consistent with the assumption that only a small volume of sediment close to the well screen was at temperatures near or above $100^{\circ} \mathrm{C}$.

Following the heating stage, the flow responded rapidly, rising to levels in excess of $30 \mathrm{scfm}$ during the initial slages of the cooldown period. Figure $5-6$ shows the relalion between flow and vacuum during the cool down period. Downhole temperature monitoring was halted during this stage of the demonstration.

\subsubsection{Well Piezometer and Temperature Relationships}

Figure 5-8 illustrates the response of the well piezometers to changes in the measured wall temperature at the applicator. During the early stages of the demonstration (March 25 to April 10) there was minimal pressure drop through the well with vacuum measurements at all piezometer locations closely tracking the well head vacuum. However, as the well wall temperature exceeded $100^{\circ} \mathrm{C}$ (approximately mid-day on April 10), the piezometers upstream and immediately downstream of the applicator $(580,270 / 300$, and $225 \mathrm{feet})$ dropped to near atmospheric pressure, indicating the onset of the steam block in the well. Increasing the vacuum applied to the well had virtually no effect on improving vacuum levels upstream of the applicator while the control temperature was in excess of $100{ }^{\circ} \mathrm{C}$ (mid April 10 to mid April 16). The piezometer located at the start of the well screen (140-foot depth) showed little response to increases in applied vacuum, maintaining a relatively constant vacuum reading near 30 inches wc. The vacuum conditions at this location and other points downstream of the applicator were more strongly influenced by the thermodynamic characteristics of the water phase change as the gas stream cuoled than by the momentum influences of the applied vacuum. A compressor capable of generating higher flow rates could be used to ensure that the water vapor is removed and an adequate vacuum is maintained. However, such a modification for this demonstration would be limited by the large hcat transfer surface provided by the relatively long transition to the surface from the heated region (approximately 24() feet). The use of vertical extraction wells, which would provide shorter paths to the region, would have alleviated this limitation. Figure 5.9 explodes the April 8 to May I portion of Figure 5-8 to make the trends clearer 
during this key period in the demonstration. The upstream piezometers responded slightly to lowering the control temperature to $100^{\circ} \mathrm{C}$ (April 16 to April 18). However, the vapor block was still significant enough to maintain a large pressure drop through the well.

The response of the piezometer nearest the applicator may be indicative of potential thermal damage within the well. This piezometer, positione: at 225 feet down hole, was approximately 15 leet downstream of the applicator's center point. While the control temperature remained below $100^{\circ} \mathrm{C}$, the vacuum level tracked with the 580- and $270 /$ 30() -foot piezomcters located upstream of the applicator. The vacuum level suddenly increased on April 10, exceeding the inlet 0 foot value as the well wall temperature increased to approximately $110^{\circ} \mathrm{C}$. It is believed at this point the 225-foot piezometer tube melted shut, which was confirmed by attempts to clear the tube with high pressure $\mathrm{N}_{2}$. All subsequent indications of vacuum at the 225-foot piczometer correspond to a significant dip in the well wall temperature, indicative of the expansion and contraction of a gas in a sealed tube. The measured temperatures of the transmission line near the coupling to the applicator (located 232 feet downhole) reached an observed maximum of $177^{\circ} \mathrm{C}$ during the later stages of heating. This measured transmission line temperature was as high as 5()$^{\circ} \mathrm{C}$ higher than the measured wall temperature used to control power to the applicator. Therefore, thermal damage could have occurred to instrument and monitoring lines or the well casing if they werc in contact with the applicator and transmission linc.

Coincident with the onset of stcam formation down hole, water llow from the air displacement pump crasc 1. Howcver, a corresponding increase in condensate collected in the vacuum knockout pot was observed. The increase in condensate indicated that the pump suction was no longer in water, but in water vapor. It is believed that the tygon suclion lubc for the pump ( $\mathrm{h}$ ated at approximately 205 feet down hole) may have been damaged by high temperatures.

A sufficient volume of steam was entering at some location in the pump line $\mathrm{rr}$ at the pump itself (located at 14 fect down hole) to allow adequate recovery of the condensatc, which could be pulled to the surface as it filled the relatively small diameter recovery line ( $1 / 4$-inch OD high(lensity polyethylene). Condensate pumping continued for li c remainder of the demonstration. Water pumping could not be restored even when well wall temperatures decreased below $1(0)^{\circ} \mathrm{C}$, thereby confirming the likelihood of thermal damage to the pump intake line.

Significant changes were observed following the heating slage as the cooldown period was monitored (after April 27 on Figure 5-8). The 14()-foot pic\%ometer indication increased and approached the well head vacuum levels while the upstream piezometer indications remained at or near atmospheric conditions. This observation indicates that the bulk of the flow enters the wel! from the screened zone nearest the vacuum source (i.e., the control zone) and/or that possible well screen damage (from exceeding the maximum rated temperature) was significant enough to block upstream flow. The positive vacuum response to the upstream piezometers (i.e., 580 foot and 270/300 foot) immediately after heating was terminated (and after the first attempt at applicator retrieval, [Figure 5-9] suggests that a flow path through the well exists. (It should be noted that the 225-foot piezometer was abandoned at this point and its corresponding gage connected to the air lift pump discharge line. Therefore, the 225-foot piezometer indication from this point for the remaincier of the demonstration was monitoring the open end of the pump suction line, a point somewhere between the 140-foot and 205-foot well position.) After approximately 24 hours of cooling, the upstream piezometer readings dropped back to near atmospheric. This drop corresponded to the initial sharp rise in PCE offgas concentrations observed in the early stages of the cooldown period (see Figure 5-10). The significant changes at this point would suggest that as the well cooled, the clayey formation became the primary source of flow in the downstream sections of the screen with minimum flow coming from the sections in the regicn upstream if the applicator (580-foot and 270/300-foot piezometers).

\subsubsection{VOC Concentrations}

idence of a direct RF-induced thermal effect on on occurred from March 25, 1993, to April 13, 195.. suring this period, there appeared to be a correlation between dips in PCE concentration measured at the well head and periods of no power output. In addition, there is a general upward trend in concentrations following the initiation of RF energy input to the formation (see Figure 5-11). This would lead to the belief that the source of the contamination detected at the wellhead would be from the soil in the vicinity of the veril screen, rather than deeper in the formation. This area would experience the, maximum temperatures produced by the RF applicator and would be the area more subject to rapid cooling because of convective flow through the well. However, it is difficult to discern whether the PCE concentration dips were caused by the direct effect of the RF applicator. During each power "off" cycle of this initial heating stage, vacuum extraction was halted, and the well was opened to atmospheric conditions for a period ranging from one-half to t. ree days. The coincident rise in offgas concentration with renewed power output from the applicator may be due in part to transient mass transfer effects characteristic of the clays. The contaminant release characteristics from clay may differ from the conventional initial concentration 
"spike" observed as the initial pore volume is flushed out in soil vacuum extraction applications from more permeable formations. During the final heating period (April 8 to April 27), the PCE concentration does appear to cycle in direct response to changes in well wall (control) temperalure (i.c., RF power output cy $\bar{y}$ cles). However, the changes detected appear to be near or within the statistical error of the sample set or may result from stripping occurring as stcam is formed (discussed later). It was unfortunate that extraction was unable to continue independently from applicator handling. Since the well had to be opened to the surlace during these times, extraction could not continue, preventing possible observation of a steady PCE concentration decrease over scveral sample periods. A one-to-one corrclation between RF input and concentration is needed 10 decisively conclude a positive RF elfect.

The tolal volume of water extracted from the well during the demonstration (approximately $25($ ) gallons) played a small role in the overall mass removal of contaminants. The removal rates for both water and condensate varied from a fow to as high as 15 gallons per day (typical rates ranged from 5 to 10 gallons per day). Samples of the water and condensate removed from the well were periodically analyzed for TCE and PCE content using an ion trap mass spectrometer (ITMS). The PCE concentrations in the waller were typically between 8() and $100 \mathrm{ppb}(\mathrm{ug} / \mathrm{l})$, while concentrations in the condensate were between 35 and 50) ppb. The TCE concentrations were below $10 \mathrm{ppb}$ in both water and condensate samples. These water concentrations are approximately an order of magnitude below levels calculated Irom Henry's Lalw constants assuming equilibrium with the measured gas-phase concentrations at the well heald during heating. It can be assumed, therefore, that the bulk of the CVOCs removed during the heating stage of the demonstration were extracted from the formation as vapor. However, small variations in the wellhead gas concentrations (on the order of 10 to 20\%) in response to the meatsured wall temperature could result from the enhanced thermal stripping of water either within the formation, inliltrating into or frec standing in the well. No water was ixtricted during the cooldown stage of the demonstration.

Figure 5.12 displays the contaminant concentrations measured at the wellhead during the cooldown portion of the demonstration. The dramatic rise in PCE and TCA levels correlates with both the increased flow and extended zone of inlluence lrom the well vacuum experienced during the cool down period. These ellects will be discussed further in Section 5.2.3.2. The TCE concentration also increased, hut not as dramatically.

The intial concentrations of TCA (1, I-1richloroethane) were close to the typical levels observed in previous soil gals measurements conducted at the site; approximately 10 to $20 \%$ of the TCE levels. Use of this solvent began in 1979, and it is estimated that it made up less than $2 \%$ of the chlorinated solvents sent through the process sewer linc (Marine and Bledsoe, October 1984, "Supplemental Technical Data Summary; M-Area Groundwater Investigation" DPSTD-84 112). The TCA concentrations continued to rise during the heating stage and surpassed TCE levels just before shutting down power to the applicator. The concentrations were estimated as no TCA gas standard was available at the time of the demonstration. The cstimate was made assuming TCA would have a response similar to TCE for the electron capture detector (typically concentrations less than $500 \mathrm{ppmv}$ ) and have a response similar to PCE for the flame ionization detector (concentrations greater than $500 \mathrm{ppmv}$ ). Subsequent analysis of a TCA gas standard has shown this assumption to be accuratc within 5 to $10 \%$. The concentration of TCA during the conldown stage of the test continued to rise dramatically approaching levels of nearly two-thirds those of PCE. The reason for this large source of TCA is uncertain. Soil concentrations in core samples for this demonstration and other tests conducted at the site are currently being studied to determine the location of the source. The presence of TCA was not critical to continued operation of the demon: stration. It is not on the SCDHEC list of toxic substances, and is actually destroyed more efficiently with the thermal catalytic offgas system.

\subsubsection{Catox System Operation}

The overall destruction efficiency for CVOCs by the Catox system was below expectations. Destruction efficiencies for PCE ranged from 75 to $90 \%$ at temperatures from 450 to $500^{\circ} \mathrm{C}$ (typical values of $80 \%$ were observed at the higher concentrations encountered at the end of the demonstration). Degradation in destruction efficiency is believed to arise from bypassing the catalyst blor! iesulting from progressively growing leaks in the ceramic insulation. It should be noted that he catalyst block mounting frame was field modified to properly fit the catalyst block. The modification was made to correct a design error in the required catalyst volume made by the system manufacturer. The destruction efficiency of TCA was higher than PCE, with typical values in the range of $90-95 \%$. The TCE concentration levels measured at the Catox inlet and stack were generally too low to make a realistic assessment of destruction performance.

Figures 5-13 and 5-14 are plots that respectively show cumulative values of contaminants extracted and system discharges for the demonstration. Table 5.1 summarizes the extraction and discharge data of all constituents for the heating portion as well as the entire demonstration. 
Final Report: In Situ Radio Frequency Heating Demonstration

Table 5.1 Total mass of chlorinated solvents extracted and total mass emissions to the atmosphere

End of Heating Stage

\begin{tabular}{lcccc}
\multicolumn{1}{c}{ Compound } & Extracted $(\mathbf{k g})$ & Emitted $(\mathbf{k g})$ & Extracted $(\mathbf{k g})$ & Emitted $(\mathbf{k g})$ \\
\hline Perchlorgethylene; & 11.8 & 1.9 & 116.5 & 24.9 \\
Trichlorocthylene & 2.0 & .01 & 6.9 & 0.9 \\
1.1.1-Trichlorocthane & .14 & .01 & 48.1 & 4.1 \\
Hydrochloric Acid (1) & - & 9.5 & - & 120.9 \\
Carbon Dinxide(1) &. & 6.0 & - & 81.3
\end{tabular}

(1) Cialculated based on complete oxidation of chlorinated organics

Table 5.2 Distances (in feet) from temperature monitoring locations to ncarest point on RF applicator (calculations based on ficld well surveys and logs).

\begin{tabular}{|c|c|c|c|}
\hline $\begin{array}{c}\text { Temperature Monitoring } \\
\text { Borehole } \\
\text { (Distance to Applicator) }\end{array}$ & $\begin{array}{l}" \Lambda " \\
(48 \mathrm{ft})\end{array}$ & $\begin{array}{l}" \mathrm{BB} " \\
(38 \mathrm{ft})\end{array}$ & $\begin{array}{l}\text { "C"" } \\
(28 \mathrm{ft})\end{array}$ \\
\hline $\begin{array}{l}\text { MHV.20T } \\
\text { (Ii) applicator feed end) }\end{array}$ & 1.3 .9 & 11.6 & 16.6 \\
\hline MHV.21T & 11.3 & 8.3 & 14.6 \\
\hline $\begin{array}{l}\text { MHV.22T } \\
\text { (1): :pplicator tip) }\end{array}$ & 12.8 & 10.1 & 15.5 \\
\hline MHV.24T & 9.4 & 6.1 & 13.7 \\
\hline
\end{tabular}

\subsubsection{Field Monitoring}

\subsubsection{Subsurface Temperature}

Figure 5-15 displays a plot of subsurlace temperature measurements at selected points in the clay (" $\mathrm{B}$ " labeled locations at a depth of 38 (eet). The points selected include the four nearest the applicator that indicated a response (MHVs -20T, $-21 \mathrm{~T},-22 \mathrm{~T}$, and $-24 \mathrm{~T}$ ) and one located in the control \%one (MHV-28T) to provide a baseline reference. Tathle 5.2 lists the distance from each heated \%one monitoring location to the applicator (located at a depth of approximately 4 () fect). The subsurface temperature sensor at the MHV-24T B position (referred to as simply 24B for this (liscusision) responded almost immediately to RF power application. This point was used as the primary indicator of heating progress throughout the demonstration.

The greatest rate of temperature increase observed at the $24 \mathrm{~B}$ sensor was $\left(2.2^{\circ} \mathrm{F} / \mathrm{hr}\right.$, which occurred during the first prolonged heating period (March 28 10) March 31). Following this period, the heatling rate dropped signiticantly, responding rapidly 10 suspension of RF energy applicalion. The emperalture rise continued without RF applica- tion at a rate of approximately $30 \%$ of the initial value. The immediate response to suspension of RF application suggests heating at the $24 \mathrm{~B}$ point was primarily caused by the RF field. The residual temperature increase observed during the period of no RF input gives an initial measure of the rate of thermal conduction within the subsurface. When applicator power output was resumed (April 3 to April 16), the rate returned to an elevated value of approximately $0.14^{\circ} \mathrm{F}$. Over the period in which the applicator control temperature was lowered (April 16 to April 19), the rate nearly leveled off, again responding rapidly to reduced power output from the applicator. As the applicator power output was stepped up over the final week of the heating stage, the rate of temperature increase responded directly, but with diminishing magnitude. The inability to achieve the initial rate of temperature increase, even at higher applicator energy output, suggests that the contribution of heat transfer due to conduction gradually increases relative to the RF field contribution (at a radial distance greater than $6 \mathrm{feet}$ ). This conclusion is supported by the observation that the rates near the end of the heating stage were equal to those observed without applicator power output following the first prolonged heating period: approximately $0.05-0.06^{\circ} \mathrm{F} / \mathrm{hr}$ (March 31 to April 3). Conduction rates at a fixed location should change as temperature gradients vary with time. However, a distinct drop in the absorption of RF energy at a fixed radial distance from the applicator is apparent. This result is consistent with the observation of increased electrical conductivity measured with electrical resistance tomography (Ramirez and Dailey 1993). The attenuation rate of radio frequency waves is proportional to the electrical conductivity of the absorbing media (sediments). As the conductivity within the heated cone rose, the attenuation increased. Therefore, more energy was absorbed in the inner, hot core surrounding the applicator. If this inner region was near or above $100^{\circ} \mathrm{C}$, the conductivity should drop as water is removed as vapor. Attenuation would decrease even further as water vapor will not absorb RF 
encrgy. However, once a significant vacuum was lost in the well when steam was formed, there was no driving force 10 remove the water vapor generated in the formalion. It is therefore possible that only a small volume was healed 10 temperatures above $100^{\circ} \mathrm{C}$, and/or that $\mathrm{RF}$ incrgy was spent heating the same water as it vaporized and condensed within the formation.

An immediate drop in temperature was measured at $24 \mathrm{~B}$ in response to stopping RF power output. The rate of decrealse all $24 \mathrm{~B}$ during the cooldown portion of the demonstration nearly matches the heating ratc, and may offer lurther evidence that heat transfer at 24B was primarily conductive in the latter period of the heating stage. However, the elfect of vacuum influence (i.c., air flow) must agan he considered when comparing the heating stage to the conling stage. The healed mone was effectively isolated from the vacuum in the well by the vapor lock, creating a virtual stagnant environment. During cooling, more air was llowing through the heated zone formation, evidenced by the greater zone of influence described later in Section 5.2.3.2. Therefore, the initial rapid drop in temperature, at rattes equal to or greatcr than during the heating stage, can be an ellect of the added heal loss to air being pulled through the formation.

Figures 5.16 and 5.17 respectively display plots of subsurface temperature measurements in the " $A$ " (48-foot depth) and "C" (28-foot depth) horizontal plane's of the monitoring horcholes. The measurem.ents in tre " $A$ " plane indicalle a greater temperature response than the " $\mathrm{C}$ " measurements becausc they are approximately 25 to $30 \%$ closer the RF applicator (sec Table 5.2). Although the flow from the lormation was limited during the heating portion of the demonstration, the bulk of what little flow was ohserved appeared to originate from the above the clay, thercby providing added cooling to the region above the applicator. This conclusion is based on the greater vacuum response at the "C" plane piezometers relative to the " $A$ " planc piesonelers throughout the demonstration (see Sec(I) 5.7 .3 .2$)$.

While the temperature monitored at $24 B$ responded rapidly to halling of RF power output, the temperature measurements for all other monitoring points continue to rise for a period after RF application was terminated on April 27. 1993. This continued risc in temperature suggests that conduction is the primary heat transfer mechanism at these distances from the applicator.

Figures 5 -18 - 5-24 are three-dimensional images of temprature distributions surrounding the applicator which show the progression of healting/cooling of the subsurface Iralla helween April 3, 199)3 and May 10, 1993. Figure 5-
25 is an image of the modeled heated zone (based on KAI modeling data). The images were generated from irregularly spaced scattered data sets using a commercially available three-dimensional (3-D) modeling software package (Interactive Volume Modeling [IVMTM], version 5.0, Dynamic Graphics, Alameda, CA). The software transforms the data sets into a regularly spaced 3-D grid using a technique of minimum tension gridding that employs a bi-cubic spline algorithm. For further information on the manipulation of parameters required to run the program, refer to the following references:

R. L. Nichols, B. B. Looney, J. E. Huddleston, "3-D Digital Imaging; Revealing the Location, Depth, and Concentration of Subsurface Pollutants," Environmental Science and Technology, 26, 1992, 642-649;

C. A. Eddy and B. B. Looney, "Three-Dimensional Digital Imaging of Environmental Data: Selection of Gridding Parameters", Int. J. Geophysical Information Systems, 7(2), 1993, 165-172

The data sets for the field test images were constructed of thermocouple data from monitoring borehole (core tem: peratures taken on the final day of heating were also used). The data sets used for images of the heating stage also included the down hole fluorescence decay fiber optic measurements at the screen wall. The images made after the termination of RF application do not include applicator temperature data as input to the gridding program. Therefore, the post-heating images were produced without data from the 40-foot depth, causing them to appear to have a center point located higher, at the 38-foot ievel (the "B" plane), above the position of the horizontal well. The data set for the model was generated by rotating a two-dimensional temperature contour plot around the applicator axis.

Table 5.3 provides a listing of calculated heated subsurfacc volumes in cubic feet, segmented by temperature ranges within the volume and total energy coupled to the lormation on the dates corresponding with Figures 5-18 5-24 and the predicted values corresponding with Figure $5-25$. It should be noted that the volumes calculated from fitting the field data with temperatures of less than $50^{\circ} \mathrm{C}$ should be adjusted upward approximately 10 to $20 \%$. This adjustment must be made to account for the position of the grid model boundaries, which clip off part of the zone north (toward MHV-23T and) and west (beyond MHV$24 \mathrm{~T}$ ) of the applicator. This clipping is performed in an cffort to limit extrapolation beyond actual data point locations to reasonable boundaries. The data from the model were fit with the same gridding parameters and clipping surfaces to ensure that any biases introduced by the fitting program are minimized. 
The KAl modeling of temperature distributions was performed without consideration of the temperature limit of the fibcrglass screen, mass transport of air and water (as liquid or vapor), nor the latent heat effect for the vaporization of water. The omission of these critical factors was the overriding cause of overestimating the predicted heated subsurface volume, and explains the differences between Figures 5-22, the actual heated volume at the termination of RF application, and Figure 5-25, the predicted heated volume. The primary focus of model used by KAI, however, is to map changes in the effective borchole impedance (casing and surrounding sediment) to ensure proper matching with the output impedance of the applicator as temperatures and diclectric properties change throughout the demonstration. Since the maximum temperature measured in the monitoring boreholes was $63^{\circ} \mathrm{C}$, the gridding program fit may not adecluately describe the hotter region surrounding the applicaltor (i.c., radtial distances within six feet). Therefore, the most accurate mealsure of the field performance retative to the model can be made by comparing volumes heated to temperatures greater than 6()$^{\circ} \mathrm{C}$. While the actual heated tone $\left(>6()^{\circ} \mathrm{C}\right)$ volume was only alpproximately $5(0 \%$ of that predicted by the KAI model, the tolal allected volume (i.e, volume raised above ambicoll temperature conditions) wals much larger than predicted. The model temperature distribution, however, was predicted following a continuous power ap, lication of 20 kW for 21 dilys. The energy delivered in the field, while very close to that used in the model, ocecurred over a 34 daly peresed. Therefore, the larger affected volume is the result of a tonger time provided for conduction of heat out from the hoter regions arround the applicator.

\subsubsection{Soil Vacuun Levels}

There was little observed influence from the well vacuum measured al the piezometers over the course of the initial ambient extraction and heating stage of the demonstration. These pic\%ometers vary in radial distance from the well, ranging from 9 to 36 lect (sed Figure 4-6). At these dislances, the low zone of inlluence is not surprising given both the low permeability of the clays and the reduced vacuum achieved in the well during the heating stage with the formation of a steam block down hole. During this peried, the measured vacuum levels rose and fell in response (o) swings in the barometric pressure. The amplilude of the swings wals dampened relative to barometric and the periodicity displayed a typical time lag of one to Iwo day's. Figures 5-26, - 5-28 display the vacuum levels incasured at each depth monitored with the piezometers (depth levels A - C respectively) over the course of the final heating periods and the initial 10 days of conldown (note that the barometric pressure is ploted as a difference above (1)()() mbar in dhe se ligures). While the drawdowns during heating were small, a distinctly greater effect, on the order of a few mbar, was observed in the " $\mathrm{C}$ " piezometers screened above the clay layer. A dramatic change in the vacuum effect is observed after heating has stopped. At this point, the drawdowns increase significantly in response to higher vacuum levels in the well as the temperature dropped and the steam block dissipated. The greatest drawdowns are, again, observed in the sediment above the clay ("C" piezometers), with the most significant effects observed in the control zone wells (MHV-27C - 29C) and the well nearest the applicator (MHV-24C). In addition, the variance observed between readings from a single well at different depths increases to values greater than 10 mbar.

The results of a "pump" test conducted three days into the cooldown stage (April 30) illustrate the effects described above. Figure 5.29 is a plot of the drawdown observed in MHV-24 following resumption of vacuum extraction. This figure displays how the vacuum effect experienced in the "C" piezometer screened above the clay layer was significantly greater than that observed both within and below the targeted clay. Figure 5-30 is a plot of the drawdown observed in several "C" piezometers located at varying distances from the wellhead (vacuum source). This figure displays how the vacuum effect diminished as one moves progressively further from the well head. The drawdown observed nearer the start of the screen zone (MHV-28C) is significantly greater than that observed beyond the applicator location (MHV-23C). The drawdowns observed at the two piezometers located at the applicator (MHV-24C and $\mathrm{MHV}-21 \mathrm{C}$ ) are intermediate to those observed upstream and downstream of the heated zone. The drawdown at MHV-24C is greater than that at MHV-21C, although both are located roughly perpendicular to the applicators center, because it is approximately twice as close to the horizontal well (a distance of 9 feet for MHV$24 \mathrm{C}$ vs 17 feet for MHV-21C; MHV-28C and MHV-23C are approximately 13 feet and 18 feet from the well, respectively). These results suggest that the bulk of the llow entering the well originates from above the clay and is strongest in the control zone at the start of the screened \%)e.

\subsubsection{Soil Gas Concentrations}

Soil gas concentrations taken at the piezometers were used (1) monitor for evidence of enhanced volatility, to observe the effects of changes in permeability, and as indicators of the primary source locations for concentrations observed in the well offgas. In general, CVOC concentrations at all the monitoring wells either rose gradually over the course of heating or showed little change. Similar to the vacuum elfects discussed above, the greates concentration 
changes were observed after heating stopped. Figure 5-31 is a graph of the PCE concentration measured at the " $C$ " piczomeices located within and surrounding the heated zone over the course of the entire demonstration. The most Iramatic rise in concentration is observed at MHV-25C, located approximately 36 lect west of the well. This dramalic rise wats also observed in the control zone piezometers localed west and south of the heated zone. The rise in concentration, coincident with the enhanced zone of influence from the well following heating suggests that a "hot" pocket of residual solvents located west and south of the heated zone, perhaps even beyond the location of the pic$\%$ meters, is a significant contributor to the total rate of contaminants extracted. This conclusion is also supported hy observing the 24 - 10 36-hour delay between resumption of vacuum extraction following heating and the rise in CVOC concentration observed in the well offgas ( $\mathrm{sec}$ Figure 5.6). Such a delay would result from the greater mean travel time required for vapors from this high concentration source to reach the horizontal well. The conclusion that the bulk of the flow into the well originates from the control zone is also supported by the soil gas data. In parlicular, the unexpected appearance of high concentrations of TCA permilted the advanugeous use of this compound as a tracer in the soil gats measurements. While the relative concentration of TCA was found to increase in nearly all the piezometers, again, the most dramalic rise was ohserved in the control zone. Figure 5-32 is a plot of the TCA/TCE ratio measured in the soil gas from the control nome piesometers logether with the TCA/TCE ratio uhserved in the well oflgas. A strong, direct correlation exists between the relative and absolute TCA concentralions observed in the control \%one and the coincident rise observed in the well olfyas. Therefore, both the draw down data and the soil gas data are consistent with the piezometer measurements laken within the horizontal well, all of which show that the bulk of the llow entering the well originates from the control zone near the start of the well sicreen.

\subsection{Demobilization}

\subsubsection{Failure to Retrieve Applicator}

During the latter stages of the demonstration it was (lecided to maximize RF energy coupling to the formation. Tha accomplish this, the control temperature was increased to $1.300^{\circ} \mathrm{C}$, exceeding the maximum temperature rating of the well liner by $10^{\circ} \mathrm{C}$. While operating at $130^{\circ} \mathrm{C}$, a hot spot on the transmission line reached a temperature as high as 170$)^{\circ} \mathrm{C}$. Therefore, it is highly probatble that either the well liner deformed and/or sagged around the applicator: or the applicator/transmission line melted into the liner. In any casc, when an allempe to retrieve the applica- tor was made it was found securely stuck at its original position even with an application of 600 pounds of tension force. Application of greater force was attempted, causing the transmission line to fail and break free at the flex-rigid coaxial cable joint. Excavation to retrieve the applicator is not planned.

\subsection{Demonstration Economics}

\subsubsection{Background For Economic Basis}

Commercial remediation costs are influenced by the physical and chemical characteristics of the targeted contaminant and sediment, the depth of the targeted sediment, and the size of the site to be remediated. The in situ RF heating demonstration at SRS was the first attempt at vacuum extraction of VOCs from a horizontal well screened entirely in a clay layer. Based on the observations at SRS, it appears that remediation by vacuum extraction from low permeable, high moisture content clay sediments will be a relatively long, time-consuming process. The subsurface vacuum levels obtained in the clay during the demonstration are approximately an order of magnitude smaller than vacuum levels obtained with similar processes operated in more permeable sediment. Assuming a direct relationship between subsurface vacuum levels and flow in the formation, remediation time may increase by as much as a factor of ten, indicating variable costs will also increase by a similar factor. In addition, the high moisture content of the clay $(\sim 80 \%-90 \%$ by weight) suggests heating the sediments will require considerable energy due to the relatively high heat capacity of water (with respect to the soil). The energy requirements for heating become even more significant if subsurface target temperatures exceed $100^{\circ} \mathrm{C}$ and latent heat effects become applicable. For the heating to be advantageous, its anticipated consequential effects (i.c., increased volatilization rates, increased soil permeability and flow because of drying and cracking of the clays, and steam stripping effects) must reduce remediation time or increase contaminant removal efficiency to a degree that justifies the cost of the added energy input.

The integrated system design, time constraints, and problems encountered in this demonstration, when viewed collectively, did not permit acquiring enough information to reasonably define a treated volume or project a total remediation time on which a commercial cost projection could be based. A lypical cost analysis should have as its basis a ureated volume (i.c., \$/yd or \$/ton) based either on a finat acceptable contaminant level or, perhaps more applicable in this instance, a volume heated to or above a predetermined temperature goal. It was understood at the outset of 
this demonstration, that a final contaminant level would be an inappropriate criteria for assessing the success of the test. Such a criteria would be inappropriate because the scalc of the contaminant plume is far larger than the zone of inlluence of either the vacuum or RF radiation. Therefore, criceria for success of thîs demonstration were focused on increases in rate of removal and heating efficiency (i.e., clficiency of the RF energy coupling to the clay). Untortunallely, the single well design adversely alfected vacuum levels attained down hole and, consequently, extraction rates when a steam block formed. In addition, the choice of woll casing material and water inllux events placed limitalions on the applicator duty cycle, which reduced the amount of energy that could be coupled to the clays over the time lrame of the test. Therefore, a projected cost based on the volume of sediments heated would be misleading. As a result, the analyses presented in this report list costs for the actual demonstration and projected costs on a kWH basis (delivered to the sediments).

\subsubsection{Demonstration Costs}

The total cost of the in situ RF heating demonstration was on the order of $\$ 85(),()()$. This cost includes enginecring costs and subcontractor lees that normally would not be considered in commercial cost projections. Table 5.3 vhows the breakdown of demonstration costs per function arcal and the bases for calculation. Table 5.4 shows how capital installed costs were determined. Capital installed costs and depreciation charges for the RF delivery equipment are not included in Table 5.3 because this equipment was "rented" at a negotiated fixed price for the entire demonstration. The capital cost of $\$ 5(\%),())($ ) provided by KAI includes lirst time engineering costs and analytical equipment costs that would not be required in a commercial unit.

\subsubsection{Commercial Cost Projections}

Since the RF heating demonstration did not provide enough information or insights to define or project a treatment volume, this analysis will focus on understanding the daily variable costs associated with a remediation operalion. Iit addition to the variable costs, there will be fixed costs that are site-dependent and site-independent. Examples of site dependent fixed costs are the costs for treatahility studies and well preparation. Independent fixed charges include inobilization, demobilization, and amortialtion of capital eyuipment.

Tabte 5.5 projects operating costs for a commércial remediation activity from clay sediments using a similar process, with energy requirements and a lime period analogous to the RF healing demonstration. Major assumptions for this cate are:
- AC electric power will be supplied by rented diesel generators at an average charge of $\$ 0.10 / \mathrm{kW}-\mathrm{hr}$ (includes both rental and fuel costs)

- Daily sampling at the Offgas Treatment unit inlet and outlet will be required by state/local regulators as a minimum.

- Samples will be secured and analyzed by a subcontracted service on a price-per-sample basis.

- Capital costs of a $25 \mathrm{~kW}$ commercial RF delivery unit will be approximately $\$ 200,000$ (based on KAI projection).

- Site selected and well design is analogous to the SRS site, including use of:

a single horizontal well with same insertion angle, liner material, transition radius, and depth vertical monitoring wells of same depth an identical vacuum extraction/catalytic oxidation system

- The horizontal well will be terminated in the subsurfacc turgeted area (i.e., well will not be open on both ends).

- RF coupling efficiencies will be approximately the same as with the SRS demonstration.

Other assumptions are listed on Table 5.4a. Table 5.4b summarizes the projected capital costs associated with the commercial system.

In this case, the daily variable costs for the remediation operation are approximately $\$ 325 /$ day. The costs assigned for the RF delivery (\$95/day), offgas treatment (\$102/day) and monitoring (\$27/day) areas are reasonably accurate based on the SRS experience. The analytical cost, however, will be dependent on permit sampling requirements and may have considerable variability from location to location. If samplins, requirements were reduced to a weekly or monthly rasis, the daily variable costs could be reduced into the $\$ 230 /$ day to $\$ 250$ /day range.

Well preparation and treatability determination costs also will vary from site to site. The costs assigned to this casc were an attempt :o fit a commercial projection to the SRS conditions and approximate minimum charges. Approximately two-thirds of these site-dependent fixed costs arc attributable to well preparation. Since horizontal well drilling charges are 8-10 times higher that of vertical well charges, careful consideration of horizontal well bencfits versus cost should be employed prior to final selection extraction/monitoring well layouts. A minimum cost on the order of $\$ 45,000$ for site-dependent fixed charges can be expected. These costs will vary directly with the number, orientation (horizontal, slant or vertical), and length of required wells (site size). Altempts to establish variance boundaries for site dependent costs would be completely 
Table 5.4 Actual Cost Associated with RF Demonstration

\author{
Total Tesi Duration (man days) i - \\ Duration of RF Operation (man days) \\ Loided SRS Labor Charge ( $\$ / \mathrm{hr})$ \\ Loaded SRS Supervision Charge ( $/ \mathrm{hr})$ \\ l.ength of Horizontal Well (fi) \\ Horizontal Well Drilling Charge (\$/ft) \\ Number of Monitoring Boreholes Req'd \\ Vertical Well Drilling Charge (S/ft) \\ Depth of Verlical Borcholde (fi) \\ Total AC Input Power to RF Generator (kW-hr) \\ Lorad for RF Aux and Monitoring Equip (kW) \\ Total Measured Forward Coupled RF Power (kW.hr) \\ RF Coupling Efficiency \\ Totial "RF on" hours \\ Tolal Hours RF FWD Coupled Power $>20 \mathrm{~kW}$ \\ Tolal AC Power Required by CATOX System (kW-hr)
}

\section{8}

40

60

1() Basis:8 hr/day

580
110
20
10
55
21200
6
13800
0.85
651
543

$74($ ()) Basis: Avg. supply - 480 volts, avg. current req'd-73 amps over the course of the job
Cists

Piactor
RF

Delivery Treatment
Well Prep/

Monitoring
Field

Analytical Support Totals
Capial Installed Cost (CIC)

Direct Production Costs

Sile ()perating Labor (OL)

Direci Supervision Latxor(s)

Electricity (diescl)

Maintenance and Repairs (M) Eest.)

() pxrating Supplicers (\% of $M$ )

lotal Direct Production Costs

Total Direct Production Costs per

Day of Operation

\section{Fixed Charges}

Westinghouse Divisional Support

Subcontract Labor (lump sum-IWR)

Depreciation (\% CIC)

Horiontal Wells

Monitoring Wells

Treitlabilicy

Fotall lixed Costs

Total Product Cost (TP()
$\$ 121,440$

$\$ 21,120$
$\$ 924$
$\$ 22,04$
$\$ 25$

$\$ 50,900$

$\$ 172340$

$\$ 2.880$

$\$ 2,880 \quad \$ 21,120$

$\$ 8,800$

$\$ 26,400$

0.1

$\$ 2.696$

$\$ 7,400$

$\$ 2,000$

0.05

5100

$\$ 100$

$\$ 16,476$

$\$ 57,020$

$\$ 648$

$\$ 251$

$\$ 84,480$

$\$ 129,600$

$\$ 35,200$

$\$ 70,400$

$\$ 11,020$

$\$ 4,000$

$\$ 7,989$

$\$ 223,009$

$\$ 2,759$

$\$ 127,469$

$\$ 1,449$

$\$ 150,000 \quad \$ 150,000$

$\$ 91,390 \quad \$ 231,036$

$\$ 2,969$

$\$ 1.244$

$\$ 4,213$

$\$ 69,510$

$\$ 69,510$

$\$ 86,481$

$\$ 89.745$

589.745

$\$ 229,391$

$\$ 2,969$

$\$ 155,991$

$\$ 1,244$

$\$ 241,390$

$\$ \times 30,985$

$\$ 245,867$

$\$ 59,989 \$ 178,035$

$\$ 128,713 \$ \$ 241,390$

$\$ 853,904$ 
Firal Report: In Situ Radio Frequency Heating Demonstration

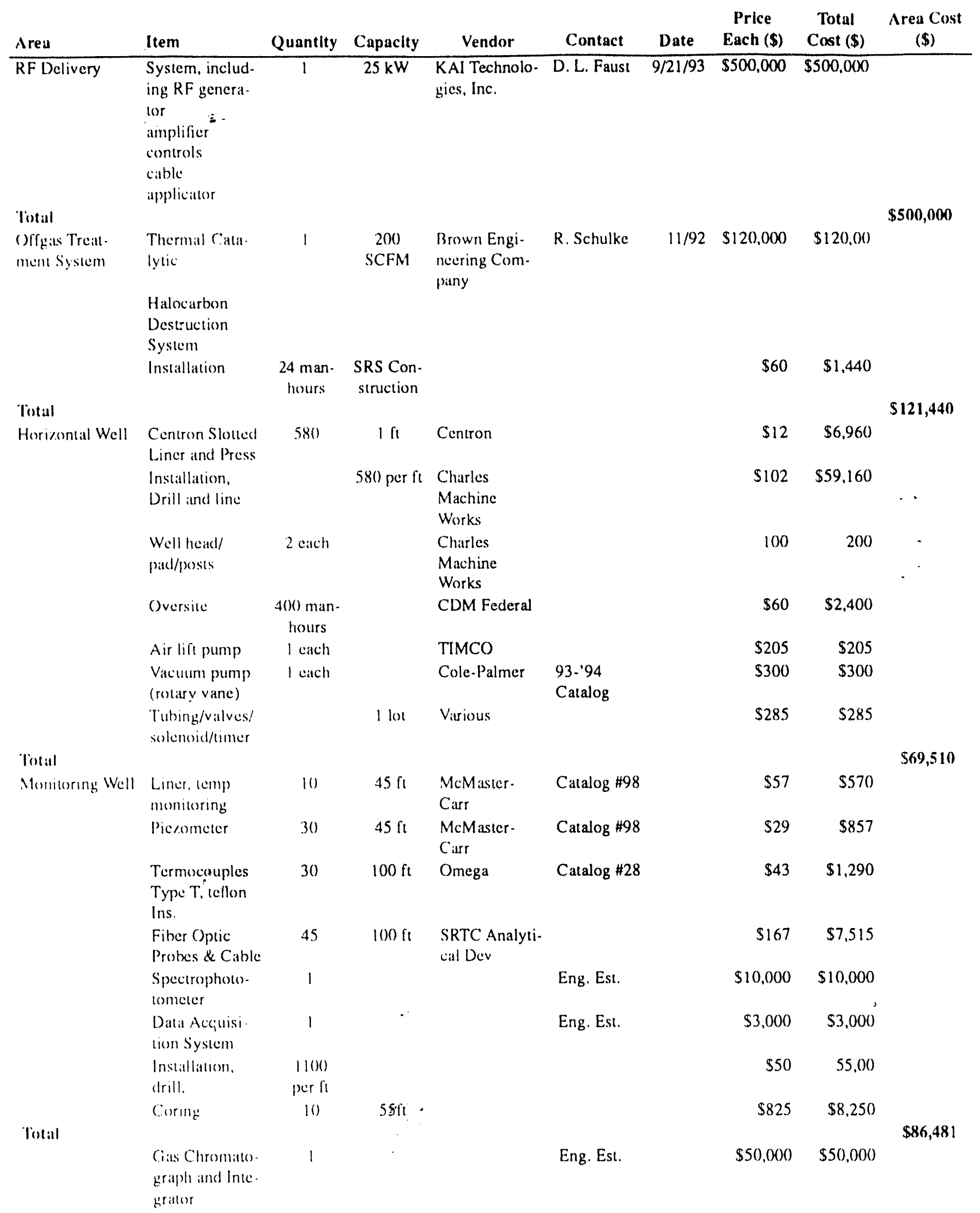


WSRC.TR.93.673

\begin{tabular}{|c|c|c|c|c|c|c|c|c|c|}
\hline Area & Item & (Quantity & Capacity & Vendor & Contact & Date & $\begin{array}{c}\text { Price } \\
\text { Each (\$) }\end{array}$ & $\begin{array}{c}\text { Total } \\
\text { Cost }(\$)\end{array}$ & $\begin{array}{l}\text { Area Cost } \\
(\$)\end{array}$ \\
\hline & Sampling & 3 & & Cole-Palmer & 93.94 & & $\$ 300$ & $\$ 900$ & \\
\hline & $\begin{array}{l}\text { Pump (roliury } \\
\text { vane) }\end{array}$ & & & & Catalog & & & & \\
\hline Total & · & & & & & & & & $\$ 828,331$ \\
\hline
\end{tabular}


Table 5.5 Commercial Cost Projection Case: Basis - Time Period and Electric Power Costs Consistent with SRS Demonstration

Nominal Treatability Determination Charge (\$)

Total Job Duration (man days)

Tine RF System AC P(zoker (man days)

Loaded Labor Charge ( $\mathrm{S} / \mathrm{hr})$

Length of Horizontal Well (ft)

Horizontal Well Preparation Charge ( $\$ / f t)$

Number of Monitoring Borcholes Req'd

Vertical Well Preparation Charge ( $\$ /(1)$

Depth of Vertical Borehole (fi)

Total AC Inpul Power to RF Generator (kW.hr)

Load for RF Aux and Monitoring Equip (kW)

Total Measured Forward Coupled RF Power (kW.hr)

RF Coupling Efficiency

Aclual RF Power Coupled io Formation ( $\mathrm{kW}$-hr $)$

Total AC Power Required by Catox System (kW-hr)

Number of Samples Required per Day

Cost per Analysis (S)

Time Required wo Mobiliz/Demobilize (man-hours) $1000(x)$

88

35

100 Bases: One Full Time (8 Hr/Day) Altendant during

Routine Operation

175
110
4
50
55
21200
6
13800
0.85
11730

74000) Basis: Avg Supply - 480 Volts, Avg Current Req'd 73 AMPS over the Course of the Job

2
50
32

\begin{tabular}{|c|c|c|c|c|c|c|}
\hline Costs & Factor & RF Dellver & $\begin{array}{l}\text { Offgas } \\
\text { Treatment }\end{array}$ & $\begin{array}{l}\text { Well Prep/ } \\
\text { Monitoring }\end{array}$ & Analytical & Totals \\
\hline Capital Installed Cost (CIC) & & $\$ 200,000$ & $S 120,000$ & & & $\$ 320,000$ \\
\hline \multicolumn{7}{|l|}{ Variable Production Costs } \\
\hline Site Operating Labor (OL) & & $\$ 183$ & $\$ 1,283$ & $\$ 1,467$ & & $\$ 2,933$ \\
\hline Electricity (diesel) & 0.1 & $\$ 2,624$ & $\$ 7.400$ & $\$ 924$ & & $\$ 10,948$ \\
\hline Maintenance and Repairs $(M)(\%$ of $C I C)$ & 0.01 & $\$ 489$ & $\$ 293$ & & & $\$ 782$ \\
\hline Operating Supplies (\% of $\mathrm{M}$ ) & 0.05 & $\$ 24$ & $\$ 15$ & & & $\$ 39$ \\
\hline Laboratory Charges & & & & & $\$ 8,800$ & $\$ 8,800$ \\
\hline Total Variable Cost (over detined time period) & & $\$ 3.321$ & $\$ 8.991$ & $\$ 2,391$ & $\$ 8,800$ & $\$ 23,503$ \\
\hline Variable Cost per Day & & $\$ 95$ & $\$ 102$ & $\$ 27$ & $\$ 100$ & $\$ 324$ \\
\hline $\begin{array}{l}\text { Variable Cost per } k W \text {-hr Rli Power } \\
\text { Delivered to formation }\end{array}$ & & 50.28 & $\$ 0.77$ & S0.20 & $\$ 0.75$ & $\$ 2.00$ \\
\hline \multicolumn{7}{|l|}{ Site Dependent lixed Charges } \\
\hline Horizontal Wells & & & & $\$ 21,350$ & & $\$ 21,350$ \\
\hline Moniloring Wells & & & & $\$ 11.843$ & & $\$ 11,843$ \\
\hline Truillability & & $510.000)$ & & & & $\$ 10,000$ \\
\hline Tiotal Site Dependent Fixed Cost & & $S 10,000$ & \$o & $\$ 33,193$ & \$o & $\$ 43.193$ \\
\hline \multicolumn{7}{|l|}{ Independent Fixed Charges } \\
\hline $\begin{array}{l}\text { Nobilization (basis: one RF deliver, one } \\
\text { olfgis treitment unit) }\end{array}$ & & $\$ 3,2() 0$ & $\$ 1,600$ & & & $\$ 4,800$ \\
\hline Depreciatum (\% ClC, ammual basis) & 0.1 & $\$ 4,889$ & $\$ 2,933$ & & & $\$ 7.822$ \\
\hline $\begin{array}{l}\text { Demobilization (hasis: one RF deliver, one offgas } \\
\text { Ireitment unit) }\end{array}$ & $\therefore$ & $\$ 3,200$ & $\$ 1,60)$ & & & $\$ 4,8(0)$ \\
\hline Tot:al Independent fixed Cost & & $\$ 11.289$ & $\$ 6,133$ & $\$ 0$ & SO & $\$ 17.422$ \\
\hline $\begin{array}{l}\text { lintal Prokfuct cost (TPC) (over defined time } \\
\text { period) }\end{array}$ & & $\$ 24,610$ & $\$ 15.125$ & $\$ 35,584$ & $\$ 8,800$ & 584,118 \\
\hline $\begin{array}{l}\text { PPC: per KlV-hr RF Power Delivered to } \\
\text { formation (88 Days) }\end{array}$ & & $\$ 2.10$ & $\$ 1.29$ & 53.03 & $\$ 0.75$ & $\$ 7.17$ \\
\hline
\end{tabular}


Final Report: In Situ Radio Frequency Heating Demonstration

\begin{tabular}{|c|c|c|c|c|c|c|c|c|c|}
\hline Area & Item & Quantity & Capacity & Vendor & Contact & Date & $\begin{array}{c}\text { Price } \\
\text { Each (\$) }\end{array}$ & $\begin{array}{c}\text { Total } \\
\text { Cost }(\$)\end{array}$ & $\begin{array}{l}\text { Area Cost } \\
\text { (\$) }\end{array}$ \\
\hline RF Delivery & $\begin{array}{l}\text { System, includ- } \\
\text { ing RF generator } \\
\text { amplificr } \\
\text { controls } \\
\text { ciable } \\
\text { applicator }\end{array}$ & 1 & $25 \mathrm{~kW}$ & $\begin{array}{l}\text { KAI Technolo- } \\
\text { gies, Inc. }\end{array}$ & D. L. Faust & $9 / 21 / 93$ & $\$ 200,000$ & $\$ 200,000$ & \\
\hline Total & & & & & & & & & $\$ 200,000$ \\
\hline \multirow[t]{4}{*}{$\begin{array}{l}\text { Ollgas Treal- } \\
\text { ment System }\end{array}$} & $\begin{array}{l}\text { Thermal. } \\
\text { Catalytic }\end{array}$ & 1 & $\begin{array}{l}200) \\
\text { SCFM }\end{array}$ & $\begin{array}{l}\text { Brown Engi- } \\
\text { necring Com- } \\
\text { pany }\end{array}$ & R. Schulke & $11 / 92$ & $\$ 120,000$ & $\$ 120,00$ & \\
\hline & Halocarbon & & & & & & & & \\
\hline & Destruction & & & & & & & & \\
\hline & Syslem & & & & & & & & \\
\hline Total & & & & & & & & & $\$ 120,000$ \\
\hline \multirow{3}{*}{$\begin{array}{l}\text { Horizontal } \\
\text { Well }\end{array}$} & Centron Slotted & 175 & $1 \mathrm{nt}$ & Centron & & & $\$ 12$ & $\$ 6.960$ & \\
\hline & Liner and l'tess & & & & & & & & \\
\hline & $\begin{array}{l}\text { Installation, } \\
\text { Drill and line }\end{array}$ & & 175 perft & $\begin{array}{l}\text { Charles } \\
\text { Machine } \\
\text { Works }\end{array}$ & & & $\$ 110$ & $\$ 19,250$ & \\
\hline Total & & & & & & & & & $\$ 21,350$ \\
\hline \multirow[t]{5}{*}{$\begin{array}{l}\text { Monitoring } \\
\text { Well }\end{array}$} & $\begin{array}{l}\text { Liner, temp } \\
\text { monitoring }\end{array}$ & 20 & $50 \mathrm{ft}$ & $\begin{array}{l}\text { McMaster- } \\
\text { Carr }\end{array}$ & Catalog \#98 & & $\$ 57$ & $\$ 114$ & $\cdots$ \\
\hline & Piezoneter & 6 & $50 \mathrm{ft}$ & $\begin{array}{l}\text { McMaster- } \\
\text { Carr }\end{array}$ & Catal.jg \#98 & & $\$ 29$ & $\$ 171$ & - \\
\hline & $\begin{array}{l}\text { Termocouples } \\
\text { Type T. Ieflon } \\
\text { Ins. }\end{array}$ & 6 & $100 \mathrm{ft}$ & Omega & Catalog $\# 28$ & & $\$ 43$ & $\$ 258$ & \\
\hline & $\begin{array}{l}\text { Installation, } \\
\text { drill,and line }\end{array}$ & 220 per lit & & & & & $\$ 50$ & $\$ 11,000$ & \\
\hline & $\begin{array}{l}\text { Sampling Pump } \\
\text { (rotiry vante) }\end{array}$ & 3 & & Cole-Palmer & $\begin{array}{l}93 \cdot 94 \\
\text { Catalog }\end{array}$ & & $\$ 300$ & $\$ 300$ & \\
\hline Total & & & & & & & & & $\$ 353,193$ \\
\hline
\end{tabular}


speculative at this point and will not be included in this analysis.

Mobiliation, demobilization, and capital depreciation charges will be incurred independent from site. These charges will typically be on the order of $\$ 18,000$ for a capital equipment investment of $\$ 320,(0)(0)$ over a 90-day operation. Total depreciation costs are time dependent and will increase linearly at a fixed rate (\$97/day) for each addilional day of operation.

In all, the total cost for a single horizontal well, 90 day operation will be on the order of $\$ 110,(00)$. This cost may vary by as much as $\pm 50 \%$ depending on particular sampling and analytical requirements. 
Final Report: In Situ Radio Frequency Heating Demonstration

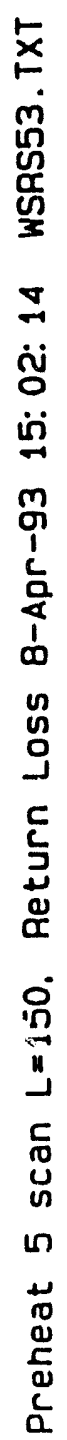
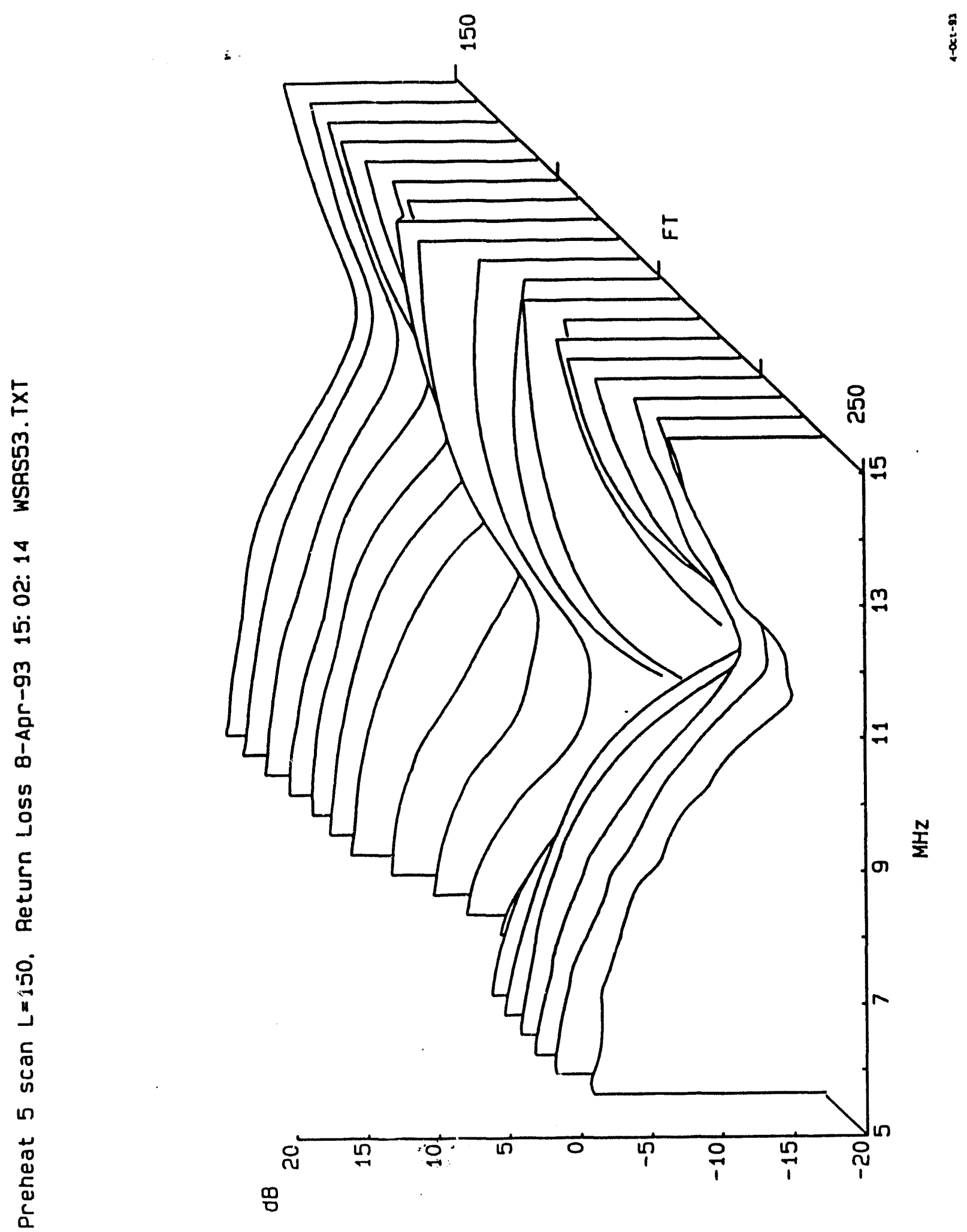

Figure 5-1. Network Analyzer Scan of hecturn Loss prior to Final Heating Period on April 8 
Preneat scan L=144 a RF. Return Loss 24-Mar-93 10:54: 44 WSRS05. TXT at 13.56MHz

$\mathrm{dB}$
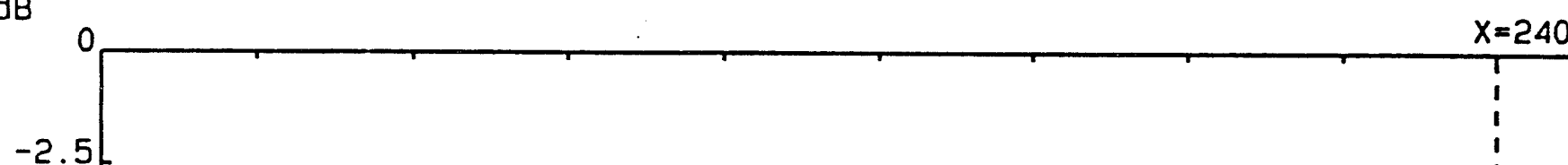

-5 .

$-7.5$

$\therefore$

$-10$

-12.5 .

$-15$

$-17.5$

$-17.5$

$-20$

160

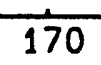

180

190

Distance FT

WSRS0501.01L NWA 1-31 Preneat scan L=144 @ RF. Return Loss 24-Mar-93 10:54: 44 WSRS0501.01L ... WSAS0520.01L 


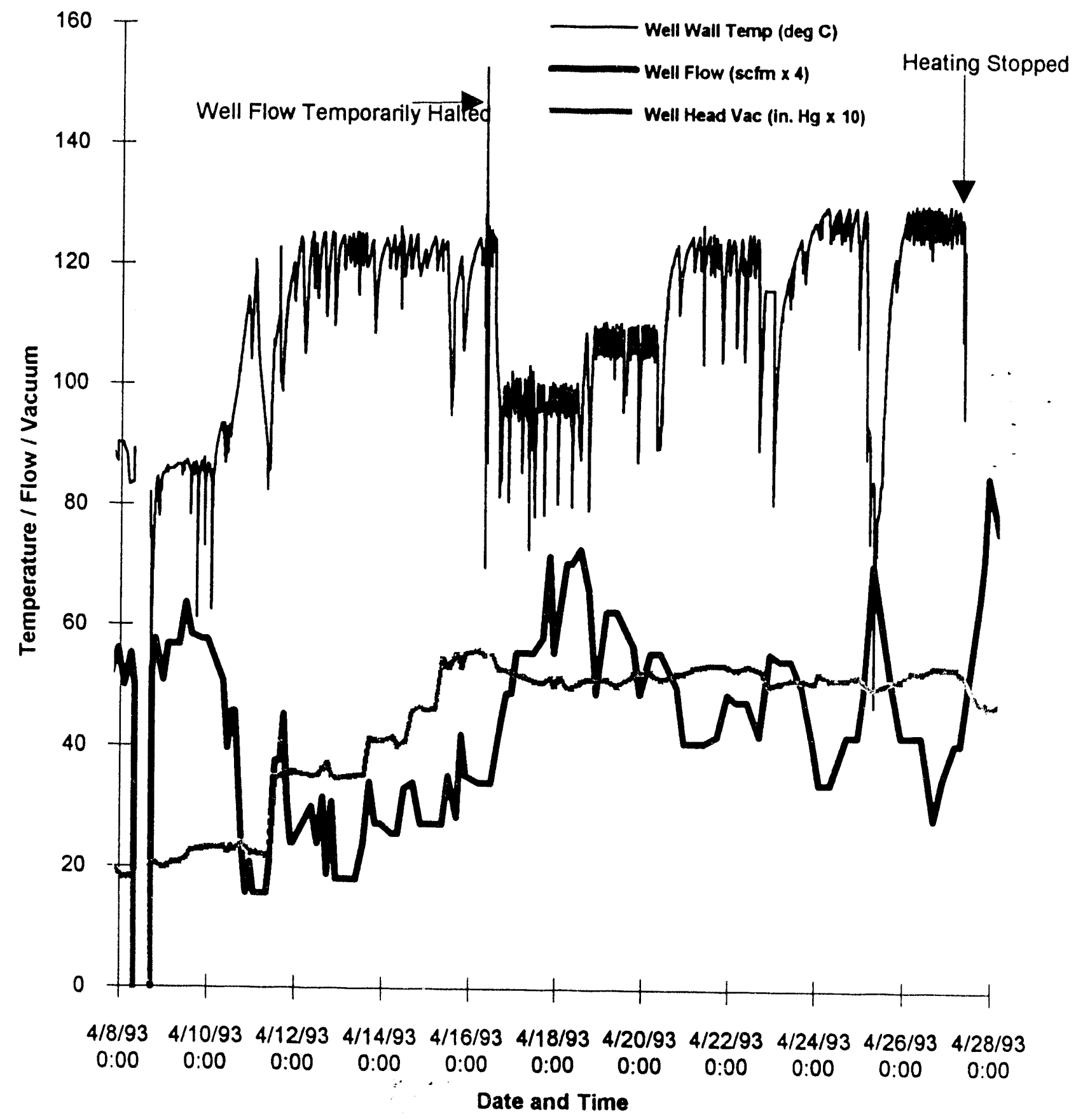

Figure 5-5. Well Flow, Applied Vacuum and Well Wall Temperature 4/8/93 - 4/27/93 


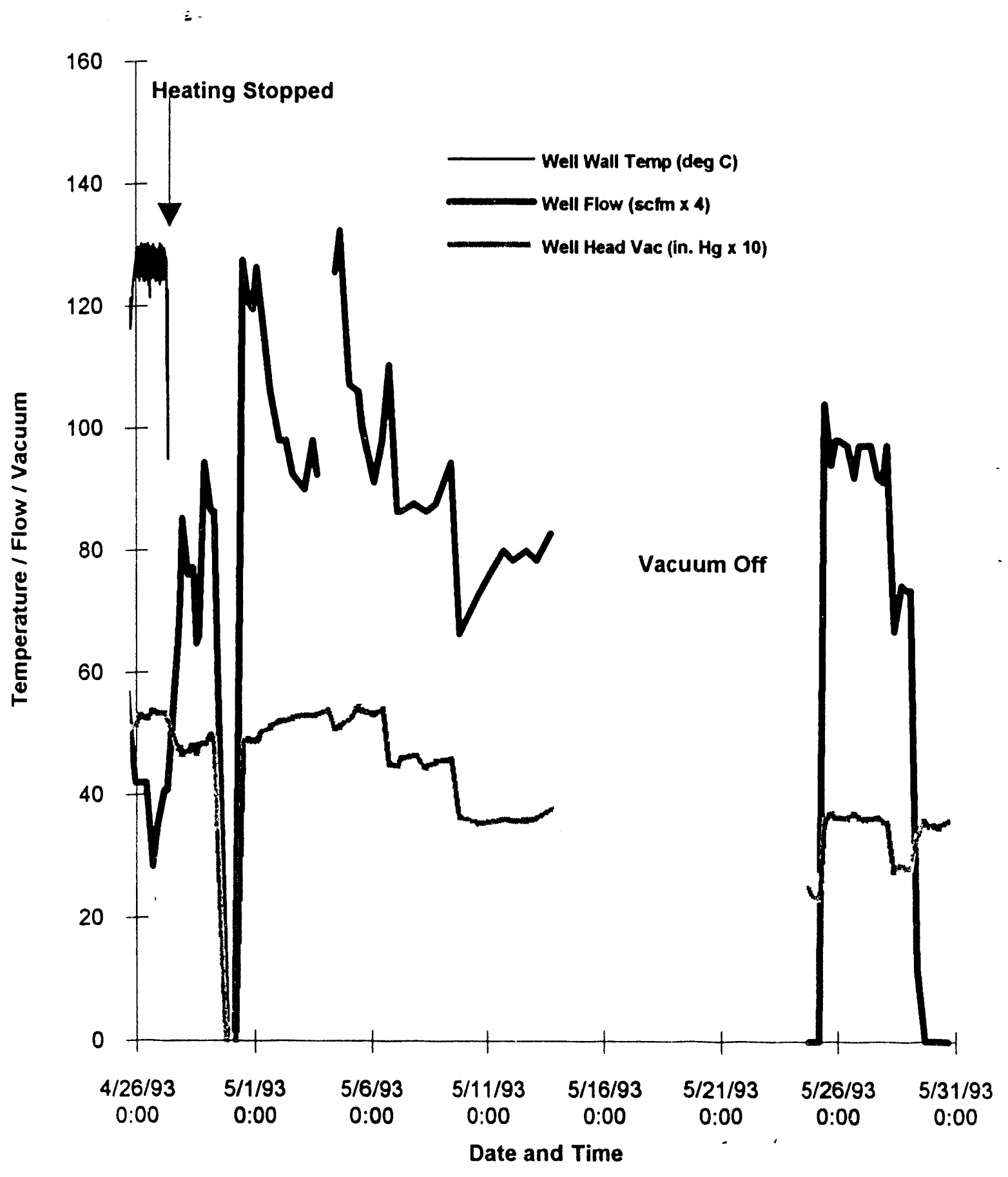

Figure 5-6. Well Flow, Applied Vacuum and Well Wall Temperature 4/27/93 - 5/31/93 (Cooldown Period) 


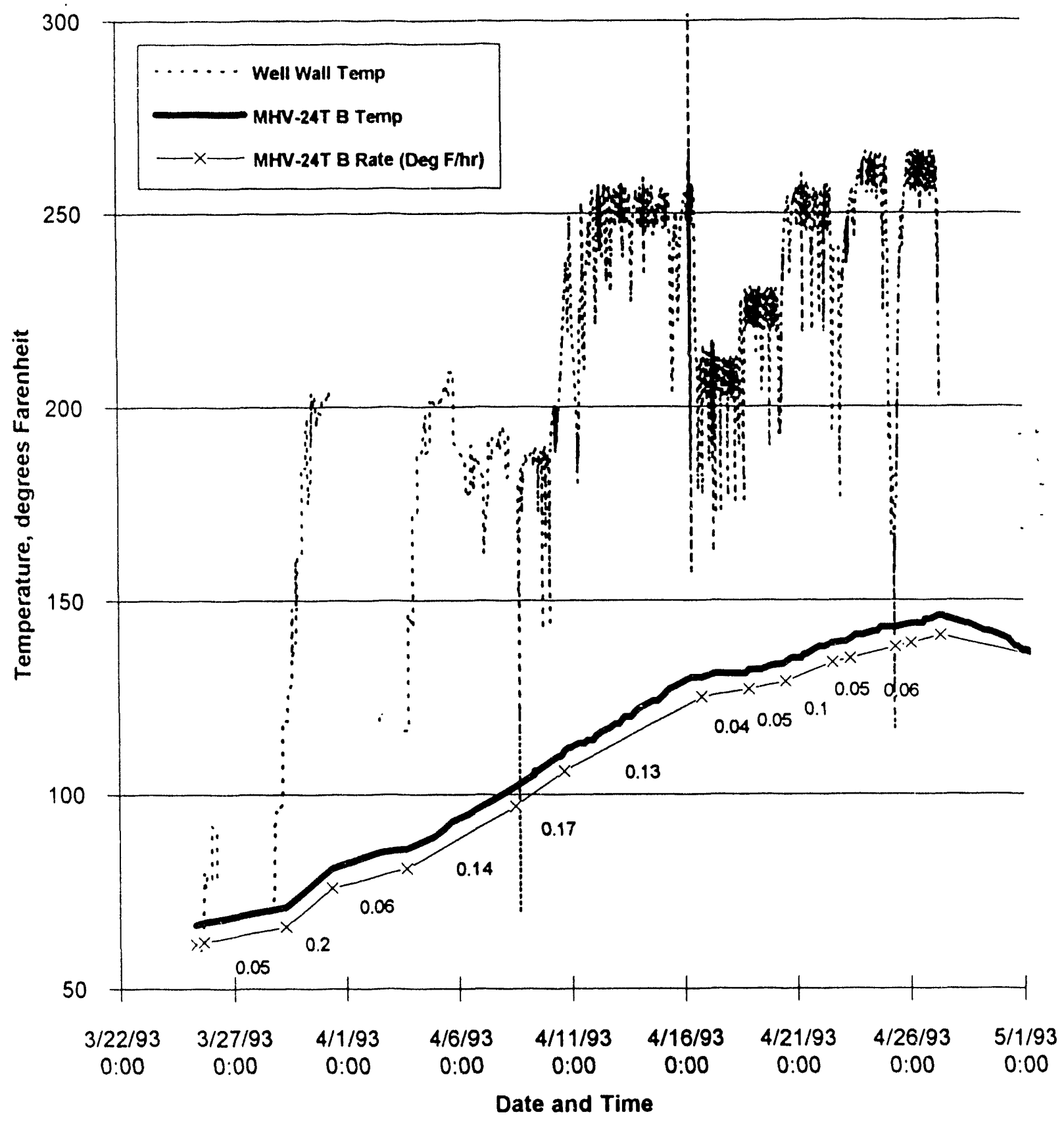

Figure 5-7. Comparison of Well Wall Temperature to Subsurface Temperature Measured @ MHV-24T "B" (38 foot (depth in clay zonc) 

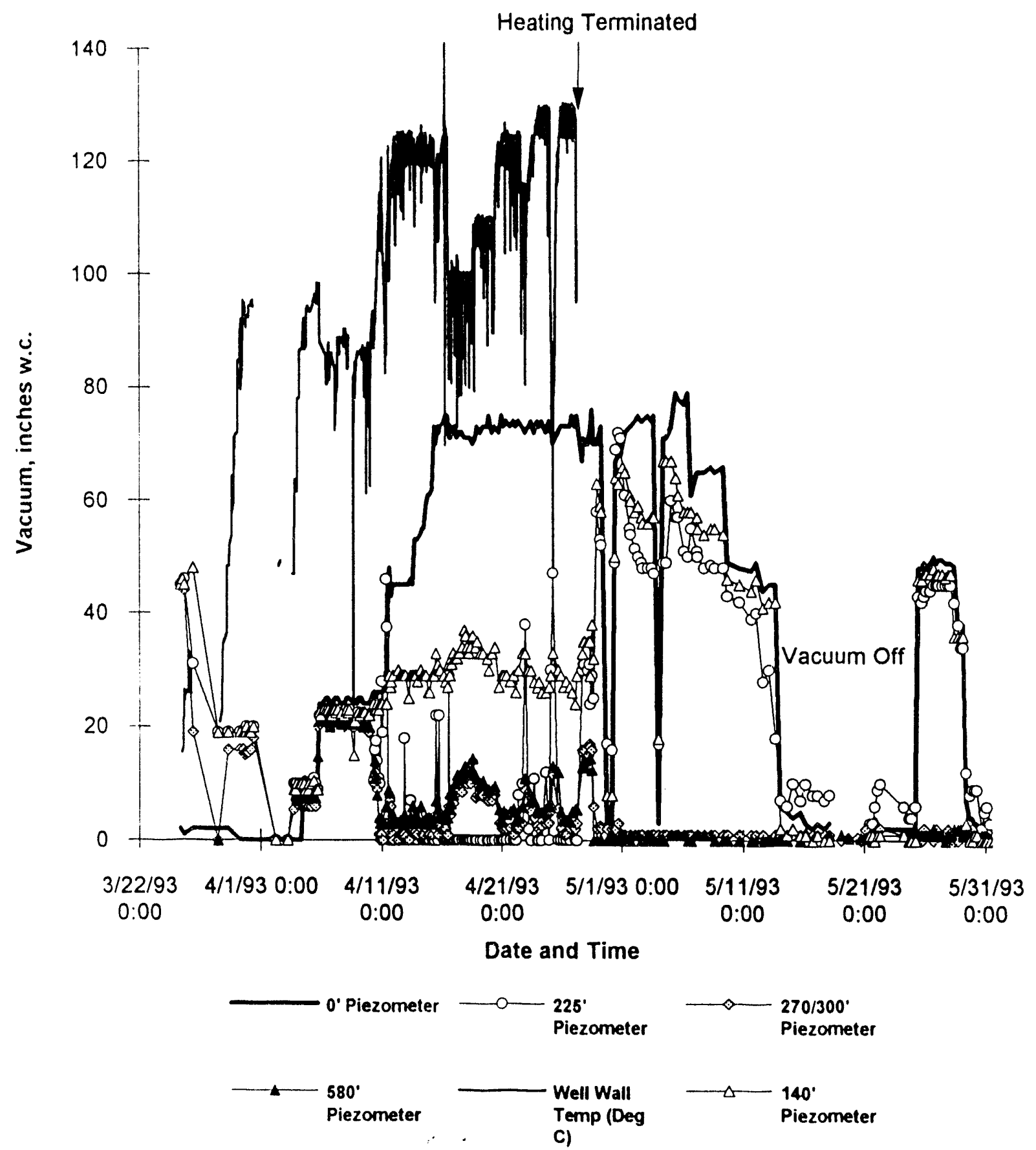

Figure 5-8. Horizontal Well Piczometer Data Related to Well Wall Temperature During RF Heating Demonstration 


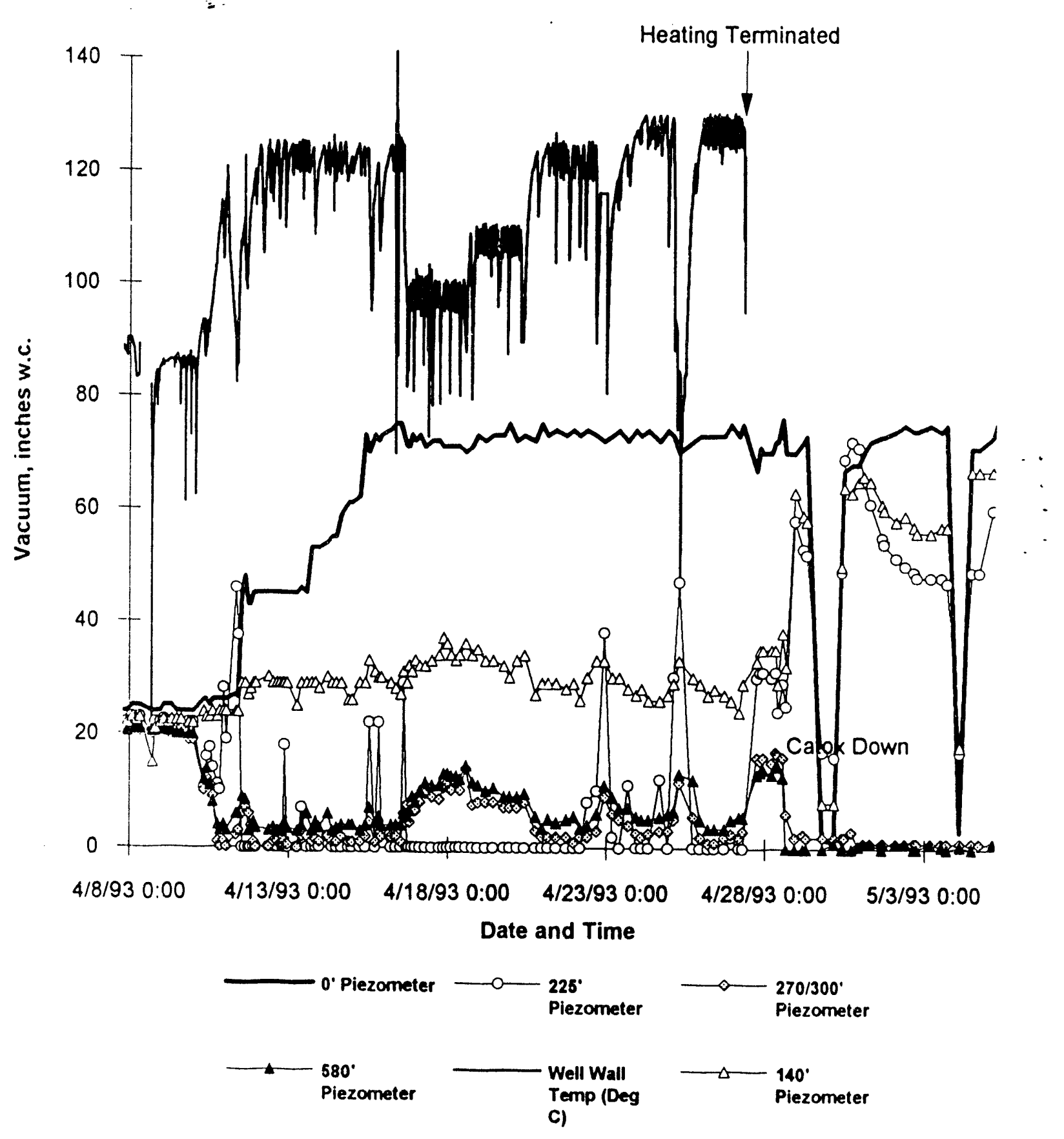

Figure 5-9. Exploded View of Figure 5-8 During the Final Heating Stage of the RF Heating Demonstration 


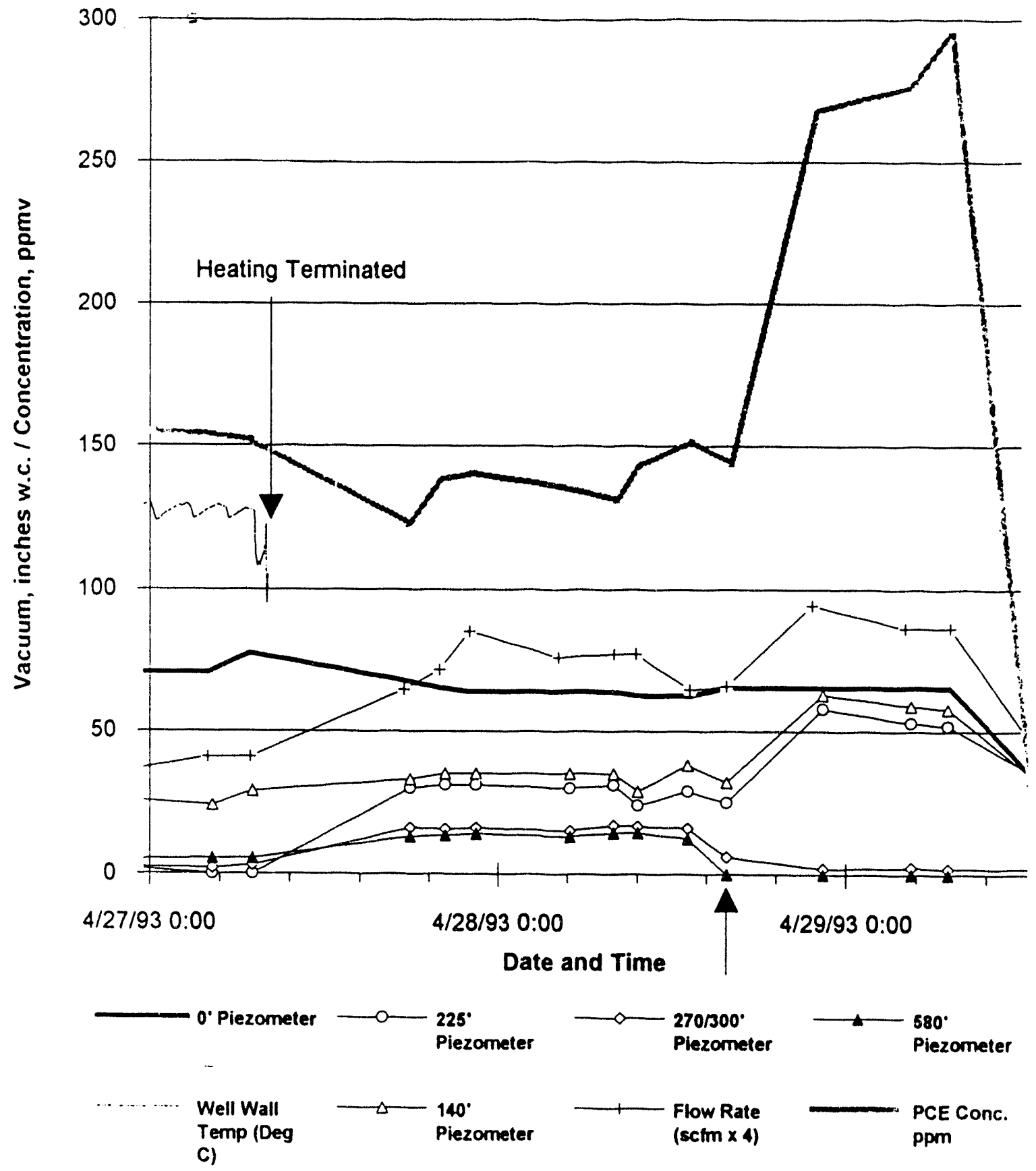

Figure 5-10. Horizontal Well Piczometer, Flow, and PCE Concentration Data During Early Stages of Cool down 


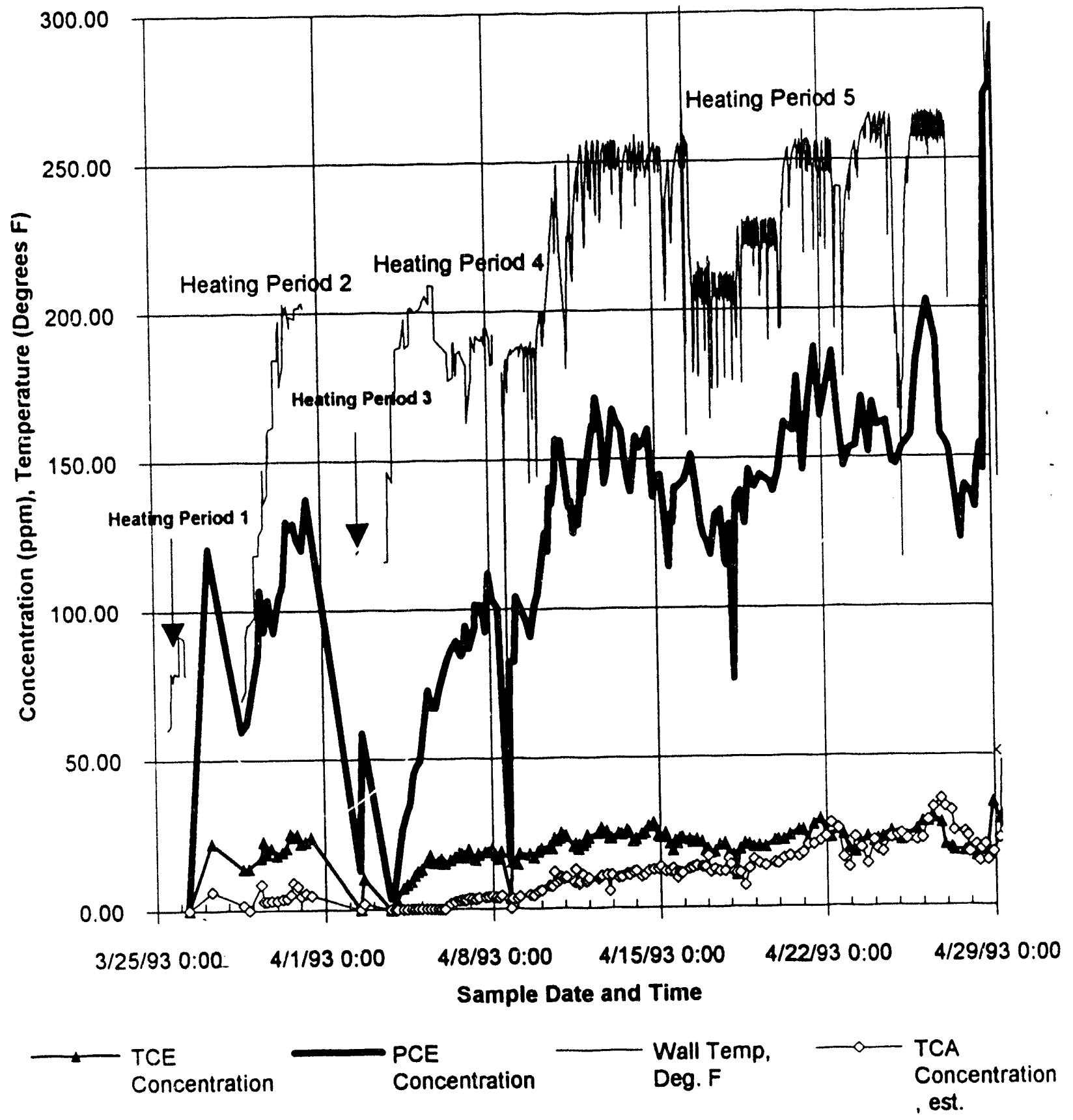

Figure 5-11. Contaminant Concentration During Heating Portion of Demonstration 


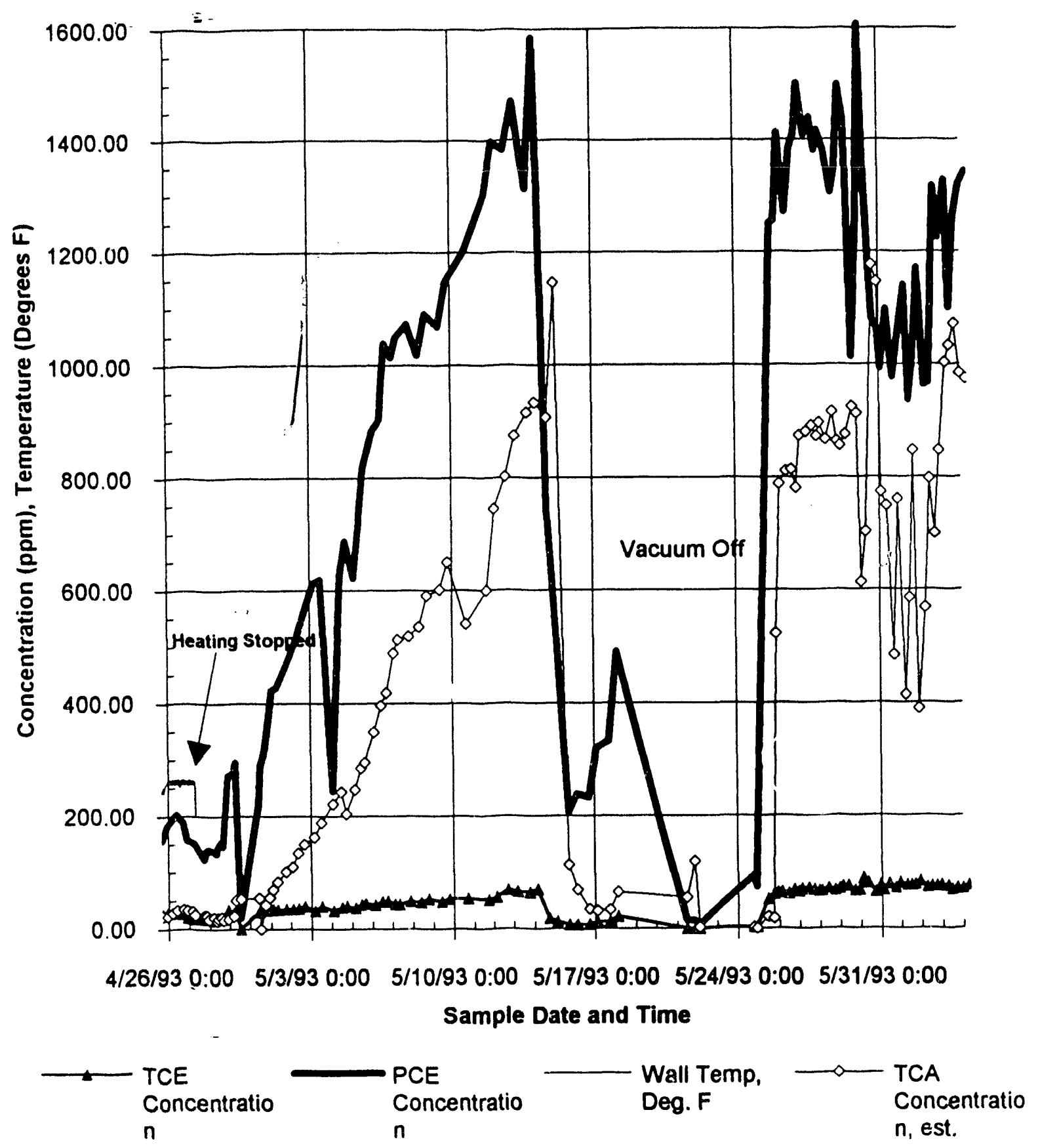

Figure 5-12. Contaminant Concentration During Cool Down Portion of Demonstration 


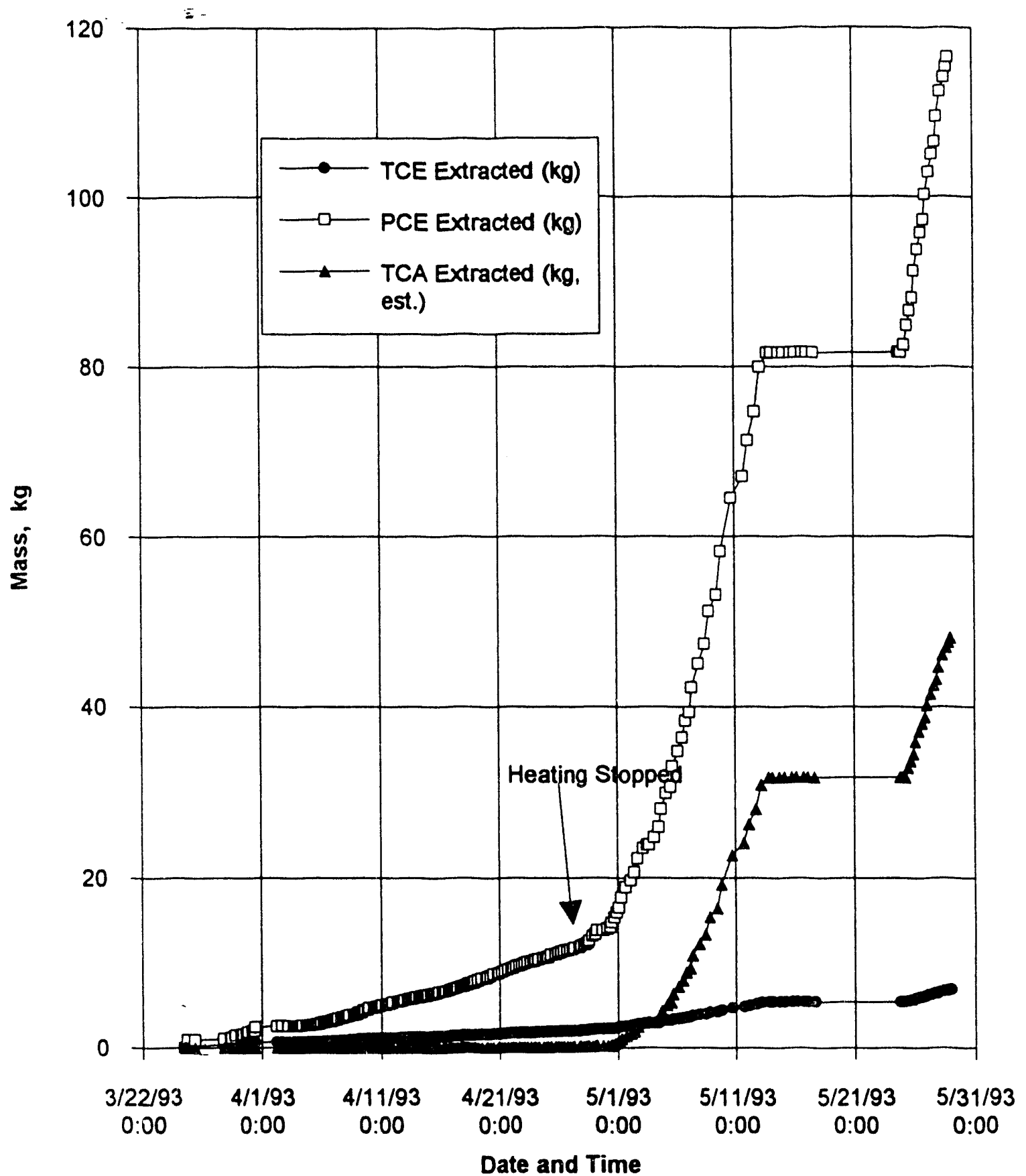

Figure 5-13. Cumulative Contaminants Extracted 


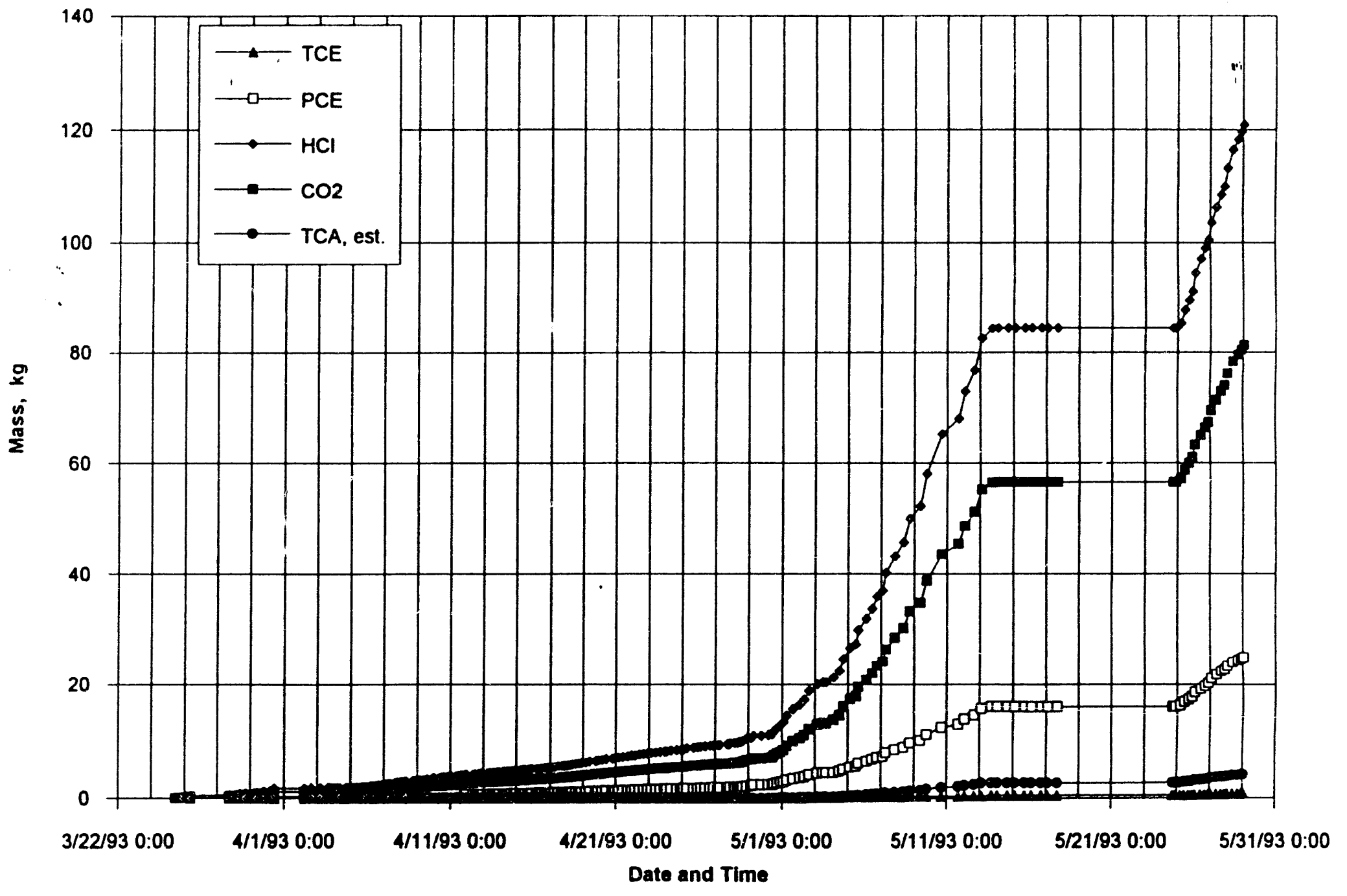




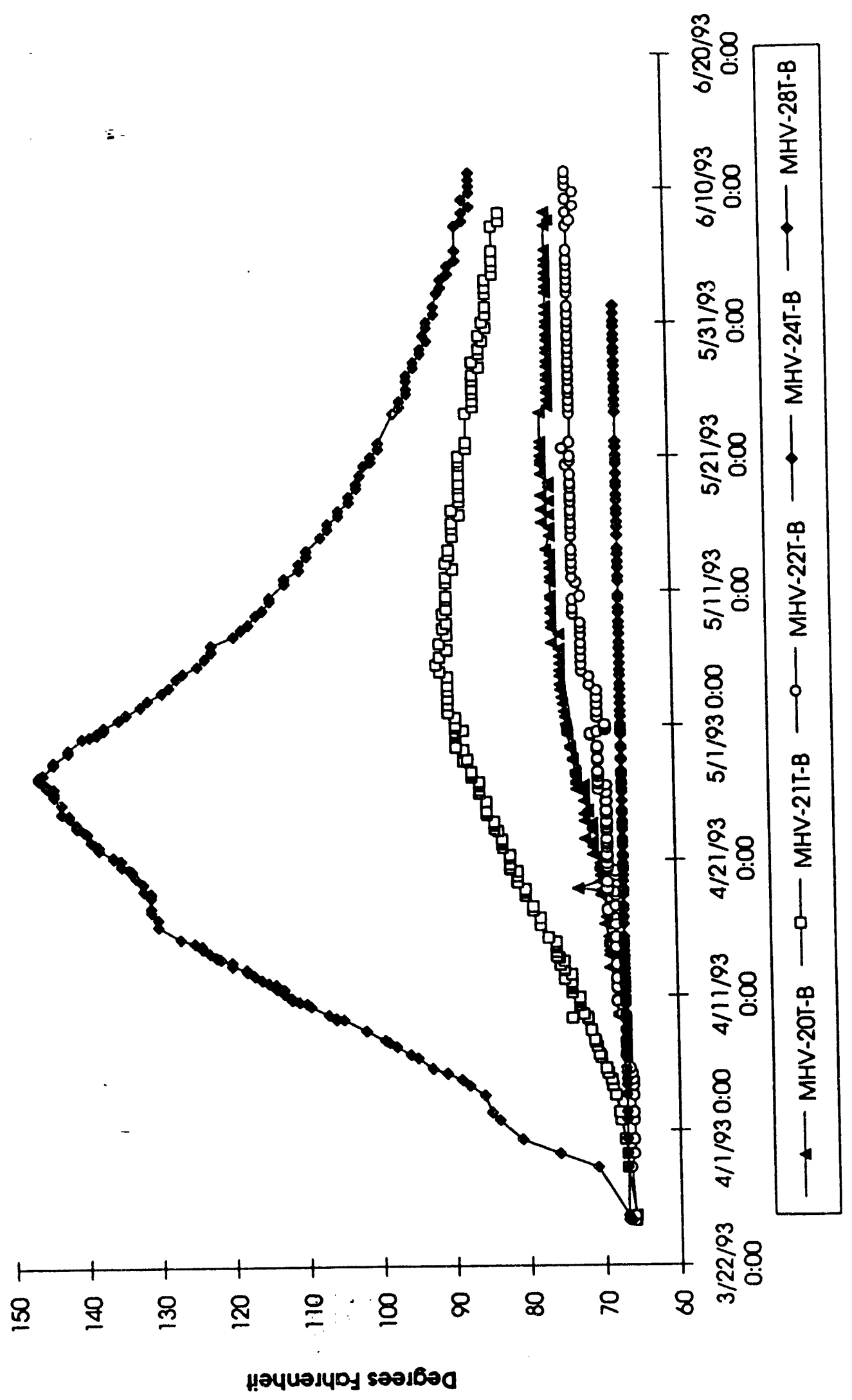

Figure 5-15. Subsurface Temperattures in Clay at 38 ft Depth 


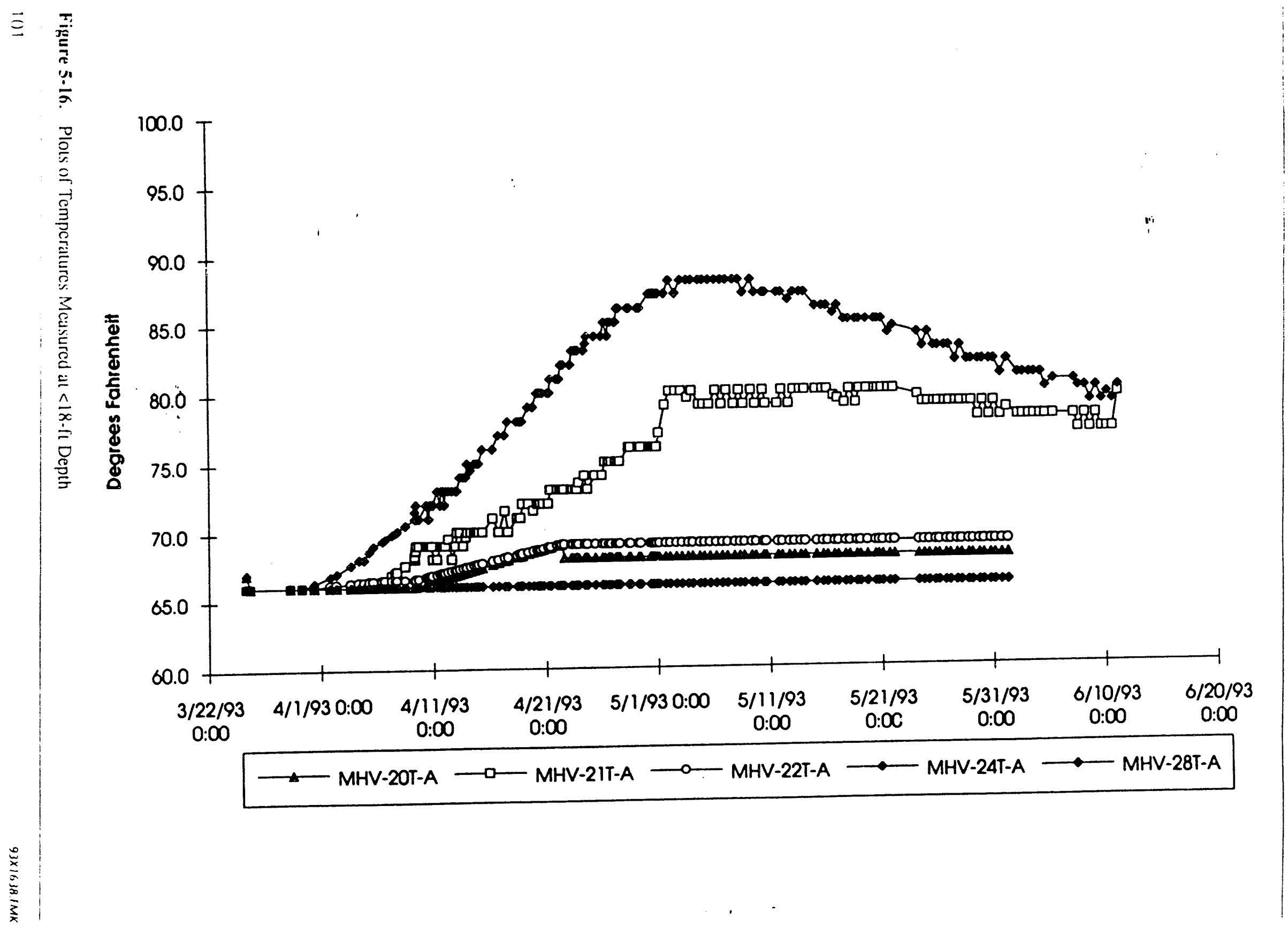




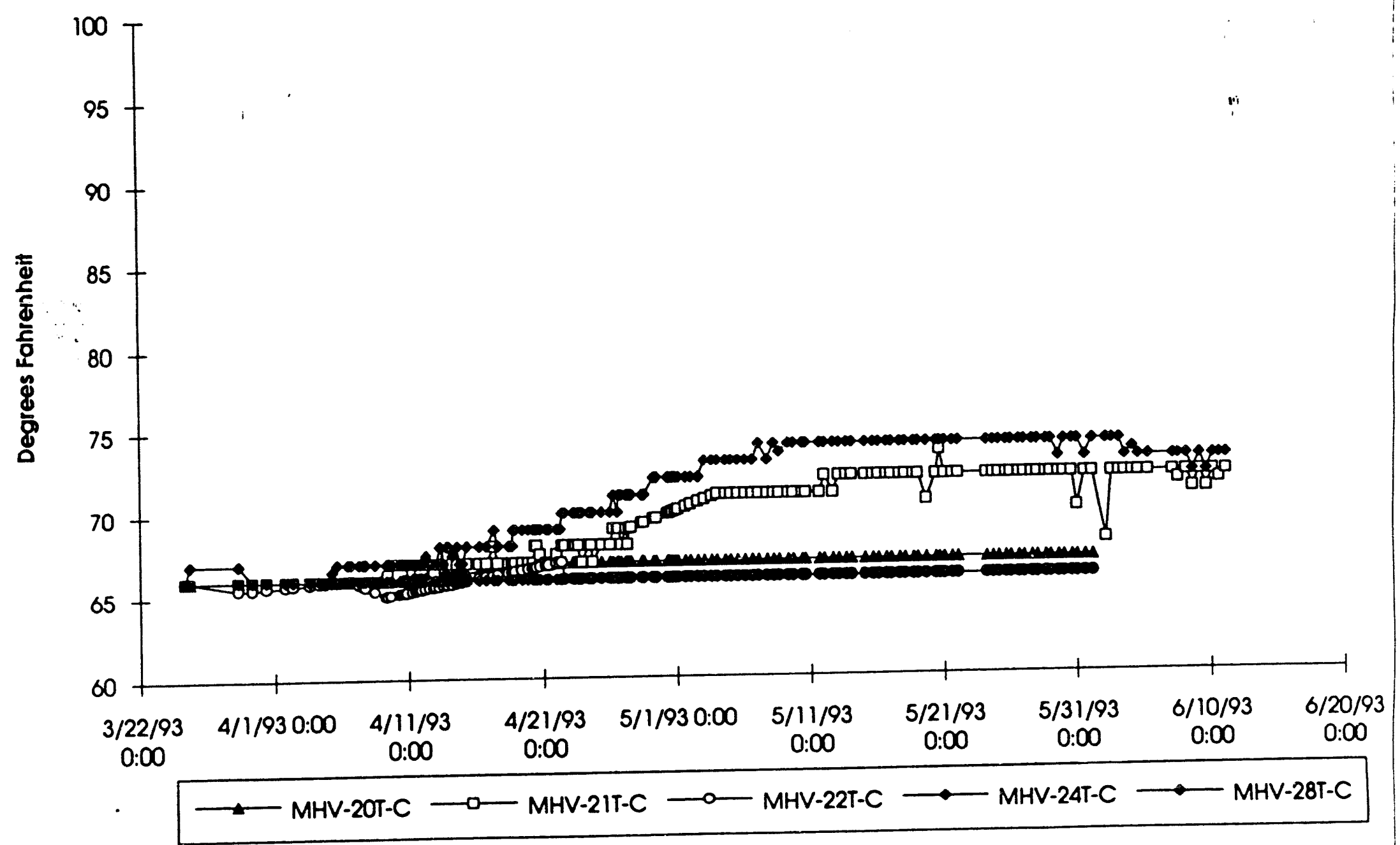




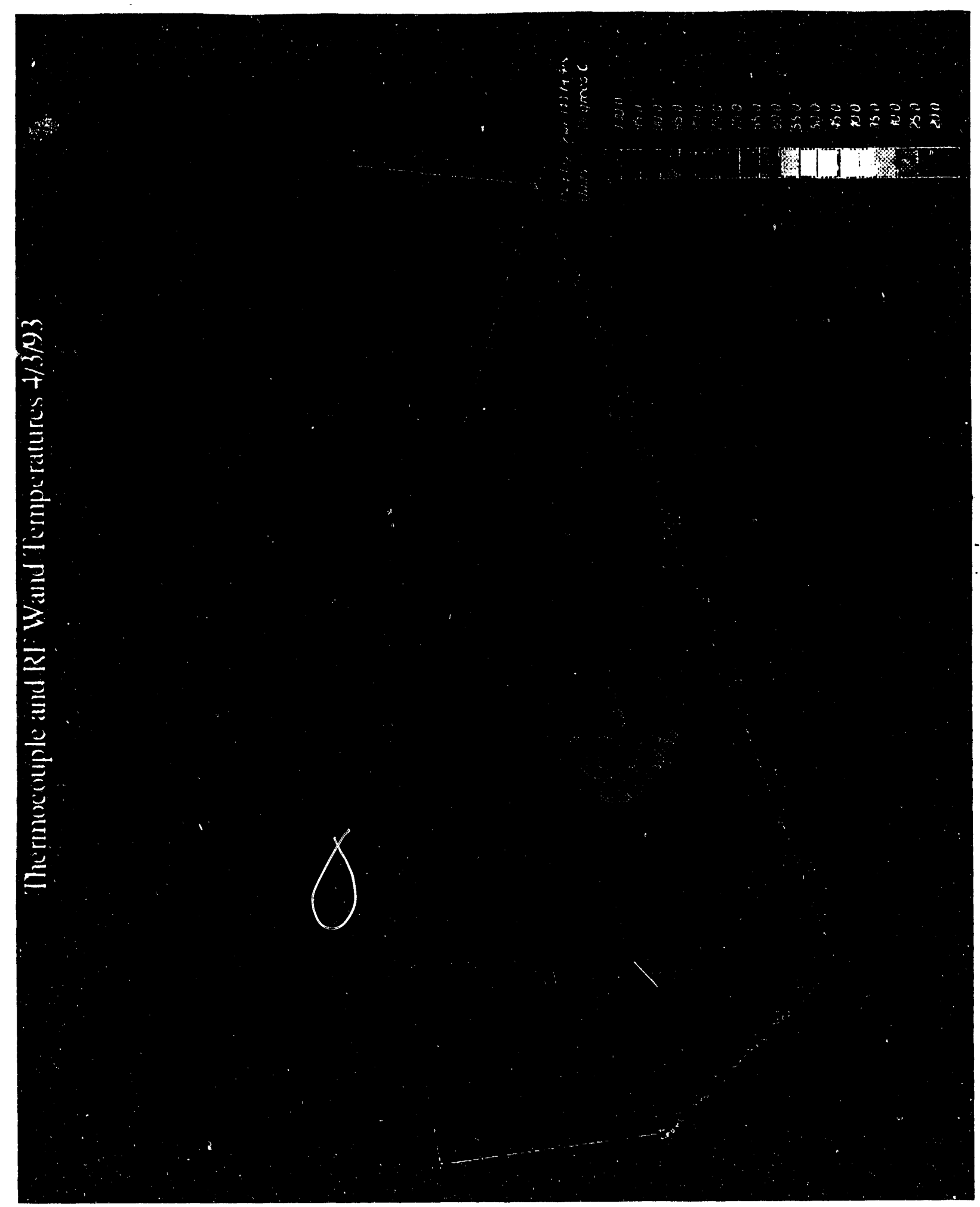

Figure 5-18. Three Dincensional Image ol Temperature Distribution on $4 / 3 / 93$ 


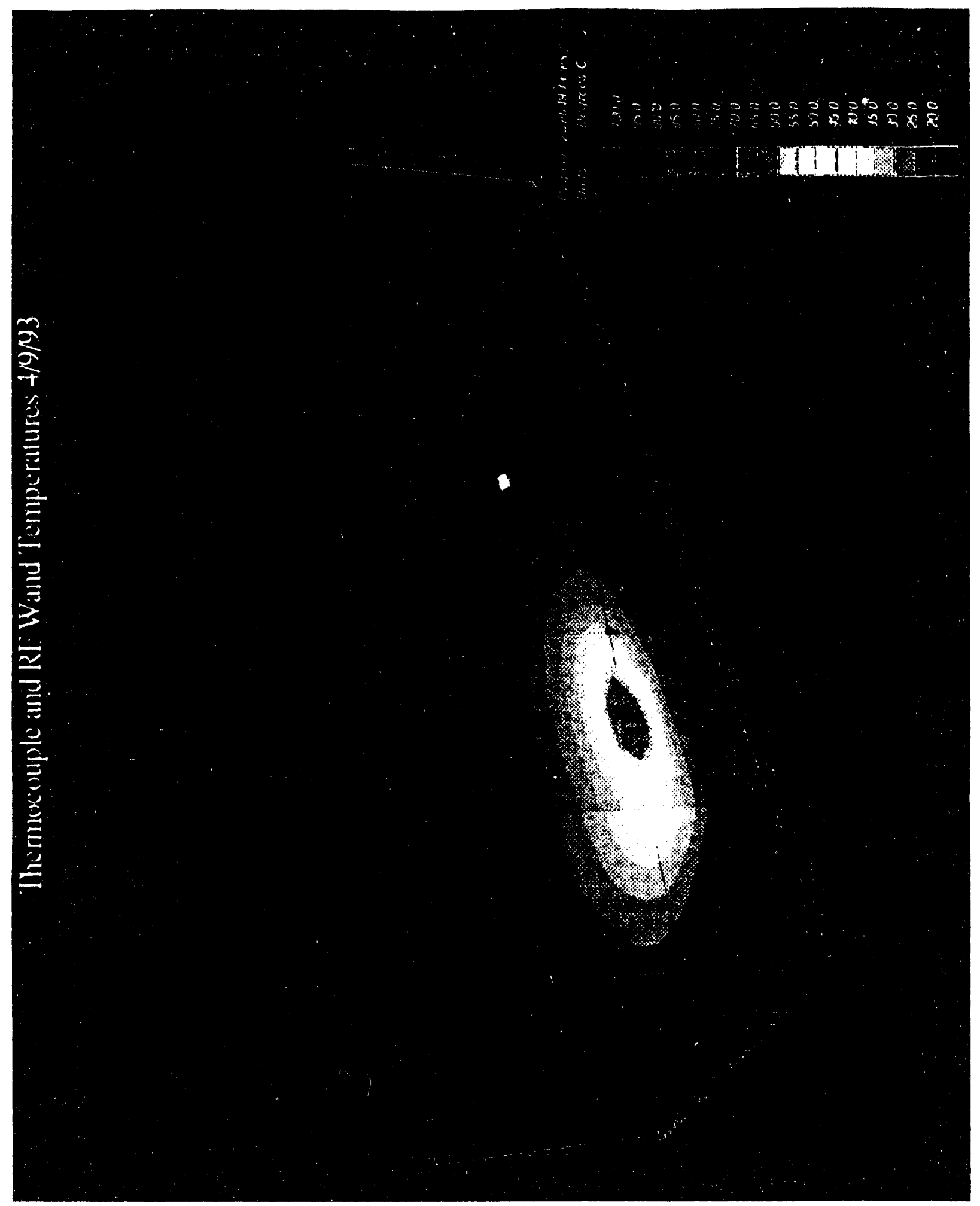

Figure 5-19. Three-Dimensional lmage of Temperature Distribution on 4/9/93 


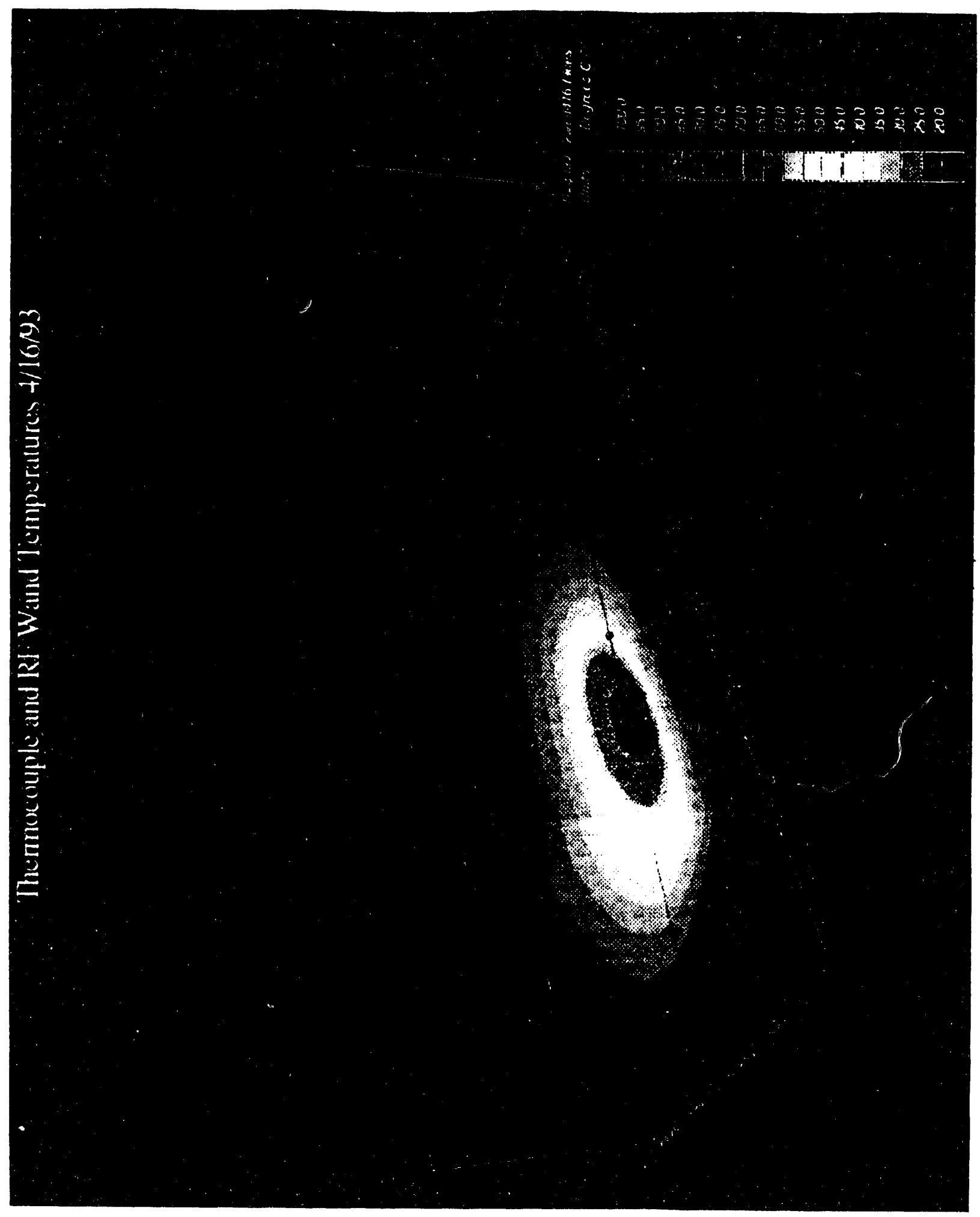

Figure 5-2(). Three-Dimensional I mage of Temperature Distribution on 4/16/93 


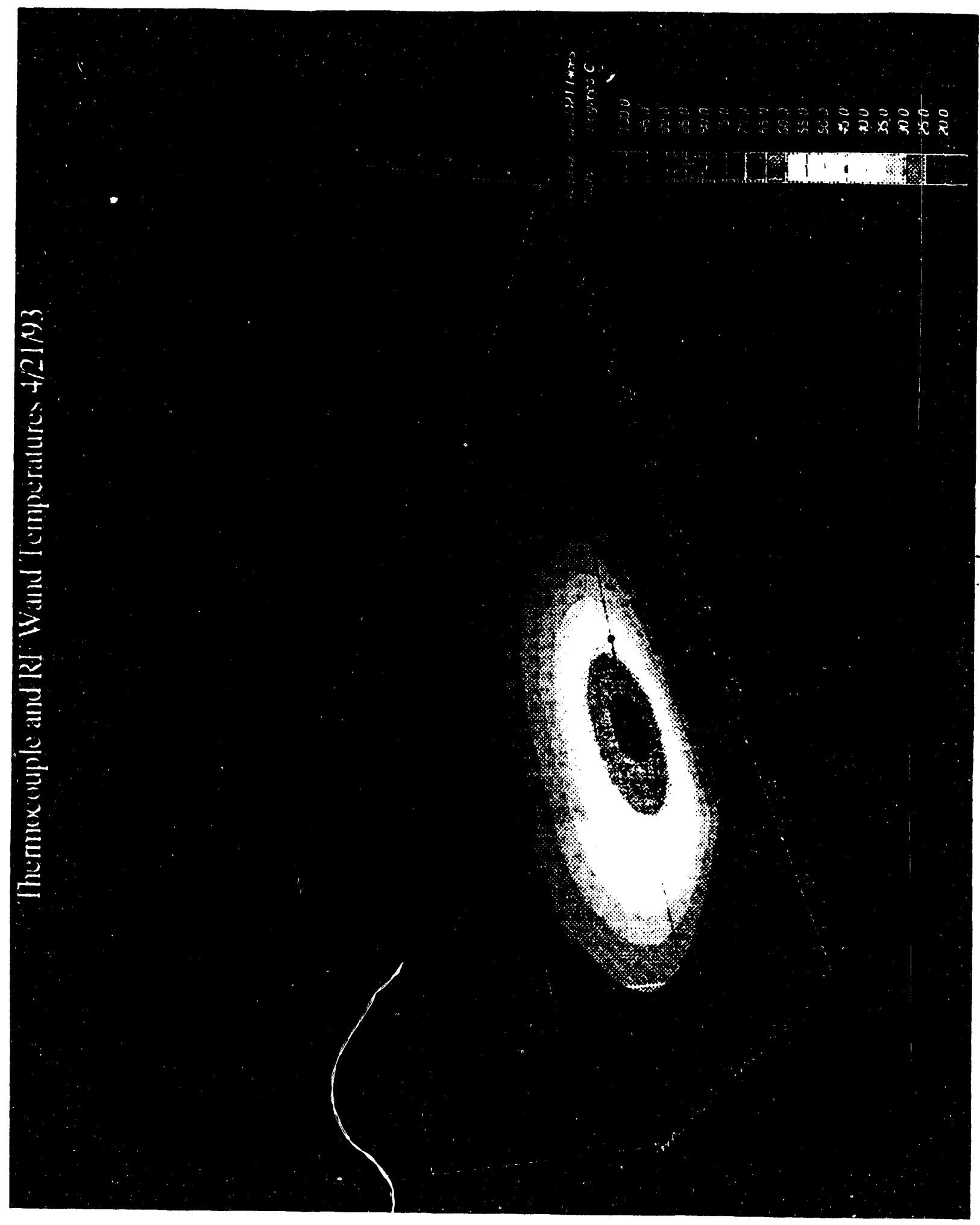

Figure 5-21. Three-Dimensional Images of Temperature Distributions on 4/21/93 


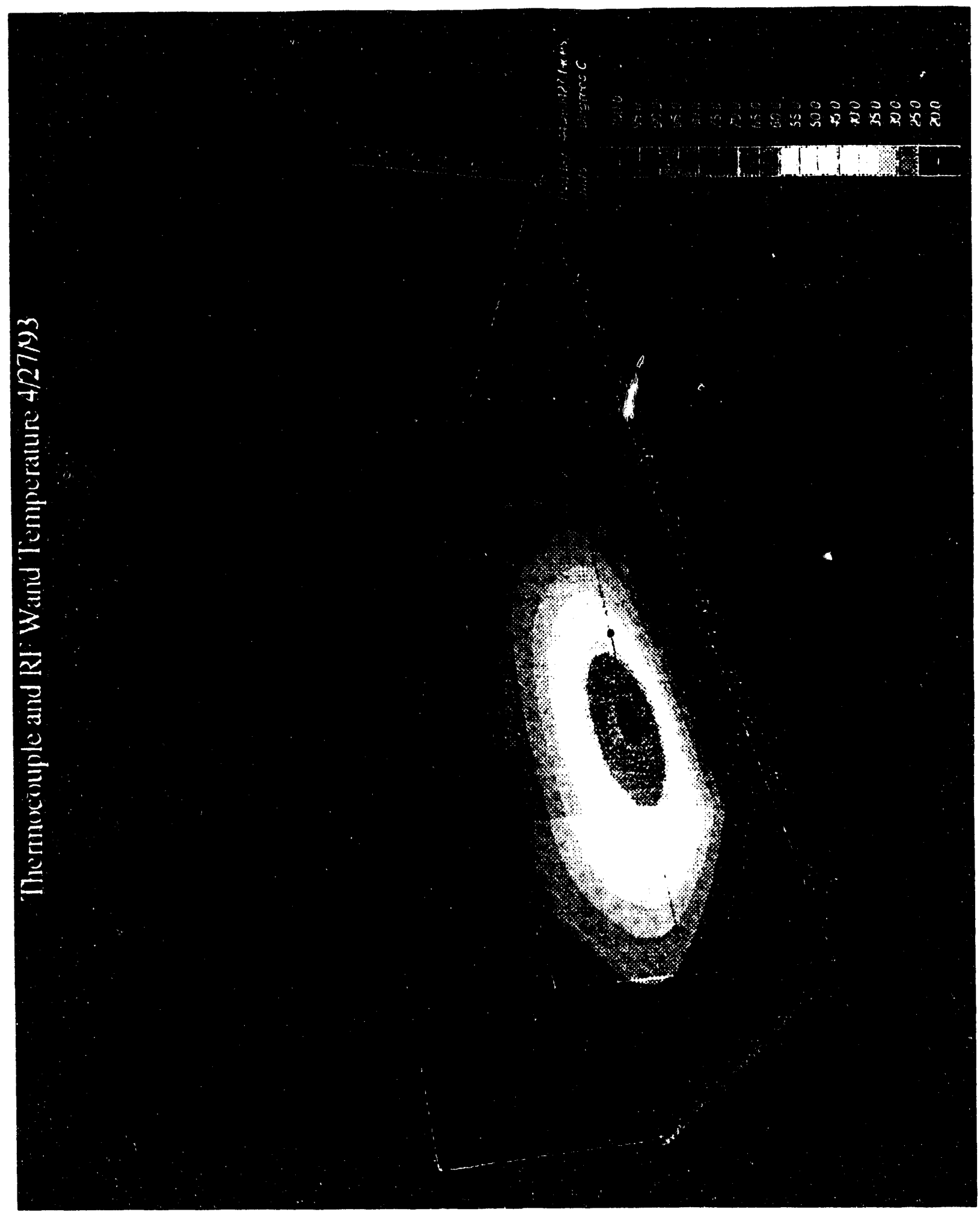

Figure 5-22. Three-Dımensional Image of Temperature Distributions on 4/27/93 


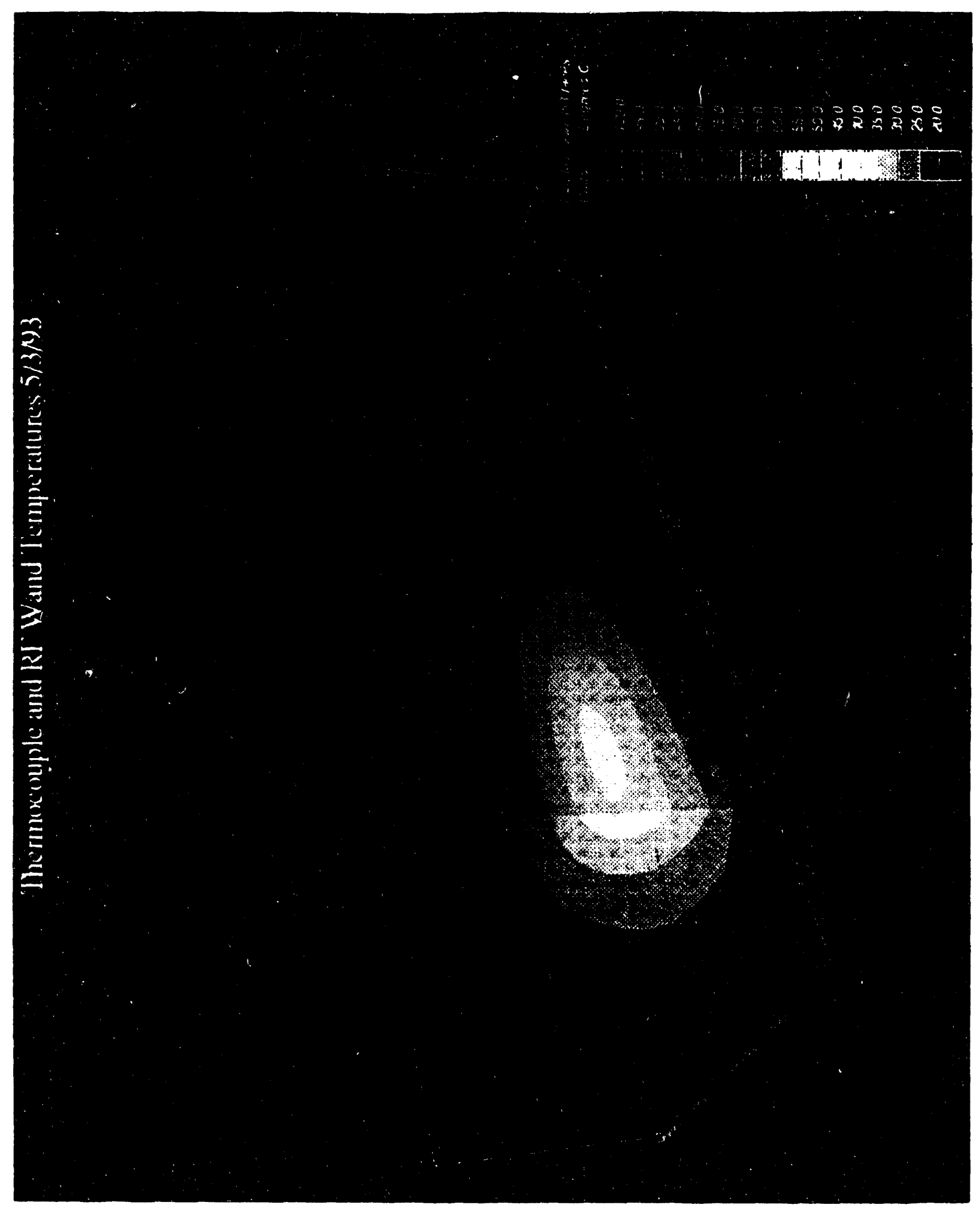

Figure 5-23. Three-Dimensional linage of Temperature Distributions on 5/3/93 


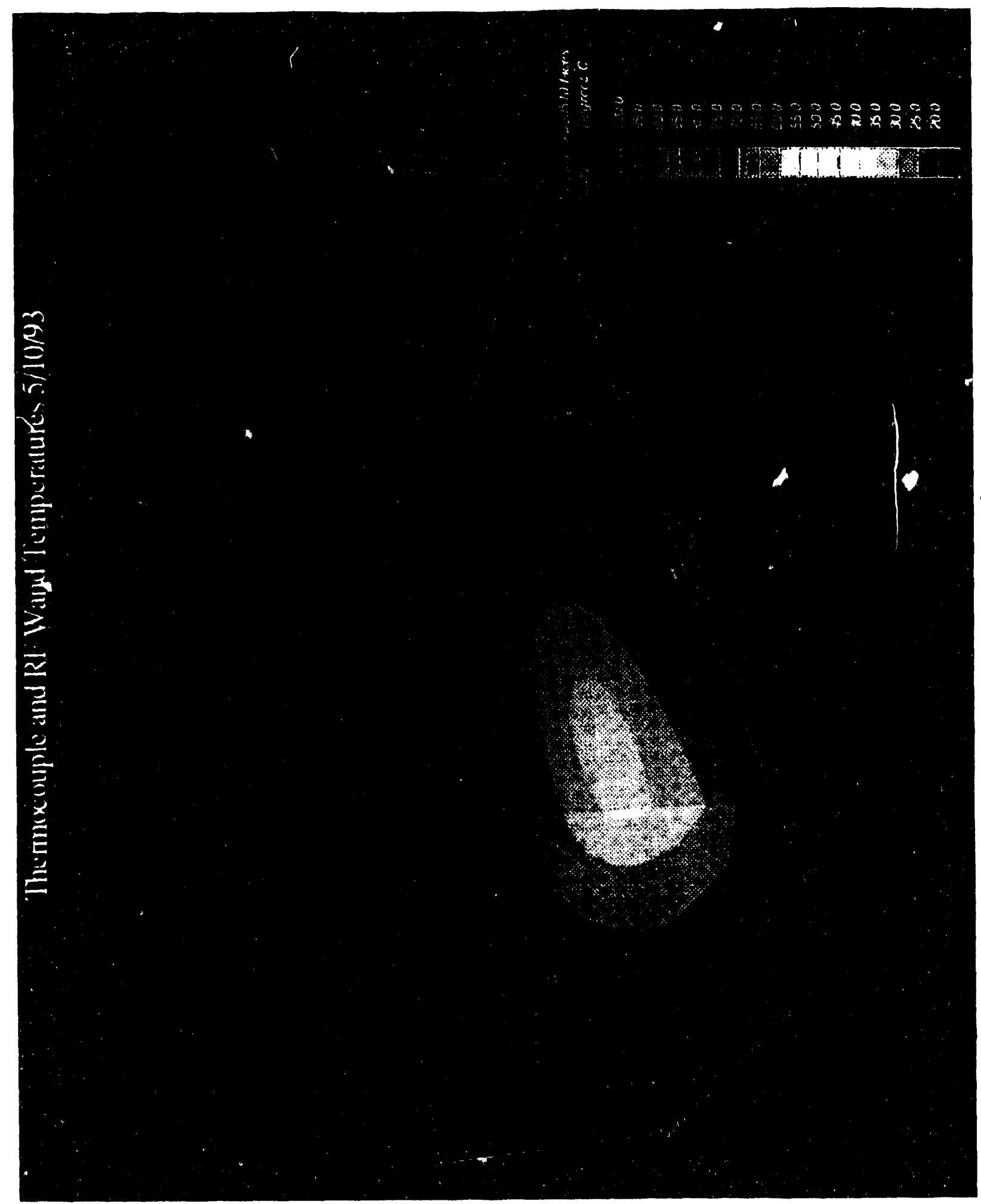

Figure 5-24. Three-Dimenstonal Image of Temperalure Distributions on 5/10/93 


\section{RF HEATING MODEL TEMPERATURE DISTRIBUTION}

Display mempartiner the

Unirs:

r. Degreds $C$

2000

1903

180.0

170.3

1600

1500

1400

1300

110.0

1000

90.0

80.0

160

500

400

30.0

4

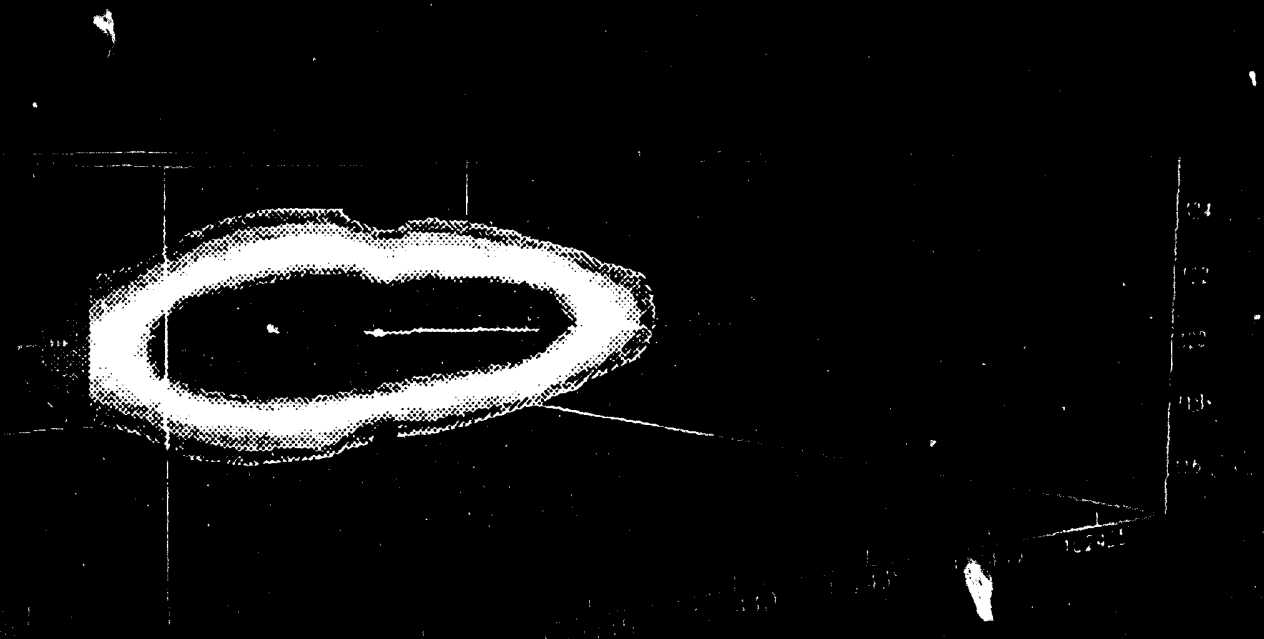

Figure 5.25. Three-[Dmensunal Image of RF Healung Model Temperature Distributuon 

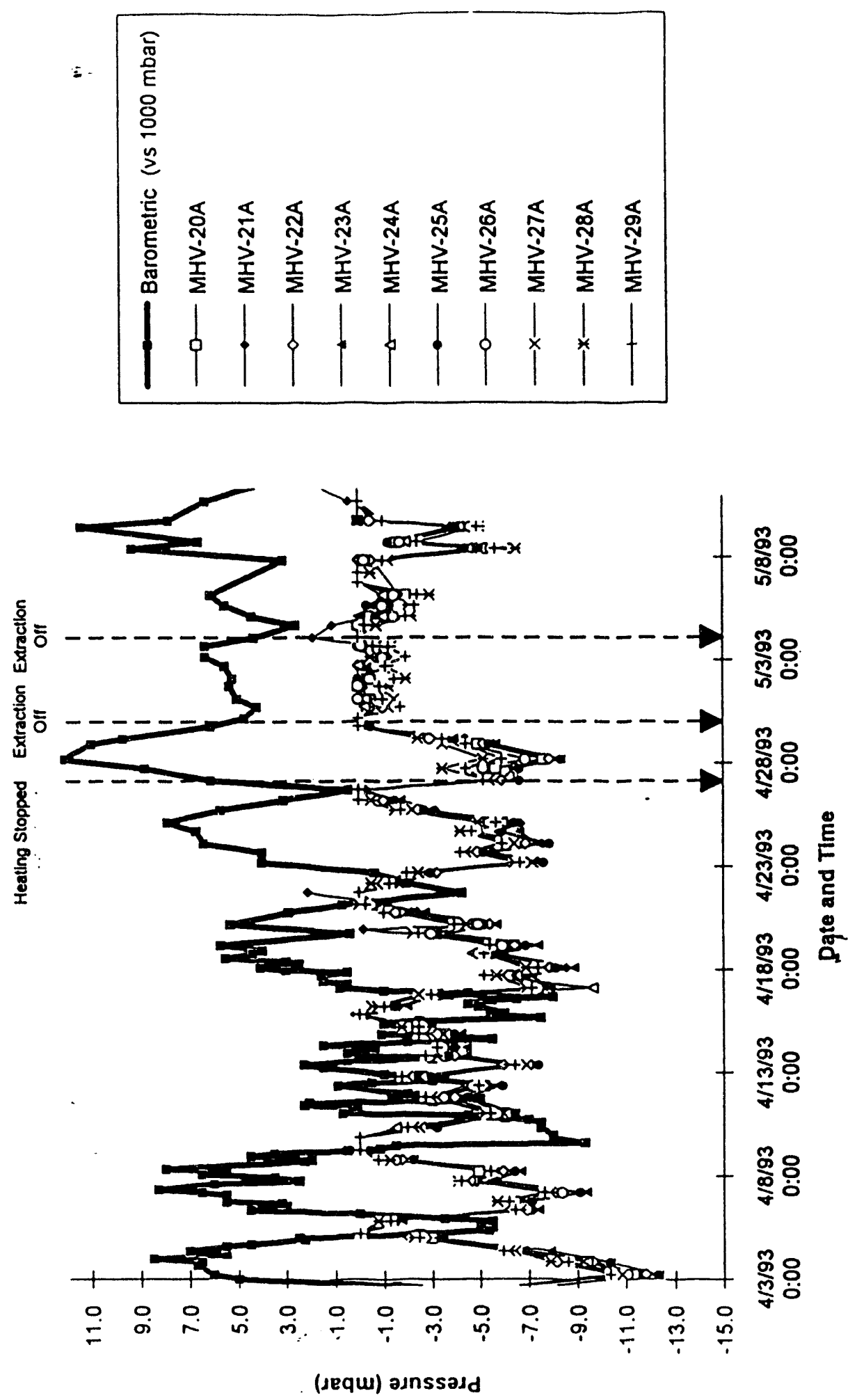

Figure 5-26. Vacuum Levels at a Depth of 48 Fect 


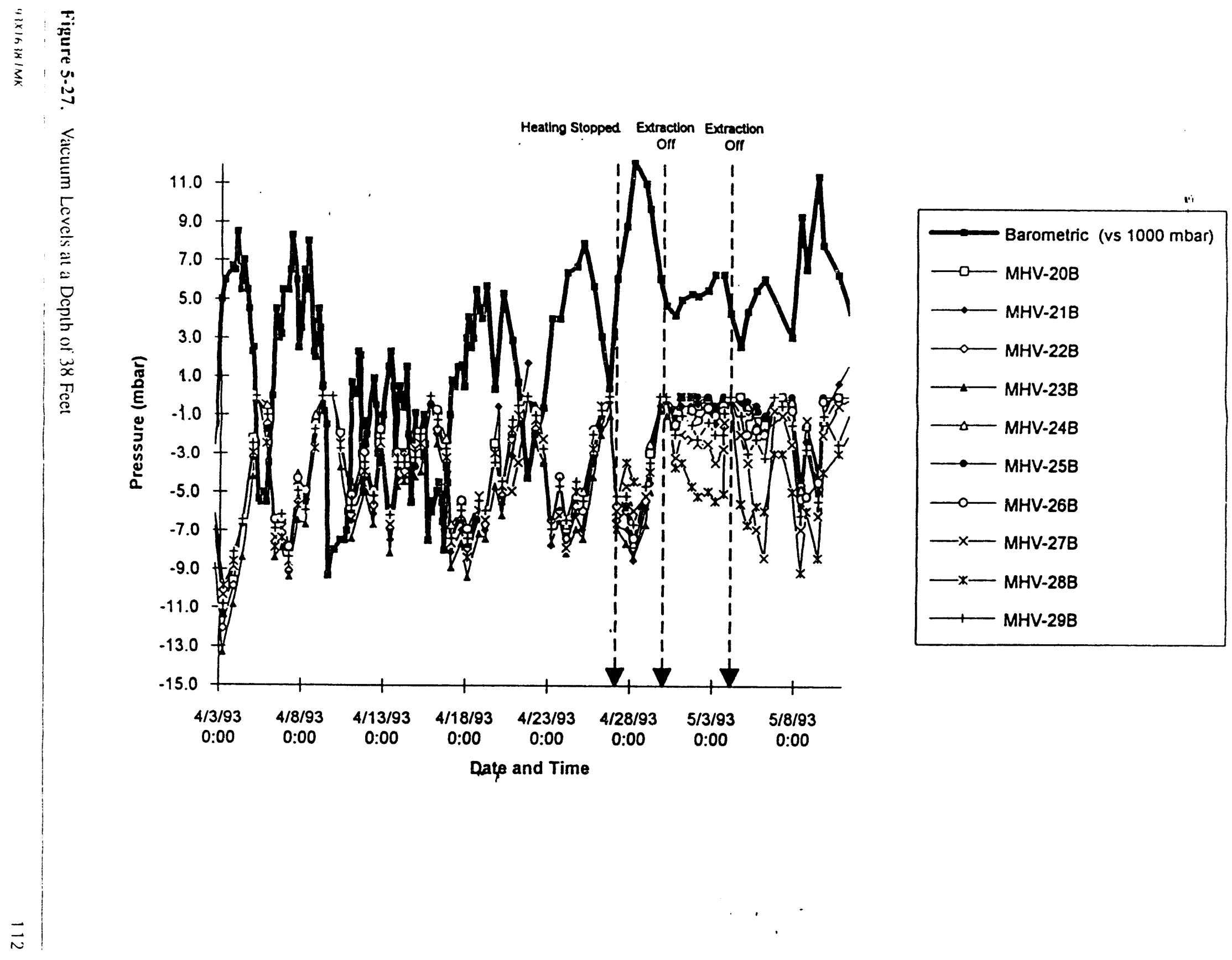



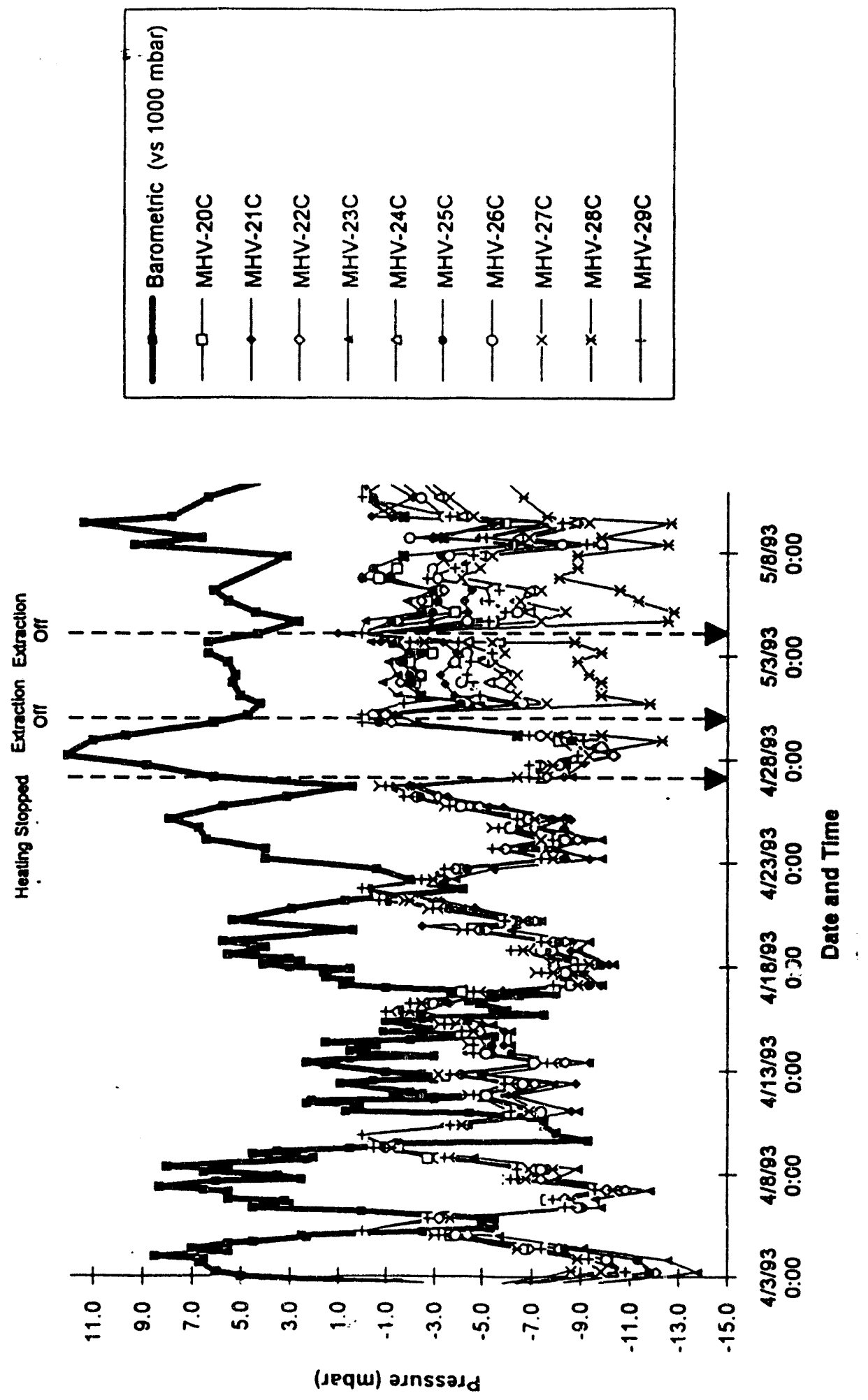

Figure 5-28. Vacuum Levels at a Depth of $28 \mathrm{Fccl}$ 


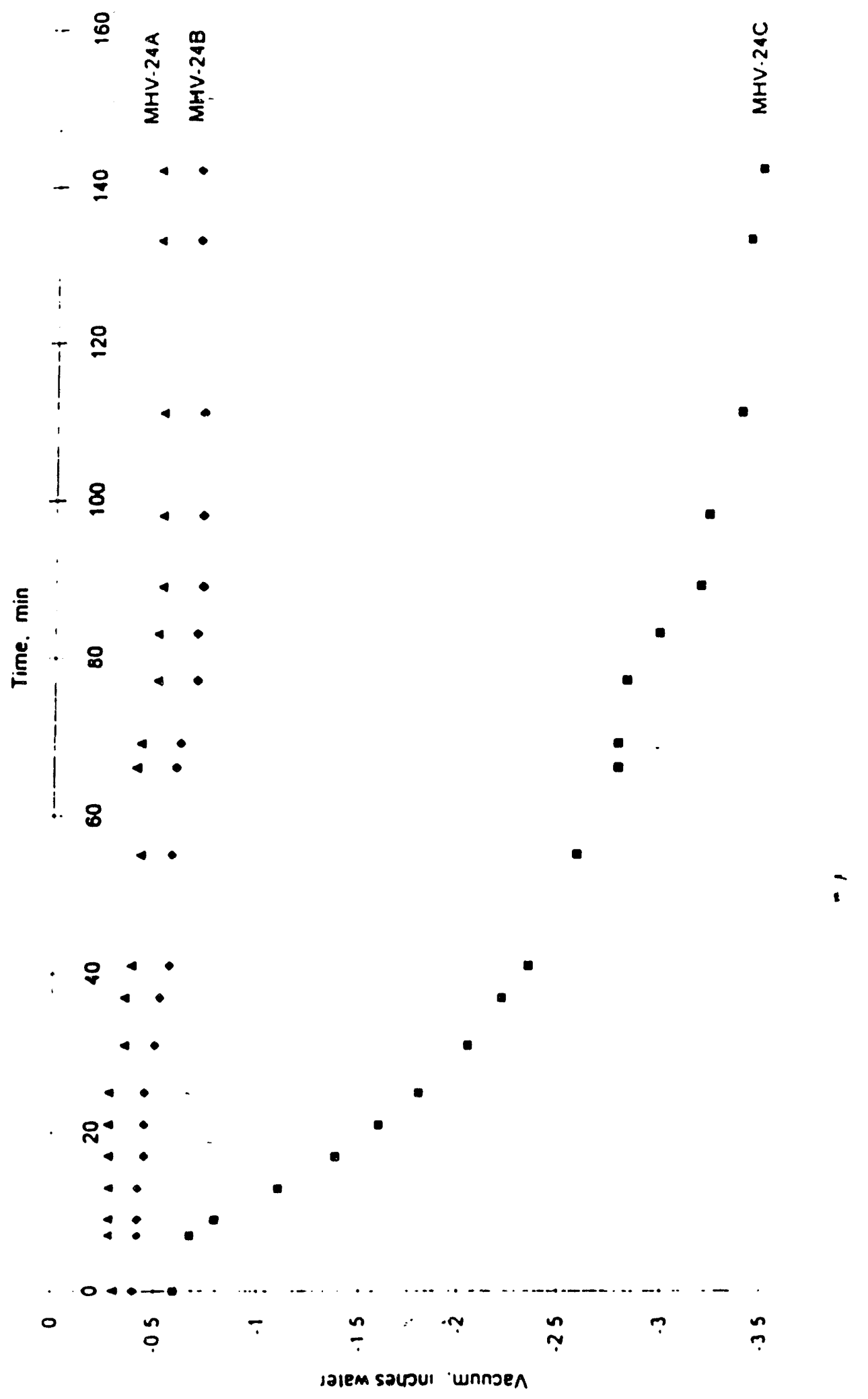

Figure 5-29. Plot of Drawdown in Well MHV-24 after Vacuum Extraction Resumed 
-

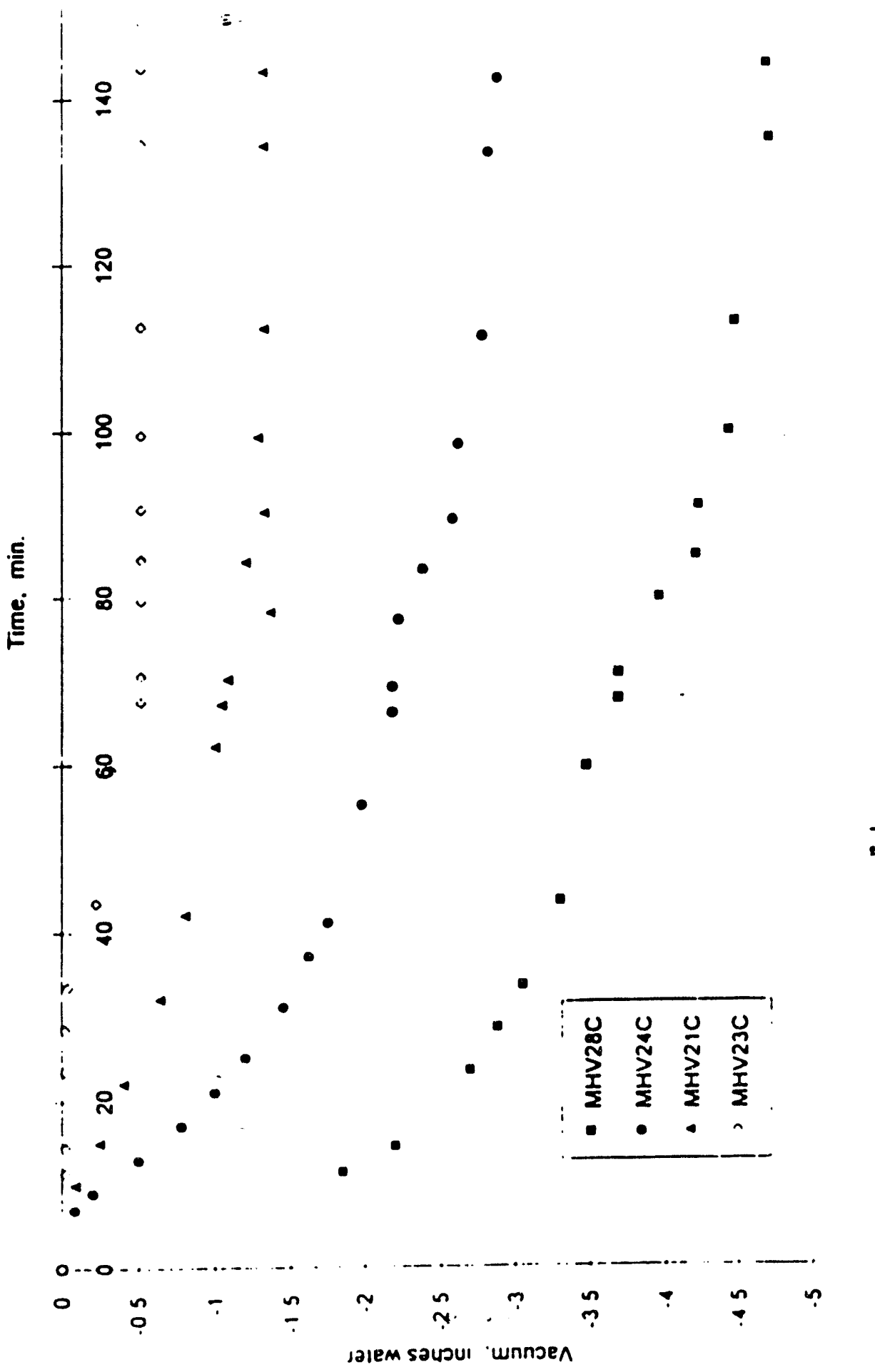

Figure 5-30. Plot of the Drawdown in Sevcral "C" Piczometers at Varying Distances from the Wellhead 


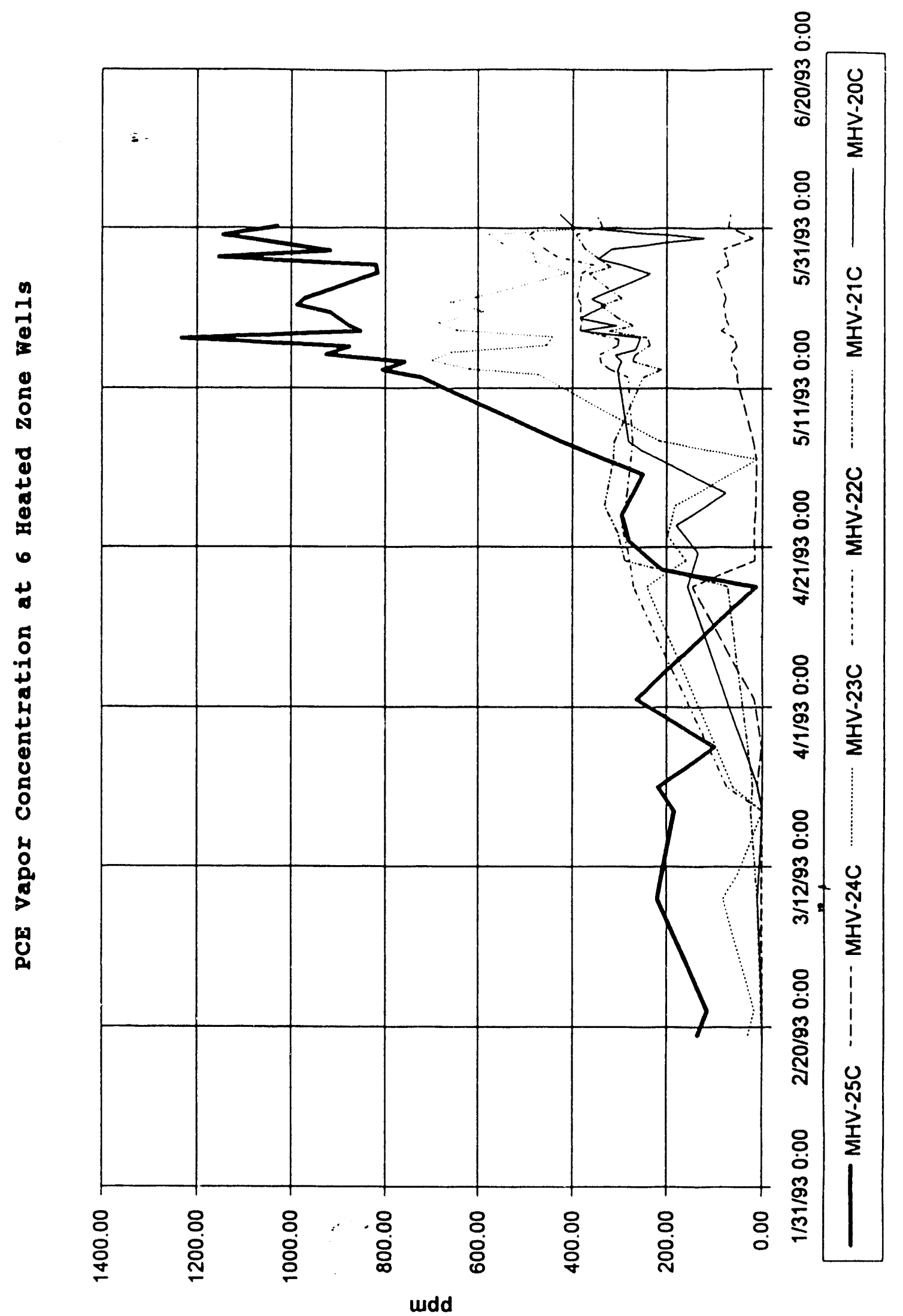

Figure 5-31. Graph of PCE Concentration at "C" Piezometers Located within and Surrounding the Heated Zone of the Demonstration 

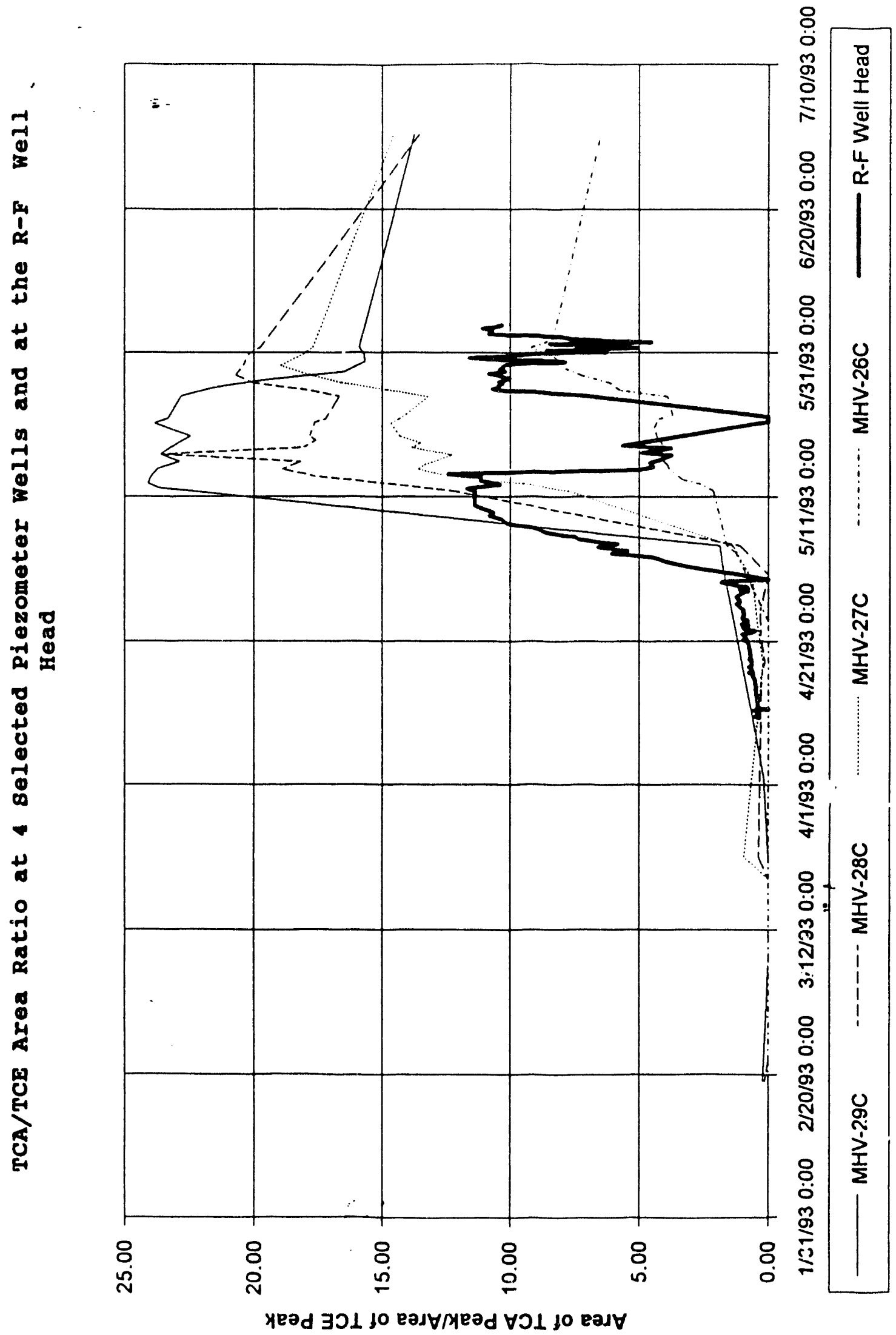

Figure 5-32. Plot of TCA/TCE Ratio Measured in the Soil Gas from the Control Zone Piezometers 


\subsection{References}

SRS In situ Radio Frequency Heating Demonstration, WSRC-RP-92-1428

Eddy ct al. 1993

Snyder, Harold, and Kasevich, 1993

Kasevich and Benham 1992

Eddy-Dilck ct al. 1993

Kasevich and Benham 1992

Eddy et. al 1992

R. T. Harold, T. S. Snyder, R. S. Kasevich, "In Silu RadioFrequency Soil Remediation Heating Demonstration: Final Report on Treatability Studics", Westinghouse Science and Technology Center Report, 93-9TDORFHET-R 1, 1993

WSRC.TR-93-()08

A. L. Ramirez and W. D. Daily, "Monitoring Radio-Frequency Hcating of Contaminated Soils Using clectrical Resistance Tomography, UCRL-ID-1 15373, 1993, LLNL

Marine and Bledsoe, October 1984, "Supplemental Technical Data Summary: M-Area Groundwater Investigation, DPSTD-84 112.

Ramirez and Daily 1993

R. L.Nichols, B. B. Looncy, and J. E. Huddleston, "3-D Digital Imaging: Revealing the Location, Depth, and Concentration of Subsurface Pollutants", Environmental Science and Technology, 26, 1992, 642-649.

C. A. Eddy and B. B. Looney, "Three-Dimensional Digital Imaging of Environmental Data: Selection of Gridding Parameters", International Journal of Geophysical Informaltion Systems, 7 (20, 1993, 165-172. 

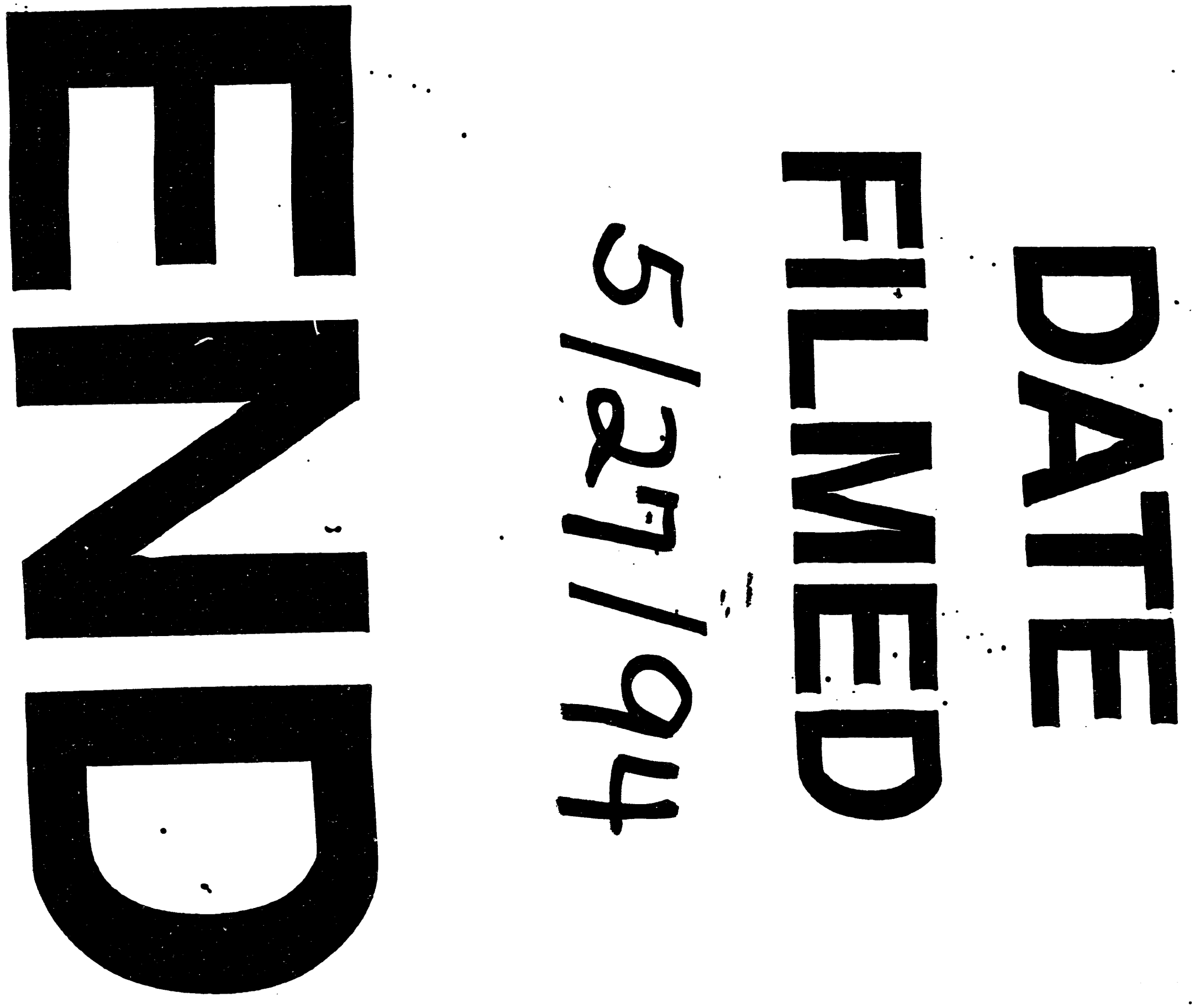
